\title{
Holocene Carbon Accumulation, Wetness Shifts and Fire History at Three Threatened Peatlands in Carmarthenshire, SW Wales, UK
}

\author{
Kristy Holder
}
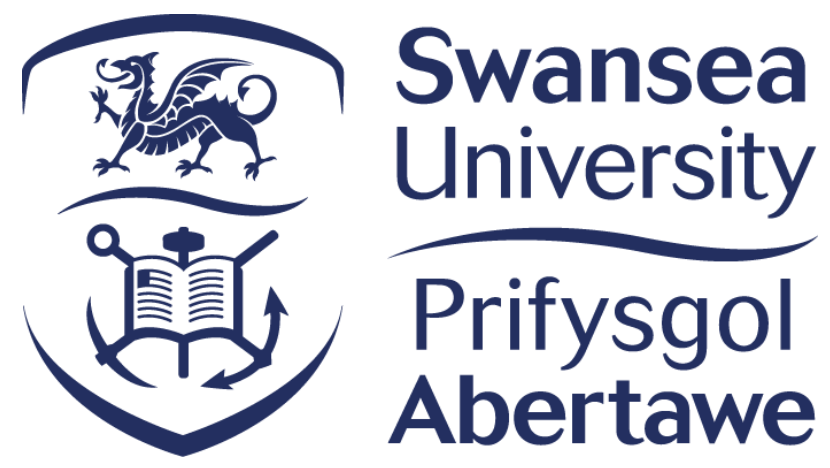

Submitted to Swansea University in fulfilment of the requirements for the Degree of Doctor of Philosophy

Swansea University

2021

Copyright: The author, Kristy Holder, 2021. 


\section{Abstract}

This project studies three peatlands in Carmarthenshire, SW Wales, UK (Figyn Common, Pyllau Cochion and Mynydd Bach) that are threatened by the impacts of continued human interference and projected climate change. The threat that human and climatic forces pose on peatland carbon storage has become a significant global concern in the fight against greenhouse gas climate forcing. A record of their Holocene environmental and developmental history is obtained via a multi-proxy analysis, including carbon:nitrogen ratio $(\mathrm{C}: \mathrm{N})$, humification, charcoal and carbon accumulation. Potential drivers of developmental change and temporal carbon accumulation are also explored. Fen peat inception occurred at ca. 10800, ca. 9730 and ca. 7960 cal yrs. BP at Figyn Common, Pyllau Cochion and Mynydd Bach (respectively). The fen to bog transition (FBT) is dated to $c a .5120$ cal yrs. BP at Pyllau Cochion and ca. 4480 cal yrs. BP at Figyn Common. The FBT does not take place at Mynydd Bach. Evidence of regional wet shifts during the late Holocene is found at $c a .2000$ and $c a$. $850 \mathrm{cal}$ yrs. BP and a dry shift is detected at $c a$. $2400 \mathrm{cal}$ yrs. BP. All three sites demonstrate evidence of burning through the Mesolithic period and on-site burning increases at all sites after $c a .4500$ cal yrs. BP. At Mynydd Bach, fire activity is linked to Bronze Age ritual practices. Long-term Apparent Rates of Carbon Accumulation (LARCA) for the three sites are 23.71, 13.09 and $42.55 \mathrm{~g} \mathrm{C} \mathrm{m}^{-2} \mathrm{yr}^{-1}$ for Pyllau Cochion, Mynydd Bach, and Figyn Common (respectively). Carbon accumulation is high in the early Holocene, likely in response to the faster accumulation rates associated with early fen stages. However, in contrast to other northern peatlands carbon accumulation is lower during the Holocene Thermal Maximum and higher in the late Holocene when neoglacial cooling persisted. This is most likely because they sit close to the bioclimatic threshold of peatland formation in a UK context. Furthermore, an association between shorter-term wet shifts and higher carbon accumulation is found at several points in the Pyllau Cochion and Figyn Common record. The findings imply that the sites accumulate more carbon during wetter/cooler conditions and less when it is warmer/drier. Therefore, it is likely that they will experience reductions in carbon accumulation in response to projected warming during the 21 st century. This adds support to the widely reported theory in the literature that peripheral peatlands will be the first to see losses in their carbon sequestration capacity because of predicted warming. This work contributes to the public understanding of the environmental history of these peatlands and the results provide valuable insight for conservation and future management strategies along with an assessment of carbon projections. 


\section{Declaration and Statements}

\section{DECLARATION}

This work has not previously been accepted in substance for any degree and is not being concurrently submitted in candidature for any degree.

Signed:

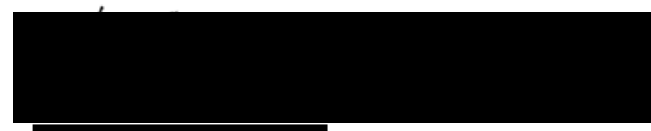

Date:

$16 / 12 / 2021$

\section{STATEMENT 1}

This thesis is the result of my own investigations, except where otherwise stated. Where correction services have been used, the extent and nature of the correction is clearly marked in a footnote(s).

Other sources are acknowledged by footnotes giving explicit references. A bibliography is appended.

Signed:

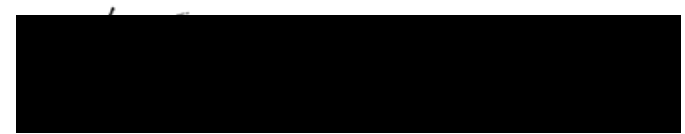

Date:

$16 / 12 / 2021$

\section{STATEMENT 2}

I hereby give consent for my thesis, if accepted, to be available for photocopying and for inter-library loan, and for the title and summary to be made available to outside organisations.

Signed:

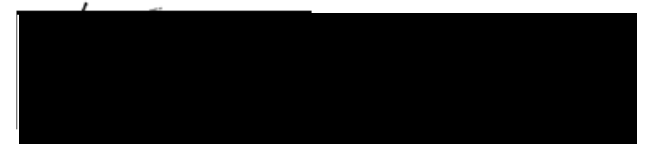

Date:

$16 / 12 / 2021$ 


\section{Contents}

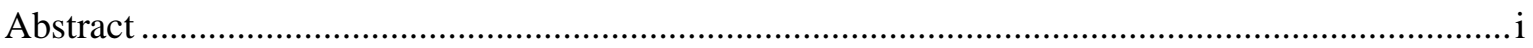

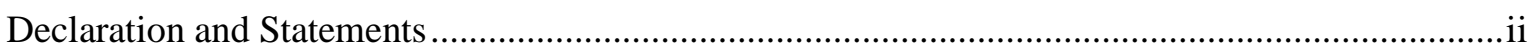

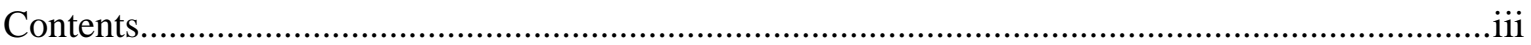

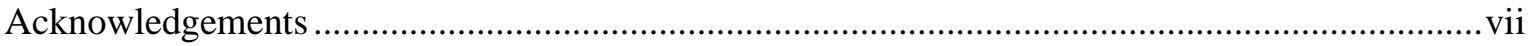

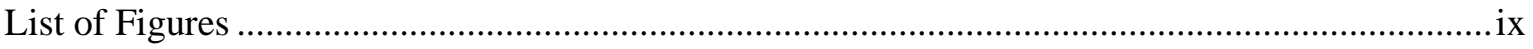

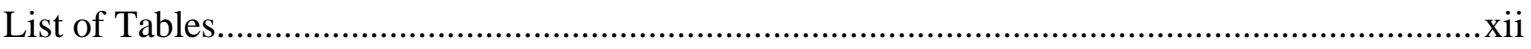

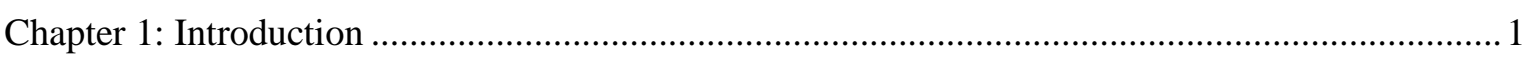

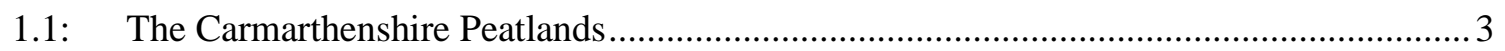

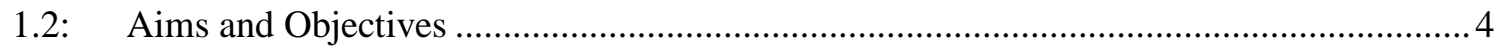

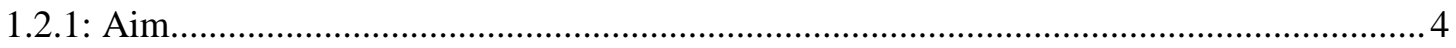

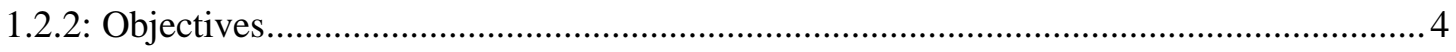

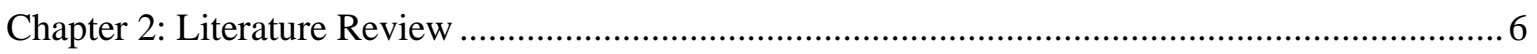

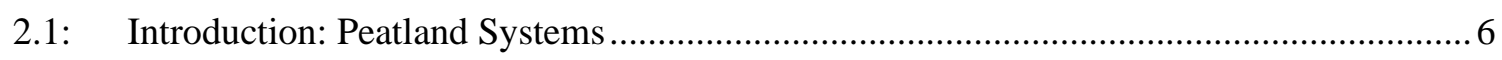

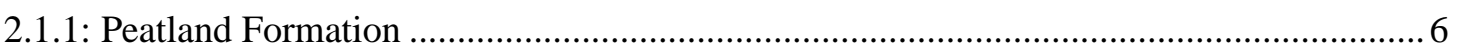

2.1.2: Timing and Drivers of Peatland Initiation.......................................................................... 10

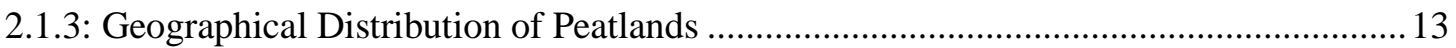

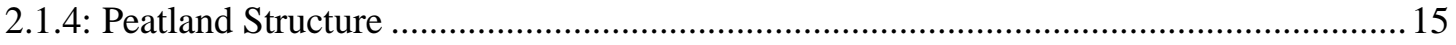

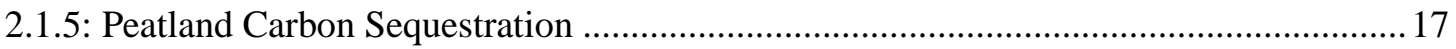

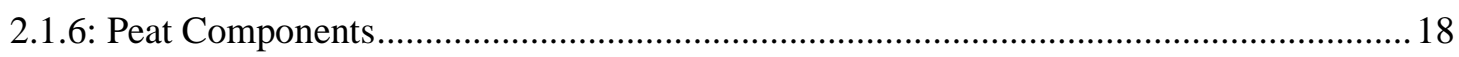

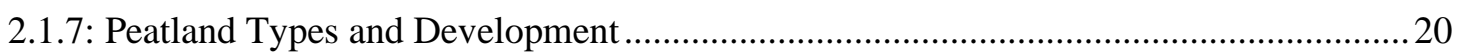

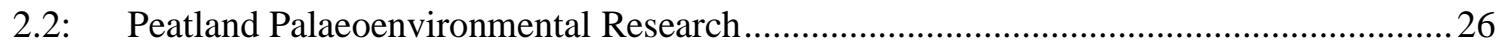

2.2.1: Building a Chronology in Peat Sequences .................................................................... 27

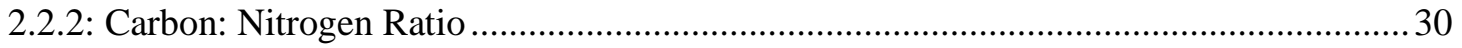

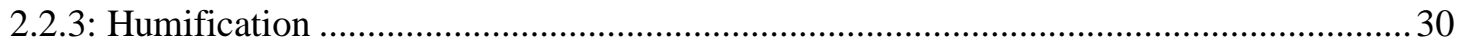

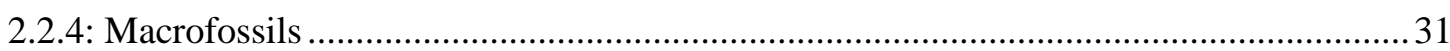

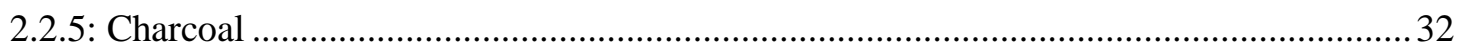

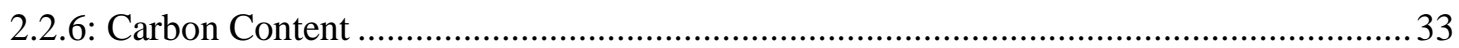

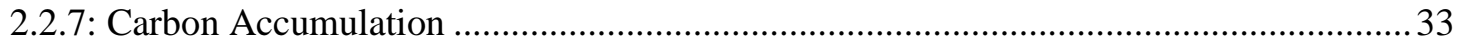

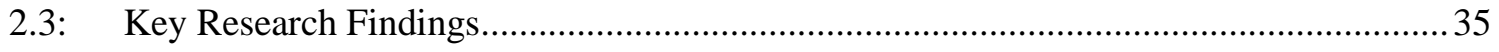

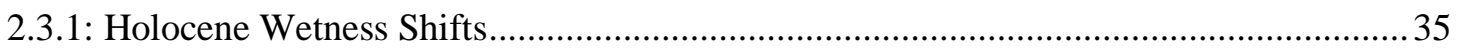

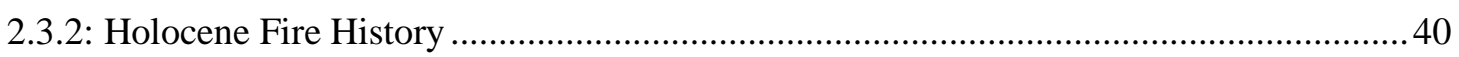

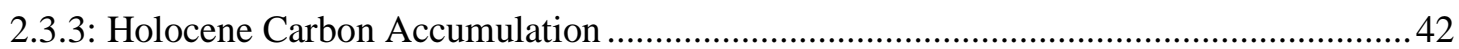

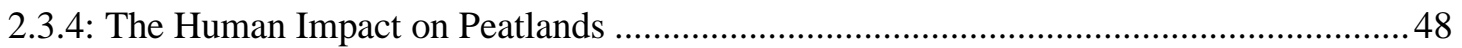

2.3.5: Paleoenvironmental Studies in Management and Conservation .................................... 49

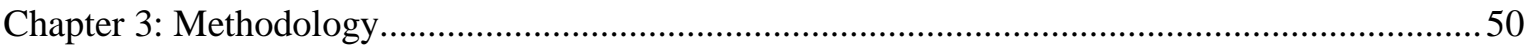




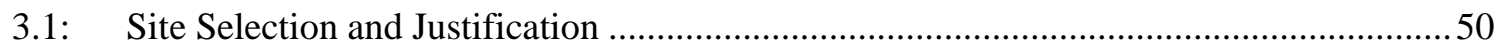

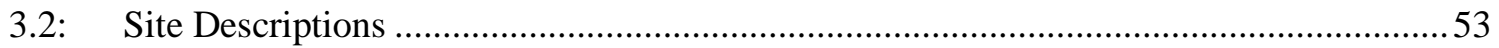

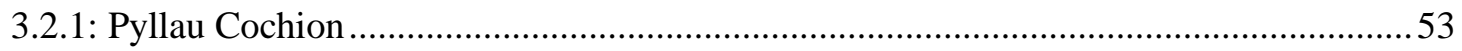

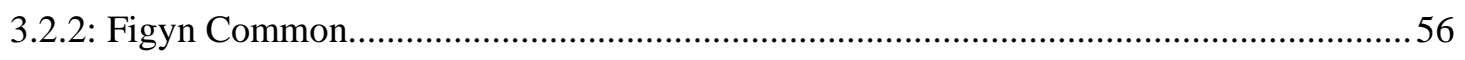

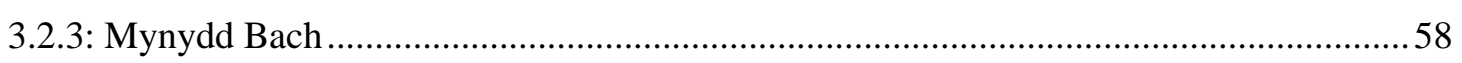

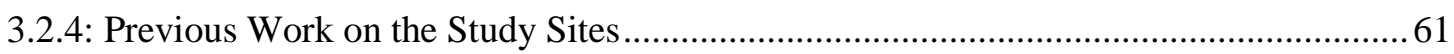

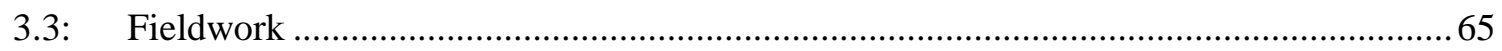

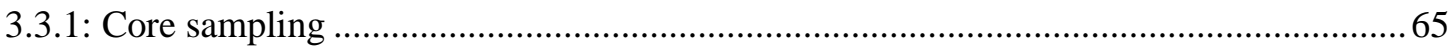

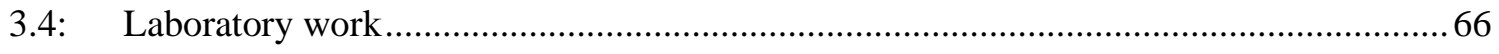

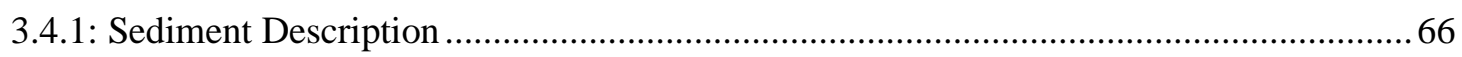

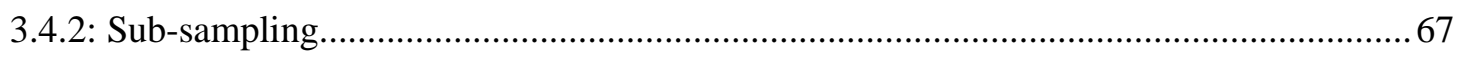

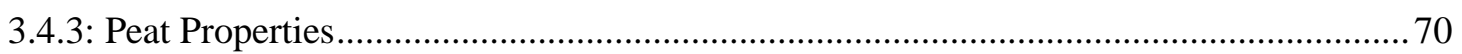

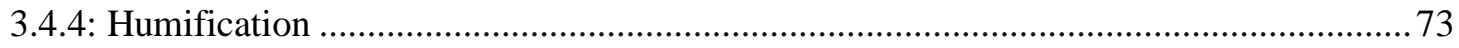

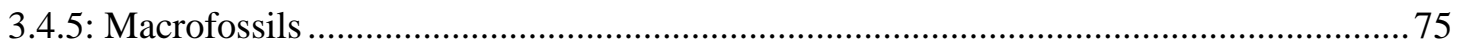

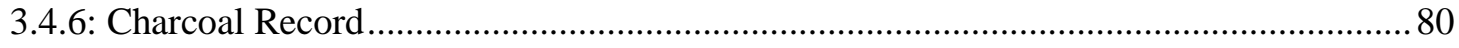

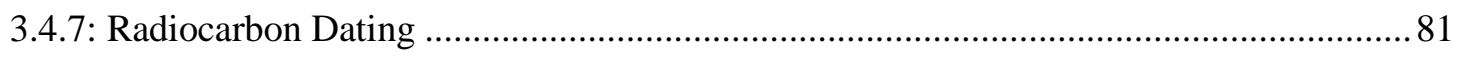

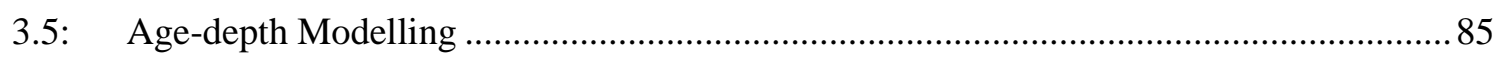

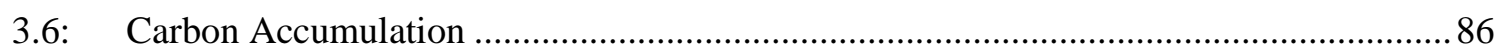

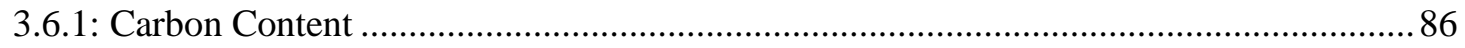

3.6.2: Peat Accumulation Rates, Carbon Density, LARCA and CARs .................................... 87

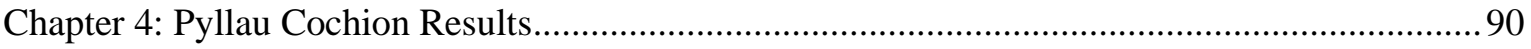

4.1: Lithostratigraphy and Sediment Composition Data .................................................... 90

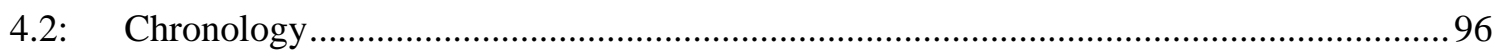

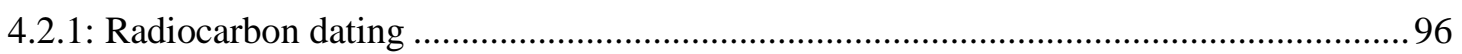

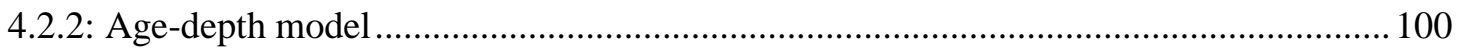

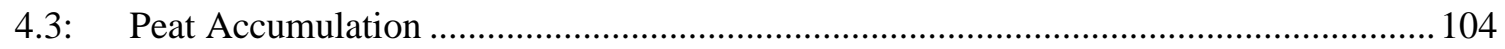

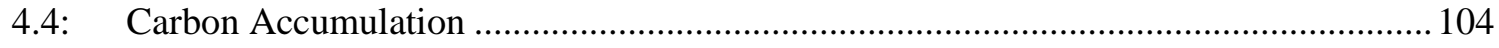

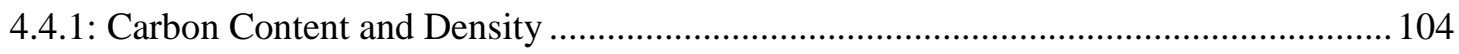

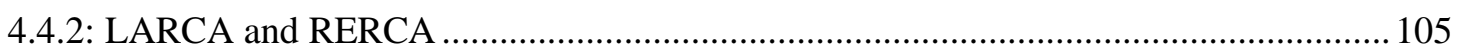

4.4.3: Temporal Carbon Accumulation Rates ...................................................................... 106

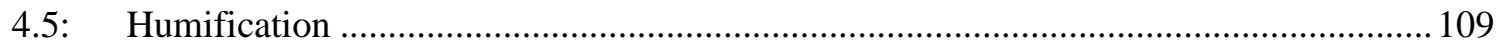

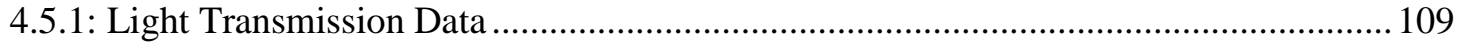

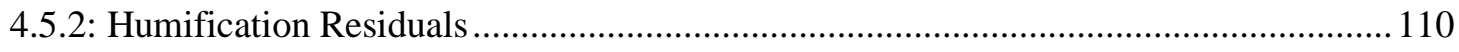

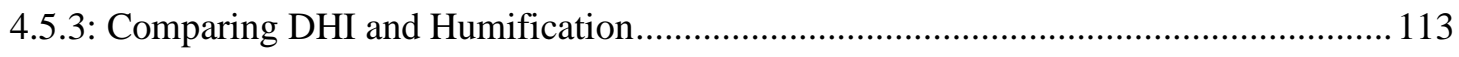

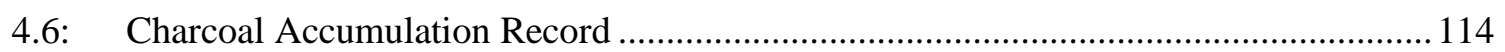

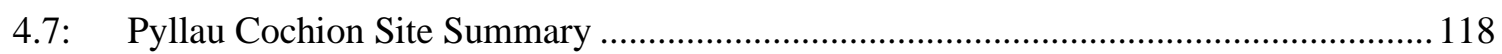

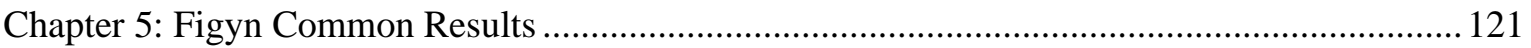




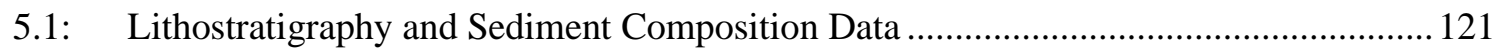

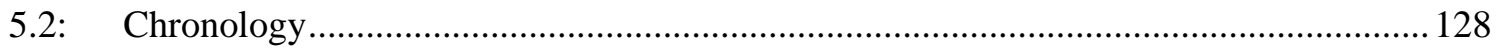

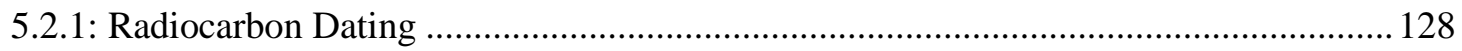

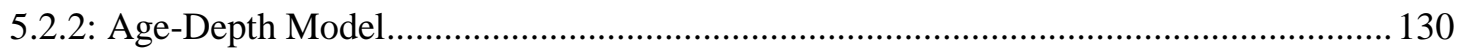

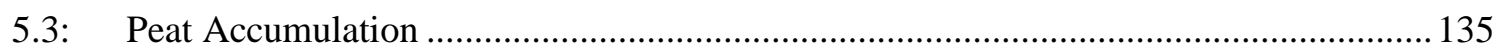

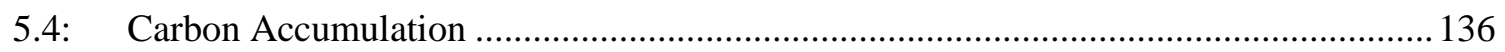

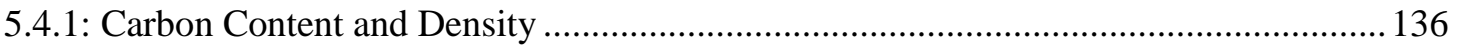

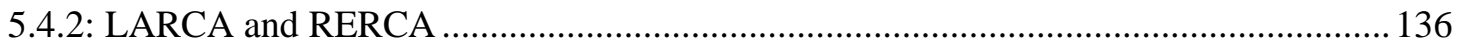

5.4.3: Temporal Carbon Accumulation Rates ........................................................................ 137

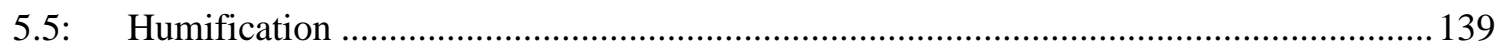

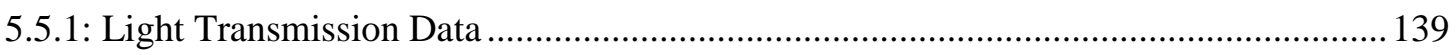

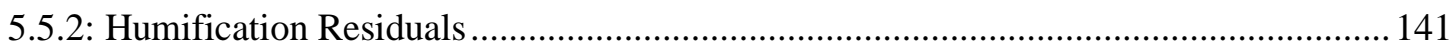

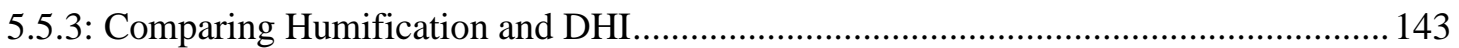

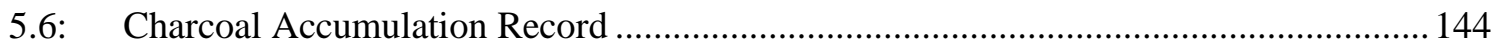

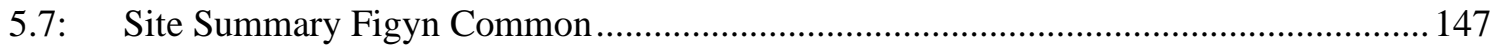

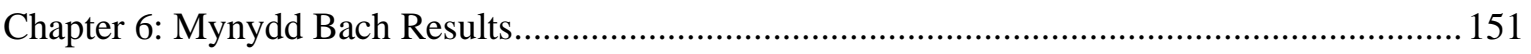

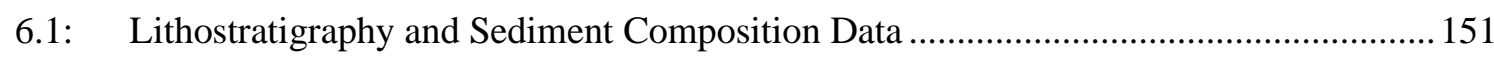

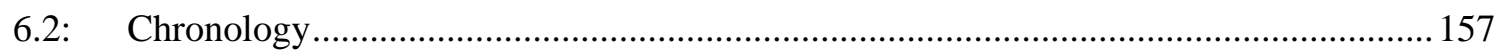

6.2.1: Radiocarbon Dating and Age-depth Model............................................................... 157

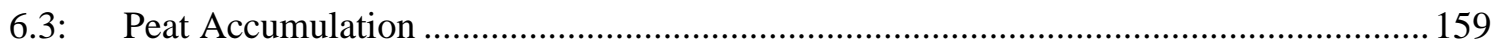

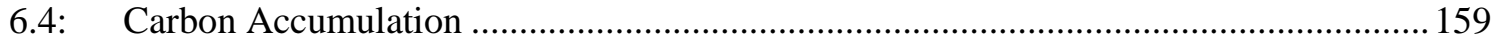

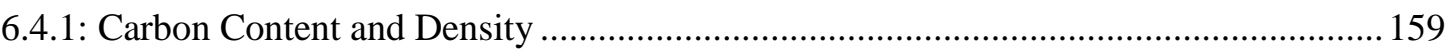

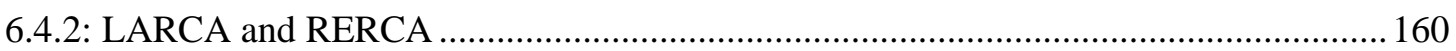

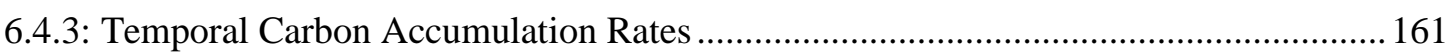

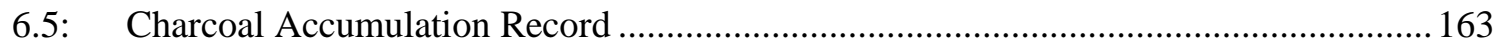

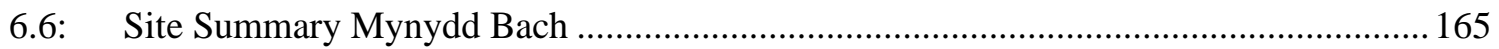

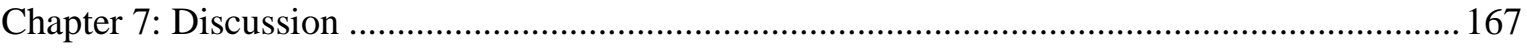

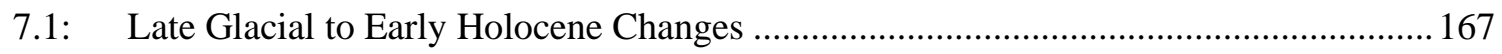

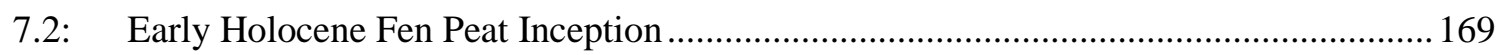

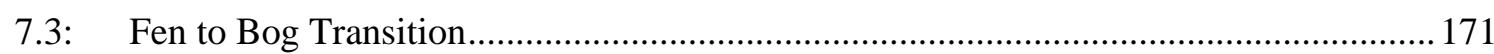

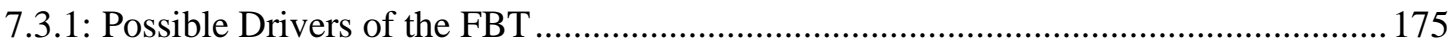

7.4: Wetness Changes During the Mid to Late Holocene .................................................... 177

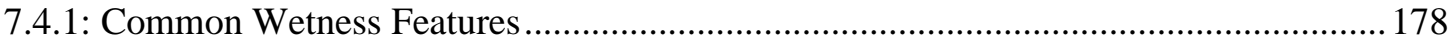

7.4.2: Inconsistencies between the surface wetness records ……........................................ 180

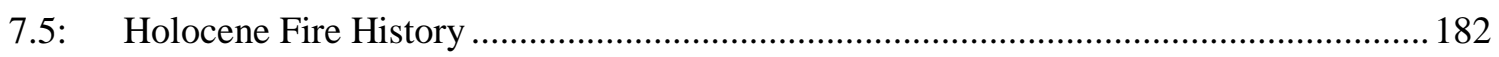

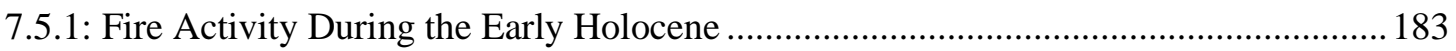

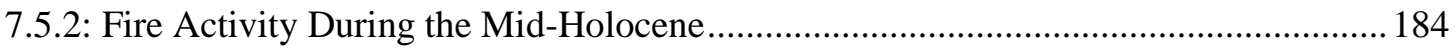


7.5.3: Fire Activity After $c a .4500$ cal yrs. BP.

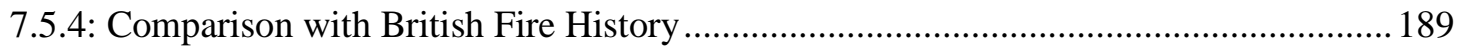

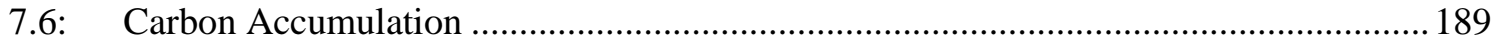

7.6.1: Long-term Rate of Carbon Accumulation (LARCA)................................................... 189

7.6.2: Holocene Carbon Accumulation Trends ...................................................................... 192

7.6.3: Short-term Wetness Shifts and Carbon Accumulation................................................... 195

7.6.4: Recent Rates of Carbon Accumulation (RERCAs)...................................................... 198

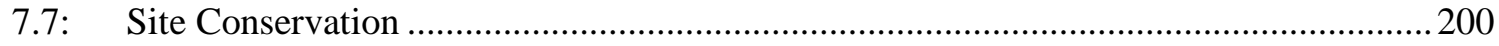

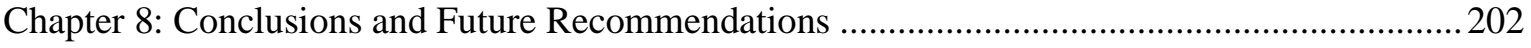

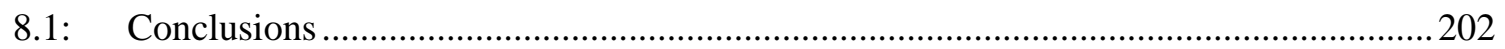

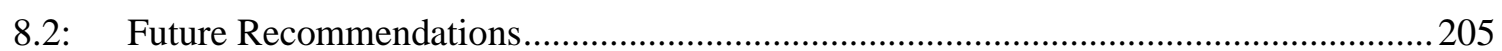

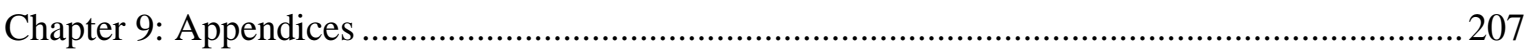

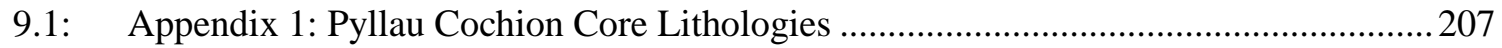

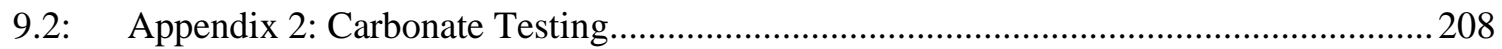

9.3: Appendix 3: Determining Carbon Content ……............................................................ 211

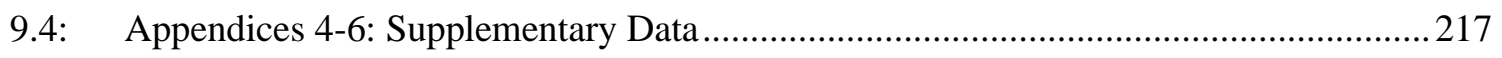

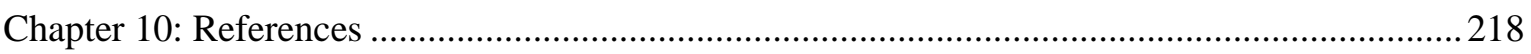




\section{Acknowledgements}

I would like to dedicate this thesis to my Mum, who was unable to fulfil her academic goals. I hope that me completing this $\mathrm{PhD}$ will give her a sense of accomplishment too. Mum, we've done it!

\section{Thanks are given to:}

- Prof. Siwan Davies, my PhD supervisor. Siwan has been extremely supportive throughout my extenuating circumstances, whilst always pushing me to produce the best research possible. I feel very fortunate to have had Siwan as my supervisor.

- My fiancé Tom. For the continuous encouragement and constant supply of fresh pears.

- My family and friends, who have supported me during my PhD. In particular; my Grandma, my Uncle Tref, Jade, Takisha and Rose.

- Josie, Rachel, and Matt: my PhD comrades.

- Rosemary Muxworthy, for the long chats and support throughout all levels of study at the university.

- Dr. Richard Staff, for helping me with radiocarbon dating and age-depth modelling.

- Matt and Pete, A.K.A. - The Coring Dream Team, for assisting me with the endless coring ventures.

- Gareth and Gwydion, for helping with coring too.

- Dr. Kath Ficken for providing me with advice during my time at Swansea.

- Donna Carless, for $\mathrm{PhD}$ guidance.

- Grahame Walters, for keeping us all safe in the lab and field. 
- Prof. Neil Loader, for running the Carbon and Nitrogen samples on the Mass Spectrometer.

- Sandra Kramcha and Allison Royal, for their continued support and for helping me to secure extra funds for a fourth $\mathrm{PhD}$ research year.

- Prof. Danny McCarroll for advice with statistical analysis.

- Isabel Macho from Carmarthenshire County Council and Alice Piper from Dyfed Archaeological Trust, for providing contextual information about the three study sites.

- The National Lottery Heritage Fund for funding some of the radiocarbon dates in this thesis.

- Paul Harries from Wellbeing.

- Rob Ellis, for providing me with Care Leavers' Support.

- Dr. Sarah Finkelstein for advice on carbon accumulation reconstructions.

- Prof. Alayne Street-Perrott for fieldwork assistance and reading recommendations. 


\section{List of Figures}

Figure 2:1: Simplified schematic showing the processes of terrestrialisation and paludification (Schumann and Joosten, 2008).

Figure 2:2: The process of terrestrialisation in a basin and lateral expansion via paludification (Klinger, 1996).

Figure 2:3: Temporal trends in northern peatland initiation (Macdonald et al., 2006)................... 11

Figure 2:4: Map of the global distribution of peatlands (Xu et al., 2018) .................................... 13

Figure 2:5: Map of peatlands and peaty soils in the UK (JNCC, 2011) ........................................ 14

Figure 2:6: The structure of a peatland in its idealised natural state (Lindsay, 2010) .................... 16

Figure 2:7: Inputs and outputs into the peatland system (Rydin and Jeglum, 2006)..................... 18

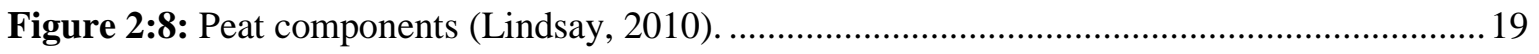

Figure 2:9: Schematic illustration of a bog and fen (Joosten, 2008(b)) ....................................... 20

Figure 2:10: Schematic of peatland types and characteristics (Sjörs, 1950; Wheeler and Proctor,

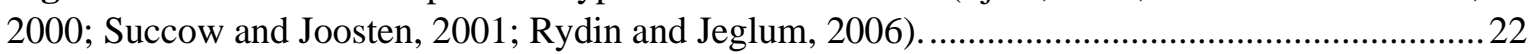

Figure 2:11: Bog surface wetness record for Walton Moss (Hughes et al., 2000) .......................... 38

Figure 2:12: The northern English testate amoebae bog surface wetness record (Charman et al., 2006) against lake water levels in France (Magny, 2004) and a residual 14C reconstruction (Stuiver

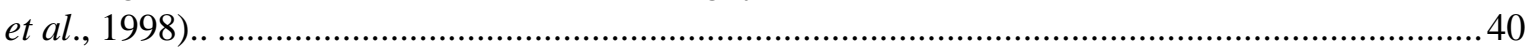

Figure 2:13: British fire history compilation (Marlon et al., 2013) ............................................ 42

Figure 2:14: The distribution of peatland carbon accumulation studies (Yu et al., 2014)............. 45

Figure 2:15: The northern peatland carbon accumulation database (Yu et al., 2014) and the Scottish carbon accumulation database (Ratcliffe et al., 2018) 45

Figure 2:16: Model showing possible future UK peat distribution changes in response to warming

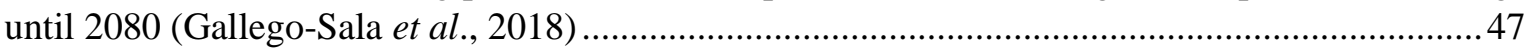

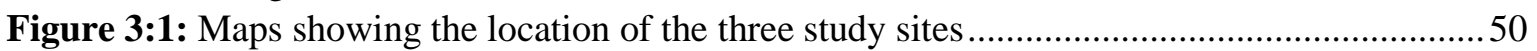

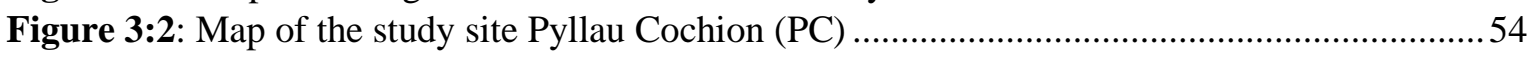

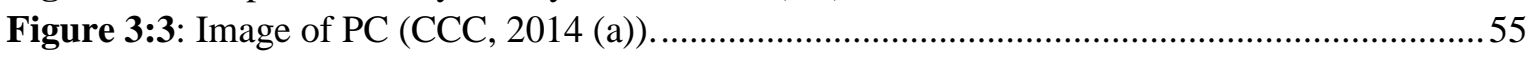

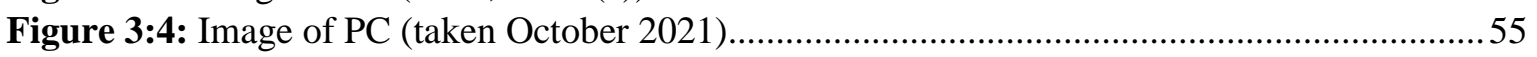

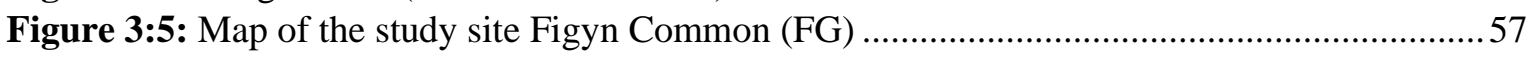

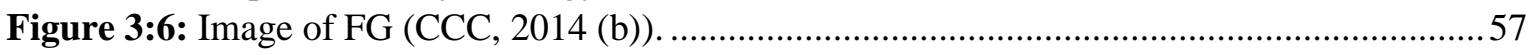

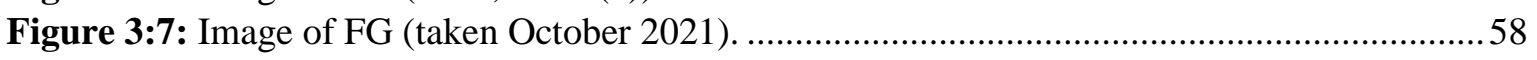

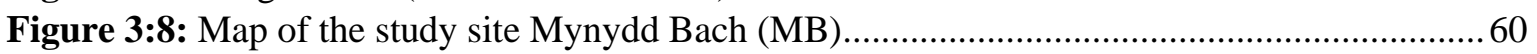

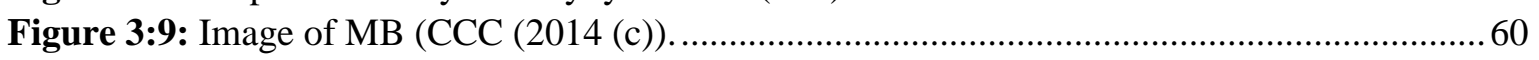

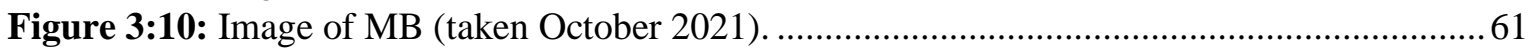

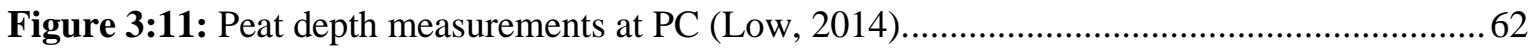

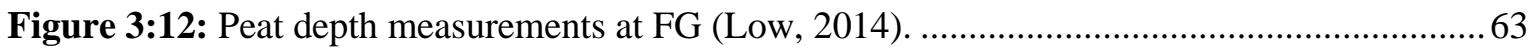

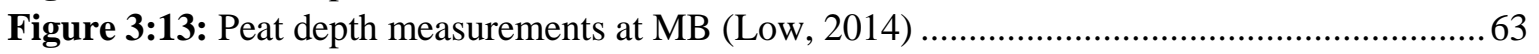

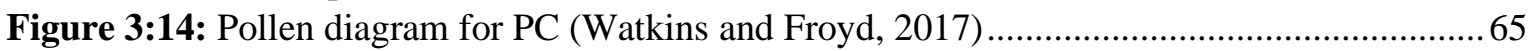

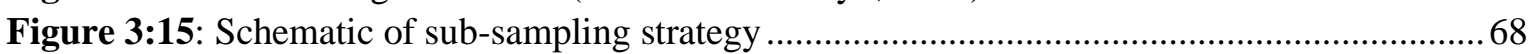

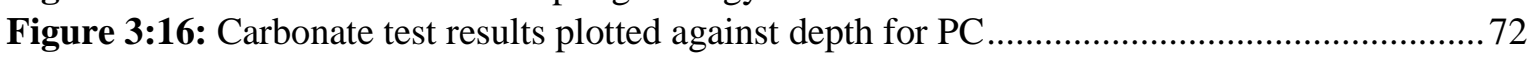

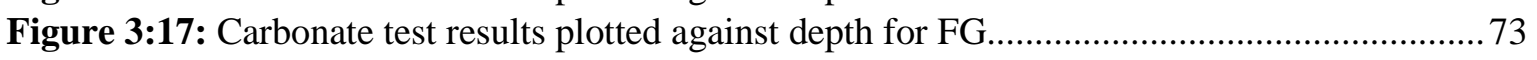

Figure 3:18: Carbonate test results plotted against depth for MB .............................................. 73

Figure 3:19: Schematic demonstrating how the relationship between TOC and OM is used to

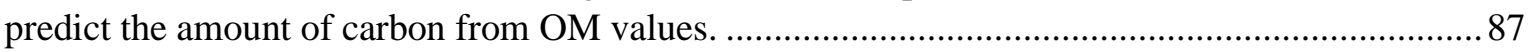

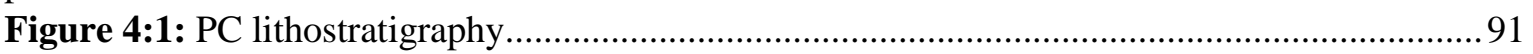

Figure 4:2: PC radiocarbon date at $127 \mathrm{~cm}$ on the Intcal20 calibration curve (Reimer et al., 2020)

Figure 4:3: PC radiocarbon date at $202 \mathrm{~cm}$ on the Intcal20 calibration curve (Reimer et al., 2020). 
Figure 4:4: PC radiocarbon date at $360 \mathrm{~cm}$ on the Intcal20 calibration curve (Reimer et al., 2020).

Figure 4:5: PC radiocarbon date at $520 \mathrm{~cm}$ (Holder, 2015) on the Intcal20 calibration curve

(Reimer et al., 2020)

Figure 4:6: PC Bayesian age-depth model and simple linear interpolation.................................... 101

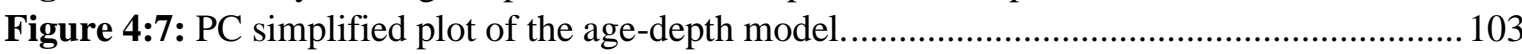

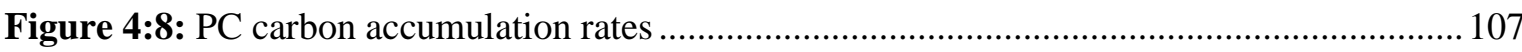

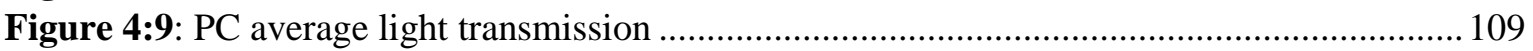

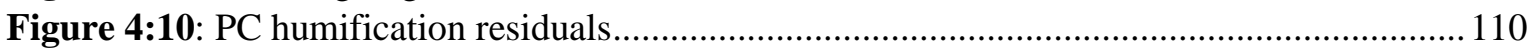

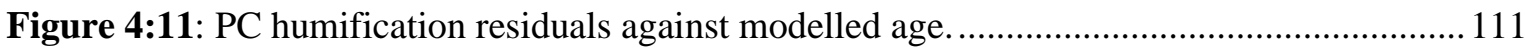

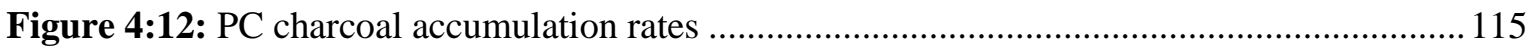

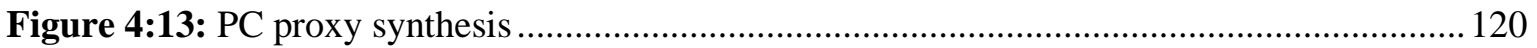

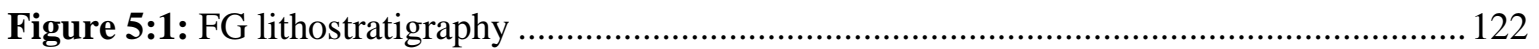

Figure 5:2: FG Bayesian age-depth model and simple linear interpolation................................ 131

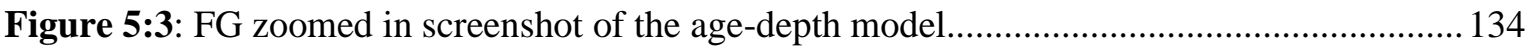

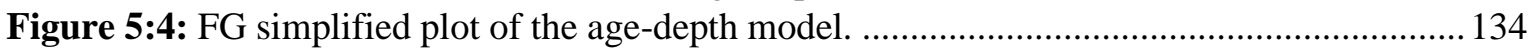

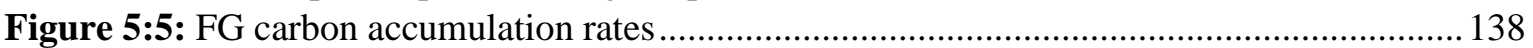

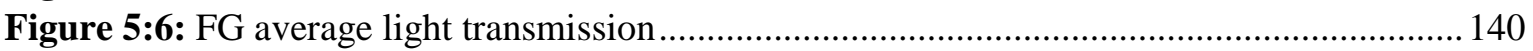

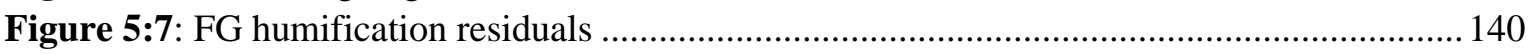

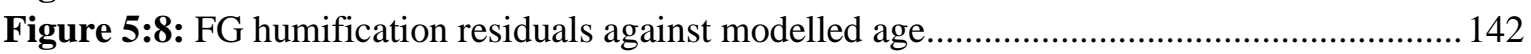

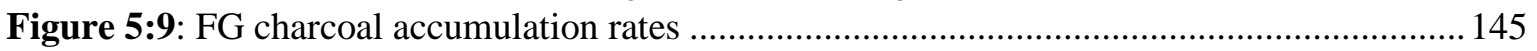

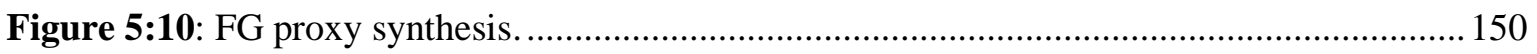

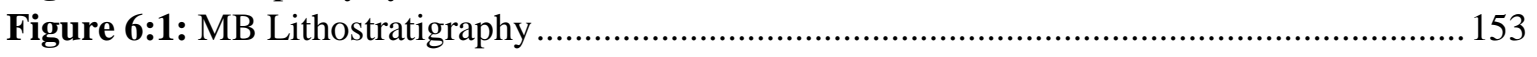

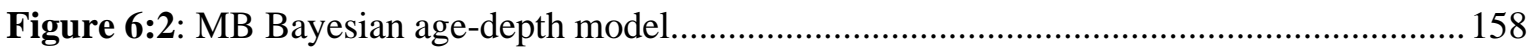

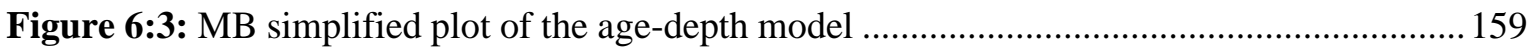

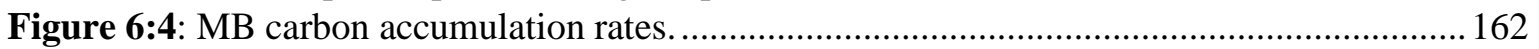

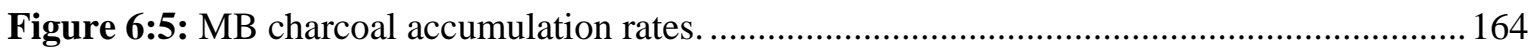

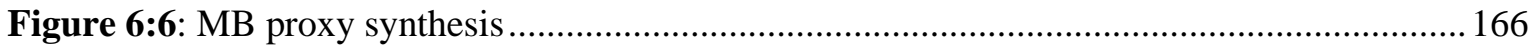

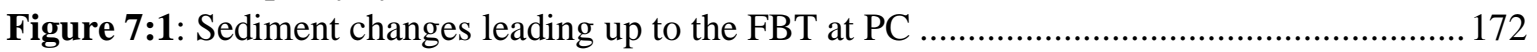

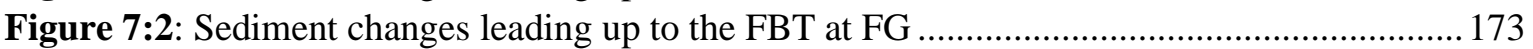

Figure 7:3: Humification residual curve for PC and FG; humification residuals for a peatland in Brecon Beacons (Chambers and Blackford, 2001); Northern English testate amoebae BSW record

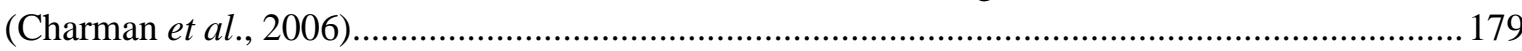

Figure 7:4: CHAR counts for PC, FG, and MB and the British Isles Holocene fire compilation

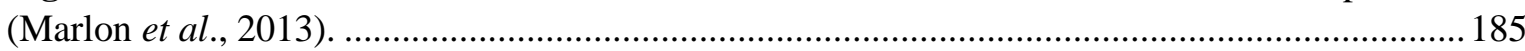

Figure 7:5: CHAR counts and humification residuals for PC and FG.................................... 187

Figure 7:6: Holocene carbon accumulation rates at PC, MB and FG, alongside the Scottish carbon accumulation database (Ratcliffe et al., 2018), the Northern carbon accumulation database (Yu et al., 2014) and a Northern Hemisphere $\left(>30^{\circ} \mathrm{N}\right)$ temperature reconstruction (Marcott et al., 2013).

Figure 7:7: PC and FG Late Holocene carbon accumulation against humification residuals ...... 197 Figure 7:8: Artistic illustrations of PC throughout the Holocene (Watkins and Froyd, 2017; CCC,

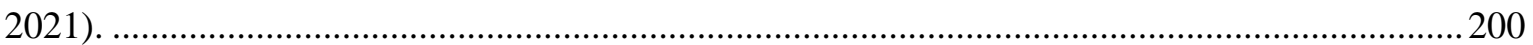

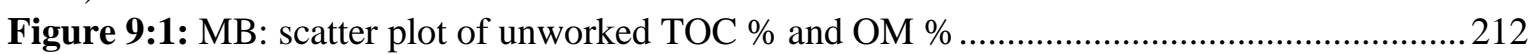

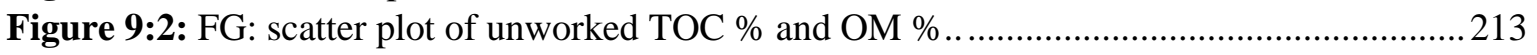

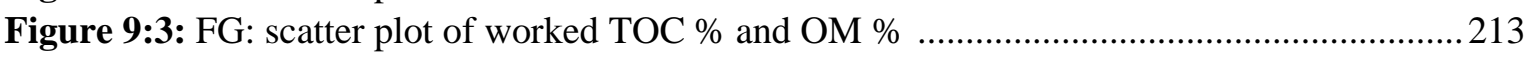

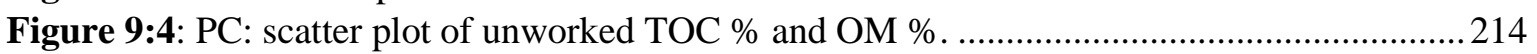

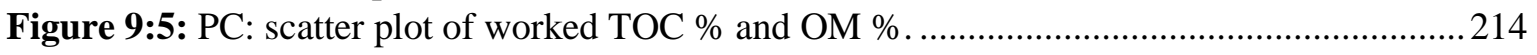

Figure 9:6: FG: line graph of ranked TOC \%, regression predicted carbon values and OM predicted carbon values. 
Figure 9:7: PC: line graph of ranked TOC \%, regression predicted carbon values and OM predicted carbon values.

Figure 9:8: MB: line graph of ranked TOC \%, regression predicted carbon values and OM predicted carbon values. 


\section{List of Tables}

Table 2:1: Peatland initiation dates for several Welsh peatlands (references in table) .................... 12

Table 2:2: Three comon dating techniques for peat sequences (references in table) .......................27

Table 2:3: Commonly identified wetness shifts in British bog surface wetness records (references

in table)

Table 2:4: A range of LARCA, CAR, and RERCA values (references in table)............................43

Table 3:1: Proxy analyses for cores from all three sites, the sampling resolution and rationale for

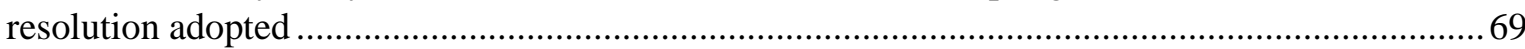

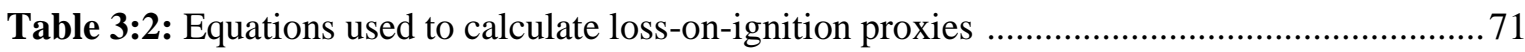

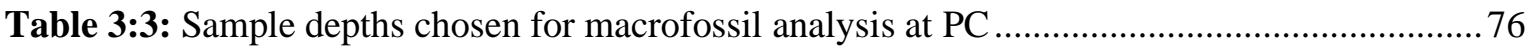

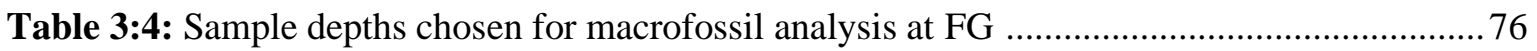

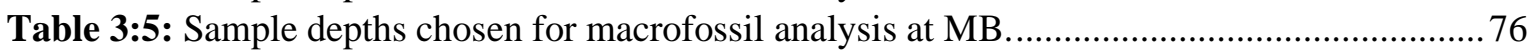

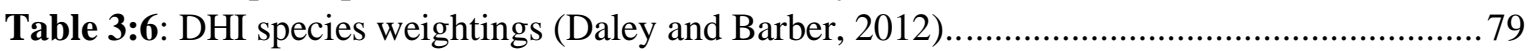

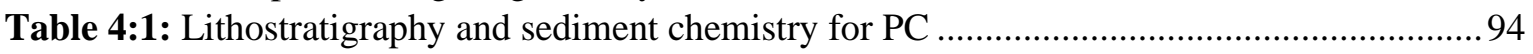

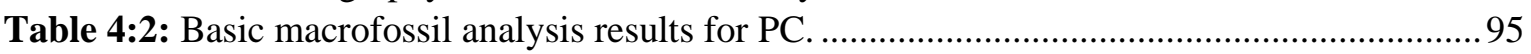

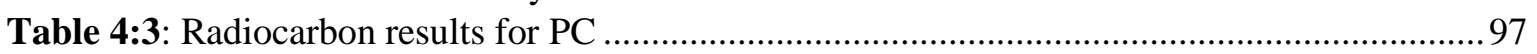

Table 4:4: PC mean accumulation rates inferred by linear interpolation...................................... 102

Table 4:5: PC Bayesian age-depth model ages between $522-518 \mathrm{~cm}$.

Table 4:6: PC mean peat accumulation rates, carbon content, carbon density, LARCA and

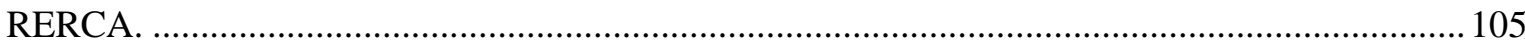

Table 4:7: PC wet and dry shifts inferred by the humification record ...................................... 113

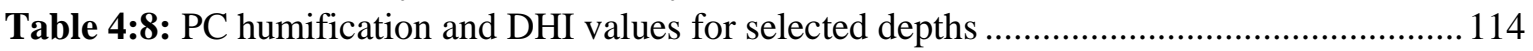

Table 4:9: PC charred plant remains observed in the $>500 \mu \mathrm{m}$ charcoal counts ............................ 117

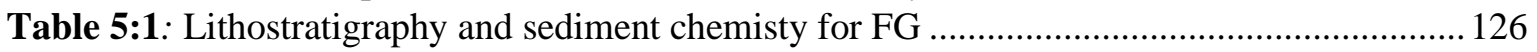

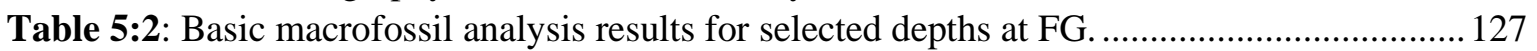

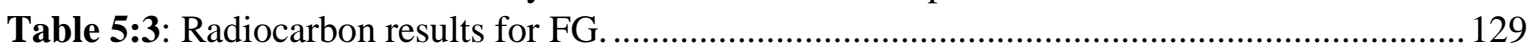

Table 5:4: FG mean accumulation rates inferred from the linear interpolation ............................ 133

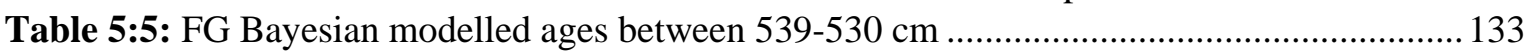

Table 5:6: FG mean peat accumulation rates, carbon content, carbon density, LARCA and

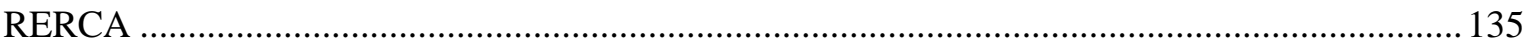

Table 5:7: FG wet and dry shifts inferred by the humification record......................................... 143

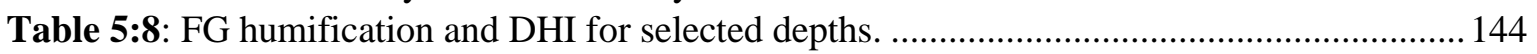

Table 5:9: FG charred plant remains observed in the $>500 \mu \mathrm{m}$ charcoal counts ............................ 147

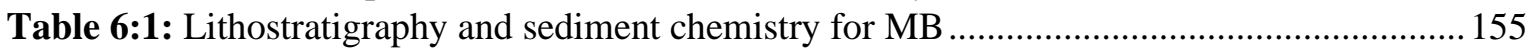

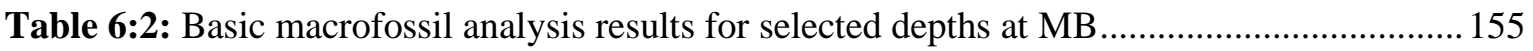

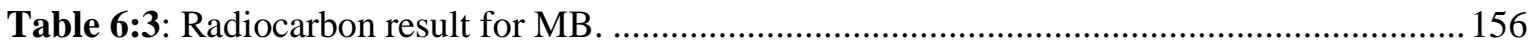

Table 6:4: MB mean peat accumulation rates, carbon content, carbon density, LARCA and

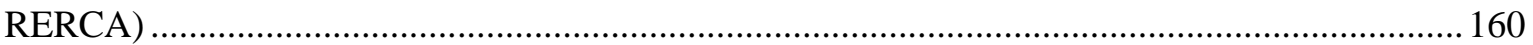

Table 9:1: Lithological boundaries and depths for the two cores taken at PC ............................ 207

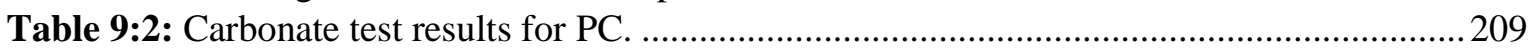

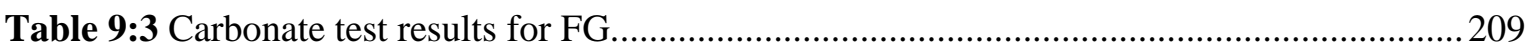

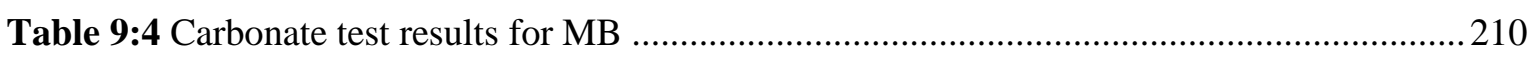




\section{Chapter 1: Introduction}

Peat is a highly organic substance, formed by the accumulation of partially decomposed plant material, in water-logged conditions, over time (Clymo, 1983). Where peat has accumulated across lateral expanses it forms a distinctive landform feature, referred to as a peatland (Charman, 2002). Although they only occupy 3\% of the earth's surface, peatlands are of great environmental significance because they hold $\sim 30 \%$ of terrestrial carbon (equating to approximately the same amount of carbon that is stored in all living plants) (Parish et al., 2008; Blundell and Holden, 2015). Many peatlands continue to sequester atmospheric $\mathrm{CO}_{2}(\mathrm{Parish}$ et al., 2008; Evans et al., 2017) and, as such, they represent an important component in the global carbon cycle (Clay et al., 2015; Blundell and Holden, 2015). In addition, they store $\sim 10 \%$ of the Earth's freshwater reserves (Joosten and Clarke, 2002). Peat accumulations also contain a record of how they developed, and provide an archive of environmental and climatic changes, that can stretch back thousands of years (JNCC, 2011). Given all of these factors, peatlands are extremely important global environments.

In recent decades, much of the peatland research focus has been centred around their carbon storage and dynamics. This focus has come about for two reasons; i) human activities on peatlands, such as burning, cutting and drainage have caused substantial carbon losses (McCarroll et al., 2014; Leifeld and Menichetti, 2018) and ii) there are concerns that predicted atmospheric warming, and shifts in hydrological regimes, might destabilise peatland carbon stocks. The latter could lead to large $\mathrm{CO}_{2}$ emissions and a self-sustaining feedback loop that could accelerate warming (Loisel et al., 2020). This threat that human and climatic forces pose on peatland carbon storage has become a significant global concern in the fight against greenhouse gas climate forcing. 
In light of these concerns, a vast number of studies have investigated peatland carbon accumulation responses to Holocene climatic changes and future projections (Anderson, 2002; Yu et al., 2009; Gallego-Sala et al., 2010; Yu et al., 2012; Charman et al., 2013; Packalen and Finkelstein, 2014; Loisel et al., 2014; van der Linden et al., 2014; Yu et al., 2014; GallegoSala et al., 2018; Ratcliffe et al., 2018; Loisel et al., 2020; Beaulne et al., 2021). Although there are still unanswered questions, the general consensus from these studies is that warming during the $21^{\text {st }}$ century will lead to enhanced carbon accumulation at northern high latitude peatlands (Yu et al., 2012; Charman et al., 2013; Loisel et al., 2014; Yu et al., 2014; GallegoSala et al., 2018). However, the threat of $\mathrm{CO}_{2}$ emissions from mid-latitude peatlands is more immediate. Studies find that peatlands that sit closer to the southernmost end of the northern hemisphere distribution range are likely to be negatively impacted by warming during the $21^{\text {st }}$ century (e.g., Gallego-Sala et al., 2010; Charman et al., 2013; Loisel et al., 2014; Charman et al., 2015; Gallego-Sala et al., 2018). This is because, at these peripheral site's moisture is the limiting factor (Charman et al., 2015). Therefore, the lower summer precipitation and higher temperatures are predicted to drive peripheral peatlands outside of the climatic threshold, resulting in lowered, or ceased, accumulation and the transformation from a carbon sink to source (Charman et al., 2015; Gallego-Sala et al., 2018). Yet, these more threatened peripheral peatlands are underrepresented in carbon accumulation studies and as such their responses are less understood (Yu et al. 2014).

In addition to the threat posed by climatic changes peatland carbon stocks are vulnerable to being further destabilised by human activities. At present, around $10 \%$ of peatlands are being cut, drained, or managed by other means, and this disturbance contributes $5-10 \%$ of annual $\mathrm{CO}_{2}$ emissions (Parish et al., 2008; Leifeld and Menichetti, 2018). Furthermore, several studies find that contemporary drainage, grazing, peat cutting, and fire have led to significant losses in peatland carbon (Garnett et al., 2000; Turetsky et al., 2002; Waddington and Price, 2013; Clay 
et al., 2015). These losses are likely to continue to rise if policies and management strategies are not implemented to conserve peatlands (Gallego-Sala et al., 2018). It is therefore important that appropriate management techniques are developed based on sound knowledge regarding long-term peatland responses. Palaeoenvironmental studies that provide such information can be used to guide conservation approaches (Chambers et al., 2007; Davies and Bunting, 2010; Blundell and Holden, 2015, McCarroll et al., 2016).

\section{1: The Carmarthenshire Peatlands}

The UK's peatlands account for 10-15\% of peatlands in Europe (Ramchunder et al., 2009) and hold carbon within the order of $\sim 2302 \mathrm{Mt}$ (Clay et al., 2015). Wales has more than 90,000 ha of peatlands and these are Wales' biggest store of terrestrial carbon (JNCC, 2011; Evans, 2015; Natural Resources Wales, 2021). However, $75 \%$ of them are already degraded with many affected by the multifaceted impacts of historic peat cutting and drainage (JNCC, 2011; Evans et al., 2015). As a result of this human interference, Welsh peatland carbon stores have been destabilised and they are estimated to be emitting $400 \mathrm{kt} \mathrm{CO}_{2}$ per year (Evans et al., 2015).

In Carmarthenshire, SW Wales, six peatlands have been identified as being within a group referred to as the Carmarthenshire Bogs. These peatlands comprise topogenous raised bogs, that have formed in pre-existing basins, and fens. The sites have attracted attention in recent years, as they represent substantial carbon stores and have visible impacts from human activity (e.g., fire activity and fly-tipping). A preliminary work indicates that they store 108 million $\mathrm{kg}$ of carbon and significantly, two are comparable in depth to the deepest bogs in Wales - Cors Fochno and Cors Caron (Low, 2014). However, these peatlands are threatened by climatic changes and persistent human interference.

The Carmarthenshire peatlands are at risk from projected climate changes because they sit close to the moisture limit of peatland formation (in a UK context) and as discussed above, peatlands 
in these positions are likely to experience carbon losses in response to climatic warming (Gallego-Sala et al., Yu et al., 2014). As such, it is important to assess how the Carmarthenshire bogs have responded in the past, to climatic forcing, so we can anticipate how they might respond in future. Furthermore, such information can inform how other marginal peatlands might respond and thus feed into global peatland carbon projections.

In addition to the threat posed by climate change, the peatlands have been subjected to recent human interference, including burning, drainage, fly-tipping and possibly peat cutting and are in a degraded state. In recent years, these sites were identified by the local authority, Carmarthenshire County Council, as sites of interest for restoration, conservation and also for increasing public awareness of the value of these sites and other peatlands. A reconstruction of long-term changes at these sites provides further context for the implementation of management strategies and public awareness work. Palaeoenvironmental study can provide these valuable insights for the Carmarthenshire peatlands and for other degraded sites.

\section{2: Aims and Objectives}

\subsection{1: Aim}

The aim of this project is to study three of the Carmarthenshire Peatlands in SW Wales (Pyllau Cochion, Figyn Common and Mynydd Bach) in order to: i) investigate their formation and developmental history; ii) reconstruct temporal Holocene carbon accumulation and palaeoenvironmental history; iii) increase educational awareness of the sites and inform management strategies; iv) suggest how these sites might respond to projected climate changes.

\subsection{2: Objectives}

The objectives for the three aforementioned sites are to: 
- Build a robust chronological framework using radiocarbon dating and age-depth modelling.

- Reconstruct high-resolution temporal carbon accumulation by using the chronological framework developed and by measuring carbon content, organic matter content and bulk density.

- Reconstruct palaeoenvironmental history at a high resolution, including surface wetness shifts and fire activity, using carbon:nitrogen ratios, humification and macrofossil charcoal analysis.

- Use the information obtained from the paleoenvironmental and carbon reconstructions to contribute to educational resources for public awareness and to guide future management strategies for the Carmarthenshire bogs.

- Assess Holocene carbon accumulation responses to past climatic changes to suggest how the peatlands might respond to projected climatic changes. 


\section{Chapter 2: Literature Review}

This literature review is structured around three themes. The first section discusses peatland systems, including their development, characteristics, and types. The second section details palaeoenvironmental proxy indicators, and the third section covers the key findings from peatland research, as relevant to this thesis.

\section{1: Introduction: Peatland Systems}

\subsection{1: Peatland Formation}

Peat accumulates over areas where the rate of plant production exceeds the rate of decay (Barber and Charman, 2014). For this to happen there either needs to be a wet climate, to supply sufficient water for waterlogging, or a cold climate, that acts to reduce decomposition, but the temperature is warm enough for plants to grow (Barber and Charman, 2014). These conditions cause a reduction in oxygenation, which in turn hinders decomposition of any surface plants (Joint Nature Conservation Committee, 2011; Rydin and Jeglum 2006; Charman, 2002). The impeded decay results in the remnants of partially decomposed plants beginning to build up in situ, and forming peat, which overtime, can accumulate to substantial depths across extensive areas (Charman, 2002).

This setting is established through a combination of climatic, hydrological, geomorphological, topographic, and biological factors (Barber and Charman, 2014). For example, the presence of suitable features in the landscape, such as basins or relatively flat expanses, that facilitate the collection of water and/or reduce runoff (respectively) (Parish et al., 2008); and a relatively impermeable bedrock geology so that water is retained on the surface (Charman, 2002). Yet, it is not necessary that each of these conditions are met for peat to form. At any given location, all, or just some, of these conditions can contribute towards peat initiation (Charman, 2002). 
For example, peatlands also form in parts of the world where the climate is less suited to peatland development, but features in the landscape, such as basins with steep sides, provide the appropriate water-logged conditions (Parish et al., 2008). Moreover, in oceanic areas, where there is a constant supply of precipitation, the usual topographical setting of reasonably flat land does not apply, here peatlands form at high elevations on steep mountain sides because condensation and clouds can support peat growth (Charman, 2002).

When the appropriate settings for peat formation are present, peatland development can occur via one of three processes, primary peat formation, paludification or infilling (terrestrialisation) (Fig.2.1) (Ruppel et al., 2013; Rydin and Jeglum, 2006).

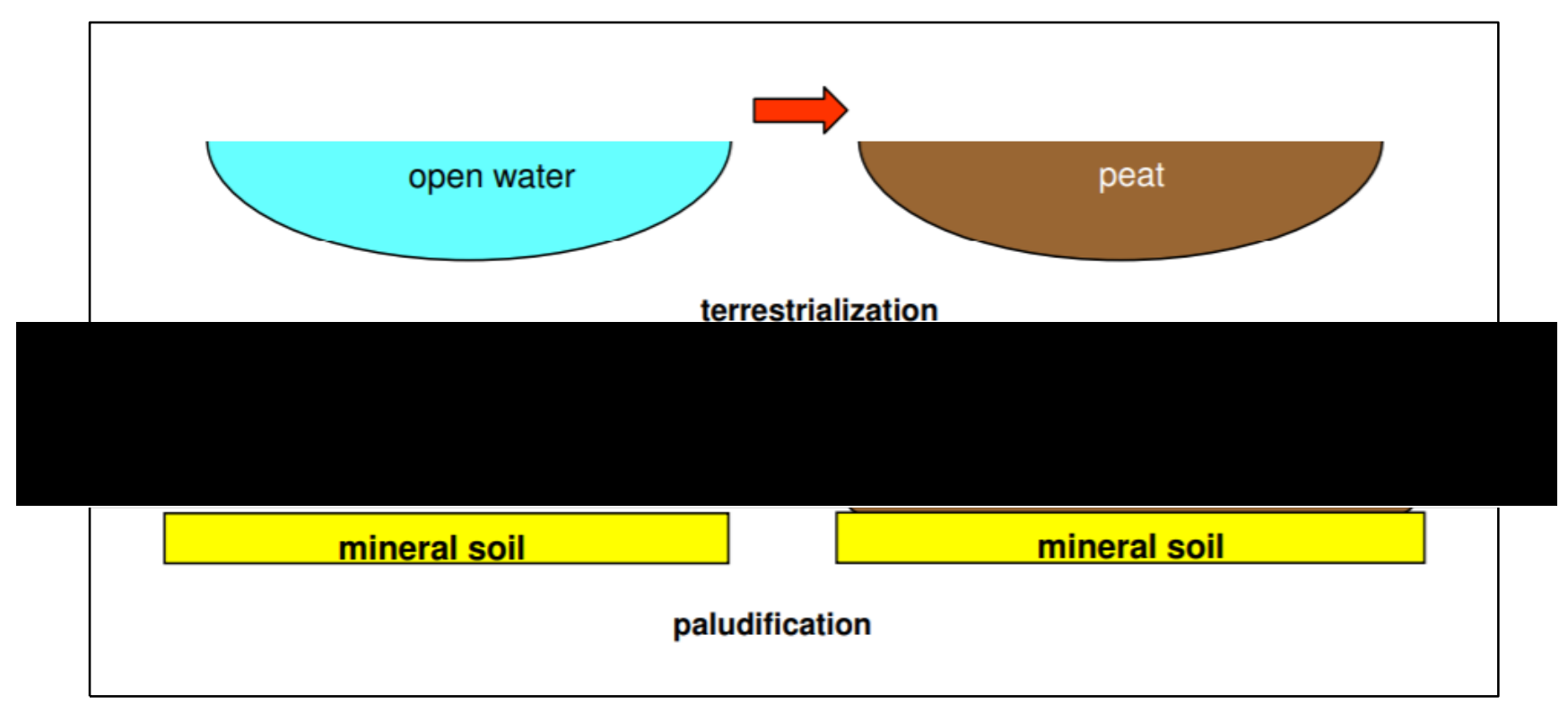

Figure 2:1: Simplified schematic showing the processes of terrestrialisation and paludification. Sourced from Schumann and Joosten (2008).

Infilling (terrestrialisation) is part of a plant community succession, termed the Hydrosere (Fig.2.1; Fig.2.2) (Kilnger, 1996). The classical model of a Hydrosere sequence involves an initial transition from aquatic to fen communities, then fen to bog and finally bog to woodland (Klinger, 1996). Infilling is the first stage of this succession and takes place when aquatic and 
terrestrial plants begin to colonise the site (Rotherham, 2020). Once the plants have established at the site, the water body becomes progressively infilled with organic and non-organic material, including dead plant remains (Rydin and Jeglum, 2006; Anderson et al., 2003; Charman, 2002). The infill of this material within the water body gives rise to reduced oxygen levels which inhibits the decomposition of the plant remains and so they accumulate as peat, usually on top of formerly deposited lake (limnic) sediments (Fig.2.2) (Rotherham, 2020; Charman, 2002).

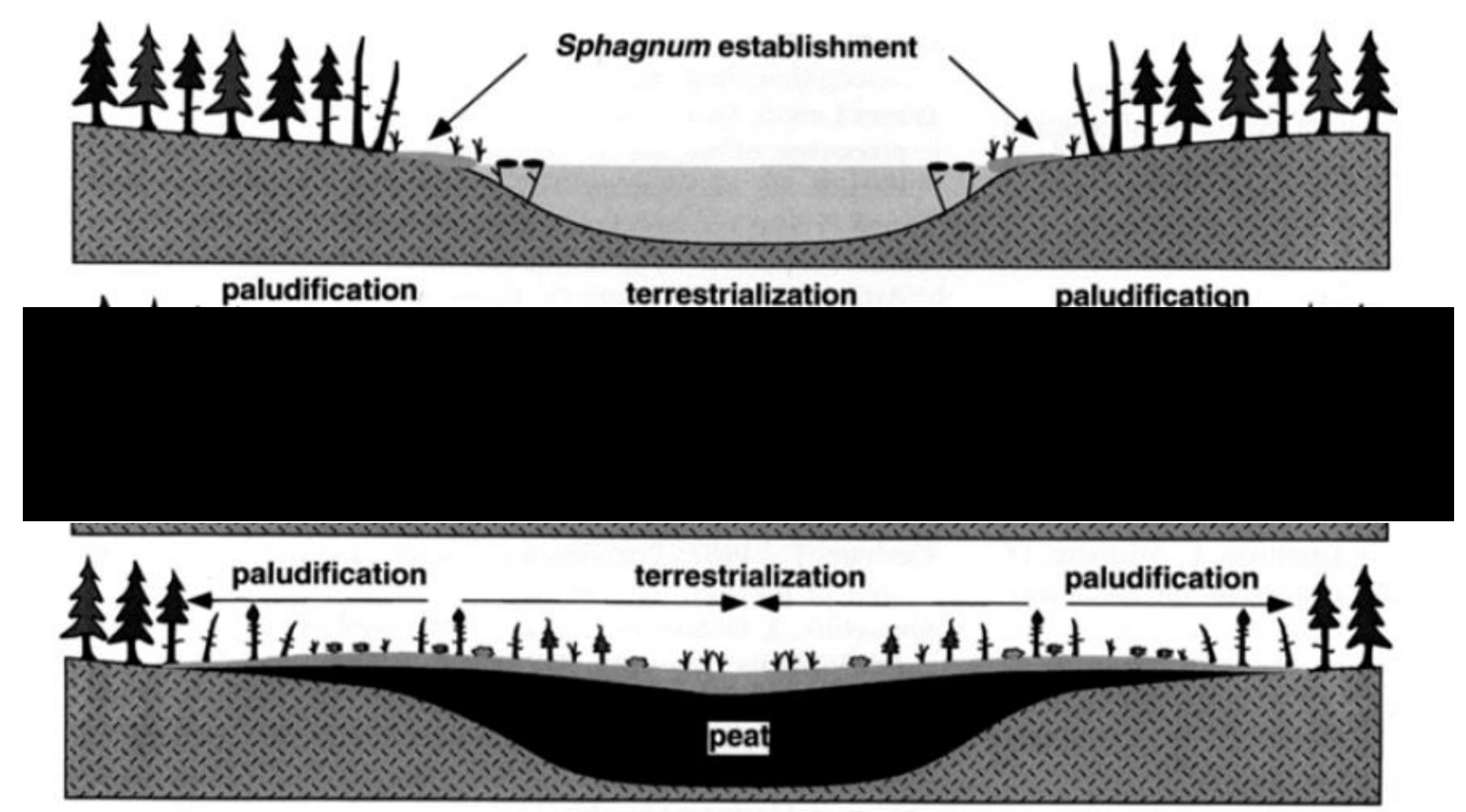

Figure 2:2: The process of terrestrialisation in a basin and lateral expansion via paludification (Klinger, 1996).

Paludification is the prosses of peat forming on a previously drier surface, usually replacing forested land, but also over grassland and bare rock (Fig.2.1; Fig.2.2) (Rydin and Jeglum, 2006; Koster and Favier, 2005; Charman, 2002; Clymo, 1991). In order for paludification to take place there must be a change in the local hydrology, or soil permeability, that stimulates conditions of surface waterlogging on once dry land (Charman, 2002). The presence of the 
water-logged conditions facilitates the growth of peat forming vegetation and reduces decay sufficiently enough for peat to accumulate (Rydin and Jeglum, 2006).

A third pathway to peatland formation is primary peat formation. This process is similar to paludification, but instead of peat accumulating on a surface that was previously dry, it develops on wet, freshly exposed, land (Belyea, 2009; Rydin and Jeglum, 2006). Some examples of where primary peat formation led to peatland development are marine areas that have emerged out of the sea because of crustal uplift, such as the Canadian Hudson Bay Lowlands (Rydin and Jeglum). The newly exposed surfaces are made wet by flowing water from within the catchment (Rydin and Jeglum, 2006). In the northern hemisphere $40 \%$ of peatlands initiated through paludification, $31 \%$ through primary peat formation and $29 \%$ by terrestrialisation (Ruppel et al., 2013).

Once established a peatland may subsequently spread outwards onto the adjacent land by the process of lateral expansion via paludification (Fig.2.2) (Ruppel et al., 2013). Lateral expansion takes place because the soil surrounding the peatland becomes saturated (Anderson, 2003; Korhola, 1992; Korhola et al., 1996). These boundary soils become saturated because the peatland gives rise to an excess in running surface water, impeded drainage, and enhanced humidity (Charman, 2002). Lateral growth can be driven exclusively by autogenic succession (Charman, 2002). If the settings are stable across space and time, a peatland would be expected to expand laterally at a uniform rate unless it faces climatic or topographical barriers (Ruppel et al., 2013; Charman, 2002). In favourable situations a peatland may advance horizontally by several metres each year (Korhola, 1994). 


\subsection{2: Timing and Drivers of Peatland Initiation}

Peatland establishment is attributed to a combination of factors that vary between regions and sites, consequently they developed at different times across the world. Peatlands began forming before $c a .20000$ cal yrs. BP in tropical regions, after $c a .17000$ cal yrs. BP in the southern hemisphere (> $\left.30^{\circ} \mathrm{S}\right)$ and around $c a .16500 \mathrm{cal}$ yrs. BP in the northern hemisphere $\left(>30^{\circ} \mathrm{N}\right)$ (Yu et al., 2010; Macdonald et al., 2006; Morris et al., 2018). This onset of peatland development in the northern hemisphere was driven by temperature increases, and increased availability of suitable sites, after deglaciation (Morris et al., 2018; Yu et al., 2010).

During and following deglaciation new, previously ice-covered, sites became available that were suitable for peatland development. For example, peatlands began to develop on top of sediments within large flat basins of recently drained postglacial lakes, previously ice-covered kettle holes and small water-filled basins (Roberts, 2014; Gorham et al., 2007). These suitable sites were able to mature into peatlands, following the stages of Hydrosere succession, paludification or primary peat formation, in response to the warmer temperatures in the Late Glacial and Holocene (Roberts, 2014).

The climatic changes during the Late Glacial and Holocene were important drivers in Northern peatland initiation $\left(>30^{\circ} \mathrm{N}\right)$. The Late Glacial was characterised by abrupt climatic shifts (Roberts, 2014; Charman, 2010). One of these shifts was the warmer Windermere interstadial that occurred between $c a$. 14700-12900 cal yrs. BP and initial upsurges in peatland establishment coincided with this (Yu et al., 2010; Macdonald et al., 2006) (Fig.2.3). However, the rate of initiation reduced slightly during the Loch Lomond stadial (ca. 12900-11700 cal yrs. BP) that saw average July temperatures fall by $4-5{ }^{\circ} \mathrm{C}$ in Britain (Fig.2.3) (Lowe et al., 1994; Roberts, 2014). Therefore, this reduction in peat initiation was likely in response to the colder conditions during this period (Yu et al., 2010; Macdonald et al., 2006). At the start of 
the Holocene there was a rapid upsurge in new peatlands that is observable until $c a .8000 \mathrm{cal}$ yrs. BP (Fig.2.3) (Yu et al., 2010; Macdonald et al., 2006). This increase in new peatlands was driven by rising temperatures at the start of the Holocene (Fig.2.3) (Yu et al., 2010; Macdonald et al., 2006). Furthermore, further peatland initiation and higher peat carbon accumulation was also driven by the Holocene Thermal Maximum (HTM) (Loisel et al., 2014) that was a period with a relatively warmer climate between $c a$. 9000-6000 cal yrs. BP (Davis et al., 2003; Renssen et al., 2009). New peatlands continued to form throughout the late Holocene, but rates of establishment decreased after ca. 4000 cal yrs. BP (Fig.2.3). However, 'new peatland area' from lateral expansion was highest between $c a$. 5000-1000 cal yrs. BP (Ruppel et al., 2013).
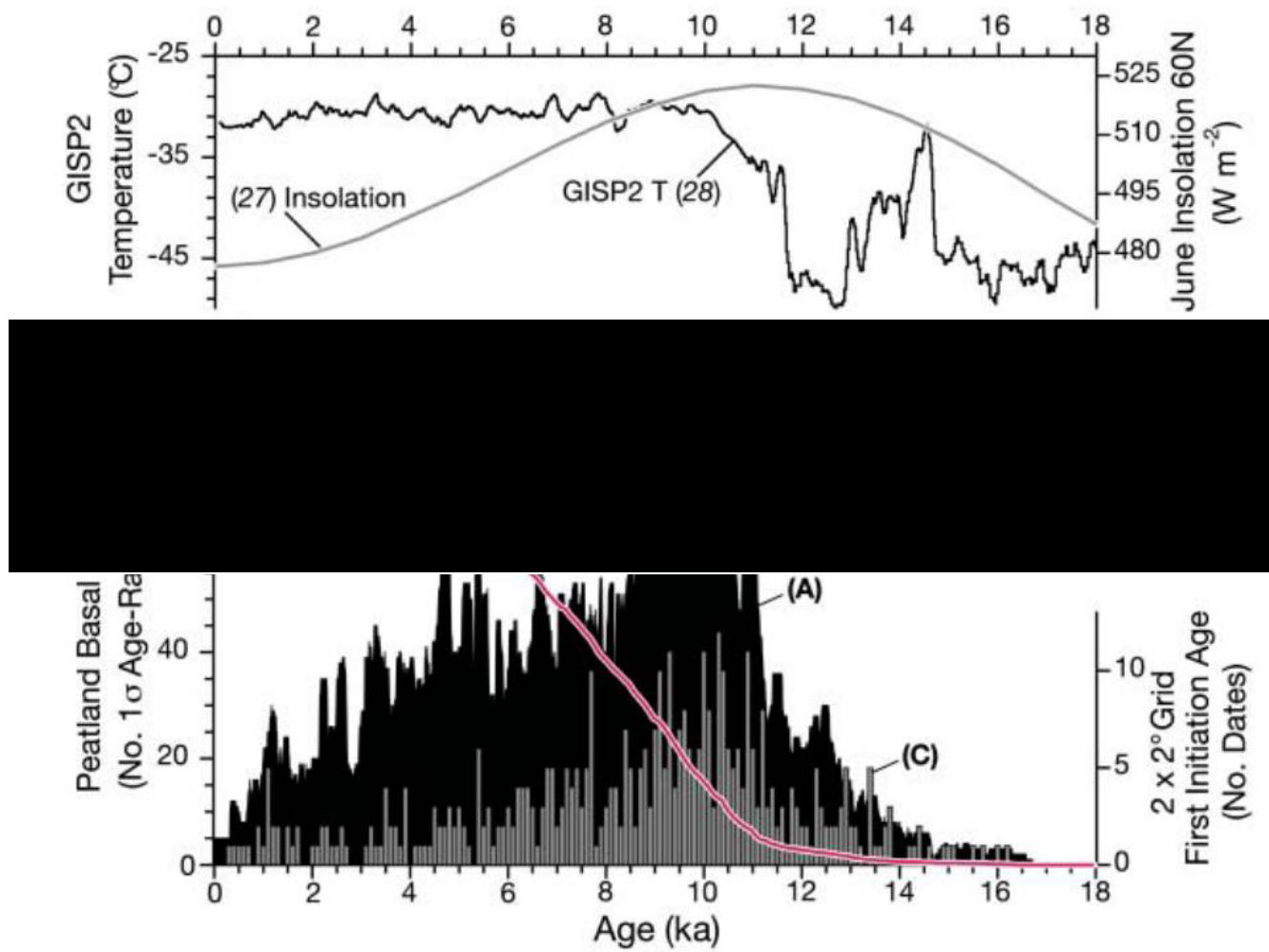

Figure 2:3: Temporal trends in the establishment of northern peatlands relative to northern hemisphere temperature and summer insolation reconstructions. The top graph shows the temperature reconstruction from the Greenland Ice Sheet Project 2 (GISP2) and the June insolation record for the northern hemisphere $\left(60^{\circ} \mathrm{N}\right)$. The bottom plot comprises: A) a frequency graph of 1516 peat basal dates, B) the cumulative basal dates curve and C) the oldest dates of peat initiation within every $2^{\circ}-$ by $-2^{\circ}$ area included in this study. Figure sourced from Macdonald et al., (2006). 
In Britain there was a peak in peatland initiation between $c a$. 8000-4000 cal yrs. BP (GallegoSala et al., 2015). This rise in initiation was first hypothesised to be the result of Mesolithic and Neolithic land use practices that led to enhanced soil impermeability and promoted the process of paludification (Simmons 2003 and 1996; Robinson and Dickson, 1988; Moore, 1973, 1975 and 1993). However, more recent studies suggest that this upsurge in blanket bog expansion was triggered solely by climatic factors, including the onset of neoglacial conditions after ca. 6000 cal yrs. BP with summers around $\sim{ }^{\circ} \mathrm{C}$ colder (Gallego-Sala et al., 2015; Tipping, 2008; Charman, 2002; Ellis and Tallis, 2000). These cooler conditions made some areas in the south, that were previously too warm, suitable for blanket bog formation (GallegoSala et al., 2015).

\subsubsection{1: Peatland initiation in Wales}

In Wales, peatland initiation was also driven by climatic changes during the Late Glacial and Holocene (Gallego-Sala et al., 2015) and the timing of initial formation varies greatly from $c a$. 3500 to $c a .12800$ cal yrs. BP (Table 2.1).

Table 2:1: Peatland initiation dates for several Welsh Peatlands. Dates reported are cal. yrs BP and presented in the format in the original source.

\begin{tabular}{|l|l|l|l|}
\hline \multicolumn{1}{|c|}{ Site } & $\begin{array}{l}\text { Peatland Initiation date } \\
\text { (ca. cal yrs. BP) (as } \\
\text { reported in the citation) }\end{array}$ & Peatland type & \multicolumn{1}{|c|}{ Reference } \\
\hline $\begin{array}{l}\text { Crymlyn Bog } \\
\text { close to Swansea, } \\
\text { south Wales }\end{array}$ & $5652-5896$ & Lowland Fen & $\begin{array}{l}\text { Hughes and Dumayne- } \\
\text { Peaty, 2002 }\end{array}$ \\
\hline $\begin{array}{l}\text { Borth Bog } \\
\text { Ceredigion, mid Wales }\end{array}$ & $6910-7170$ & Raised bog & $\begin{array}{l}\text { Hughes and Schulz, } \\
2001\end{array}$ \\
\hline $\begin{array}{l}\text { Tregaron Bog } \\
\text { Ceredigion, mid Wales }\end{array}$ & $7520-7695$ & Raised bog & $\begin{array}{l}\text { Hughes } \text { et al., 2007 } \\
\text { and references Hughes } \\
\text { et al., 2001 therein }\end{array}$ \\
\hline $\begin{array}{l}\text { Rhos Goch Common } \\
\text { Powys, mid-east Wales }\end{array}$ & $9790-10195$ & Raised bog & Hughes et al., 2007 \\
\hline $\begin{array}{l}\text { Un-named site } \\
\text { Brecon Beacons }\end{array}$ & 4295 & Blanket Bog & Chambers, 1982 \\
\hline Cefn Ffordd & 3500 & Blanket Bog & Chambers, 1982 \\
\hline
\end{tabular}




\begin{tabular}{|l|l|l|l|}
\hline $\begin{array}{l}\text { close to the Rhondda } \\
\text { Valley }\end{array}$ & & & \\
\hline $\begin{array}{l}\text { Waun-Fignen-Felen in } \\
\text { the Brecon Beacons }\end{array}$ & 7600 & Raised Bog & $\begin{array}{l}\text { Smith and Cloutman, } \\
1988\end{array}$ \\
\hline $\begin{array}{l}\text { Cefn Glas } \\
\text { close to the Rhondda } \\
\text { Valley }\end{array}$ & $3600-4100$ & Valley Bog & Smith and Green, 1995 \\
\hline $\begin{array}{l}\text { Craig y Ciliau } \\
\text { Brecon Beacons }\end{array}$ & 11214 & Raised bog & Carless, 2015 \\
\hline $\begin{array}{l}\text { Gwaun Nant Ddu } \\
\text { Brecon Becons }\end{array}$ & 12837 & Raised bog & Carless, 2015 \\
\hline $\begin{array}{l}\text { Mawnbwll Du Marw } \\
\text { Brecon Beacons }\end{array}$ & 4853 & Raised bog & Carless, 2015 \\
\hline
\end{tabular}

\subsection{3: Geographical Distribution of Peatlands}

Peatlands are most abundant in wet areas, i.e., tropical, and oceanic regions, and in cold subarctic and boreal regions (Fig.2.4) (Parish et al., 2008). However, there are peatlands in nearly every country around the World (Fig.2.4) (Bain et al., 2011) and they occupy an estimated 4.23 million $\mathrm{km}^{2}(\sim 2.84 \%)$ of the Earth's land area (Xu et al., 2018).

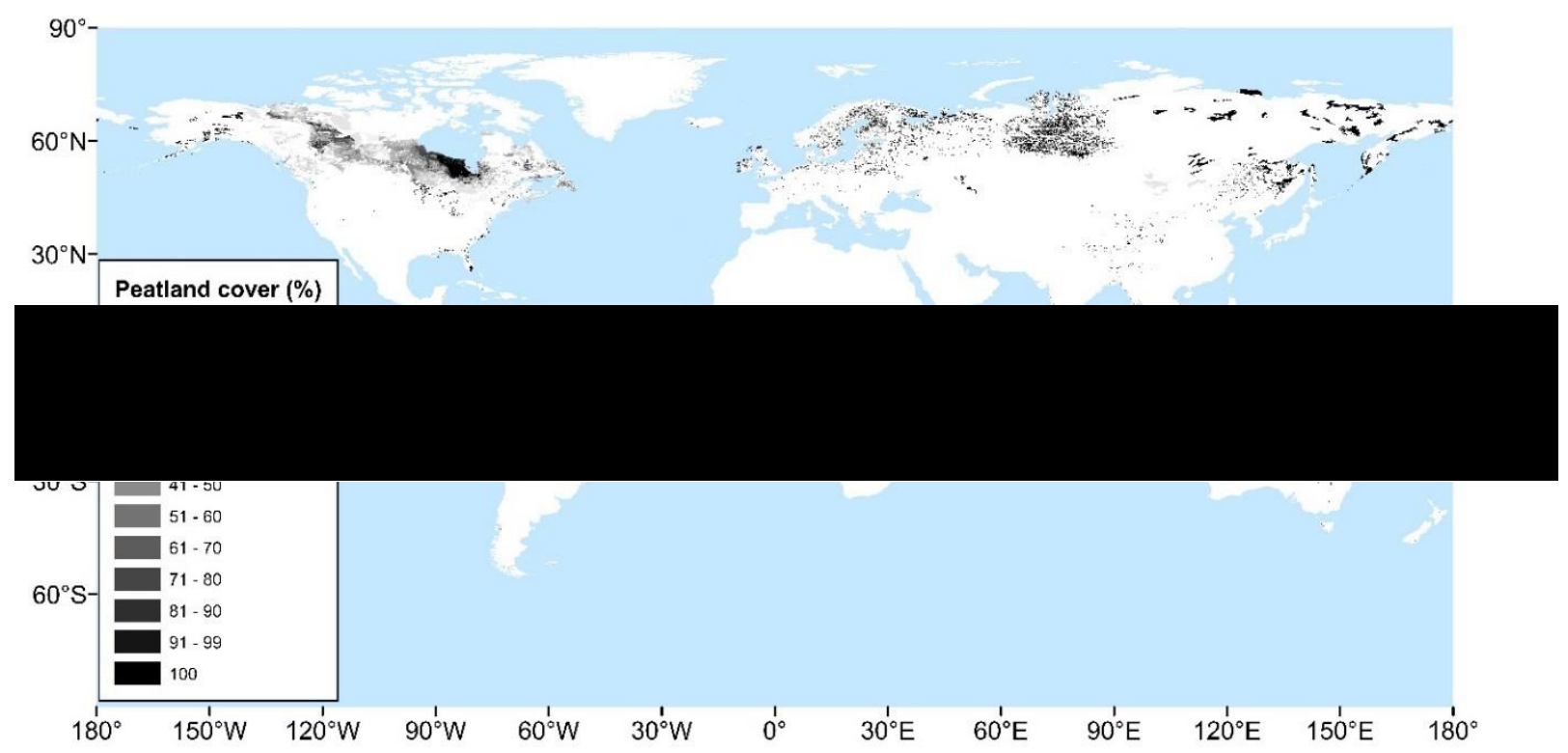

Figure 2:4: Map of the global distribution of peatlands. Sourced from Xu et al., (2018).

The estimated land area occupied by peatlands is distributed unevenly across the globe, with $38.4 \%$ of it in Asia, $31.6 \%$ in North America, $12.5 \%$ in Europe, $11.5 \%$ in South America, $4.4 \%$ in Africa, and 1.6\% in Oceania and Australasia (Xu et al., 2018) (Fig.2.4). Of the peatlands in 
Europe, around $9-15 \%$ of them are located in the UK (Montanarella et al., 2006) where peatlands cover approximately $11 \%\left(\sim 27,000 \mathrm{~km}^{2}\right)$ of the land area (Fig.2.5) (Tanneberger et al., 2017). In the UK, Scotland has the highest peatland area, with $23,269 \mathrm{~km}^{2}$, followed by England $\left(6,799 \mathrm{~km}^{2}\right)$, Northern Ireland $\left(2,064 \mathrm{~km}^{2}\right)$ and Wales, with $706 \mathrm{~km}^{2}$ (Fig.2.5) (Bain et al., 2011).

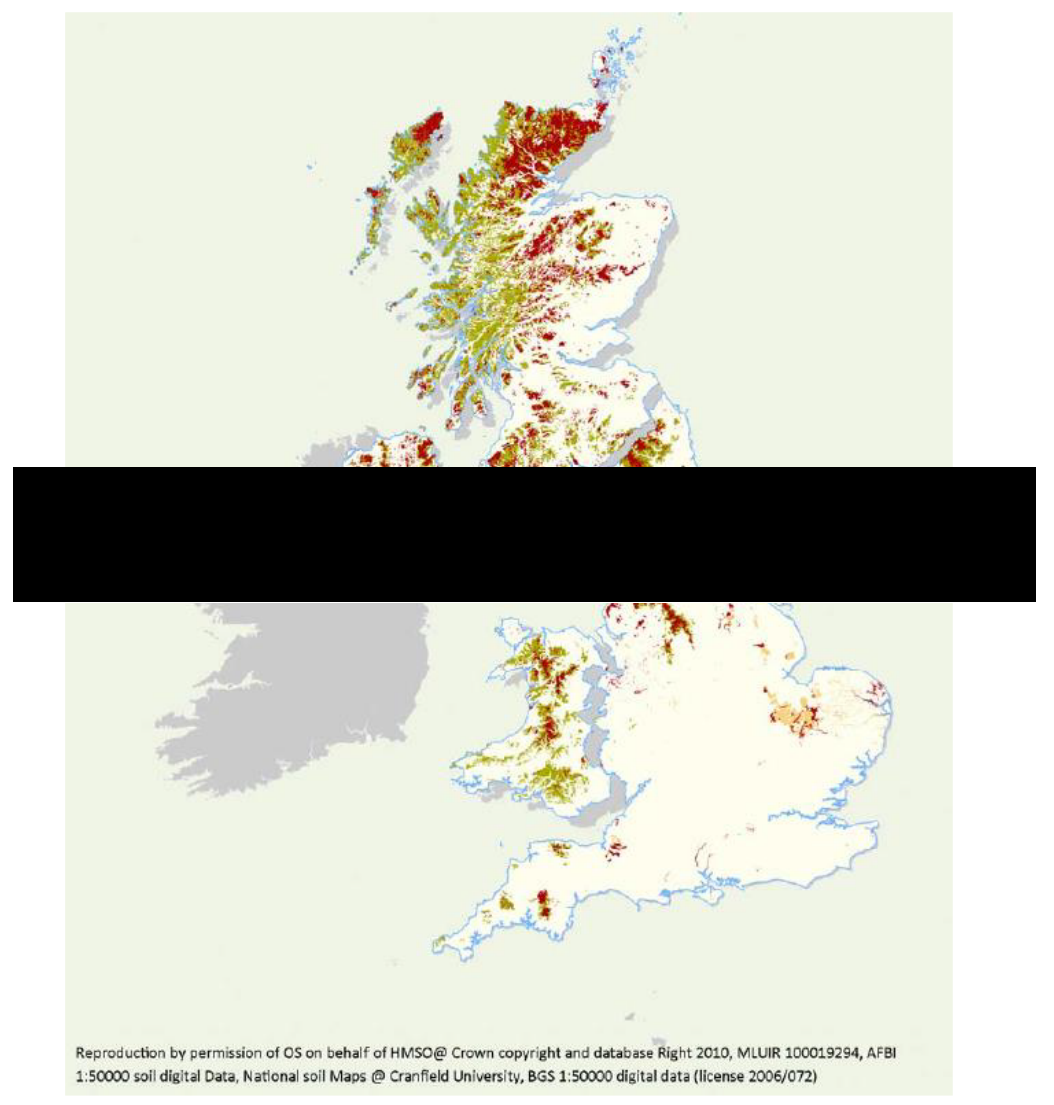

Figure 2:5: A map of peatlands (dark red) and peaty soils (green) in the UK. In this figure peaty soils, in Northern Ireland, and Scotland, are areas that have $10-50 \mathrm{~cm}$ peat, and in England and Wales 10$40 \mathrm{~cm}$ of peat. A peatland is an area with 'deep peaty soils' i.e., with peat deposits in excess of the depths above. Sourced from JNCC (2011).

Wales has $\sim 90,000$ ha of peatlands (Fig.2.5) (Natural Resources Wales, 2021). Blanket bogs are by far the most common peatland type. However, low-land peatlands also exist, although vast stretches are rare, excluding Cors Caron (Tregaron) and Cors Fochno (Borth). On the other hand, smaller scale low-land peatlands are common, such as the Carmarthenshire bogs in SW Wales - the focus of this study. 
Although comprehensive databases of global peatland coverage exist (e.g., Xu et al., 2018 and Parish et al., 2008) it is theorised that many peatlands have yet to be reported, including large areas in South America, central Asia, and Africa (Parish et al., 2008). There is evidence to support this this theory, including a modelling analysis by Gumbricht et al., (2017), that suggests peatland area in tropical regions might be threefold the amount that is currently estimated. Furthermore, the recent discovery of an enormous peatland $(\sim 145,500 \mathrm{~km} 2)$ in the Congolese Basin (Africa) (Dargie et al., 2017) indicates that there could be other unidentified peatlands. In addition, smaller scale peatlands are also commonly overlooked, such as the Carmarthenshire peatlands, for example, that are not included in the UK's peatland distribution map (Fig.2.5). This suggests that current peatland maps underestimate the distribution.

\subsection{4: Peatland Structure}

\subsubsection{1: Diplotelmic Model (Acrotelm-Catotelm)}

The structure of a peatland is referred to as diplotelmic because it is comprised of two distinct zones, the acrotelm and the catotelm (Fig.2.6) (Rydin and Jeglum, 2006). The acrotelm sits above the lowest depth that the water table falls to and the catotelm sits below it (Fig.2.6) (Rydin and Jeglum, 2006). The uppermost layer, the acrotelm, or active zone, is relatively thin and can range anywhere between $3-75 \mathrm{~cm}$ in depth (Lindsay, 2010). Within the acrotelm the water table fluctuates seasonally, typically between $5-25 \mathrm{~cm}$ below the ground surface (Evans et al., 1999) and because of this fluctuation much of the acrotelm is subject to the action of oxygenation and thus aerobic decay (Lindsay, 2010). The rate of acrotelm decay is therefore significantly affected by water table height, as when it is lower more peat is exposed and available for aerobic decay (Clymo, 1983). However, other factors such as temperature and plant composition also influence decay rates in the acrotelm (Charman, 2002). In this active zone there is a surface layer of living vegetation and an underlying layer of mostly dead 
vegetation (Fig.2.6) (Clymo, 1992). The dead vegetation becomes partially decomposed and flattened with depth until it begins to accumulate below the water table, in the lowermost 'inactive' zone - the catotelm, where further decay is reduced significantly by the water-logged oxygen deprived conditions (Fig.2.6) (Clymo, 1992). The boundary between the two zones is typically characterised by a sharp increase in bulk density as you move down profile, to the denser, more humified (decomposed) catotelm peat (Clymo, 1992; Clymo, 1984). The catotelm comprises most of the peatland volume (Rydin and Jeglum, 2006).

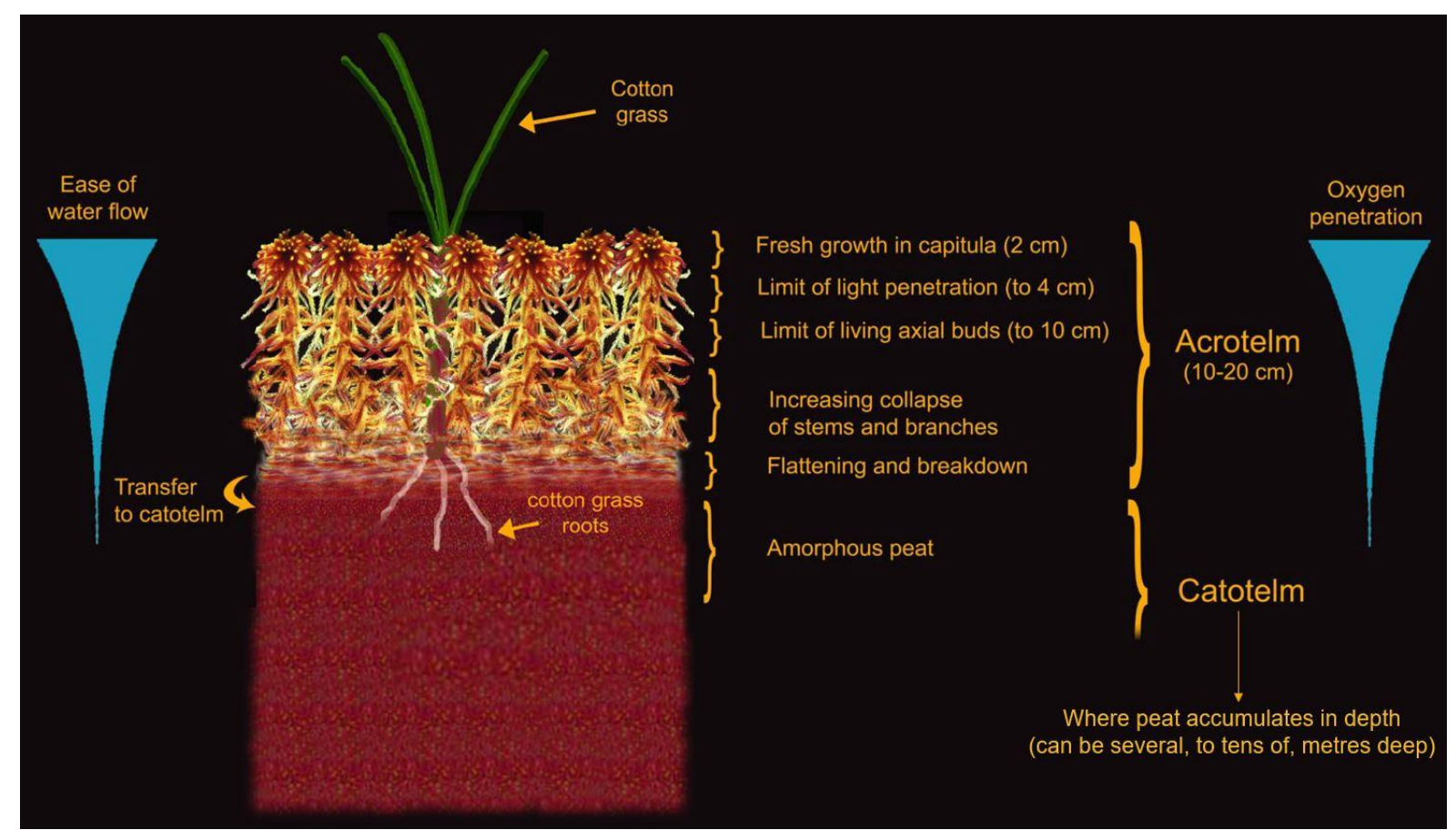

Figure 2:6: The structure of a peatland in its idealised natural state. The processes that take place in the acrotelm and catotelm layers are shown to illustrate how they lead to the accumulation of peat. Sourced and adapted from Lindsay (2010), based on the model from Clymo (1983 and 1992).

\subsubsection{2: Criticisms of the Diplotelmic Model (Acrotelm-Catotelm)}

The diplotelmic model (acrotelm-catotelm) has been used to describe peatland dynamics for several decades, but more recent research suggests that it is an oversimplification of the peatland structure (e.g., Morris et al., 2011). This view on the diplotelmic model has developed for several reasons. One of the arguments is that the boundaries between the acrotelm and 
catotelm are not static and homogenous, like the model suggests (Morris et al., 2011). Furthermore, the changes in rate of decay and hydraulic conductivity, that underpin the acrotelm-catotelm model, are not synchronous and should be investigated as separate variables (Morris et al., 2011). In addition to this, it places too much emphasis on the role of the water table, as other factors, such as the presence of gas bubbles, can influence hydraulic conductivity and decay in a peatland (Baird and Waldron, 2003; Morris et al., 2011). There are also issues with the cut-off points of the boundary used for the diplotelmic model. To elaborate, the model specifies that the acrotelm sits above the lowest point that the water table reaches, but this is typically only reached during extreme periods of drought and therefore is more commonly part of the catotelm (Siegel and Glaser, 2006; Morris et al., 2011). A more appropriate cut-off might be to base the acrotelm boundary on the mean annual water table depth (Siegel and Glaser, 2006). Considering these arguments, it has been suggested that the terms anoxic-oxic, saturated-unsaturated, low decay-high decay or hot/cold spots may be more appropriate to describe the more active and less active zones of a peatland, as these are clearer and allow for more flexibility and heterogeneity (Morris et al., 2011).

\subsection{5: Peatland Carbon Sequestration}

Carbon is sequestered by peatlands because inputs of carbon to the system outweigh the outputs and so it acts as a carbon 'sink' (Charman, 2002). The main source of peatland carbon is carbon dioxide $\left(\mathrm{CO}_{2}\right)$ from the atmosphere which is incorporated into the system through plant photosynthesis (Charman, 2002) (Fig.2.7). This process takes place in every terrestrial ecosystem, and typically, once a plant dies it decomposes rapidly from the effects of oxygen exposure and emits much of the carbon stored within it back into the atmosphere as $\mathrm{CO}_{2}$ (Joosten, 2008 (b)). However, in a peatland, dead vegetation is only subjected to aerobic decomposition for a short time because it is soon transferred into the oxygen deprived, waterlogged catotelm (Clymo, 1984). As a result of this situation the dead plant matter in peatlands 
does not decay fully and so some of its carbon is retained and stored as peat in the catotelm, where it is only subjected to a very slow rate of anaerobic decay (Fig.2.7) (Clymo, 1984).

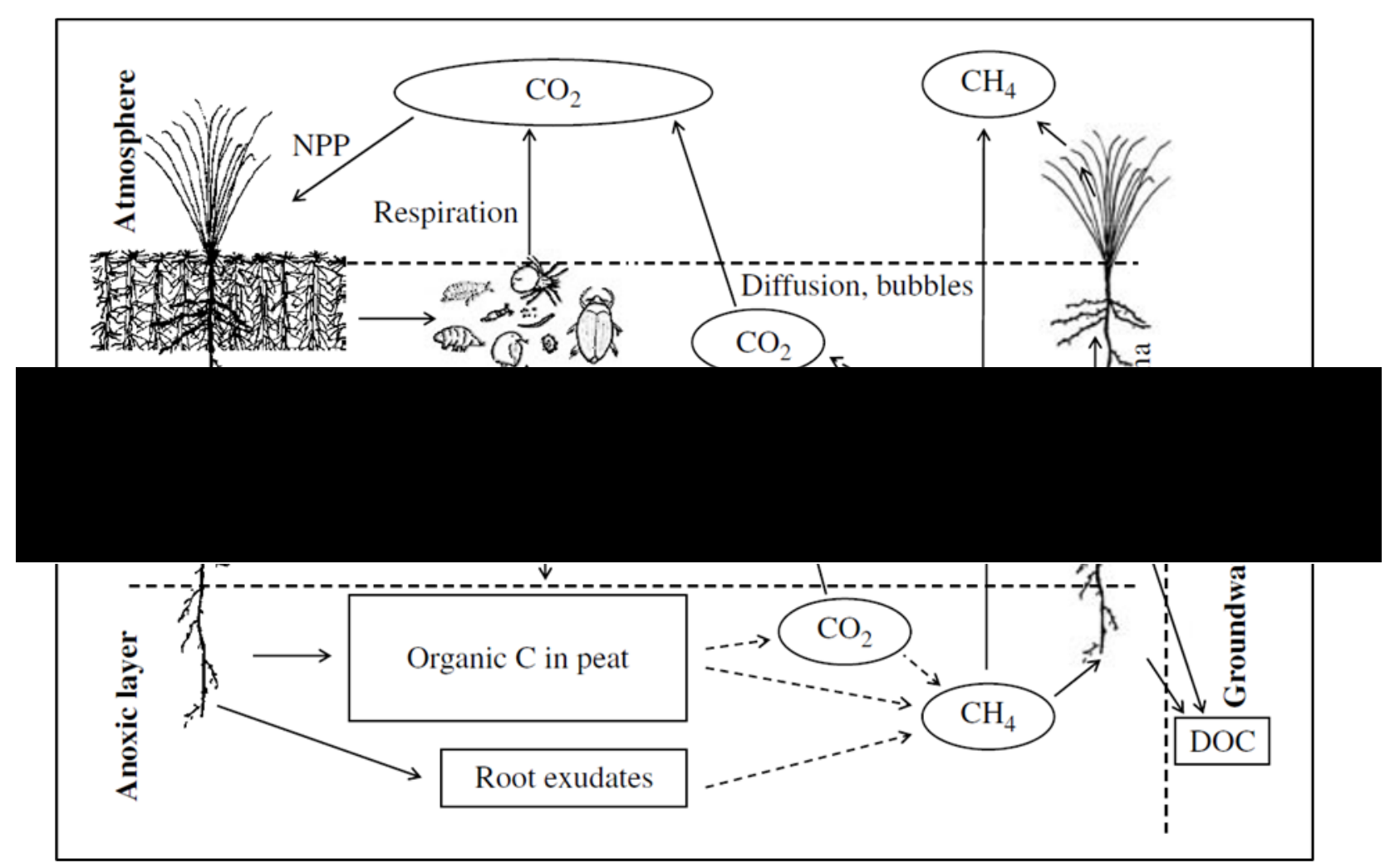

Figure 2:7: The carbon inputs and outputs into the peatland system. The upper oxic layer is the acrotelm and the lower anoxic layer is the catotelm. Gas components are circled, and solid components are outlined with squares. Dashed arrows indicate microbial action. Net primary production (NPP) equals the difference between plants' respiration and photosynthesis. Dissolved organic carbon (DOC) percolates out from the two peatland layers through the groundwater (Rydin and Jeglum, 2006).

\subsection{6: Peat Components}

The biggest component of peat is water, that makes up 85-98\% of its weight (Fig.2.8) (Lindsay, 2010; Schumann and Joosten, 2008 (a)). The remaining 2-15\% of peat is dry solid matter (Fig.2.8) (Lindsay, 2010) comprised of organic, and to a lesser extent, inorganic material (Fig.2.8). Peat bulk density typically ranges between $0.05-0.2 \mathrm{~g} \mathrm{~cm}^{3}$ in mid to high latitudes (Charman, 2002). 


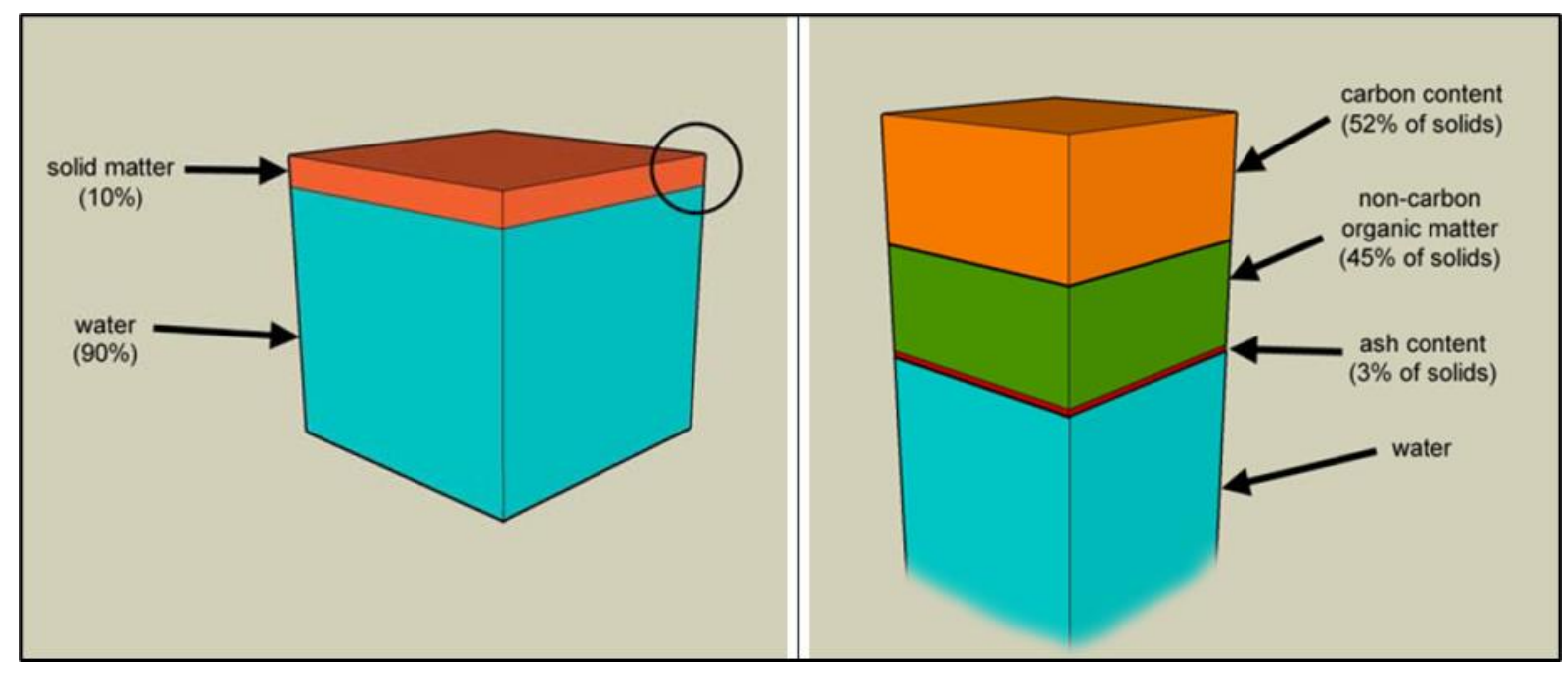

Figure 2:8: Peat components: Left: the relative amounts of water and solid matter, by weight, within a typical peat block. Right: the part circled in the left diagram is scaled up to give more detail on the relative fractions of ash (mineral) and organic (carbon and non-carbon) content in the solid matter component of the peat block. The diagram is based on data from an amalgamation of peatland research and sourced from Lindsay (2010).

It is difficult to state exactly what percentage of peat is organic and inorganic because numerous figures exist for the minimum accepted proportions. Soil maps tend to classify a peat as any soil with $>30 \%$ organic content, however, ecologists would consider a typical peat, i.e., the deep accumulations in bogs and fens, to have a minimum of $80-90 \%$ organics and therefore a mineral matter content lower than 20\% (Rydin and Jeglum, 2006). Furthermore, the inorganic content varies depending on peatland type, for ombrotrophic bogs it is very low, typically 14\% (Lindsay, 2010) whereas in fens, it can be much higher (Lindsay et al., 2014). This is because fens receive mineral inputs from precipitation and mineral-rich ground water, in contrast to ombrotrophic bogs that are solely precipitation-fed (Barber and Charman, 2014). Therefore, generally speaking, the solid component of peat can have an organic matter percentage of between $30-90 \%$, or more. The organic fraction of peat is approximately $50 \%$ carbon and 50\% non-carbon (Fig.2.8); therefore, peat is very carbon rich (Joosten, 2008(a)). 


\subsection{7: Peatland Types and Development}

\subsubsection{1: Fens and Bogs}

There are numerous peatland types, and they are classified based on various attributes. The term mire is used to refer to peatlands that are actively accumulating peat (Rydin and Jeglum, 2006; Dunn and Freeman, 2011).

A key distinction in the literature is made between fen and bog. This division is classically based on the source of water to the peatland (Parish et al., 2008; Wheeler and Proctor, 2000). A peatland that is fed by groundwater and precipitation is a 'minerotrophic fen' and peatland that receives water from atmospheric sources is referred to as an 'ombrotrophic bog' (Fig.2.9) (Parish et al., 2008; Rydin and Jeglum, 2006; Charman, 2002; Wheeler and Proctor, 2000).

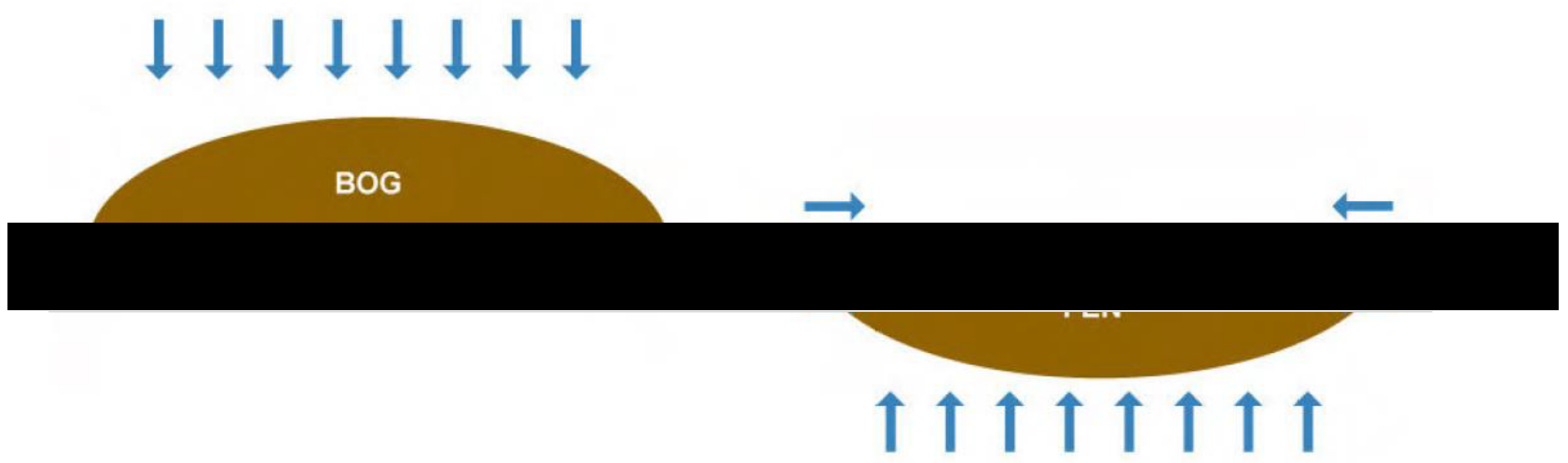

Figure 2:9: Schematic illustration of the difference between a bog and a fen in terms of their position on the ground surface and water inputs (blue arrows). Sourced from Joosten (2008(b)).

Bogs are reliant on atmospheric water because they sit above the ground surface and resultantly become isolated from groundwater (Joosten, 2008 (b)) (Fig.2.9). However, many bogs will still be influenced by ground water inputs if only to a minor extent but will display the same vegetational and trophic status as ombrotrophic bogs because they are predominantly precipitation-fed (Wheeler and Proctor, 2000). Therefore, the definition of bogs is sometimes 
widened to include those that are mostly fed by atmospheric inputs and display the same attributes (Wheeler and Proctor, 2000). Bogs and fens contrast markedly in terms of their nutrient status, mineral content, $\mathrm{pH}$, and vegetation (Fig.2.10). These attributes can be used to identify one from another.

Bogs are typically oligotrophic (nutrient deficient) and highly acidic because they mainly receive inputs from nutrient poor precipitation (Charman, 2002) (Fig.2.9). Whereas the nutrient levels of fens are more variable, as they receive nutrients from atmospheric and telluric sources (Charman, 2002). Consequently, a fen can be weakly oligotrophic, mesotrophic (intermediate nutrient status) or eutrophic (nutrient rich), depending on the surrounding geology (Charman, 2002; Succow and Joosten, 2001). This increasing nutrient availability and decreasing acidity corresponds with the different types of fens cited, poor, intermediate, or rich fen (Fig.2.10).

These contrasting water inputs, nutrient status, and $\mathrm{pH}$ characteristics are associated with different types of vegetation composition (Fig.2.10) (Wheeler and Proctor, 2000). In general, an undisturbed bog in the UK is dominated by only a few plants, including Sphagnum moss, dwarf shrubs and sedges (Lindsay et al., 2014; Rydin and Jeglum, 2006). Sphagnum moss plays a significant role because it often provides a surface for the growth of other plants and is decay resistant so promotes peat accumulation (Lindsay et al., 2014). Fens can also be populated with bryophytes, but to a lesser extent, and because of their varying nutrient and $\mathrm{pH}$ status they typically comprise a wider array of plants than bogs. These plants include Carex sedges, reeds, and sparse tall shrubs, often referred to as shrub carr (Lindsay et al., 2014; Rydin and Jeglum, 2006). 


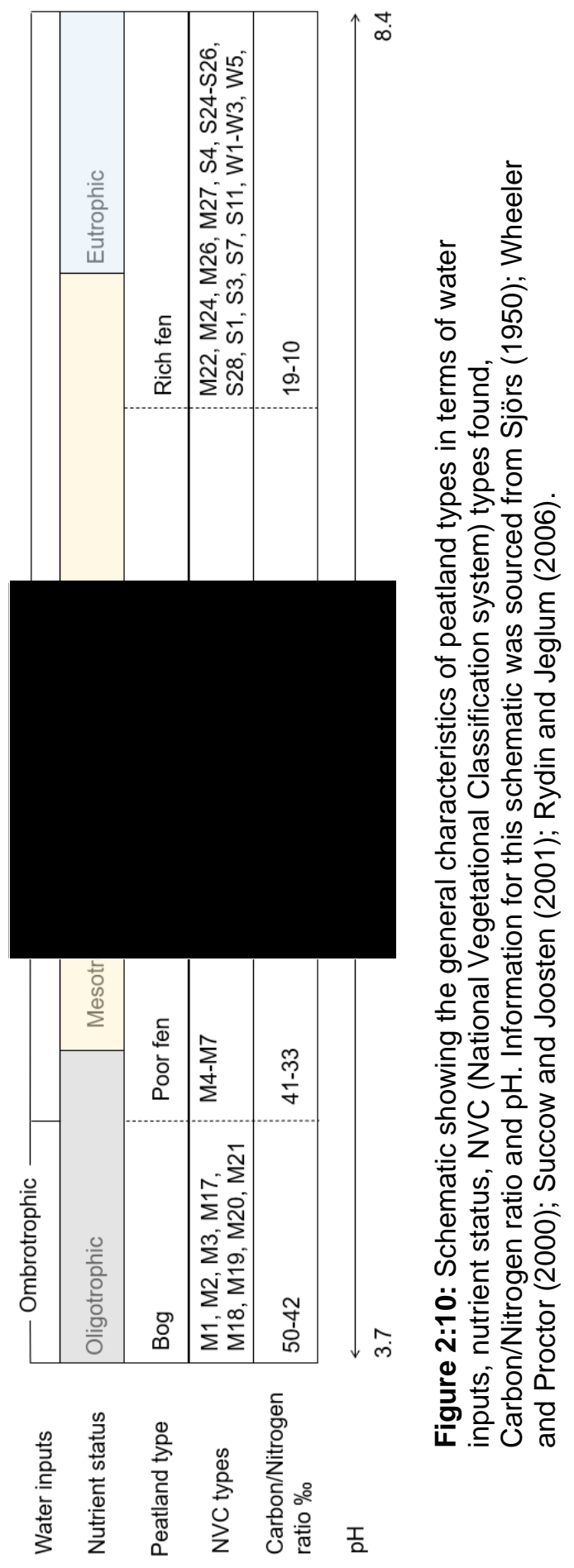

In addition to vegetation differences, the resulting peat accumulations that develop also differ in character. For example, a bog peat will typically have a mineral content as low as $2 \%$ 
whereas a fen peat will have higher mineral matter because they are fed by mineral-rich groundwaters (Lindsay et al., 2014).

A bog and fen also vary in terms of resilience and distribution. Fens tend to be more resilient to changes in evapotranspiration and can prevail in a variety of climates, because they receive constant groundwater inputs (Barber and Charman, 2014; Charman, 2008; Parish et al., 2008). In contrast, bogs are highly receptive to hydrological shifts and exist predominantly in wet climatic settings as they are dependent on atmospheric influences (Barber and Charman, 2014; Charman, 2002).

Peatlands can also change in status and from a bog to a fen or vice versa, due to autogenic development, shifts in climate or human interference (Hughes et al., 2007). Resultantly a peat sequence can comprise sections of both fen and bog peat.

\subsubsection{2: The Fen to Bog Transition}

The majority of peatlands initially develop as minerotrophic fens and a large proportion of them transition to ombrotrophic bogs (Loisel and Bunsen, 2020). This shift is commonly referred to as the fen to bog transition (FBT). The FBT is viewed as part of the Hydrosere sequence (see peatland formation section). For the FBT to take place the peat surface must become perched above the fen ground water table (Belyea, 2009). There are several ways in which the FBT can take place.

Autogenic development can facilitate the FBT, when separation from the fen groundwater table happens because the peat accumulates to a height that is above it (Belyea, 2009). This progression is then enhanced through 'Sphagnum engineering' as it alters the chemical and physical environment making it more and more suited to peat accumulation (Belyea, 2009). 
Alternatively, the peat surface may become perched above the water table because of allogenic changes, such as increases in precipitation. For example, Hughes and Barber (2004) theorised that increased precipitation around the $8.2 \mathrm{ka}$ event flushed out minerogenic ground water and encouraged the growth of Sphagnum lawns at an Irish peatland. These Sphagnum lawns continued to grow upward and meant that the peat surface then sat above the ground water table (Hughes and Barber, 2004). In addition to this, evidence of high precipitation aiding the FBT, through promoting tussock development and subsequent nutrient leaching, has also been found in South Wales around ca. 2600 cal yrs. BP (Hughes and Dumayne-Peaty, 2002) and in Ireland, at ca. 5400 cal yrs. BP (Hughes and Barber, 2004). Furthermore, a widespread shift to ombrotrophication in British peatlands, around $c a .5000$ cal yrs. BP, is thought to be associated with the onset on wetter conditions that prevailed after $c a .6000$ cal yrs. BP (Barber et al., 2003).

The third way in which peat might become raised above the ground water table surface is because of decreases in precipitation, or drought phases. These drier conditions can lead to a lowering of the water table and isolate some of the peat surface above it (Hughes, 1997; Hughes et al., 2000; Hughes, 2000; Hughes and Dumayne-Peaty, 2002; Hughes and Barber, 2004). Such drought induced bog transitions are found in the early Holocene when the climate was warmer and drier (Barber et al., 2003). For instance, the FBT at Bolton Fell Moss that occurred at ca. 9800 cal yrs. BP (Hughes and Barber, 2004).

Volcanic activity has also been found to promote the FBT in peatlands proximal to volcanic activity in Patagonia (Loisel and Bunsen, 2020). It is hypothesised that volcanic sulphur dioxide plumes led to enhanced peatland acidification and a subsequent shift to ombrotrophication (Loisel and Bunsen, 2020). However, they speculate that the volcanic activity only acted as a 'tipping point' as the once fen environments were already experiencing drying due to autogenic development (Loisel and Bunsen, 2020). They therefore propose a 
model that portrays the FBT as a partially autogenic Hydroseral succession that can be triggered by allogenic factors (Loisel and Bunsen, 2020). This notion is supported by the work of Hughes and Dumayne-Peaty (2002) who find that a mature fen can be pushed to shift into a bog by allogenic forcing, but the thresholds of change vary largely (Hughes and DumaynePeaty, 2002).

Another important factor in the FBT is the maintenance of a raised bog water table after the transition. It is theorised that this is maintained by the development of an impermeable catotelm layer (Ingram 1982). There is limited research about the mechanisms that create this impermeable layer. However, peatland investigations in England and Wales, find evidence that the impermeable layer is created through water table instability in the newly raised peat (Hughes, 1997; Hughes et al., 2000; Hughes and Dumayne-Peaty, 2002; Hughes and Barber, 2004).

This instability is theorised to be because a deep enough raised catotelm zone had not yet been formed and therefore it could not maintain a near surface water table (Hughes et al., 2000). Resultantly, the newly raised peat was significantly affected by seasonal changes in precipitation and at times experienced desiccation (Hughes et al., 2000). The drier conditions promoted growth of Eriophorum and Calluna plants that were rapidly decayed, and this highly decayed material provided a suitably impermeable peat stratum on top of which a stable raised water table and ombrotrophic bog, could be maintained (Hughes, 1997; Hughes et al., 2000; Hughes and Dumayne-Peaty, 2002; Hughes and Barber, 2004). Highly humified layers of peat are commonly found just before the onset of raised bog conditions and are thought to represent this period when the water table was unstable in the newly raised peat (Hughes et al., 2000).

The development of an impermeable surface leading up to the transition has been reported to last as long as hundreds, or even thousands of years before the raised water table stabilises 
(Hughes et al., 2000; Anderson, 2002). Whilst this process is taking place, peat accumulation is slower as the fluctuating water tables cause rates of decomposition to be higher (Anderson, 2002).

\section{2: Peatland Palaeoenvironmental Research}

Peat is very suitable for Holocene centennial scale environmental reconstructions as it has a fast rate of accumulation (around 5-20 years per $\mathrm{cm}$ ), and deposits can span the Late Glacial to the present day (Charman, 2010). Early research on peatlands includes the work of Blytt (1876), Sernander (1908), and Von Post and Sernander (1910) who found that peat sequences held some information on past climate changes. This work was developed further from the 1960s onwards by academics such as Clymo (1965, 1983, 1984), Moore and Bellamy (1974) and Schlesinger (1977) who widened the understanding of peatland behaviour, particularly in terms of the acrotelm-catotelm exchanges. In addition to this, studies in Danish peats found that peat decomposition was related to local fluctuations in humidity (Aaby and Tauber, 1975; Aaby, 1976). Following this, the notable research by Barber (1981) indicated that rates of peat accumulation were dependent on environmental factors and therefore contain some information about environmental changes throughout the past (Barber, 1981). Peatlands are now widely used to reconstruct paleoenvironmental changes through the Holocene.

A wide range of palaeoenvironmental and palaeoclimatic proxies are used in peat profiles. In a review by Chambers et al., (2012), twenty-five different proxies were listed and grouped into geochemical indicators, microfossils, and macrofossils. These include testate amoebae (e.g., Charman et al., 2006; Blundell et al., 2008; Booth et al., 2011; Swindles et al., 2012; Swindles et al., 2019), stable isotope analysis (e.g., van Geel, 1996; Tillman et al., 2010; Jones et al., 2014; Roland et al., 2015; Loader et al., 2016) and the increasing use of biomarkers (Nichols 
et al., 2006; Nichols, 2011; Huang and Meyers, 2019; Naafs et al., 2019). The forthcoming sections will discuss building a chronology in peat sequences using radiocarbon dating, and the proxies that are used within this thesis, including the carbon: nitrogen ratio, humification, macrofossils, charcoal, and carbon accumulation rates.

\subsection{1: Building a Chronology in Peat Sequences}

Well constrained chronologies are essential for palaeoenvironmental studies. The most commonly used dating techniques for peat sequences are radiocarbon dating, tephrochronology, spheroidal carbonaceous particles (SCP's) and Lead-210. Caesium and americium dating are also used but to a lesser extent. Radiocarbon dating is used in this study and so that will be discussed in more detail below. Table 2.2 gives a brief description of the 3 other commonly used dating methods and some example references.

Table 2:2: The three other dating techniques that are commonly employed to build a chronology in peat

\begin{tabular}{|c|c|c|}
\hline Dating Technique & Description & Example References \\
\hline Tephrochronology & $\begin{array}{c}\text { The use of volcanic ash (tephra) } \\
\text { to date sediment. }\end{array}$ & $\begin{array}{l}\text { Dugmore and Newton, 1992; Pilcher and } \\
\text { Hall, 1992; Hall and Pilcher, 2002; } \\
\text { Langdon et al., 2003; Swindles et al., } \\
\text { 2010(a); Lowe, 2011; Watson et al., } \\
2015\end{array}$ \\
\hline SCPs & $\begin{array}{l}\text { Dating more recent peat }(>1850) \\
\text { using particles that are produced } \\
\text { by the partial incineration of } \\
\text { fossil fuels at high temperatures } \\
\text { from anthropogenic industry. }\end{array}$ & $\begin{array}{l}\text { Oldfield, 1995; Rose, 2008; Swindles, } \\
\text { 2010; Barber et al., 2000; Turner et al., } \\
\text { 2014; Blundell et al., } 2016\end{array}$ \\
\hline Lead210 & $\begin{array}{c}\text { Calculating the remaining } \\
\text { unstable isotope, Lead-210, to } \\
\text { determine peat ages in the last } \\
100-150 \text { years. }\end{array}$ & $\begin{array}{c}\text { Olsson, 1986; Walker, 2005; Le Roux } \\
\text { and Marshall, } 2011\end{array}$ \\
\hline
\end{tabular}




\subsubsection{1: Radiocarbon Dating}

The use of radiocarbon dating for archaeology and geology was first developed by chemist Willard Libby in the early 20th century (Taylor, 1987). Radiocarbon $\left({ }^{14} \mathrm{C}\right)$ is the least abundant form of naturally occurring carbon and is compatible for dating because unlike ${ }^{12} \mathrm{C}$ and ${ }^{13} \mathrm{C}$ it is an unstable isotope and decays into a form of nitrogen $\left({ }^{14} \mathrm{~N}\right)$, in a process referred to as radioactive decay (Walker, 2005). This decay begins as soon as an organism dies and the ${ }^{14} \mathrm{C}$ decays at a steady rate (Walker, 2005). The degree of ${ }^{14} \mathrm{C}$ decay within a dead organism can be compared to modern standards and an age can be calculated for its death (Walker, 2005). Radiocarbon ages are most commonly measured using AMS (Accelerator Mass Spectrometry) (Piotrowska et al., 2011).

For a peat sample, the determined radiocarbon age given should represent the time when the peat forming plants died (Piotrowska et al., 2011). Sphagnum mosses have been found to yield the most reliable dates as they do not have long roots (Nilsson et al., 2001; Piotrowska et al., 2011). Other above ground plants like Erica tetralix and Calluna vulgaris can also be used but they tend to have larger errors (Killian et al., 1995). However, when peat is highly humified and identifiable macrofossils cannot be selected, 'bulk peat samples' can be dated. The bulk sample can also be chemically or physically divided into different fractions for dating, such as the humic acid fraction (Shore et al., 1995). Ages from bulk and humic fractions have been found to be less accurate than dates derived from macrofossils in some instances (e.g., Shore et al., 1995). But Blaauw et al., (2004) and Holmquist et al., (2016) found no significant differences in ages of Sphagnum samples and bulk peat.

Once a radiocarbon age is determined it is adjusted to calendar years using a calibration curve. The most recent calibration curves are Intcal20 (Reimer et al., 2020) and Marine20 (Heaton et $a l ., 2020)$. These calibration curves are used to calculate the probability that a radiocarbon age 
lies within a certain calendar age range, typically at a 2-sigma and 3-sigma probability level (Blaauw and Christen, 2005).

\subsubsection{2: Age-depth Models}

Budget restrictions limit the number of dates that can be retrieved and therefore, a degree of interpolation between dates is usually employed to estimate the age of the non-dated levels (Blaauw and Christen, 2005). This can be done using an age-depth model. The most simplistic age-depth model is constructed using linear interpolation. To do this, a 'monotonic relationship' between dated and non-dated levels is assumed (Blaauw and Christen, 2005). There are, however, substantial limitations with this approach as peat does not accumulate at a steady rate throughout time. There are periods of rapid and slower accumulation as well as growth hiatuses (Blaauw and Christen, 2005). Using linear interpolation means that such changes in accumulation are either randomly guessed or simply ignored and therefore it is typically considered to be an oversimplified method of estimating peat ages (Blaauw, 2003).

To overcome this issue, Bayesian statistics have become more commonly used (Bronk Ramsey, 2008). This approach gives rise to probable age ranges for undated core sections by interpolating between the dated depths and the overall trend of sedimentation (Blaauw and Christen, 2005). A Bayesian age-depth model is thought to provide more reliable age estimates because it considers the full range of age possibilities for undated depths (Bronk Ramsey, 2008). A variety of Bayesian age-depth models can be used, and the model chosen depends largely on the expected degree of randomness within a sedimentary sequence (Bronk Ramsey, 2008). For peat sequences a commonly used age-depth model is a Poisson sequence. This considers sedimentation to be mostly uniform but accounts for some variability and randomisation (Blaauw and Christen, 2005; Bronk Ramsey, 2008; Piotrowska et al., 2011). 


\subsection{2: Carbon: Nitrogen Ratio}

Changes in the carbon:nitrogen ratio $(\mathrm{C}: \mathrm{N})$ have been found to be associated with significant vegetation shifts in Holocene peat records, whereby a higher $\mathrm{C}: \mathrm{N}$ ratio is associated with Sphagnum-dominated bogs and a lower C:N is related to fen or marsh like environments (McClymont et al., 2010; Burrows et al., 2014; Loisel et al., 2014; Shriller et al., 2014). Succow and Joosten (2001) find that ombrotrophic bogs will typically have a C:N between 33$50 \%$ and a mesotrophic fen will range from 20-33\% (see Fig. 2.10). Furthermore, in more recent times, shifts to lower C:Ns are thought to be associated with nutrient enrichment caused by human interference, such as grazing, peat cutting and drainage (Turner et al., 2014).

\subsection{3: Humification}

Humification (the degree of peat decay) analysis is one of three proxies, along with testate amoebae and macrofossil analysis, used to infer changes in Bog Surface Wetness (BSW). Humification is dependent on water table height i.e., bog surface wetness (BSW). At times when the water table is lowered the peat is exposed to more oxygenation and thus is more decayed. Whereas when the water table is higher less of the peat surface is decomposed (De Jong et al., 2010). Differences in water table height are believed to be the product of changes in the balance of precipitation-evaporation during the growing season or extended summer period, as apart from this a bog typically remains fully waterlogged (Charman, 2010). The difference in water table height during the growing season is a function of climate and therefore, changes in peat humification, that reflect BSW, can inform shifts from relatively wetter to drier climatic conditions (Aaby and Tauber, 1975; Barber 1981; De Jong et al., 2010).

To measure humification the colorimetric method is used (Bahnson, 1968; Aaby and Tauber, 1975). This method can produce percentage absorbance and light transmission data (Chambers et al., 2011). Wetter scenarios are signified by lower absorbance values and thus, higher 
transmission values (Carless, 2015). However, transmission values have been found to produce more reliable humification data (Blackford and Chambers, 1995). There are concerns that humification can be influenced by changes in vegetational composition (Hughes et al., 2012). However, Chiverrell (2001), Langdon et al., (2003) and Blundell et al., (2008) find similar trends in all three BSW proxies. Nonetheless, using several sites, and proxies, can help to ensure that regional changes are being depicted (Daley and Barber, 2012).

A large number of studies have used humification to reconstruct Holocene wetness shifts (Aaby and Tauber, 1975; Blackford and Chambers, 1991 and 1995; Chambers et al., 1997; Anderson, 1998; Ellis and Tallis, 2000; Blundell et al., 2008; Daley and Barber, 2012; Swindles et al., 2012; Turner et al., 2014).

\subsection{4: Macrofossils}

Macrofossils are the remains of plants living on the peat surface that are preserved as it accumulates (De Jong et al., 2010). Peatland vegetation is highly receptive to changes in BSW and as such variations of macrofossil assemblage are used to reconstruct past wetness shifts and infer climate changes, like humification (Barber et al., 1998; Hughes et al., 2000; Mauquoy et al., 2002; De Jong et al., 2010).

The most commonly used method to reconstruct macrofossil assemblages is the Quadrat and Leaf count (QLC) method (Barber et al., 1994). The macrofossil results are then converted into BSW records using ordination and either Detrended Correspondence Analysis (DCA) (Barber et al., 1994; Hughes et al., 2000; Barber et al., 2003; Blundell and Barber, 2005; Daley and Barber, 2012) or Non-metric Multidimensional Scaling (NMDS) (Daley and Barber, 2012). Alternatively, the Dupont Hydroclimatic Index (DHI) can be used (Barber et al., 2003; Mauquoy et al., 2008; Turner et al., 2014; Blundell et al., 2016). 
The DHI was developed by Dupont (1986). This BSW index has been found to be most reliable in long peat core records that comprise contrasting peat types (Daley and Barber, 2012). The DHI determines relative BSW by assigning weightings to species based on the modern conditions that they are associated with, lower DHIs imply wetter conditions and a higher DHI is associated with drier settings (Daley and Barber, 2012).

\subsection{5: Charcoal}

Fire history is reconstructed through the analysis of charcoal fragments produced during a fire that are preserved in peat accumulations. Charcoal fragments are preserved as they are not decomposed by microbial action (Mooney and Tinner, 2011). Charcoal counts are typically conducted using optical techniques (Mooney and Tinner, 2011). A regional record of fire can be obtained by analysing microscopic charcoal $(<100 \mu \mathrm{m})$ and a record of local, and 'on-site', fire can be constructed by analysing macrofossil fragments $(>125 \mu \mathrm{m}$ ) (Whitlock and Millspaugh, 1996). In the macrofossil category fragments have been sub-divided as research indicates that fragments between $125-500 \mu \mathrm{m}$ give a record of fires within a $7 \mathrm{~km}$ radius (Whitlock and Millspaugh, 1996) and fragments above $500 \mu \mathrm{m}$ provide strong evidence of 'onsite' fires (Magnan et al., 2012; Ohlson and Tryterud, 2000). Charred plant remains can also signify on-site burning (Magnan et al., 2012). The procedures for conducting macroscopic and microscopic charcoal analysis are standardised in methodological manuals (Mooney and Tinner, 2011; Whitlock and Anderson, 2003; Whitlock and Larsen, 2001).

There is a large body of research that has reconstructed fire dynamics from peatland records in the United States and Canada and many of the underlying fire history principles arose as a result (e.g., Swain, 1978; MacDonald et al., 1991; Whitlock and Milspaugh, 1995; Millspaugh et al., 2000). There are also numerous palaeofire records for Britain and these will be discussed in the key findings section later. 


\subsection{6: Carbon Content}

Organic matter content $(\mathrm{OM})$ and bulk density $(\mathrm{BD})$ can be used to derive organic carbon percentage and carbon density (Chambers et al., 2011). Peat organic carbon content (OC) is calculated in various ways. It will commonly be estimated by assuming that it is equal to $50 \%$ of OM (e.g., Ratcliffe et al., 2018). This is because, peat carbon values tend to be around this amount (Lindsay, 2010). However, organic carbon content can vary substantially between peatlands and in a meta-analysis of 215 northern peatlands by Loisel et al., (2014) organic carbon content was found to vary between $30-60 \%$. The most robust method to determine OC is to directly measure the Total Organic Carbon percentage (TOC) of each sample using mass spectrometry (Chambers et al., 2011). However, this is not always possible due to budget restrictions. In such instances an alternative approach can be used whereby a regression analysis between high-resolution OM and low-resolution TOC is conducted and the statistical relationship between the two is used to estimate OC from OM (Loisel et al., 2014; Dean, 1974). By using this approach more reliable OC datum should be produced than if the $50 \%$ OM assumption is used (Chambers et al., 2011).

\subsection{7: Carbon Accumulation}

\subsubsection{1: Long-term and Temporal Rates of Carbon Accumulation}

Carbon accumulation in the catotelm is typically calculated as an average rate as the 'Longterm (Apparent) Rate of Carbon Accumulation' (LARCA) or as temporal carbon accumulation rates (CAR). To calculate LARCA, the average rate of peat accumulation is multiplied against the mean carbon density $\left(\mathrm{cm}^{3}\right)$ (volume of carbon) (Tolonen and Turunen, 1996; Robinson and Moore 1999; Anderson 2002; Turunen et al., 2002; Packalen and Finkelstien, 2014). LARCA provides an overview into how much carbon a peatland has typically been accumulating throughout its history (Turunen et al., 2002). LARCA figures are very useful as they are widely 
reported within peat carbon research and as such, they allow for quick between site comparisons that can place peatlands in the context of others from similar regions.

Temporal changes in carbon sequestration are reconstructed by dividing the carbon density of each depth increment by the number of years within that depth (as stipulated by the age-depth model) (Ratcliffe et al., 2018). CARs are most commonly employed to provide insight into long-term temporal changes in the rate of peatland carbon accumulation throughout the Holocene (Mauquoy et al., 2002; Yu et al., 2009; Loisel and Garneau, 2010; van Bellen et al., 2011; Loisel et al., 2014; van der Linden et al., 2014; Carless, 2015; Ratcliffe et al., 2018; Beaulne et al., 2021).

\subsubsection{2: Recent Rates of Carbon Accumulation and the Acrotelm Effect}

Recent Rates of Carbon Accumulation (RERCAs) in the uppermost peat (above $50 \mathrm{~cm}$ depth) are typically calculated separately. This separation is done because of the acrotelm effect. The acrotelm effect refers to the increase in carbon accumulation that is typically observed in the uppermost peat. This increase is an artefact of peatland dynamics and is not representative of true carbon accumulation (Clymo et al., 1998; Charman et al., 2013). This artefact is present because the uppermost peat has undergone significantly less decay than the deeper, older peat, and therefore has a higher carbon accumulation rate (Young et al., 2019). However, much of this carbon will not become stored in the deeper peat profile as peat near to the surface is within the zone of water table fluctuation and therefore, is often exposed to oxygenation and decomposition (Young et al., 2019). Resultantly, rates of carbon accumulation within the acrotelm cannot be used to give reliable estimates of peatland carbon sequestration at the time as approximately only $10 \%$ of it will be retained (Clymo, 1983). Moreover, the acrotelm effect means that recent rates of carbon accumulation cannot be compared to long-term rates (Beaulne 
et al., 2019; Young et al., 2019). However, RERCAs are used to compare recent rates of accumulation spatially and between sites (e.g., Beaulne et al., 2021).

The RERCA can be calculated above the point assigned to be the acrotelm boundary (or above $50 \mathrm{~cm}$ depth) as an average (in the same way that LARCA is determined) or as temporal timeweighted RERCAs (like CARs) (Tolonen and Turunen, 1996; van de Linder et al., 2014).

\subsubsection{3: Apparent Rates of Carbon Accumulation}

The peat and carbon accumulation rates that have been described so far are all 'apparent' rates. They are apparent rates because they do not consider the slow decay that is believed to take place in the catotelm (Clymo, 1984). As such, apparent rates are thought to somewhat overestimate true carbon accumulation (Clymo, 1984; Clymo et al., 1998; Robinson and Moore, 1999; Turunen et al., 2002; van Bellen et al., 2011). Some studies have calculated the 'Actual Rate of Carbon Accumulation (ARCA)’ using Clymo's (1984) decay coefficient (e.g., Clymo, 1984; Korhola et al., 1995 and 1996; Tolonen and Turunen, 1996; Clymo et al., 1998; Loisel and Yu, 2013). However, apparent CARs are predominantly used because they do effectively depict relative changes in carbon sequestration throughout the Holocene (Mauquoy et al., 2002; Yu et al., 2009; Loisel and Garneau, 2010; van Bellen et al., 2011; Loisel et al., 2014; van de Linden et al., 2014; Ratcliffe et al., 2018; Beaulne et al., 2021).

\section{3: Key Research Findings}

\subsection{1: Holocene Wetness Shifts}

One of the earliest Holocene climate records was the Blytt and Sernander framework (Sernander, 1908; Blytt 1876). This framework sub-divided the Holocene into 5 stages based 
on the degree of humification and vegetational composition changes in peat. These five stages are the pre-Boreal (cool and dry) (ca. 11700-10500 cal yrs. BP), Boreal (warm and dry) (ca. 10500-7800 cal yrs. BP), Atlantic (warm and wet) (ca. 7800-5700 cal yrs. BP), Sub-Boreal (warm and dry) (ca. 5700-2600 cal yrs. BP) and the Sub-Atlantic (cool and wet) (ca. 2600present) (Sernander, 1908; Blytt 1876). Along with the changes in peat stratigraphy, pollen records were also found to correlate with these wetness shifts (Roberts, 2014). However, this classification is no longer widely used because it oversimplifies peat wetness shifts during the Holocene (Roberts, 2014).

In more recent times BSW records have identified that the Holocene was comprised of numerous shifts to wetter and drier conditions. In a UK context, some of these wetness shifts have been found to correspond in numerous BSW reconstructions and these commonly identified shifts are detailed in Table 2.3. These wetness shifts indicate cooler periods with higher effective precipitation during the summer (Charman, 2010).

Table 2:3: Commonly identified wetness shifts in British BSW records. The date implies the start of the wetter conditions.

\begin{tabular}{|c|c|c|}
\hline $\begin{array}{l}\text { Commonly identified wet } \\
\text { shifts in British BSW } \\
\text { studies (ca. cal yrs. BP) }\end{array}$ & $\begin{array}{c}\text { Reference of } \\
\text { specific timing listed }\end{array}$ & $\begin{array}{l}\text { BSW records with a similarly timed } \\
\text { wetness shift (within } 100 \text { years) }\end{array}$ \\
\hline 7800 & Hughes et al., 2000 & Hughes, 1997 \\
\hline 6650 & Langdon et al., 2003 & Anderson, 1998; Hughes et al., 2000 \\
\hline 5300 & Hughes et al., 2000 & Tipping, 1995; Langdon et al., 2003; \\
\hline 4200 & $\begin{array}{l}\text { Daley and Barber, } \\
2012\end{array}$ & $\begin{array}{l}\text { Barber, } 1981 \text { and 1994; Tipping, 1995; } \\
\text { Hughes et al., 2000; Barber et al., 2003; } \\
\text { Langdon et al., } 2003\end{array}$ \\
\hline 3600 & $\begin{array}{l}\text { Charman et al., } \\
2006\end{array}$ & $\begin{array}{l}\text { Barber, } 1981 \text { and 1994; Chambers et al., } \\
\text { 1997; Hughes, 1997; Hughes et al., } \\
\text { 2000; Langdon et al., } 2003\end{array}$ \\
\hline 2800 & $\begin{array}{l}\text { Charman et al., } \\
2006\end{array}$ & $\begin{array}{l}\text { Barber, } 1981 \text { and 1994; Charman, 1990; } \\
\text { Chambers et al., 1997; Hughes et al., } \\
\text { 2000; Langdon et al., 2003; Daley and } \\
\text { Barber, } 2012\end{array}$ \\
\hline
\end{tabular}




\begin{tabular}{|c|c|c|}
\hline 1600 & $\begin{array}{l}\text { Charman et al., } \\
2006\end{array}$ & $\begin{array}{l}\text { Chambers et al., 1997; Hughes et al., } \\
\text { 2000; Blundell et al., 2008; Daley and } \\
\text { Barber, } 2012\end{array}$ \\
\hline 1400 & Barber et al., 2003 & Langdon et al., 2003 \\
\hline 3060 & $\begin{array}{l}\text { Charman et al., } \\
2006\end{array}$ & $\begin{array}{l}\text { Barber, } 1981 \text { and 1994; Chambers et al., } \\
\text { 1997; Hughes } \text { et al., } 2000\end{array}$ \\
\hline 2050 & $\begin{array}{l}\text { Charman et al., } \\
2006\end{array}$ & $\begin{array}{l}\text { Barber, } 1981 \text { and 1994; Blackford and } \\
\text { Chambers, } 1995 \text { and 1991; Tipping, } \\
\text { 1995; Hughes et al., 2000; Blundell et al., } \\
2008\end{array}$ \\
\hline 1260 & $\begin{array}{l}\text { Charman et al., } \\
2006\end{array}$ & $\begin{array}{l}\text { Barber, } 1981 \text { and 1994; Blackford and } \\
\text { Chambers 1991; Tipping, 1995; } \\
\text { Chambers et al., 1997; Langdon et al., } \\
\text { 2003; Blundell et al., 2008. }\end{array}$ \\
\hline 860 & $\begin{array}{l}\text { Charman et al., } \\
2006\end{array}$ & $\begin{array}{l}\text { Ellis and Tallis, 2000; Barber et al., 2003; } \\
\text { Blundell et al., } 2008\end{array}$ \\
\hline 550 & $\begin{array}{l}\text { Charman et al., } \\
2006\end{array}$ & $\begin{array}{l}\text { Barber } 1981 \text { and 1994; Blackford and } \\
\text { Chambers, 1991; Tipping, 1995; } \\
\text { Chambers et al., 1997; Ellis and Tallis, } \\
\text { 2000; Barber et al., 2003; Blundell et al., } \\
\text { 2008; Daley and Barber, } 2012\end{array}$ \\
\hline 260 & $\begin{array}{l}\text { Charman et al., } \\
2006\end{array}$ & $\begin{array}{l}\text { Barber } 1994 \text { and } 1981 \text {; Ellis and Tallis, } \\
\text { 2000; Hughes } \text { et al., } 2000\end{array}$ \\
\hline
\end{tabular}

There are a limited number of British BSW studies for the early and mid-Holocene with Daley and Barber (2012), Mauquoy et al., (2002), Langdon et al., (2003) and Hughes et al., (2000) being some of the few. The earliest Holocene wetness shift is identified by Hughes et al., (2000), at ca. 7800 cal yrs. BP (Fig.2:11) (Table 2.3). A wet shift around ca. 8000 cal yrs. BP is also found in Finland and Germany (van Geel, 1978; Korhola, 1995). The wetter conditions at $c a .7800$ cal yrs. BP are tentatively linked to the short-lived, cold event that took place around the North Atlantic between $c a$. 8400-8000 cal yrs. BP referred to as the ' 8.2 ka event' (Alley et al., 1997; Mayewski et al., 2004). This event is believed to have been caused by a rapid release of freshwater into the Labrador Sea that led to colder ocean heat transfer southwards (Aguiar et al., 2021). During this event much of the Northern hemisphere was cooler (Mayewski et al., 2004). 


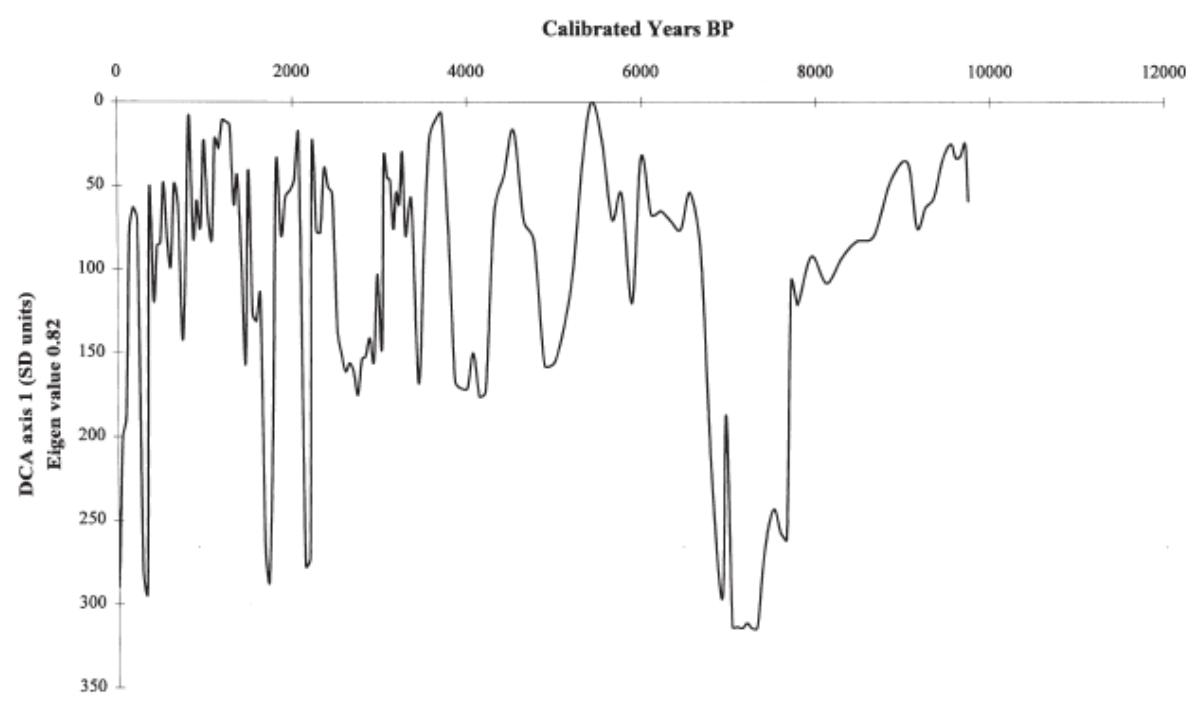

Figure 2:11: Bog surface wetness reconstruction for Walton Moss, England (Hughes et al., 2000). Wetter values are downwards.

In the later middle Holocene, a wet/cooler shift around ca. $5300 \mathrm{cal}$ yrs. BP is identified in BSW, and stable oxygen isotope, records (Table 2.3) (Tipping, 1995; Hughes et al., 2000; Langdon et al., 2003; Roland et al. 2015). This cooling is referred to as the 5.2 ka event and is documented around NW Europe (Mayewski et al., 2004). It is thought to be related to changes in North Atlantic Ocean circulation that strengthened the Westerlies (Mayewski et al., 2004).

There are many more BSW studies that span the late Holocene, especially from $c a .4200$ cal yrs. BP to the present (Walker et al., 2019) (Table 2.3). These studies demonstrate that during the middle Holocene there have been several shifts from relatively drier to wetter conditions. The most widely cited wetness shifts are at $c a .4200,3600,2800,2050$ and 550 cal yrs. BP (Table 2.3) (e.g., Barber, 1981 and 1994; Chambers et al., 1997; Hughes et al., 2000; Langdon et al., 2003; Chaman et al., 2006; Blundell et al., 2008). Several of these wetness shifts are also identified across NW Europe (e.g., Aaby 1976; Nilsson and Vorren, 1991; Daley and Barber, 2012). A compilation of northern English testate amoebae records, that depicts these shifts, has become one of the most widely cited BSW reconstructions (Fig.2.12) (Charman et al., 2006). 
This record finds that each shift lasted for around 100-200 years before a return to drier conditions (Charman et al., 2006). In addition to wetness shifts, Swindles et al., (2010b) identify four phases of summer drought in Northern Ireland at ca. 3100 to 2750, ca. 2270-1800, ca. 1700-1480 and ca.100 to -50 cal yrs. BP. And similarly timed drought phases are present in other British records (e.g., Blundell et al., 2008; Mauquoy et al., 2008).

Several studies link these wet and dry intervals, during the late Holocene, to changes in solar variability (Charman et al., 2006; Mauquoy et al., 2008; Swindles et al. 2010b; Swindles et al., 2012). The changes in solar activity alter the westerly storm courses and increase water availability by changing the P:E balance (Charman et al., 2006). These changes are also found to correspond with a reconstruction of changing lake levels in France and Switzerland by Magny (2004) (Hughes et al., 2000; Charman et al., 2006; Swindles et al., 2010b). The links between solar activity and French lake levels is shown in Figure 2.12. Furthermore, the wetness shifts around $c a$. 4200, 2800 and 1600 cal yrs. BP correspond with increases in ice-rafted debris in ocean core records from the North Atlantic, signifying cooler climatic periods, when colder ocean waters circulated more south (Langdon et al., 2003; Bond et al., 1997). These factors imply that many of these wetness shifts identified occurred widely across NW Europe.

More recently, increased peatland dryness during the last two centuries, in Britain and Ireland is associated with a significant reduction in summer precipitation (as much as $25 \mathrm{~mm}$ every quarter) and a general increase of summer temperatures (as large as $1^{\circ} \mathrm{C}$ since 1950) (Swindles et al., 2019). 


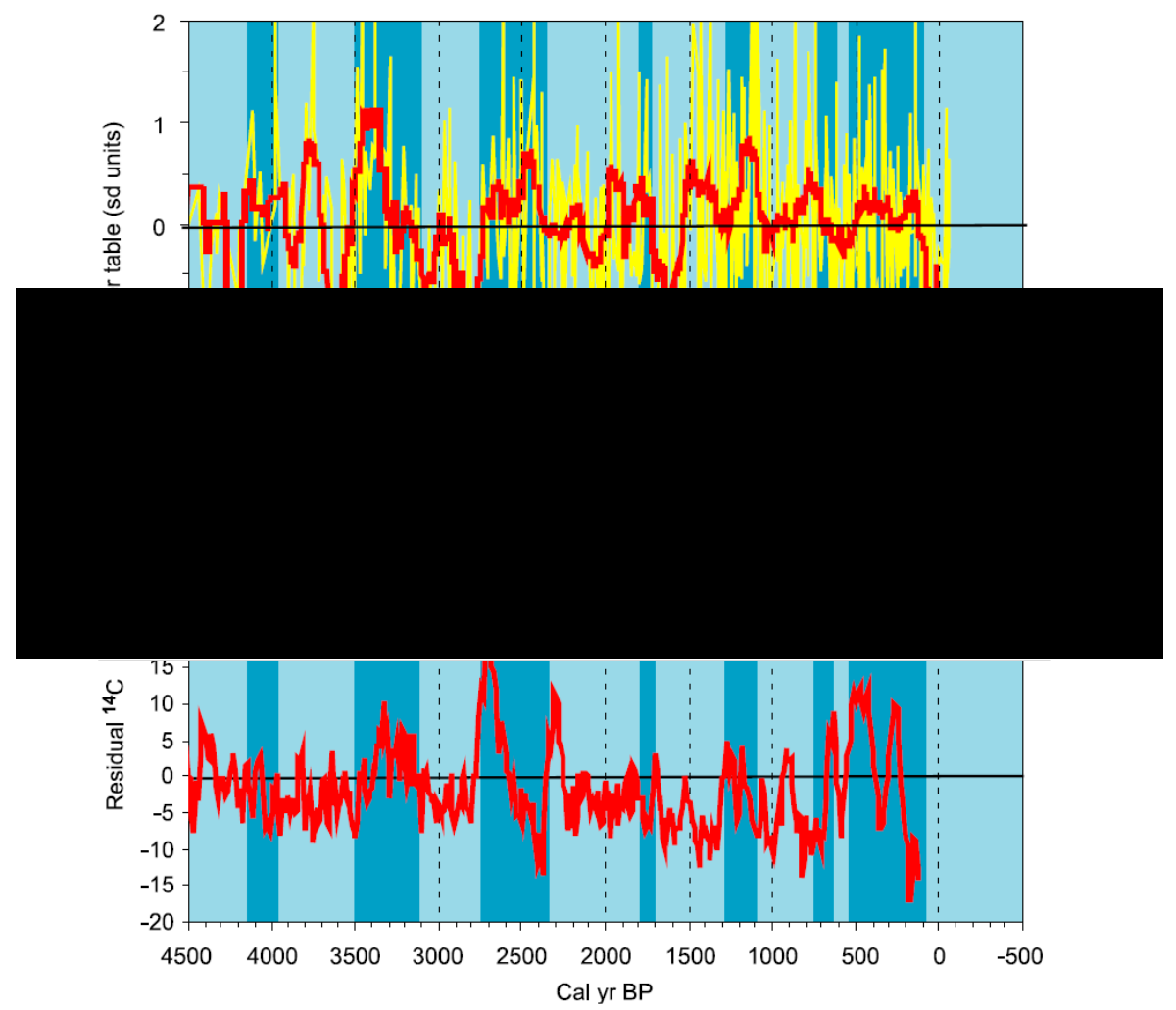

Figure 2:12: Top - the northern English testate amoebae BSW record at 100-year moving average, with blue bars showing where wetness intervals correspond to changing lake water levels reported by Magny, 2004); Bottom - residual 14C reconstruction (Stuiver et al., 1998). Sourced from Charman et al., (2006).

\subsection{2: Holocene Fire History}

Most British palaeofire records are derived from microscopic charcoal and therefore provide regional histories (e.g., Innes and Simmons, 2000; Fyfe et al., 2003; Smith and Cloutman, 1988; Grant, 2012; Edwards et al., 2007; Innes et al., 2013; Swindles et al., 2021). Fewer studies have investigated local and onsite burning (Ellis and Tallis, 2001; Froyd 2006; Turner et al., 2014; Abrook et al., 2020). However, in all records fire activity is found throughout the Holocene to varying degrees.

Fire occurrence in Britain from the early to mid-Holocene has mostly been attributed to climatic forcing. For example, fires close to the start of the Holocene ( $c a .11300$ cal yrs. BP) have been linked to proxy indications of warming temperatures and aridity which could have 
made sites more suitable for the proliferation of natural fires (Abrook et al., 2020). Furthermore, higher fire activity during the early Holocene has been found to correspond with northern hemisphere increases in summer temperatures and insolation (Zennaro et al., 2015).

Burning during the Middle Holocene is linked to climate and anthropogenic activities. For example, an upsurge in fire incidence, around $c a .8000$ cal yrs. BP, found in numerous British palaeofire records, is typically linked to Mesolithic land management (Fig.2.13) (Smith and Cloutman, 1988; Fyfe et al., 2003; Edwards et al., 2007; Grant, 2012; Innes et al., 2013; Marlon et al., 2013). Specifically, deforestation by fire to improve animal hunting and provide suitable grazing sites (Fyfe et al., 2003). In addition to a human cause, some of this fire is also attributed to the higher temperatures that persisted during the Holocene Thermal Maximum (Marlon et al., 2013; Zennaro et al., 2015). However, disentangling anthropogenic and climatic induced fires can be difficult and Innes and Simmons (2000) state that a high regularity of fires is unlikely to be attributed solely to climate.

Between $c a$. 6000-5000 cal yrs. BP there is sharp reduction in British fire occurrence (Fig.2.13) This trend is thought to be associated with the Elm decline, but it is not known if it is attributable to a human or climate cause (Marlon et al., 2013). After ca. 5000 cal yrs. BP fires increase sharply and are highest after ca. 4000, until ca. 2000 cal yrs. BP (Fig.2.13) (Marlon et $a l ., 2013)$. The upsurge in fire activity post $c a .5000$ cal yrs. BP is associated with widespread woodland opening to improve grazing and cultivation (Marlon et al., 2013). Fire incidence was lower after $c a .2000$ cal yrs. BP and this was most likely due to changing cultivation practices and land-use, that involve less fire (Fig.2.13) (Fyfe et al., 2003). 


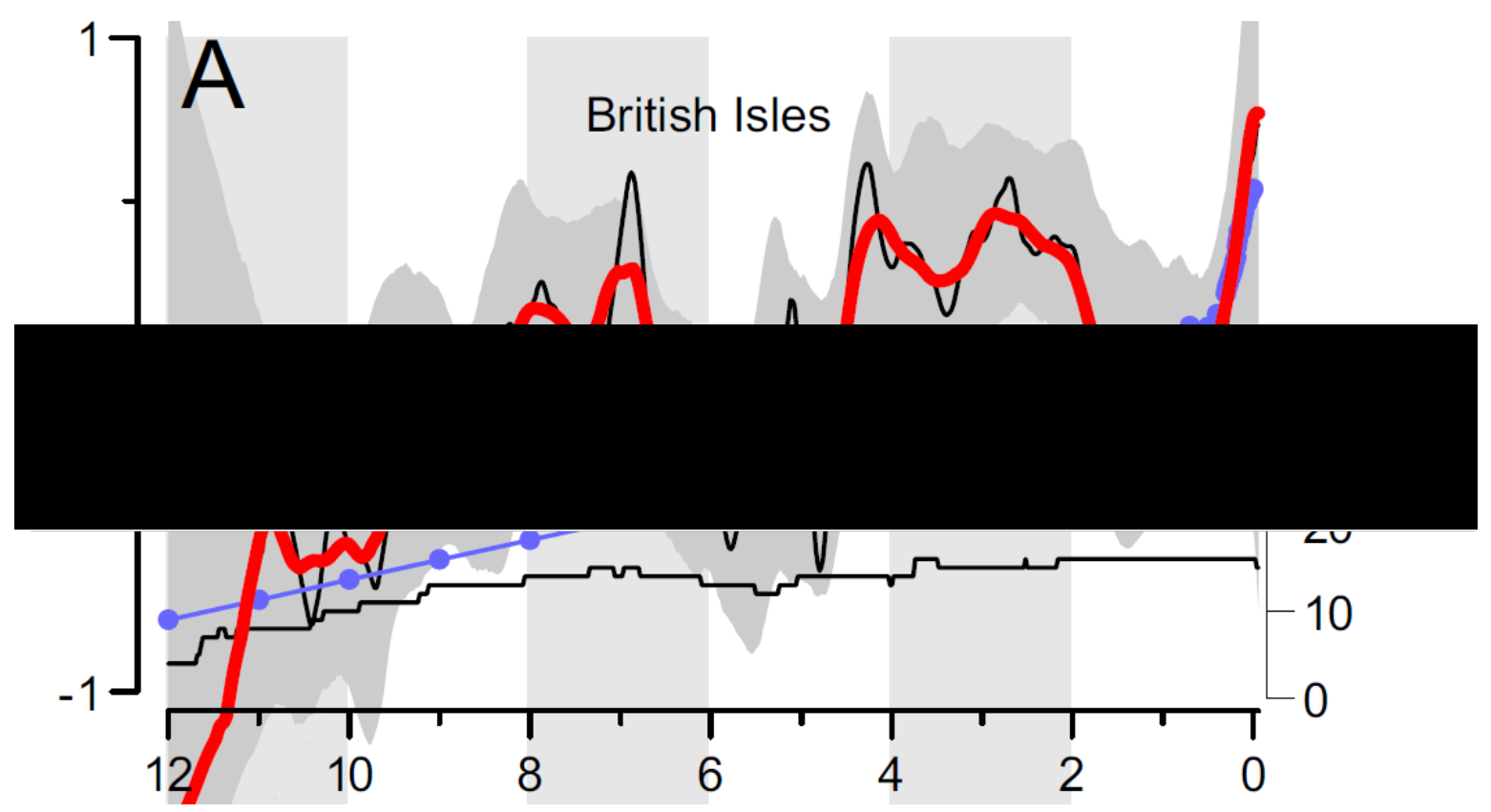

Figure 2:13: British fire history as standardised units from a compilation of 20 British palaeofire records. Red line is a 250-year moving average, left axis shows the number of studies contributing to the curve. From Marlon et al., (2013).

\subsection{3: Holocene Carbon Accumulation}

Carbon accumulation rates have been constructed across many regions, including Alaska (Nichols et al., 2014), Germany (van de Linden et al., 2014), Finland (Korhola et al., 1995; Turunen et al., 2002) Britain (Mauquoy et al., 2002; Carless, 2015; Ratcliffe et al., 2018), North America (Charman et al., 2015), South America (Loisel and Yu, 2013) and Canada (Packalen and Finkelstein, 2014; Beaulne et al., 2021). The reported LARCA, CAR and RERCA values vary greatly across these regions (see Table 2.4). 
Table 2:4: A range of $L A R C A, C A R$, and RERCA values from the literature

\begin{tabular}{|c|c|c|c|}
\hline $\begin{array}{l}\text { Carbon } \\
\text { accumulation } \\
\text { indicator }\end{array}$ & $\begin{array}{l}\text { Peat zone its } \\
\text { applicable to }\end{array}$ & $\begin{array}{l}\text { Example Figures } \\
\text { from the literature } \\
\qquad \mathrm{g} \mathrm{C} \mathrm{m}^{-2} \mathrm{yr}^{-1}\end{array}$ & $\begin{array}{c}\text { References } \\
\text { (Respectively) }\end{array}$ \\
\hline LARCA & Catotelm & $\begin{array}{c}\text { LARCA range at } \\
\text { multiple site studies: } \\
\\
14-16 \\
15-72.5 \\
16.3 \\
4.6-85.8 \\
11.2-28.5\end{array}$ & $\begin{array}{c}\text { Carless, 2015; Anderson, 2002; } \\
\text { Ratcliffe et al., 2018; Korhola et } \\
\text { al., 1995; Packalen and } \\
\text { Finkelstein, } 2014\end{array}$ \\
\hline CARs & Catotelm & $\begin{array}{c}\text { Mean CARs: } \\
\begin{array}{c}60 \\
17.9 \\
21.3 \\
22.9 \\
31.1\end{array}\end{array}$ & $\begin{array}{l}\text { Carless, 2015; Anderson, 2002; } \\
\text { Ratcliffe et al., 2018; Loisel et al., } \\
\text { 2014; Yu et al., } 2003 .\end{array}$ \\
\hline RERCA & Acrotelm & $\begin{array}{l}\text { Mean RERCAs: } \\
\begin{array}{c}126.5 \\
102\end{array}\end{array}$ & $\begin{array}{l}\text { Turunen et al., 2002; Piilo et al., } \\
\qquad 2019\end{array}$ \\
\hline $\begin{array}{l}\text { Temporal } \\
\text { RERCAs }\end{array}$ & Acrotelm & $\begin{array}{l}\text { Median temporal } \\
\text { RERCAs: } \\
\begin{array}{c}\text { 6-73 g and } 9-127 \\
20-40 \\
80-90\end{array}\end{array}$ & $\begin{array}{l}\text { Young et al., 2019; Ratcliffe et al., } \\
\text { 2018; Beaulne et al., } 2021\end{array}$ \\
\hline
\end{tabular}

Overall, the research suggests that Sphagnum dominated bogs accumulate more carbon than fens (Turunen et al., 2002; Granath et al., 2010; Loisel and Bunsen, 2020). This is because fens experience higher decay rates as their mineral-rich water source and fluctuating water levels promote microbial activity and enhance oxygenation (respectively) (Loisel and Bunsen, 2020). Furthermore, Sphagnum peat is highly resistant to decay and therefore can accumulate much faster than fens that comprise more easily decomposed plant matter (Loisel and Bunsen, 2020). However, in some climatic regime's fen peat has been found to hold more carbon (Loisel et al. 
2014). For example, in boreal regions where productivity is lower, the higher density of fen peat can lead to greater carbon stores than the more slowly accumulating Sphagnum peat (Loisel et al., 2014). The period around the fen to bog transition has also been found to be associated with lower carbon accumulation due to the unstable water tables during this succession (Anderson, 2002).

In terms of Holocene temporal changes in carbon accumulation, the largest amount of knowledge has been gained for Northern peatlands (> $\left.30^{\circ} \mathrm{N}\right)$ (e.g., Charman et al., 2013; Loisel et al., 2014; Yu et al., 2014). Figure 2.14 shows the sites that are included in the large compilation by Loisel et al., (2014) and Yu et al., (2014). The general consensus from these databases is that for most Northern peatlands, climate is the greatest driver of carbon accumulation change (Loisel et al., 2014). In most cases a warmer climate has led to higher carbon sequestration during the Holocene, for example during the climatic optimum ( $c a .9000$ 6000 cal yrs. BP) and neoglacial cooling, after $c a .6000$ cal yrs. BP, has led to lower carbon accumulation (Fig.2.15) (e.g., Yu et al., 2009; Yu et al., 2012; Loisel et al., 2014; Yu et al., 2014; Ratcliffe et al., 2018). Furthermore, during the last 1000 years northern peatlands have accumulated more carbon when it has been warmer, e.g., during the Medieval Climatic anomaly, and less when conditions are cold, such as the Little Ice Age (Charman et al., 2013). This trend is thought to be because the warmer conditions lengthen the growing season, leading to higher net primary productivity (NPP) and greater carbon accumulation (Yu et al., 2009; Loisel et al., 2014). 


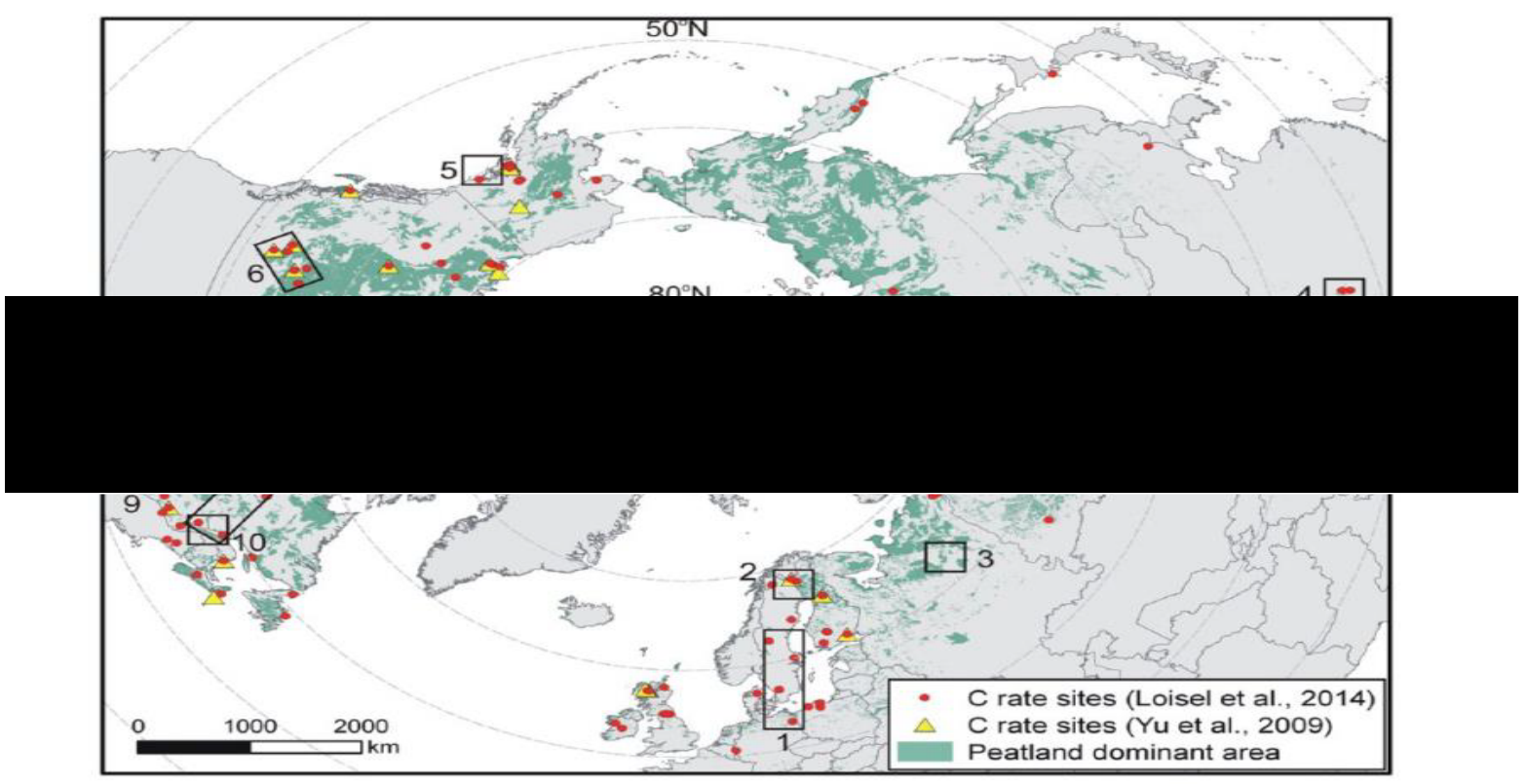

Figure 2:14: Map showing the distribution of peatland carbon accumulation studies. The boxes indicate areas that have recently experienced an upsurge in peatland carbon studies. From Yu et al., (2014).
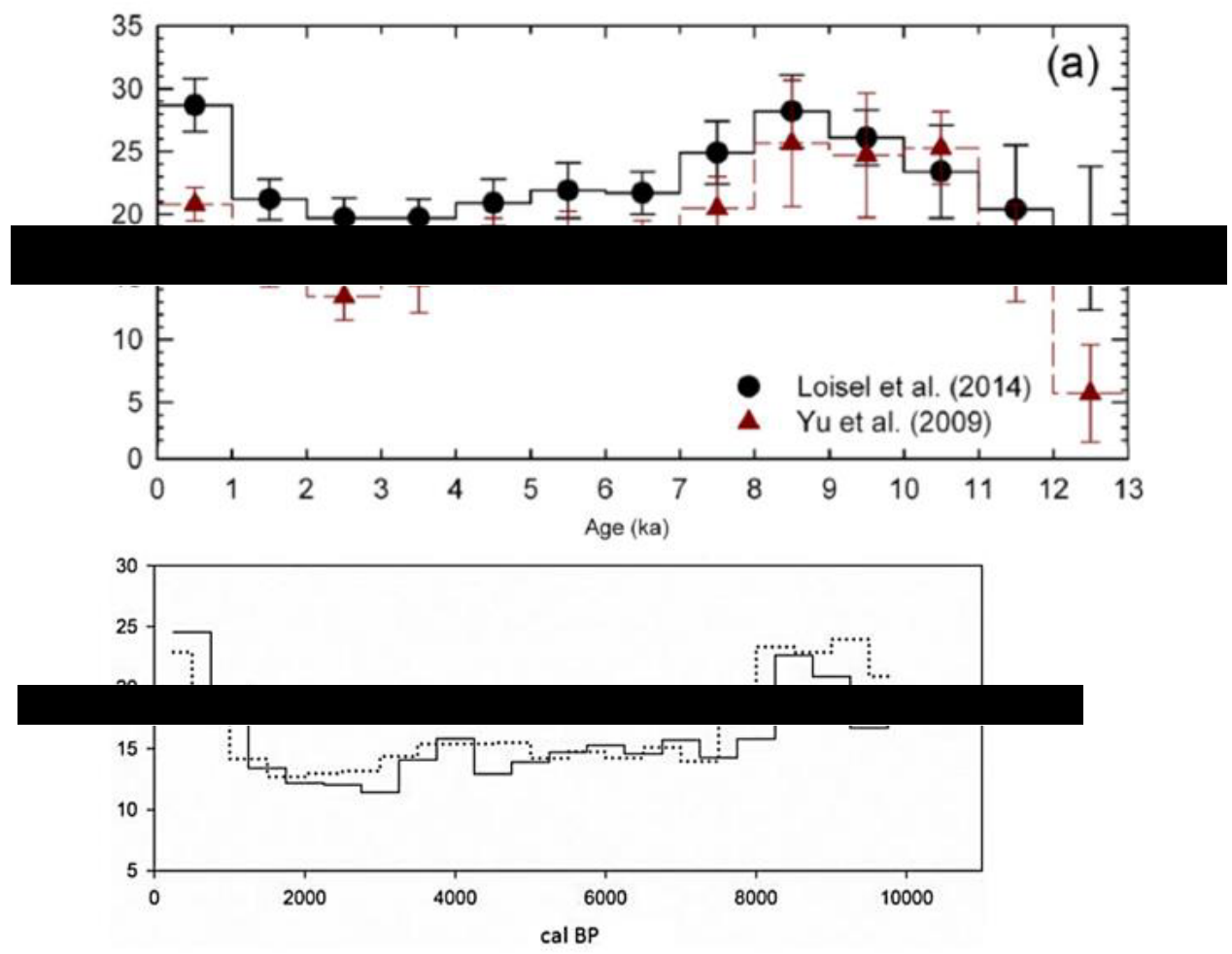

Figure 2:15: Top: Northern peatland carbon accumulation database, in 1000-year bins, based on 253 peatland records (Yu et al., 2014); Bottom: Scottish carbon accumulation database, in 500-year bins, based on 43 peatlands (Ratcliffe et al., 2018) 
However, studies found that this Holocene trend was not observed at sites that sit closer to the bioclimatic range of northern peatland distribution. Instead, these sites displayed lower carbon accumulation during the HTM and enhanced carbon sequestration during the cooler neoglacial conditions than after ca. 6000 cal yrs. BP (Loisel et al., 2014; van de Linden; 2014; Yu et al., 2014; Charman et al., 2015). This is because at more southern peatlands, that generally exist under warmer climates, moisture is a limiting factor (Waddington and Price, 2013; Charman et al., 2015). Therefore, at times when it has been warmer these sites may have been less suitable for peat growth and carbon accumulation (Charman et al., 2015).

As a result of these findings, it is thought that the larger northern, boreal, peatlands will experience enhanced carbon accumulation under future warming scenarios, but mid-latitude peripheral peatlands will undergo reductions or even cessations in carbon accumulation (Charman et al., 2013; Loisel et al., 2014; Yu et al., 2014; Charman et al., 2015). However less work has been done on peripheral sites, even though they pose the greatest threat of contributing to carbon emissions this century. Furthermore, within the current peatland carbon database there is a substantial bias towards Alaskan, Canadian and Northern European peatlands (Fig.2.14). This underrepresentation of marginal peatlands in the research means that their responses are less well understood. It is important that more peripheral sites are studied, from a variety of regions, so that accurate predictions of peatland carbon contributions to climate change can be made (Yu et al., 2014).

\subsubsection{1: Future Projections of Peatland Carbon}

Projection models assessing likely peatland carbon responses to climatic warming have been constructed by Gallego-Sala et al., (2010 and 2018). These projections imply that during the $21^{\text {st }}$ century high-latitude northern peatlands will experience an increase in carbon accumulation (Gallego-Sala et al., 2018). However, after this century their carbon sequestration 
rates will decline and they could become a source of $\mathrm{CO}_{2}$ (Gallego-Sala et al., 2018). The threat from mid-latitude peripheral peatlands is more immediate and warming is already expected to be tipping the balance to a point where decay rates outweigh productivity (Gallego-Sala et al., 2018). This will cause a reduction in carbon accumulation and the carbon sink (Gallego-Sala et al., 2018). In a UK context, under a warming scenario of $2{ }^{\circ} \mathrm{C}$ by 2050 , the peatland bioclimatic envelope is predicted to shrink markedly in Wales and England and would no longer include the area encompassing the study sites in SW Wales (Fig.2.16) (Gallego-Sala et al., 2010). However, as discussed above, there is greater uncertainty about lower latitude peatlands as these are underrepresented in the dataset and more research is required to better predict their responses (Gallego-Sala et al., 2018). Furthermore, the fate of these marginal peatlands will depend not only on future climatic shifts but also on policy and management practices (Gallego-Sala et al., 2010).

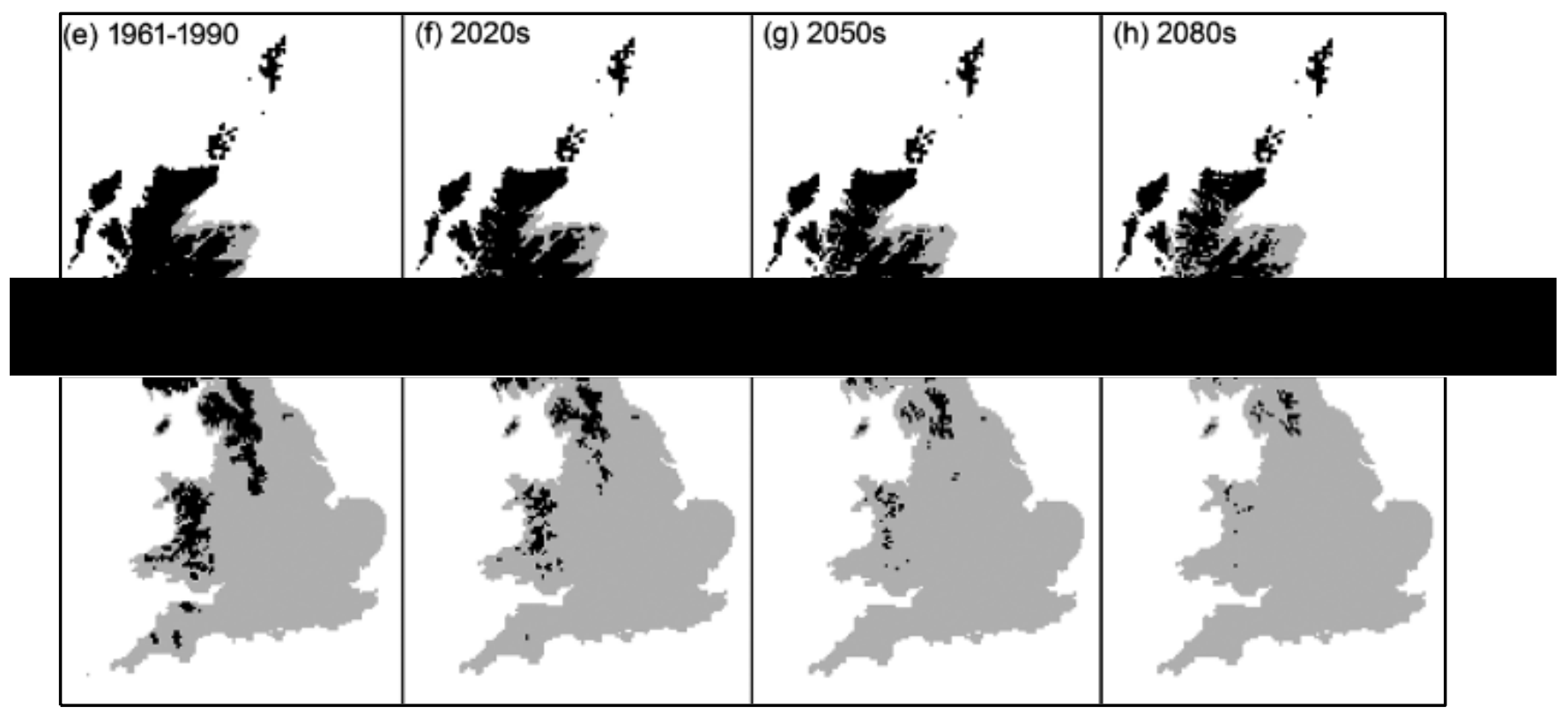

Figure 2:16: Model showing possible future UK peat distribution changes in response to warming until 2080. From Gallego-Sala et al., (2018) 


\subsection{4: The Human Impact on Peatlands}

As mentioned in the introduction, around $10 \%$ of peatlands are being cut drained, or managed by other means, including fire or grazing, and this disturbance contributes $5-10 \%$ of annual $\mathrm{CO}_{2}$ emissions (Parish et al., 2008; Leifeld and Menichetti, 2018). As such, a significant body of work has focused on an assessment of human interference impacts on peatlands.

The reported impacts of fire range widely within the literature, however, the majority of studies report that fire activity leads to carbon losses. In boreal peatlands fire was identified as the main disturbance and found to be causing significant $\mathrm{CO}_{2}$ emissions (Turetsky et al., 2002). In addition, in British and European peatlands, burning has been found to be related to increased dryness and a lowering of the water table (Holden et al., 2004; Marcisz et al., 2015). This drying promotes the growth of dwarf shrubs, like Calluna vulgaris, that are suited to drier conditions, and reduce the presence of important peat forming species including Sphagnum and Eriophorum vaginatum (McCaroll et al., 2016; Noble et al., 2019). Moreover, Pitkänen et al., (1999) find a strong correlation between higher fire activity and a lower average peat height. Despite this, there is some research that finds that fire does not always lead to lower carbon accumulation. For instance, both Magnan et al., (2012) and Blundell and Holden (2015) find that peatland vegetation was resilient to fire until higher intensity and regularity during the late Holocene tipped the balance. Furthermore, fire intensity can be altered by the peatland hydrology, for example a peatland with a high-water table is less susceptible to fire than a site that has been severely drained (Garnett et al., 2000; Turetsky et al., 2002). These findings suggest that the impacts of fire can vary depending on the peatland and the level of fire activity.

In terms of drainage, studies find that it leaves peatlands in a desiccated state, with lower water tables, poorer water quality, higher rates of oxidation and lowered rates of carbon accumulation (e.g., Waddington and Price, 2013; Kettridge et al., 2015). Moreover, continued drainage, 
coupled with fire, was found to cause a positive feedback loop, that will eventually lead to a peatland transitioning into a dry shrub-land and becoming a significant source of $\mathrm{CO}_{2}$ (Kettridge et al., 2015).

The impacts of peat cutting are also known to be severe. Peat removal results in the loss of the acrotelm layer, the destruction of the diplotelmic system and the lowering of the raised mire surface (Waddington et al., 2002; Waddington and Price, 2013). The water table becomes unstable, evapotranspiration is higher, and the lowered raised peat surface may become subject to nutrient enrichment from surface run-off (Price, 1996). Waddington et al., (2002) found that carbon emissions can be $\sim 300 \%$ higher in cutover peatlands. Peat cutting is therefore a highly damaging form of human disturbance.

\subsection{5: Paleoenvironmental Studies in Management and Conservation}

Palaeoenvironmental studies have been used to inform restoration strategies (e.g., Davies and Bunting, 2010; Blundell and Holden, 2015, McCarroll et al., 2016 and Chambers et al., 2007). Paleoenvironmental work can help by providing baseline information about a site prior to disturbance and identifying key drivers of change. For instance, Chambers et al., (2007) demonstrated that the current high presence of Molinia grass, in a Welsh upland site, was associated with human disturbance. They therefore advocated for management strategies that promoted a reduction in Molina (Chambers et al., 2007). In addition, a macrofossil and stratigraphy study by Blundell and Holden (2015) helped a local water company to implement appropriate restoration. Such palaeoenvironmental studies are important because they can provide an insight into long-term peatland responses over centuries (Davies and Bunting, 2010). The information acquired by this thesis will also provide such insights for management of the Carmarthenshire bogs. 


\section{Chapter 3: Methodology}

\section{1: Site Selection and Justification}

Three peatlands, located in Carmarthenshire, SW Wales, UK, were chosen for this study Pyllau Cochion, Figyn Common and Mynydd Bach (Fig.3.1).
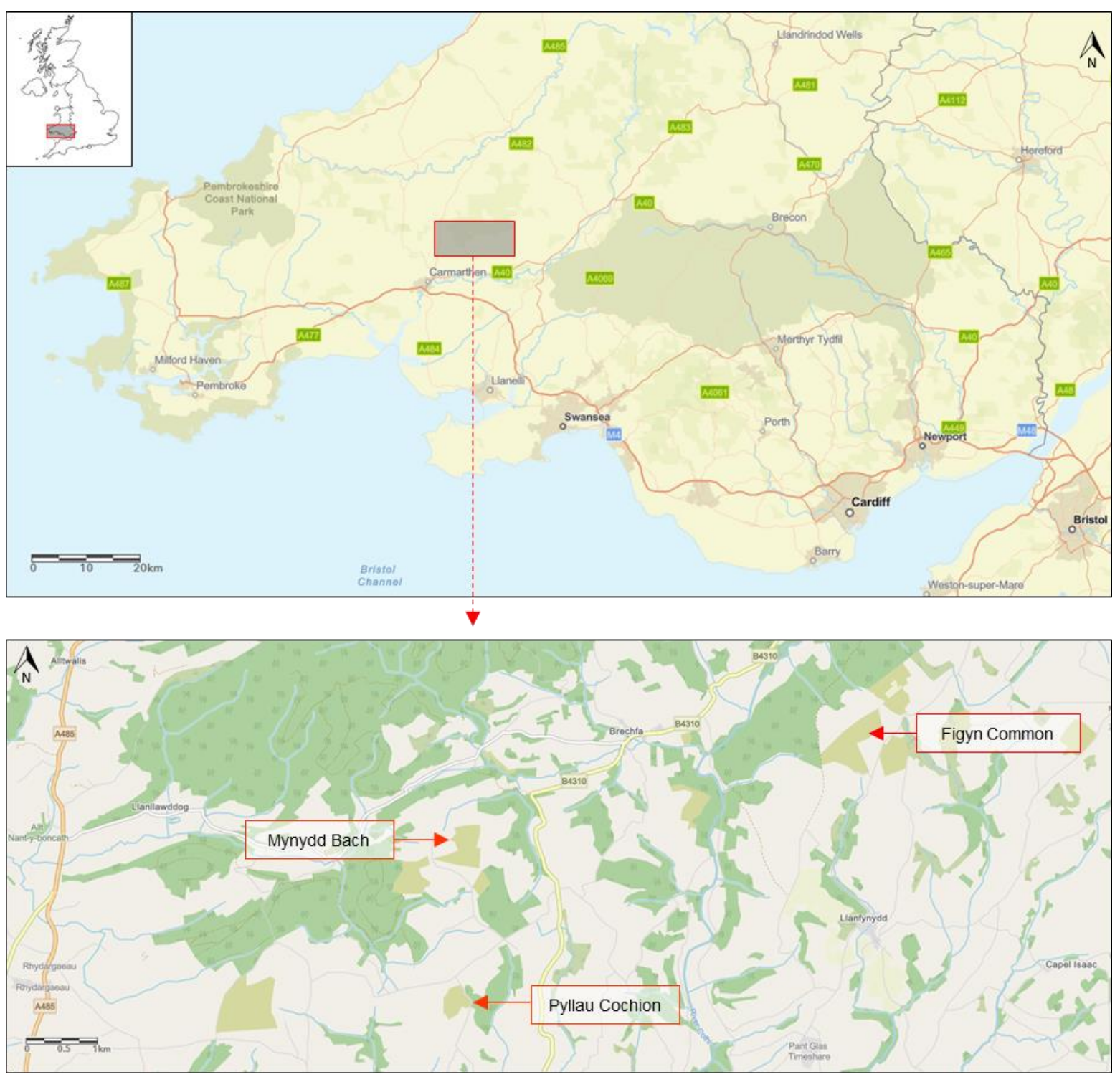

Figure 3:1: Maps showing the location of SW Wales in the UK (top left), the location of the study area in SW Wales (top) and the location of the 3 sites in the study area (bottom). Map data references: Esri UK, HERE, FAO, Garmin, USGS, NASA/METI (top map); OpenStreetMap and ESRI (bottom map). 
These sites were selected according to the following criteria:

1. A region where carbon and environmental histories had not been previously determined.

2. Peatlands that are located in marginal, climate-sensitive, areas and are likely to be impacted by future climate change.

3. Sites in close proximity that have similar geology and climate conditions.

4. Sites that have been previously impacted by human activity.

5. Sites that need information to underpin management strategies.

In reference to the first point, there is currently no existing research that investigates the carbon history of peatlands in southern Britain (see Figure 2.15 in literature review), therefore, studying these sites will help to fill in this geographical research gap. It is important that this gap is filled in order to gain an understanding of how peatland carbon accumulation varies by region and this information can be used to inform projections of regional, and global, peatland carbon responses for the future (Yu, 2012; Loisel et al., 2014). Furthermore, very little research has been conducted at the sites (see previous work section). Therefore, studying the sites will reveal important information about the history of the peatlands and provide an insight into the development of the surrounding landscape. This work will represent the first environmental and chronological framework for the sites and reveal their palaeoenvironmental potential. This is an important step in paving the way for these valuable archives to be utilised.

The sites fit the second criteria because, in a UK context, they are most likely to be negatively affected by climate change, and contribute to $\mathrm{CO}_{2}$ emissions, because they are situated at the 
bioclimatic limits of peatland formation in Britain (Yu et al., 2014; Gallego et al., 2010). Considering this factor, it is useful to study how these peatbogs have responded in the past, to climatic forcing, so that we can anticipate how they, and other peripheral peatlands, might respond to climate changes in the future.

In terms of the third requirement, the sites are all located closely together. This is important because their proximity to each other will help to distinguish between past peatland changes that are the result of autogenic processes and those associated with regional climatic shifts. This is because, one of the simplest ways to detect climate driven peatland responses is to find synchronous changes in peat records from nearby sites that have similar geology and regional climate (Hughes et al., 2000).

Lastly, appertaining to the fourth point, all three peatlands have been subjected to recent human interference, including burning, drainage and peat cutting. Such human interference is beneficial to this study because the impacts on carbon accumulation can be assessed. This information can then be used to support, and direct, the implementation of peatland conservation measures.

The fifth reason to study these peatlands is that this research will be used to underpin management strategies for the sites. The sites were first brought to our attention by local authority (Carmarthenshire County Council) who had identified them to be at risk, they had an ongoing aspiration to preserve the sites and for them to be designated as SSSI's (A Site of Special Scientific Interest) in the future (CCC, 2014 (a)). This aspiration has seen the council collaborate with peatland researchers from Swansea University to obtain information that might guide management strategies and educate the public on the history of these sites. Funded by the Heritage Lottery Fund, the Carmarthenshire Bogs Project (CBT) led by Carmarthenshire County Council, paid for some of the analyses at Pyllau Cochion. Considering this open 
dialogue, between the council, who manage the sites, and the university, this research informs their management work for the future conservation of the sites.

\section{2: Site Descriptions}

\subsection{1: Pyllau Cochion}

Pyllau Cochion is located close to Brechfa in Carmarthenshire, SW Wales (Fig.3.1) and sits at an altitude of 278-280 m a.s.l (Fig.3.2). The peatland covers an area of 40,378 $\mathrm{m}^{2}$ (Low, 2014) and is surrounded by farmland in all directions aside from a small expanse of forest to the northeast (Fig.3.2). The bedrock geology at the site is the Yr Allt Formation (BGS, 2020). This geology is comprised of interbedded sandstones and mudstones and was formed in the late Ordovician subdivision - the Ashgill ( 444 - 449 m.y.a) (BGS, 2020).

Pyllau Cochion comprises a topogenous oligotrophic raised peat bog that formed within a preexisting basin, with marshy grassland and wet heath on the peripheral areas (Figs. 3.3 and 3.4) (CCC, 2014 (a)). The raised bog dome is no longer present, and this is believed to have been lost through peat cutting (CCC, 2014 (a)). The vegetation at Pyllau Cochion, Figyn and Mynydd Bach was surveyed in 2008, and categorised based on the National Vegetation Classification (NVC) scheme. The three dominant vegetation categories at Pyllau Cochion are ombrogenous bog, wet heath, and woodland and scrub (respectively) (CCC, 2014 (a)). Some examples of vegetation found at the site include Sphagnum cuspidatum, Sphagnum recurvum, Molinia caerulea, Erica tetralix and willow scrub.

The peatland is in a degraded state (CCC, 2014 (a)). This degradation has been caused by the following factors:

- A drainage ditch at the northern part of the site (CCC, 2014 (a)). 
- The site has been illegally burnt, at least once a year, over the last decade and this has damaged the peatland surface and its vegetation (CCC, 2014 (a)). Visible evidence of this burning was observable in the site.

- A significant amount of household, and construction waste has been illegally dumped on the site (fly-tipping) in the north-east and south-west corners. This fly-tipping has resulted in Japanese knotweed establishing at these corners, but as it stands it is has not spread across the peatland (CCC, 2014 (a)).

- It is suspected that peat cutting has taken place at the site as microtopographical features indicative of peat extraction are present at the northernmost edge of the site (Low, 2014). The extent of the peat cutting is unknown.

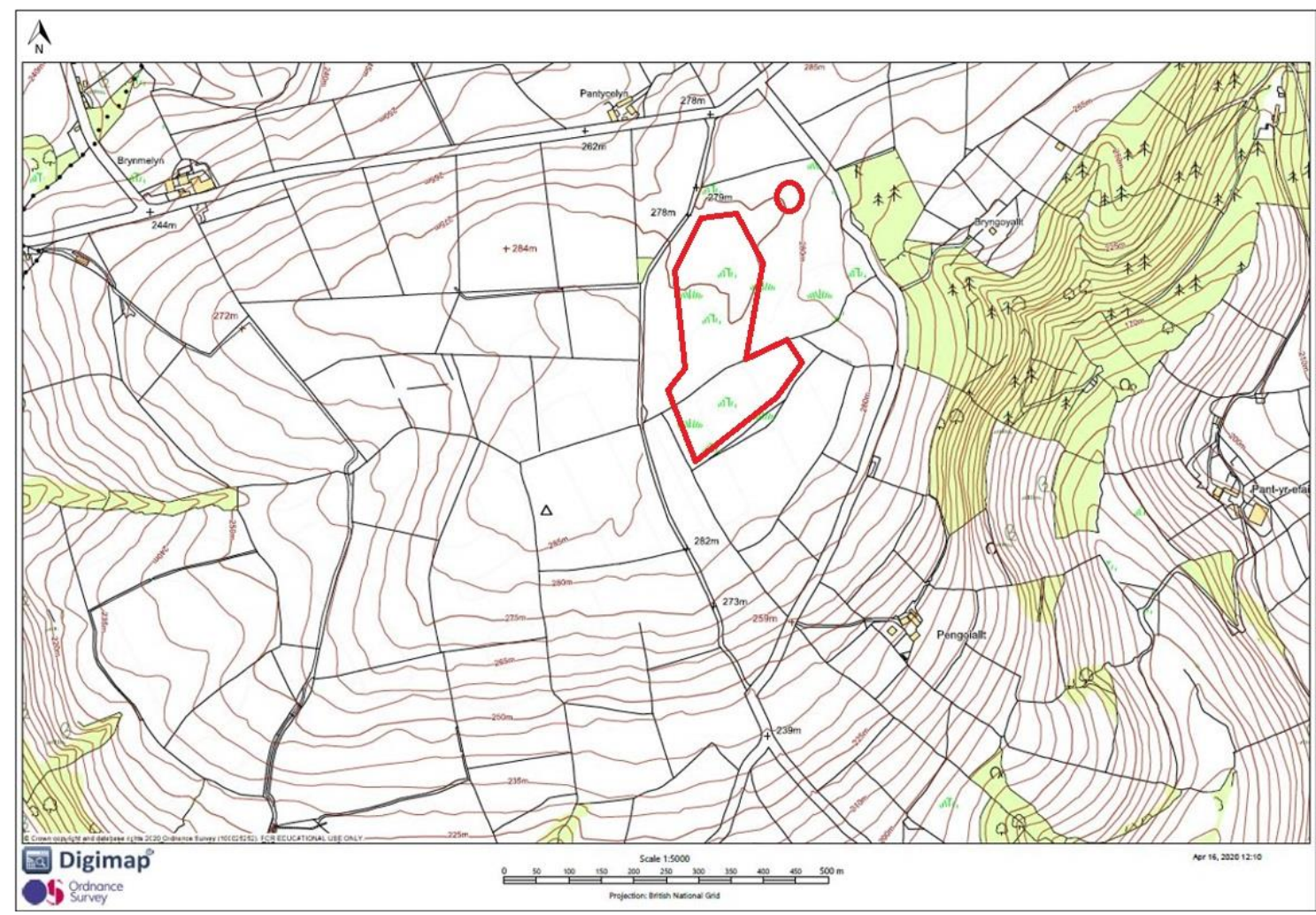

Figure 3:2: A map of the study site Pyllau Cochion (outlined in red). Map reference: Holder (2020) (a). 


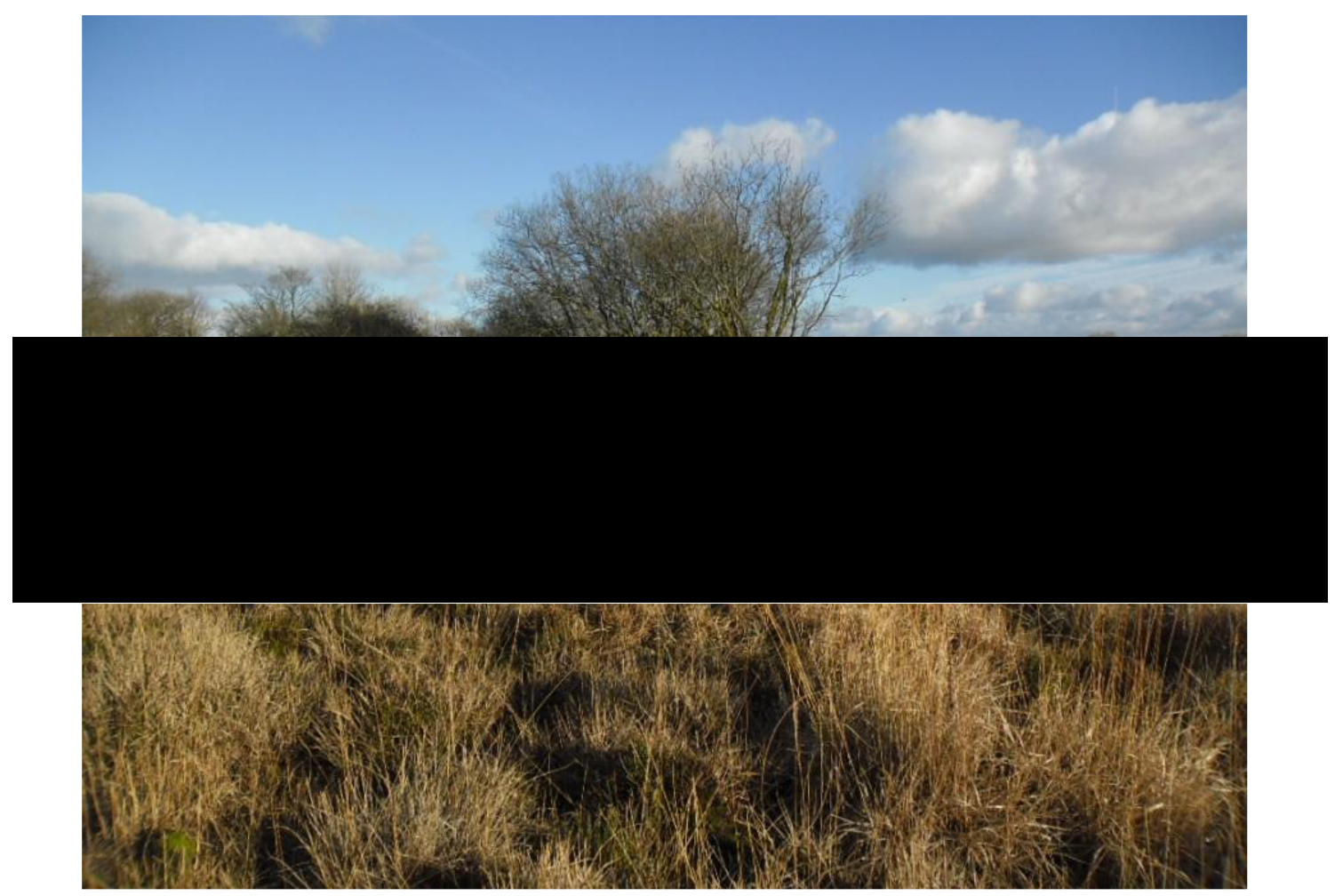

Figure 3:3: Image of Pyllau Cochion. Sourced from CCC (2014 (a)).

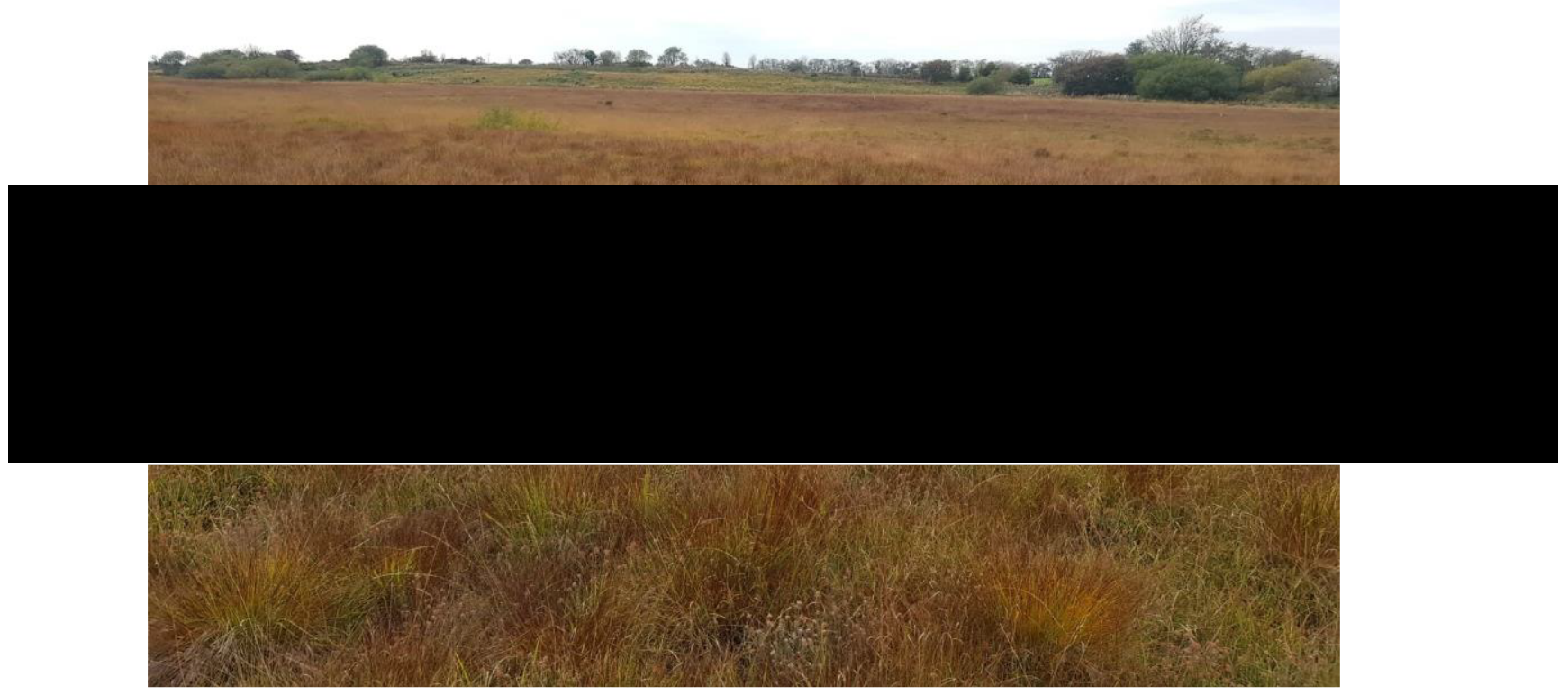

Figure 3:4: Image of Pyllau Cochion (Holder, 2021). 


\subsection{2: Figyn Common}

Figyn Common is located in Llanfynydd, Carmarthenshire (Fig.3.1) and sits at an altitude of $316 \mathrm{~m}$ a.s.1 (Fig.3.5). The site covers an area of $61,728 \mathrm{~m}^{2}$ (Low, 2014). The common is bordered by farmland and commercial forest to the north-west (Fig.3.5). Like Pyllau Cochion, the bedrock geology at the site is the Yr Allt Formation (BGS, 2020).

Figyn common is also classified as a topogenous oligotrophic raised peat bog that formed in a pre-existing steep-sided basin (Figs. 3.6 and 3.7). However, the raised dome here is distinct and intact (CCC, 2014 (b)). Most of the vegetation types found at the site are associated with raised peat bog conditions, however some ecologically undesirable vegetation is also present (more detail given in the paragraph below). The three dominant vegetation categories at Figyn Common are topogenous fen, ombrogenous bog and woodland and scrub (respectively) (CCC, 2014 (b)). Some examples of plants found at the site include Sphagnum cuspidatum, Sphagnum recurvum, Carex echinate, Vaccinium oxycoccos and willow scrub.

The whole site area has been deemed to be in an 'unfavourable condition' (CCC, 2014 (b)). Its poor condition is due to five factors. First, current grazing levels at the site are very low and because of this rank vegetation covers most of the site. The high presence of rank vegetation means that the peatland is more susceptible to burning (CCC, 2014 (b)). Second, the bog has been subjected to burning in recent times, including a devastating fire in 2013 and there is visible evidence of fire at the site (CCC, 2014 (b)). Third, some of the eastern area of the site has been subjected to historic peat cutting (Low, 2014). The limit of this peat cutting has been identified and the coring site is not thought to have been cut over. Fourth, there is a drainage ditch on the easternmost edge of the site (CCC, 2014 (b)). Fifth, undesirable vegetation has established on the peripheral areas, including bramble and willow scrub, willow and conifer trees, and Molina caerulea (purple moor grass) (Figs. 3.6 and 3.7) (CCC, 2014 (b)). 


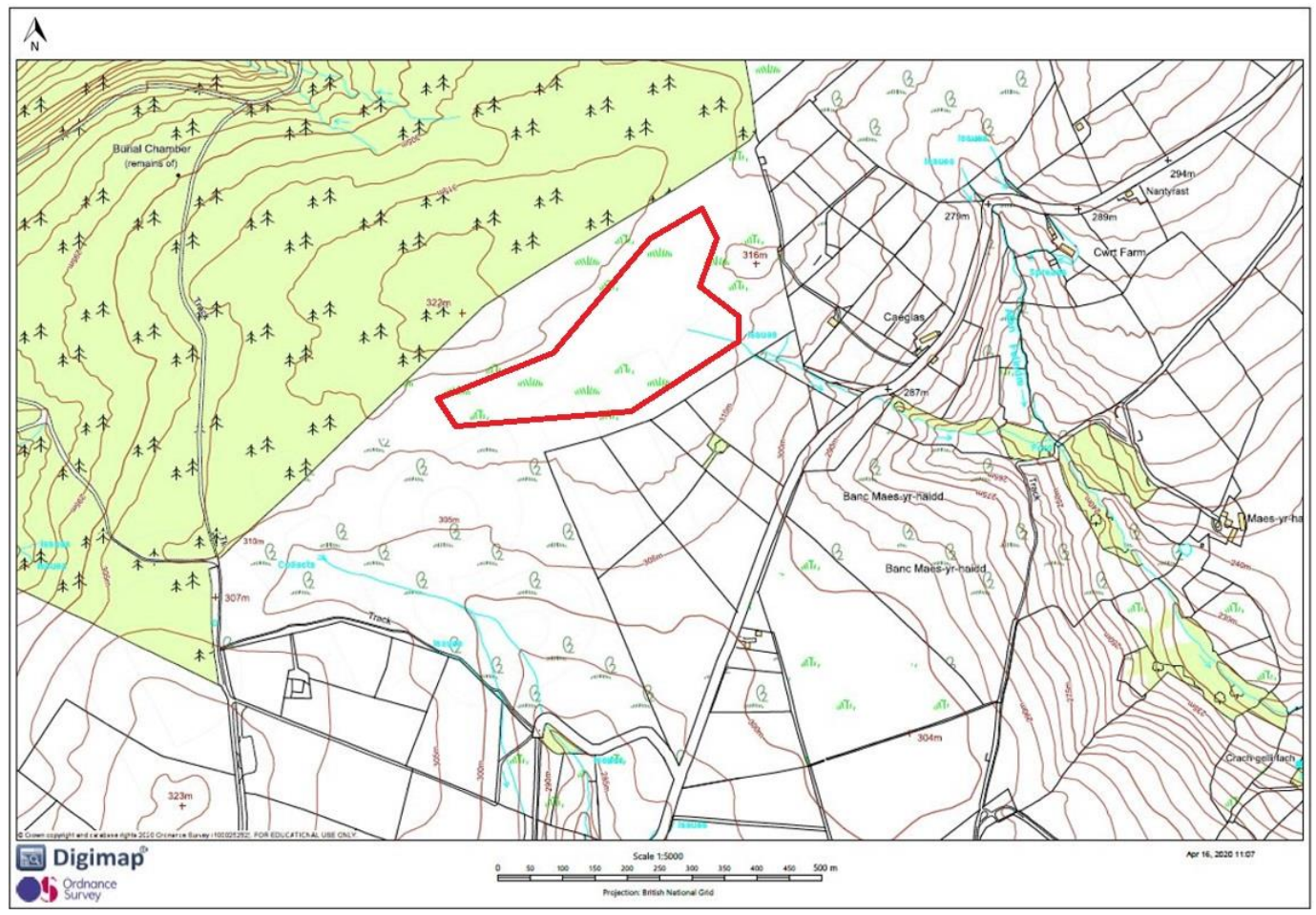

Figure 3:5: A map of the study site Figyn Common (outlined in red). Map reference: Holder (2020) (b).

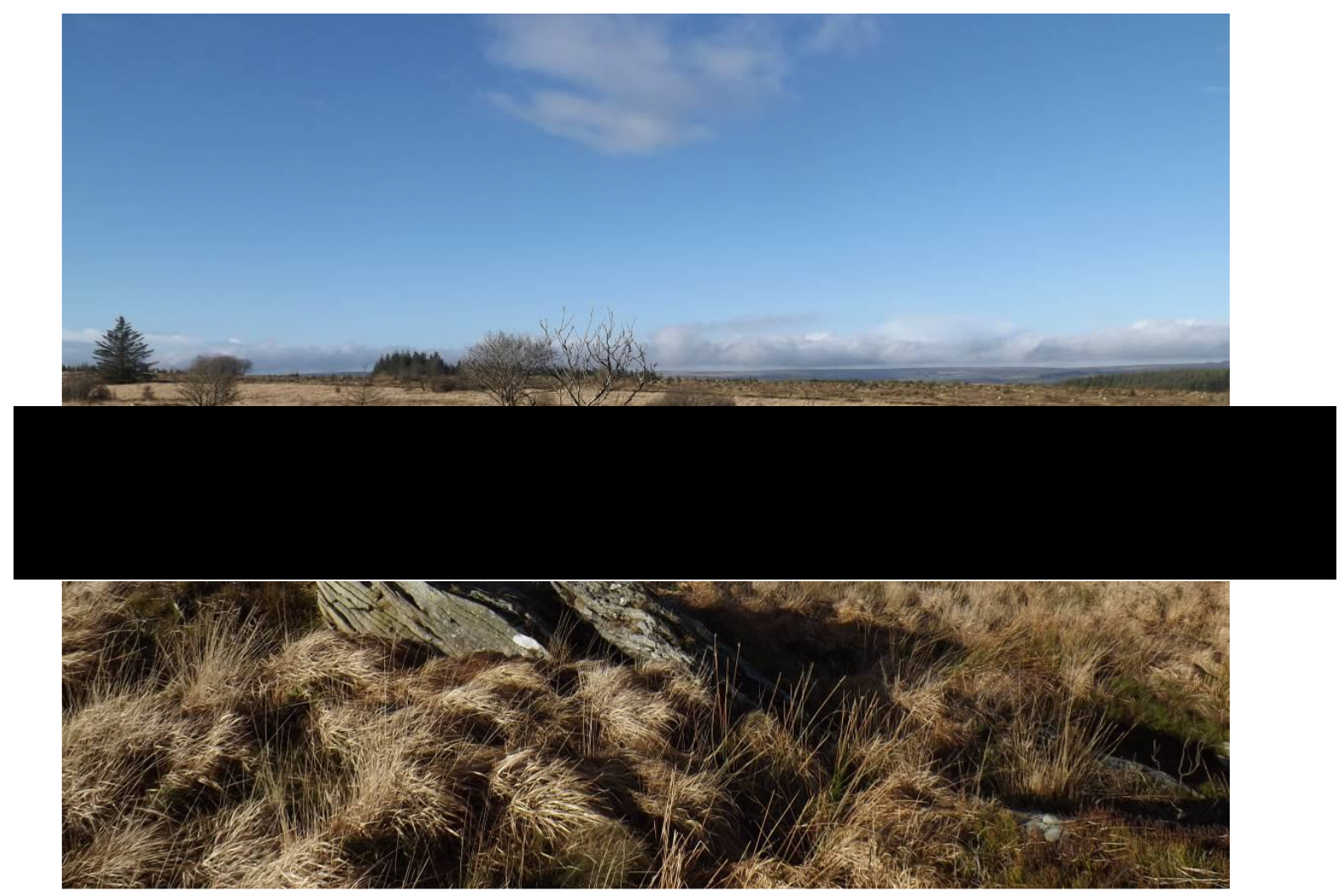

Figure 3:6: Image of Figyn Common. Sourced from CCC (2014 (b)). 


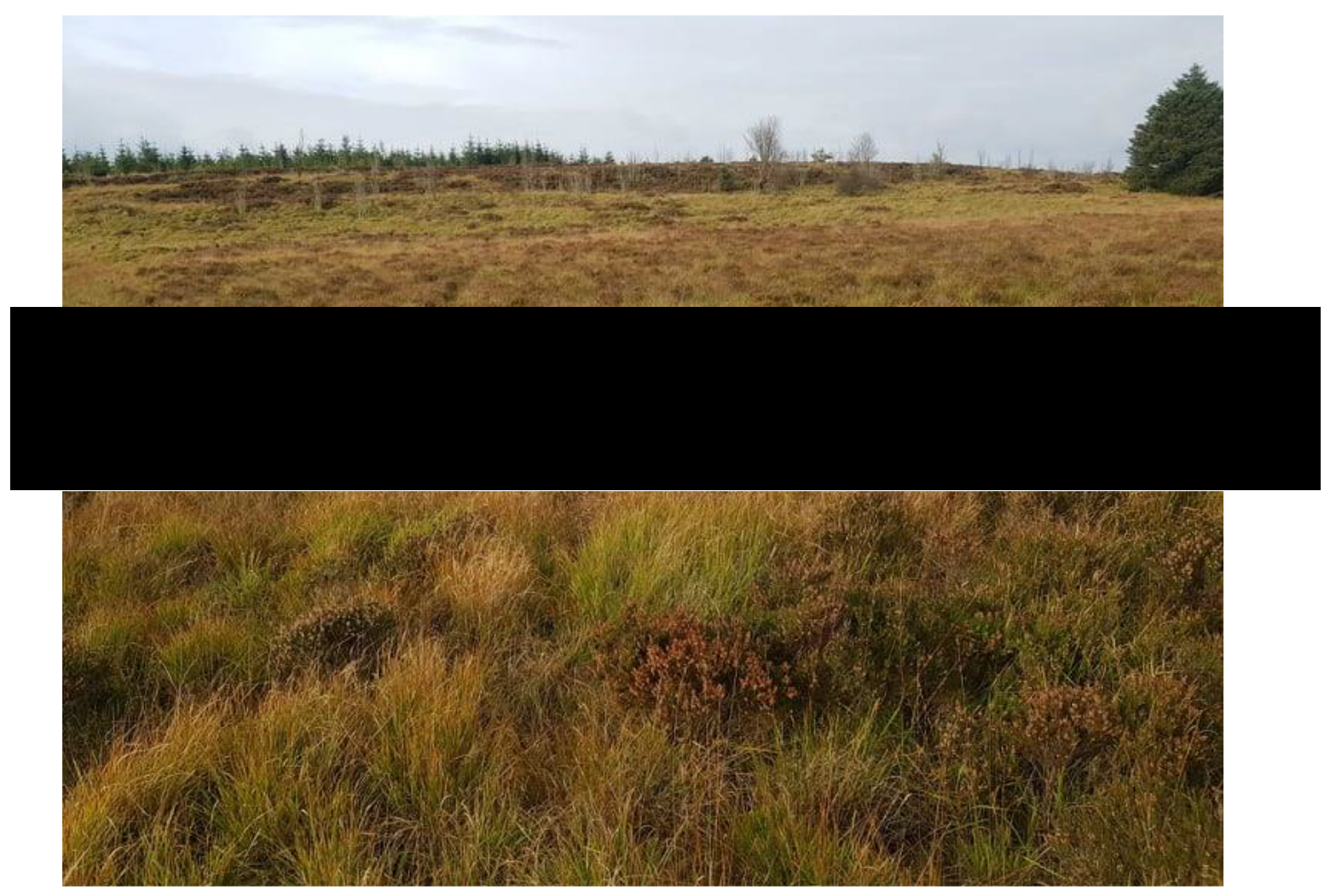

Figure 3:7: Image of Figyn Common (Holder, 2021).

\subsection{3: Mynydd Bach}

Mynydd Bach is located close to Brechfa in Carmarthenshire, SW Wales (Fig.3.1) and sits at an altitude of 310-315 $\mathrm{m}$ a.s.1 (Fig.3.8). The site covers an area of 16,275 $\mathrm{m}^{2}$ (Low, 2014) and is surrounded by farmland (Fig.3.8). The site is underlain by the same geology as Pyllau Cochion and Figyn Common.

Mynydd Bach is a mesotrophic fen that sits at the base of hill (Figs. 3.8, 3.9 and 3.10). The three dominant vegetation types at Mynydd Bach are wet heath, topogenous fen and ombrogenous bog (respectively) (CCC, 2014 (c)). The types of plant species found at the site include, Scirpus cespitosus, Molinia caerulea, willow scrub, Eriophorum vaginatum and Sphagnum cuspidatum. 
The site is archaeologically important as it contains four Scheduled Ancient Monuments (SAMs). These are Bronze Age (2750-4450 cal yrs. BP (Adkins et al., 2017)) burial mounds (Fig.3.8) that are collectively referred to as the Crugiau Round Barrows and are nationally important monuments (CCC, 2014 (c)). Palaeoenvironmental work on the adjacent peat deposits will provide some contextual information about the sites history that will complement its archaeology.

The peatland is in an 'unfavourable condition' (CCC, 2014 (c)) and this is likely due to three factors:

- Drainage ditches that have been dug around the borders of the peatland. Most of the ditches are poorly maintained and are not carrying substantial volumes of water, except the ditch at the north-eastern edge which could be having a detrimental impact on the peatland water table (CCC,2014 (c)).

- The site is heavily grazed, with 6 livestock units permitted for each hectare (much higher than is advised for this type of environment) and this is having a negative impact on the vegetation (CCC, 2014 (c)).

- There is evidence of past peat cutting at the north-eastern corner of the site (CCC, 2014 (c)). 


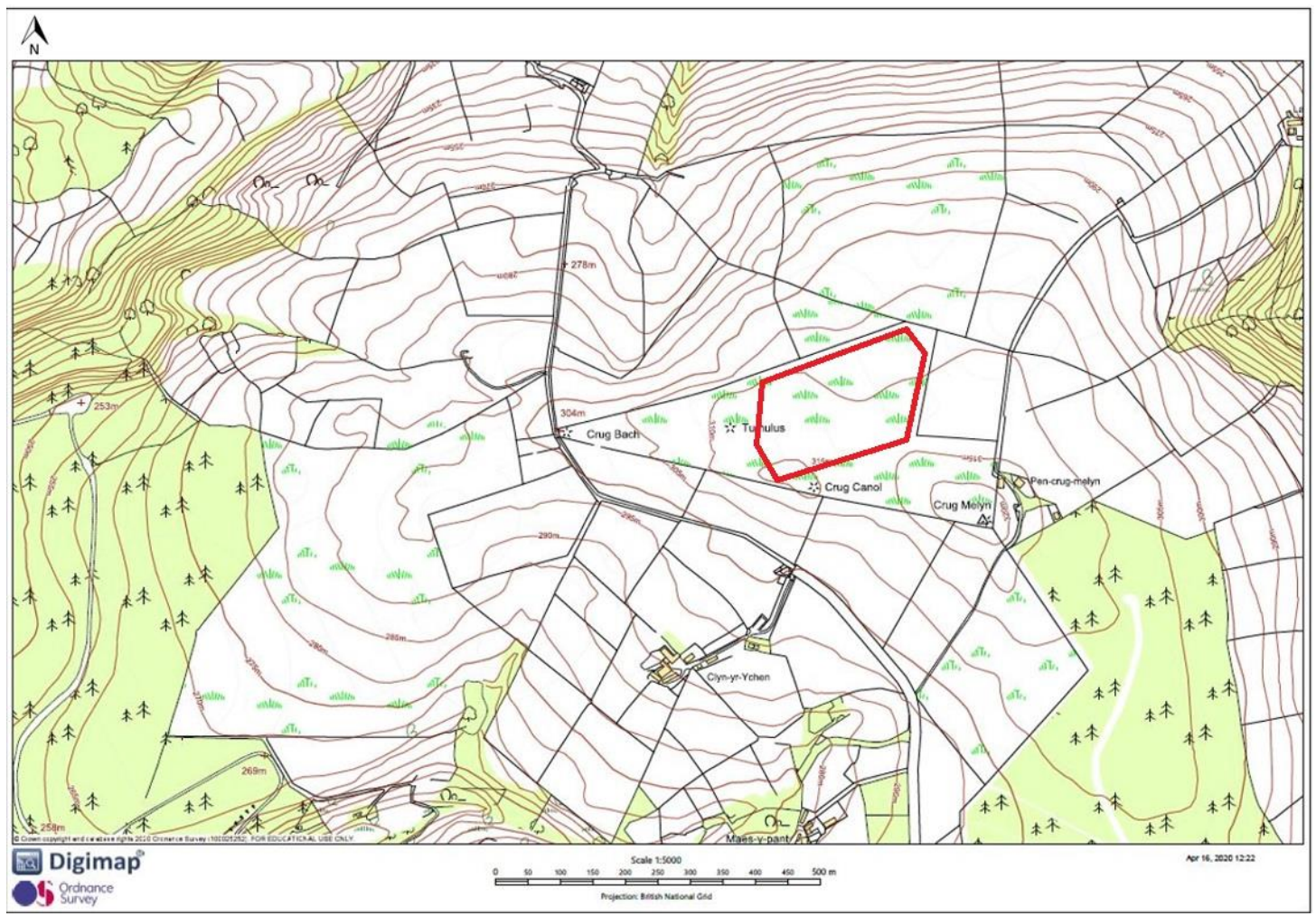

Figure 3:8: A map of the study site Mynydd Bach (outlined in red). Points of archaeological interest on the site are shown also (marked with stars). Map reference: Holder (2020) (c).

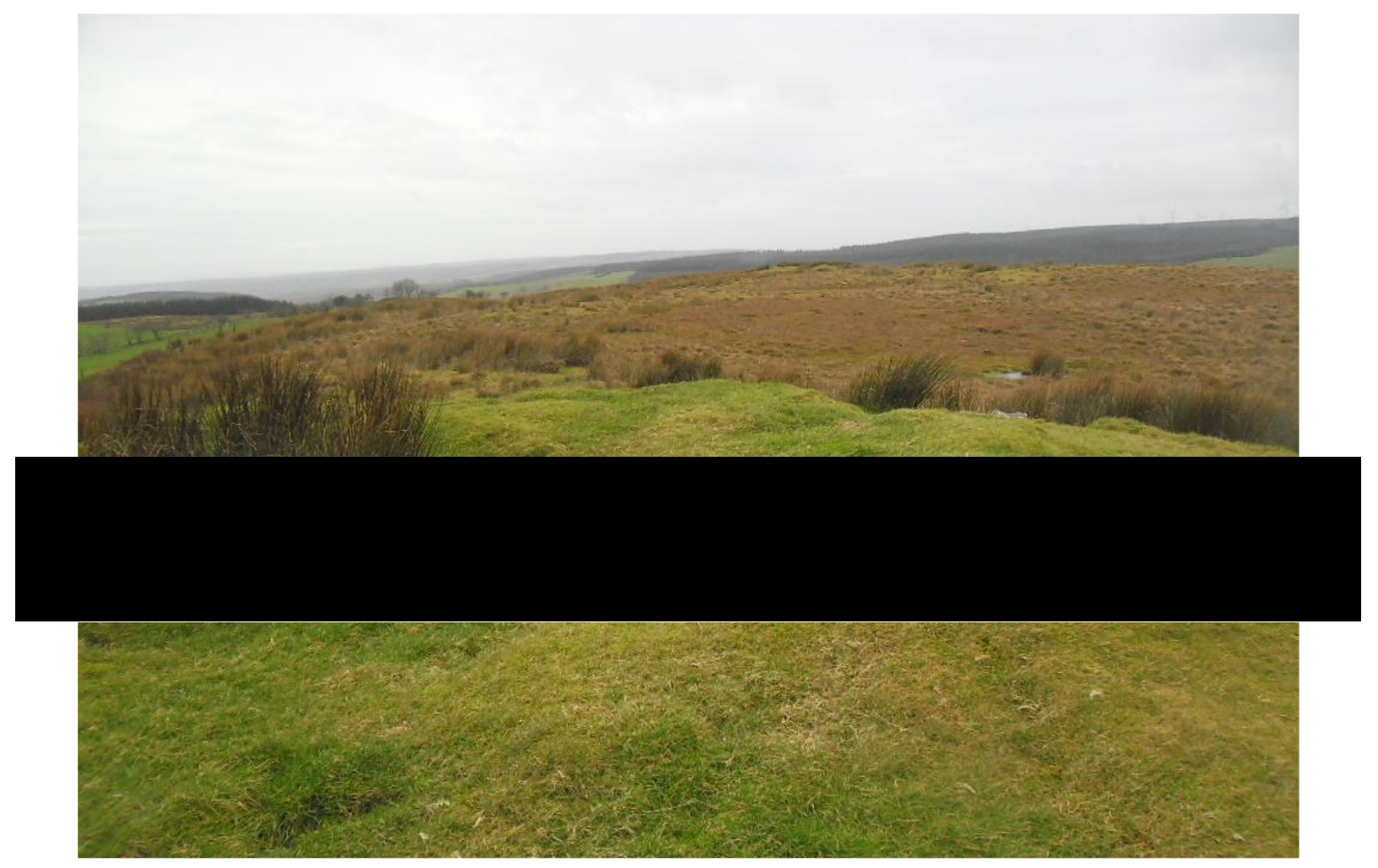

Figure 3:9: Image of Mynydd Bach. Sourced from CCC (2014 (c)). 


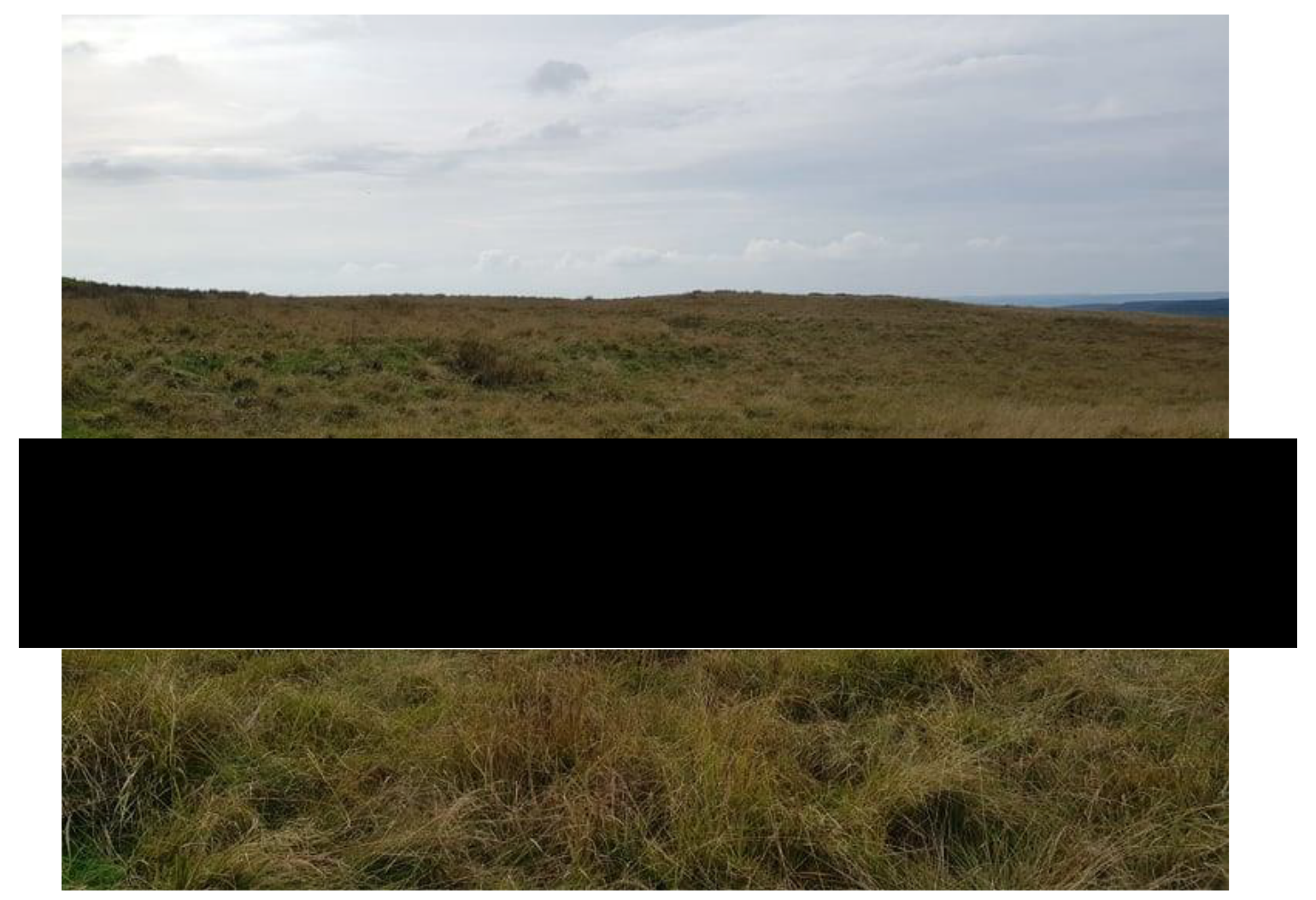

Figure 3:10: Image of Mynydd Bach (Holder, 2021).

\subsection{4: Previous Work on the Study Sites}

A field survey report was carried out by Rob Low, of Rigare Limited, on behalf of Carmarthenshire County Council, in 2014. The survey measured the peat depths, and estimated the volume of peat, at five peatlands located in Carmarthenshire, including the three sites selected for this thesis. The results of the report are discussed below.

For Pyllau Cochion, the survey reported that the greatest peat depth was $8.63 \mathrm{~m}$ and that the average peat depth was $2.84 \mathrm{~m}$ (Fig.3.11) (Low, 2014). The deepest part of the peat bog was found in the northern region of the peatland, where there is a small deep basin, with steep sides (Fig.3.11) (Low, 2014). The depths for the southernmost part of the peatland were not measured as that part was inaccessible at the time of the study (Fig.3.11) (Low, 2014). From the area that was assessed an estimated peat volume of $70,897 \mathrm{~m}^{3}$ was calculated (Low, 2014). 


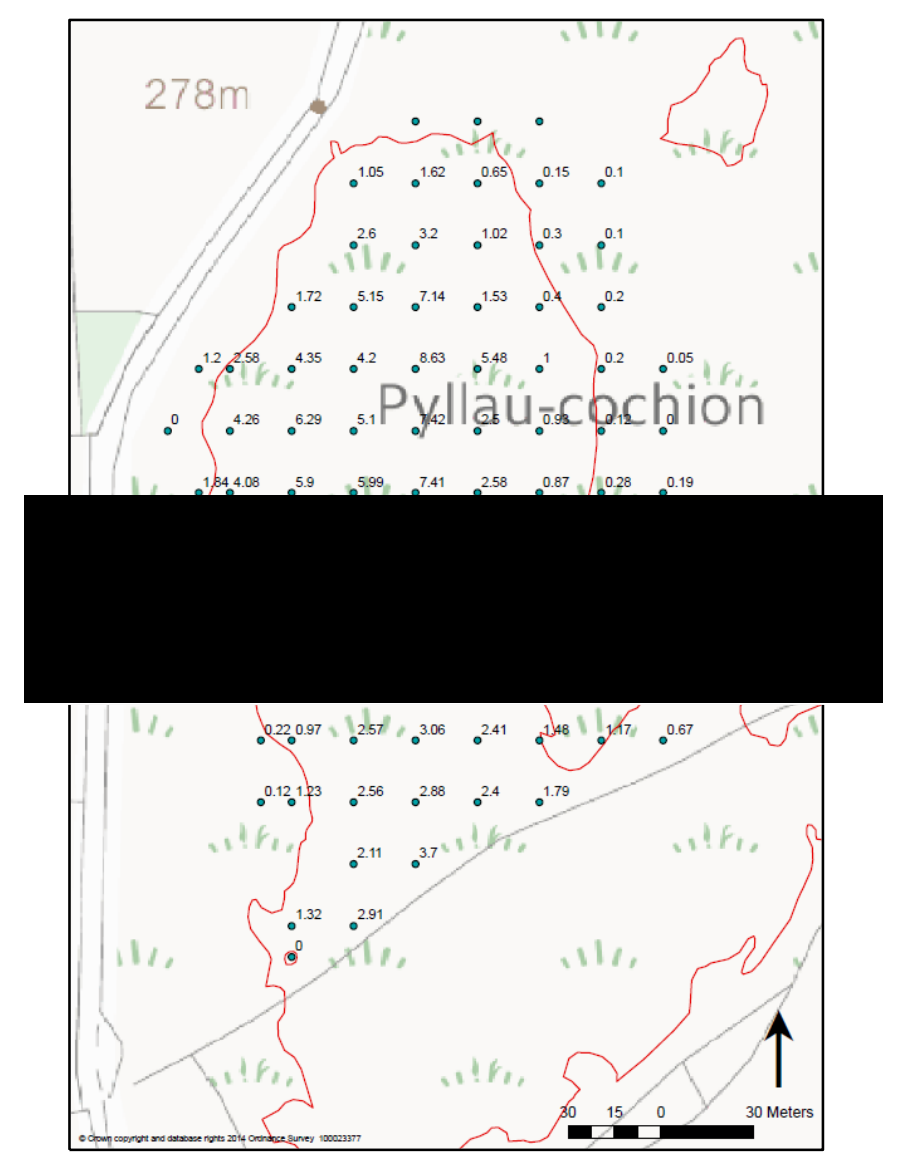

Figure 3:11: Peat depth measurements at Pyllau Cochion. Note the division line showing the southernmost part of the site that was inaccessible at the time of the study. Sourced from Low (2014).

For Figyn Common, Low (2014) reported that the maximum peat depth could not be determined because the sediment depth, at two points, extended beyond the range of the depth probe that was used - $9.18 \mathrm{~m}$. Consequently, $9.18 \mathrm{~m}$ was the deepest point measured (Fig.3.12). Low (2014) hypothesised that because of the nature of the surrounding peat depths it was unlikely that the depth would exceed $10 \mathrm{~m}$ at these two positions. The deepest deposits were found in a small deep basin, with steep sides, that is situated approximately at the centre of the peat bog (Fig.3.12) (Low, 2014). An average peat depth of $1.78 \mathrm{~m}$ was calculated and the peat volume at the site was estimated to be $109,918 \mathrm{~m}^{3}$ (Low, 2014). Low (2014) also mapped the limit of peat cut area and the drainage at the site. 


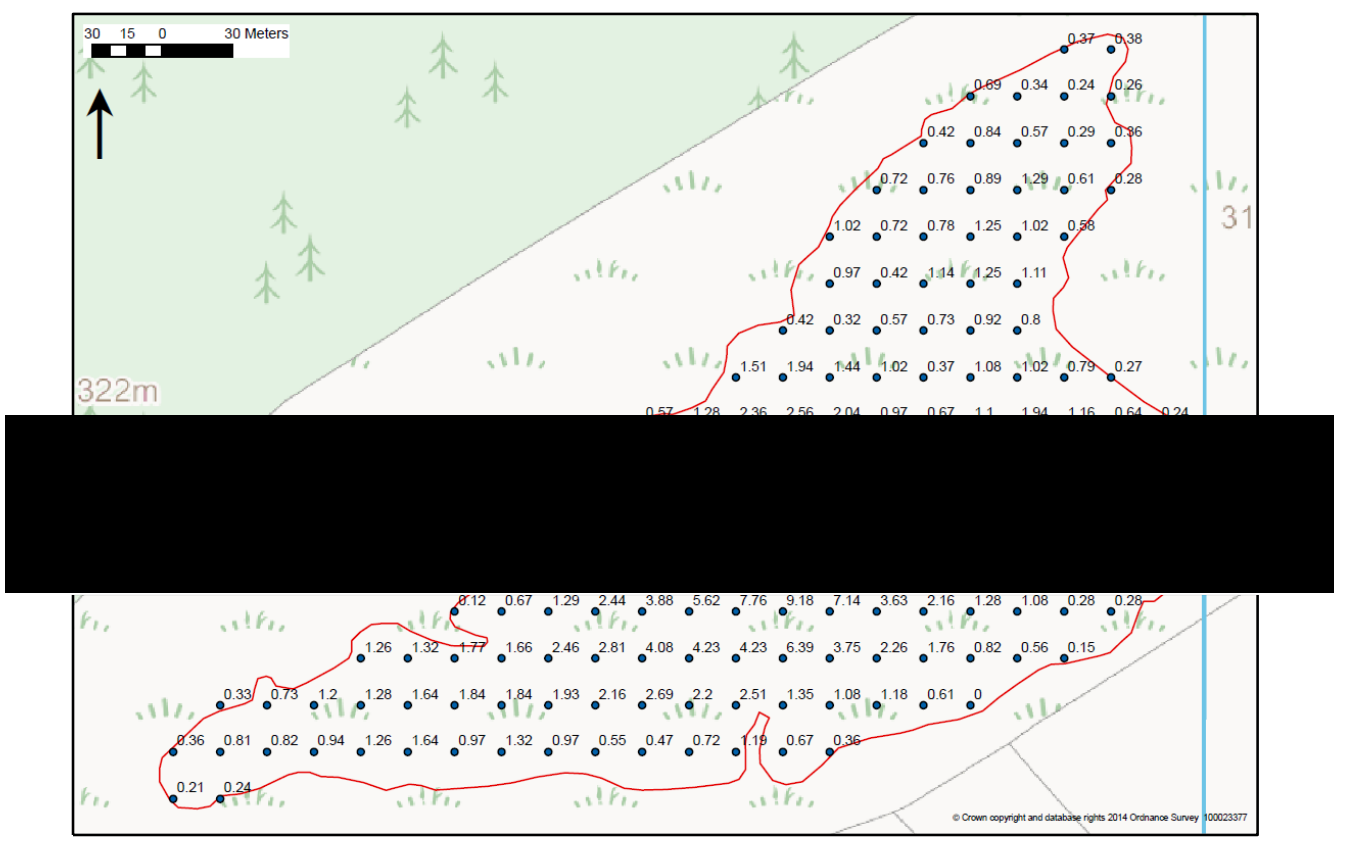

Figure 3:12: Peat depth measurements at Figyn Common. Sourced from Low (2014).

At Mynydd Bach the greatest peat depth was $1.16 \mathrm{~m}$, and the average peat depth was $0.42 \mathrm{~m}$ (Fig.3.13). The depth profile indicated that the underlying bedrock surface undulates gently and is comprised of several irregularly spaced runnels and troughs, where shallow peat deposits have accumulated (Low, 2014) (Fig.3.13). The peat volume at the site was estimated to be $6,815 \mathrm{~m}^{3}$.

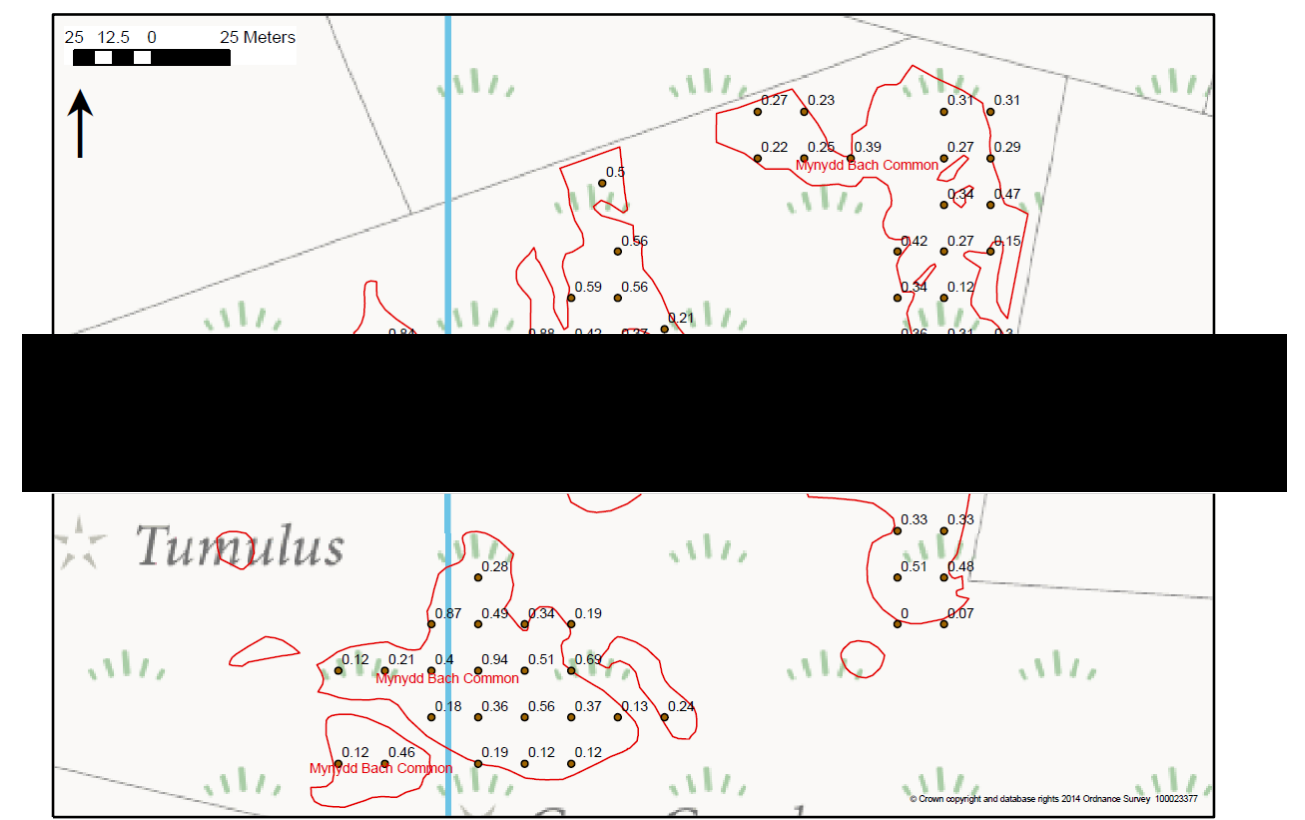

Figure 3:13: Peat depth measurements at Mynydd Bach. Sourced from Low (2014) 
The results of Low (2014), are very valuable as they provide an estimate of the peat resource, in terms of depth and volume, at each site. However, the peat depths reported may be misleading because the composition of the sediments was not considered and all measured depths were assumed to be peat, but a peat layer is commonly underlain by clay or silt deposits. Furthermore, as mentioned above, the maximum depth of peat was not measured at Figyn Common due to it being beyond the limit of the depth probe used. As a result of these two methodological limitations, the peat depths, and subsequent volume estimations are conservative.

In addition to the work by Low (2014), preliminary work was carried out at Pyllau Cochion as part of a MSc dissertation (Holder, 2015). One radiocarbon date of $c a .9783$ cal yrs. BP was obtained for the depth of $520 \mathrm{~cm}$ along with some low-resolution proxy data $(8 \mathrm{~cm}$ resolution) - loss on ignition, carbon and nitrogen, and charcoal (Holder, 2015). Furthermore, lowresolution (every $32 \mathrm{~cm}$ ) pollen work was conducted by Watkins and Froyd (2017) as part of the Carmarthenshire Bogs Project (Fig.3.14). The pollen record at Pyllau Cochion shows that from the start of the Bronze age period tree presence declines and shrub and herbs increase, suggesting deforestation and cultivation (CCC, 2017). From ca. 3000-2000 cal yrs. BP deforestation continues and plant species, indicative of human activity (such as Plantago) increase (CCC, 2017). This provides an important insight into the anthropogenic history of the site and local area. 


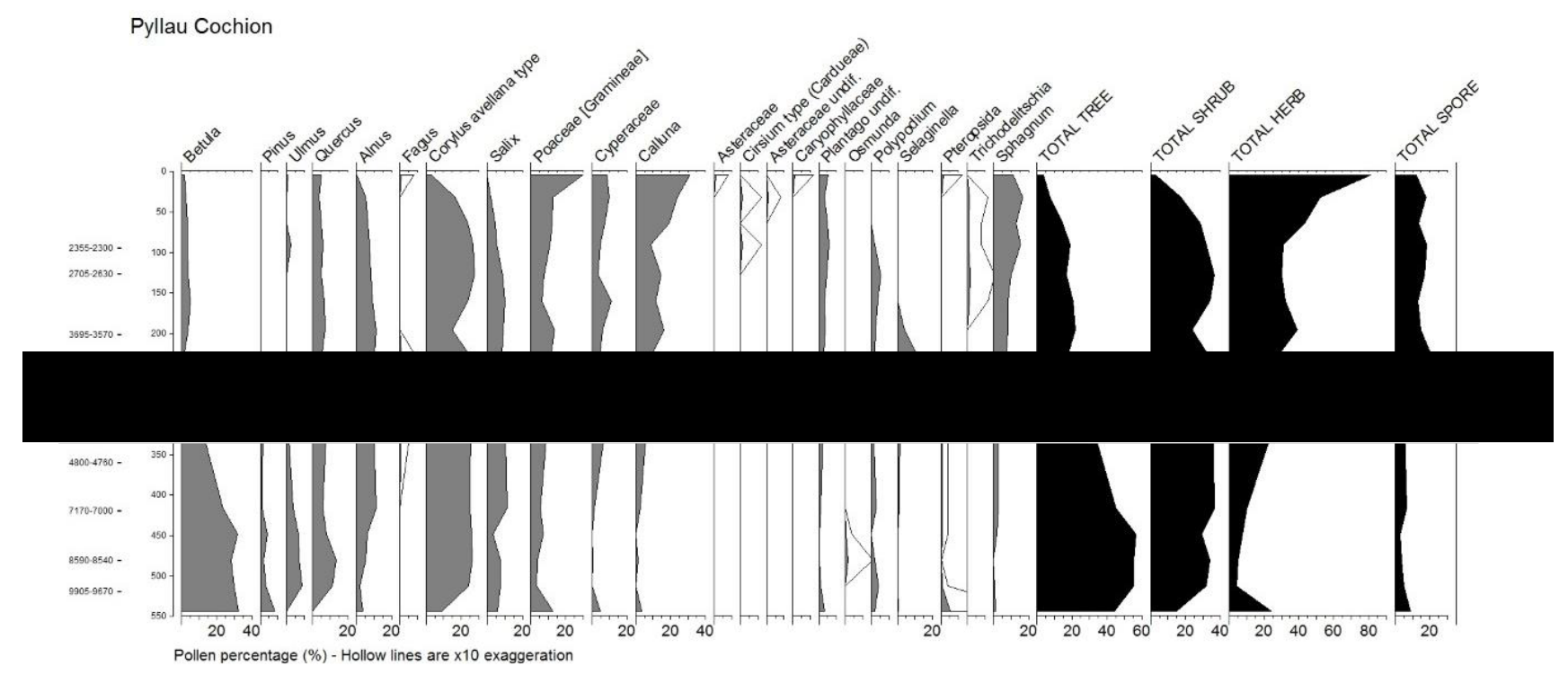

Figure 3:14: Pollen diagram for Pyllau Cochion (Watkins and Froyd, 2017)

\section{3: Fieldwork}

\subsection{1: Core sampling}

Peat cores were sampled at the deepest point within each basin in order to reconstruct a detailed record of palaeoenvironmental changes. The deepest point was chosen as this was suspected to be where peat accumulation began at the sites and therefore, should provide the longest record (Low, 2014). The location of the deepest peat was identified according to peat thickness maps (Low, 2014) (Figs. 3.11-3.13) and a gauge corer was used to check that the deepest point was correctly identified in the field. Once satisfied that the deepest point had been located the cores were sampled.

The cores were taken using a $0.5 \mathrm{~m}$ or $1 \mathrm{~m}$ Russian corer (both with a $5 \mathrm{~cm}$ diameter). The head of the corer disrupts the top $5 / 10 \mathrm{~cm}$ of the underlying sample. In order to obtain a continuous core, overlapping samples were alternately taken from two adjacent boreholes, following the protocols of Vleeschouwer et al., (2011). Core sections were taken with an overlap of 5 / 10 
$\mathrm{cm}$ depending on whether the $50 \mathrm{~cm}$ or $1 \mathrm{~m}$ Russian was used (respectively) and the overlaps were considered to produce an overall depth profile for each site. The coring equipment was carefully cleaned before sampling each core section to prevent cross contamination. At Mynydd Bach, because the surface peat was highly compacted, the uppermost $50 \mathrm{~cm}$ was sampled with a spade and the lowermost depths were taken with the Russian corer as described above. Once retrieved, each core section was photographed and lithological changes were noted, in the field, as the visibility of such features can diminish quickly with time due to colour changes and oxidation (Vleeschouwer et al., 2011). The samples were then wrapped in cling film and placed in well-sealed, carefully labelled, halved plastic tubes that were stored in the cold store upon return to the university.

One complete core was taken at Figyn Common (FGC1), Mynydd Bach (MBC1) and Pyllau Cochion (PCC1). A second replicate core of the uppermost peat section was sampled at Pyllau Cochion (PCC2), as more material was required. The lithological depth profiles, in PCC1 and PCC2, were compared and found to be highly similar (within $1 \mathrm{~cm}$ of each other) and therefore a depth correction was not necessary, and the two cores were compared like for like (see appendices).

\section{4: Laboratory work}

\subsection{1: Sediment Description}

Each core section was cleaned thoroughly in the laboratory by carefully removing the surface sediment across the width of the core, and any other visible contamination, with a scalpel. The samples were described using the Troels-Smith classification system (Troels-Smith, 1955) as detailed in Aaby and Berglund (1986). This system was chosen to describe the samples as an accepted framework that accounts for the complexity of organic sediments, like peats, 
recognising that they are typically comprised of a mixture of components (Birks and Birks, 1980). The physical characteristics, extent of humification, dominant deposit elements and trace components of each zone were noted according to the Troels-Smith 5-point scale. This description, alongside the observations made in the field, was used to sub-divide the cores into different lithological zones. To verify the composition of the lithological zones with higher confidence macrofossil analysis of one sample in each lithological zone, as suggested by Birks (1981), was performed. The methods used for this are covered in the later macrofossils section.

\subsection{2: Sub-sampling}

Sub-samples were taken from the cores using a scalpel and a volumetric syringe. Samples for loss on ignition (LOI) and bulk density (BD) were taken contiguously at a $2 \mathrm{~cm}$ resolution (Fig.3.15). A $2 \mathrm{~cm}$ sampling resolution was used because there was not time to sample all the full core depths at a $1 \mathrm{~cm}$ resolution. Contiguous $2 \mathrm{~cm}$ samples were taken to ensure that approximations of temporal carbon accumulation were representative of the full vertical profile, following the protocols set out by Charman et al., (2013). Care was taken to retrieve equal amounts from each centimetre within the $2 \mathrm{~cm}$ depth increment when sampling.

The $2 \mathrm{~cm}$ sampling approach, used for LOI and BD, meant that the samples for the other proxies also needed to be taken contiguously, so that they were comparable. Although this is a nonconventional approach for the other proxies, usually taken from $1 \mathrm{~cm}$ intervals, it is important that all of the data sets are comparable, in terms of sampled depth intervals, to address the research questions, such as, the impact that wetness shifts, and burning, on carbon fluctuations. Figure 3.15 illustrates the sub-sampling strategy adopted. 


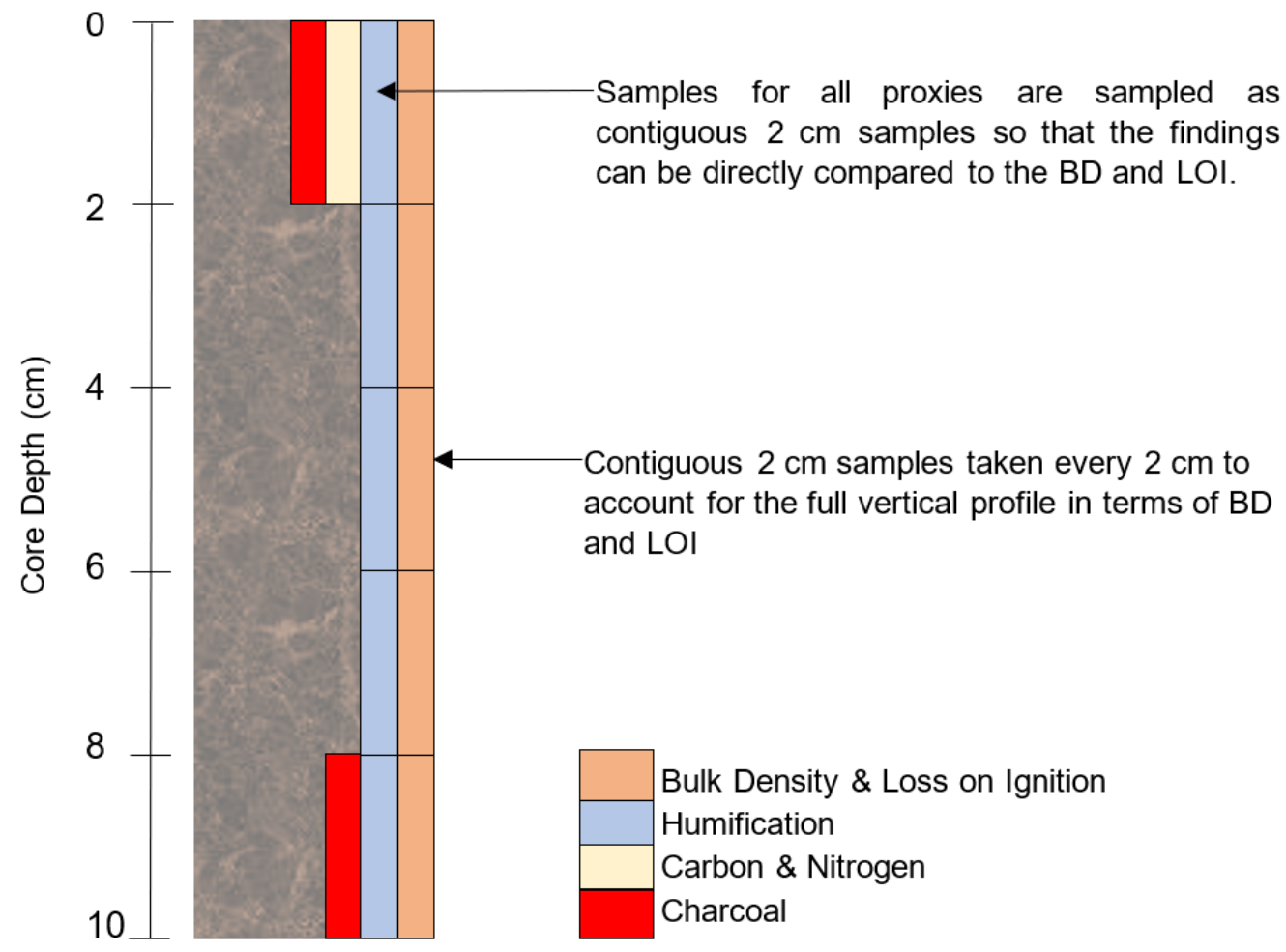

Figure 3:15: Schematic of sub-sampling strategy for each site illustrated on a theoretical $10 \mathrm{~cm}$ core section. $2 \mathrm{~cm}$ contiguous samples were extracted for $\mathrm{LOI}, \mathrm{BD}$, humification, $\mathrm{CN}$ and charcoal. Radiocarbon dating and macrofossil analysis are not shown as they are done at specific selected depths.

To make decisions about the different proxy resolutions two points were considered at all sites; 1) answering the $\mathrm{PhD}$ research questions (carbon accumulation, wetness shifts and fire history) and 2) the construction of a chronological framework. At Pyllau Cochion a third objective was taken into consideration and that was to ensure that all the necessary information for the Carmarthenshire Bogs Project (CBP) was delivered within a given time period. This was because the funding requirements stipulated that certain data needed to be provided within a short timeframe (see Table 3.1).

In order to meet the timing stipulations of the $\mathrm{CBP}$, and answer the $\mathrm{PhD}$ research questions, some repetition of proxies at Pyllau Cochion was necessary. The BD and LOI in PCC1 were firstly done at a lower resolution ( $4 \mathrm{~cm}$ contiguous samples) to provide a crude framework for 
selecting the radiocarbon dates that were funded by the CBP. However, although this satisfied the requirements of the $\mathrm{CBP}$, the lower resolution was not adequate for the higher resolution carbon accumulation that is required to answer the $\mathrm{PhD}$ research questions. For that reason, another core was collected (PCC2) so that more material was available to construct BD and LOI at the higher resolution $(2 \mathrm{~cm})$.

Table 3:1: Proxy analyses for cores from all three sites, the sampling resolution and rationale for resolution adopted. Abbreviations used in table - OC (Organic Carbon \%) and OM (Organic Matter $\%)$.

\begin{tabular}{|c|c|c|c|}
\hline Proxy & Core & Resolution (cm) & Justification \\
\hline \multirow[t]{4}{*}{$\begin{array}{l}\text { Loss on } \\
\text { ignition }\end{array}$} & PCC2 & 2 & $\begin{array}{l}\text { High resolution record of OM }(0-600 \mathrm{~cm}) \text { to } \\
\text { reconstruct carbon accumulation of peat section }\end{array}$ \\
\hline & PCC1 & 4 & $\begin{array}{l}\text { Low-resolution record of OM }(0-820 \mathrm{~cm}) \text { for } \\
\text { sampling }{ }^{14} \mathrm{C} \text { dates and to meet CBP project } \\
\text { milestones }\end{array}$ \\
\hline & FGC1 & 2 & $\begin{array}{l}\text { High resolution record of } \mathrm{OM} \text { to reconstruct carbon } \\
\text { accumulation }\end{array}$ \\
\hline & MBC1 & 2 & $\begin{array}{l}\text { High resolution OM to reconstruct carbon } \\
\text { accumulation }\end{array}$ \\
\hline \multirow[t]{4}{*}{ Bulk Density } & PCC2 & 2 & $\begin{array}{l}\text { High resolution BD to reconstruct carbon } \\
\text { accumulation }\end{array}$ \\
\hline & PCC1 & 4 & $\begin{array}{l}\text { Low-resolution BD record for sampling }{ }^{14} \mathrm{C} \text { dates } \\
\text { and to meet CBP project milestones }\end{array}$ \\
\hline & FGC1 & 2 & $\begin{array}{l}\text { High resolution BD to reconstruct carbon } \\
\text { accumulation }\end{array}$ \\
\hline & MBC1 & 2 & $\begin{array}{l}\text { High resolution BD to reconstruct carbon } \\
\text { accumulation }\end{array}$ \\
\hline \multirow[t]{4}{*}{$\begin{array}{l}\text { Radiocarbon } \\
\text { dating }\end{array}$} & PCC1 & $\begin{array}{l}{ }^{*} 9 \text { selected } \\
\text { depths }\end{array}$ & To build a chronological framework \\
\hline & PCC2 & *1 selected depth & To build a chronological framework \\
\hline & FGC1 & $\begin{array}{l}{ }^{*} 9 \text { selected } \\
\text { depths }\end{array}$ & To build a chronological framework \\
\hline & MBC1 & ${ }^{*} 1$ selected depth & To build a chronological framework \\
\hline
\end{tabular}




\begin{tabular}{|c|c|c|c|}
\hline \multirow[t]{4}{*}{$\begin{array}{l}\text { Carbon and } \\
\text { Nitrogen }\end{array}$} & PCC2 & $\begin{array}{c}16 \\
\text { (Only up to } 609 \\
\text { cm depth) }\end{array}$ & $\begin{array}{l}\text { To constrain estimations of } \mathrm{OC} \text { from } \mathrm{OM} \text { in peat } \\
\text { section, test for carbonates and infer vegetation } \\
\text { shifts. }\end{array}$ \\
\hline & PCC1 & $\begin{array}{l}{ }^{*} 6 \text { selected } \\
\text { depths }\end{array}$ & Carbonate presence test \\
\hline & FGC1 & 16 & $\begin{array}{l}\text { To constrain estimations of } \mathrm{OC} \text { from } \mathrm{OM} \text { in peat } \\
\text { section, test for carbonates and infer vegetation } \\
\text { shifts. }\end{array}$ \\
\hline & MBC1 & 16 & $\begin{array}{l}\text { To constrain estimations of OC from OM in peat } \\
\text { section, test for carbonates and infer vegetation } \\
\text { shifts. }\end{array}$ \\
\hline \multirow[t]{2}{*}{ Humification } & PCC1 & 2 & $\begin{array}{l}\text { High resolution record of wetness shifts to assess } \\
\text { impact on carbon accumulation in bog peat section } \\
(0-362 \mathrm{~cm}) \text { and reconstruct BSW. }\end{array}$ \\
\hline & FGC1 & 2 & $\begin{array}{l}\text { High resolution record of wetness shifts to assess } \\
\text { impact on carbon accumulation in bog peat section } \\
(0-526 \mathrm{~cm}) \text { and reconstruct BSW. }\end{array}$ \\
\hline \multirow[t]{3}{*}{ Charcoal } & PCC2 & 8 & $\begin{array}{l}\text { To assess whether fire has been a recurrent feature } \\
\text { of the site throughout the Holocene. }\end{array}$ \\
\hline & FGC1 & 8 & $\begin{array}{l}\text { To assess whether fire has been a recurrent feature } \\
\text { of the site throughout the Holocene. }\end{array}$ \\
\hline & MBC1 & 8 & $\begin{array}{l}\text { To assess whether fire has been a recurrent feature } \\
\text { of the site throughout the Holocene. }\end{array}$ \\
\hline \multirow[t]{3}{*}{ Macrofossils } & PCC2 & $\begin{array}{l}{ }^{*} 6 \text { selected } \\
\text { depths }\end{array}$ & $\begin{array}{l}\text { To verify the composition of lithological zones with } \\
\text { higher confidence and to check the reliability of } \\
\text { humification data. }\end{array}$ \\
\hline & FGC1 & $\begin{array}{l}\text { *7 selected } \\
\text { depths }\end{array}$ & $\begin{array}{l}\text { To verify the composition of lithological zones with } \\
\text { higher confidence and to check the reliability of } \\
\text { humification data. }\end{array}$ \\
\hline & MBC1 & $\begin{array}{l}\text { *2 selected } \\
\text { depths }\end{array}$ & $\begin{array}{l}\text { To verify the composition of lithological zones with } \\
\text { higher confidence. }\end{array}$ \\
\hline
\end{tabular}

\subsection{3: Peat Properties}

\subsubsection{1: Organic Matter and Bulk Density}

To determine organic matter content (OM) bulk density (BD) and ash free bulk density loss on ignition was carried out following the standardised procedure, and calculations, outlined by Chambers et al., (2011) (Table 3.2). Using a volumetric syringe, a known volume (V) was 
removed from each contiguous $2 \mathrm{~cm}$ section and care was taken to ensure that an equal amount was taken from each centimetre within the $2 \mathrm{~cm}$ increment. The samples were then weighed on a precision microbalance to obtain the wet weight (g) (WW), dried overnight in an oven at $100^{\circ} \mathrm{C}$, and re-weighed to obtain the dry weight (g) (DW). After this they were placed in a furnace, for 4 hours, at $550^{\circ} \mathrm{C}$, so that the organic material would be burnt off, and weighed a final time to get the ashed weight (g) (AW). The results for BD and ash-free bulk density are calculated to give a value per centimetre. These values are viewed as a typical per centimetre value within that $2 \mathrm{~cm}$ depth increment and both centimetres within it are assigned the same value. Meaning that there is a value for each $\mathrm{cm}$ in the depth profile.

Table 3:2: Equations used to calculate loss-on-ignition and organic matter weight (g), organic matter percentage (\%), dry bulk density $\left(\mathrm{g} \mathrm{cm}^{3}\right)$ and ash-free bulk density $\left(\mathrm{g} \mathrm{cm}^{3}\right)$ following Chambers et al., (2011). DW: Dry weight, AW: ashed weight, $\mathrm{V}=$ volume.

\begin{tabular}{|l|l|}
\hline \multicolumn{1}{|c|}{ Proxy } & \multicolumn{1}{|c|}{ Equation } \\
\hline Organic matter percentage (\%) & $(\mathrm{DW}-\mathrm{AW}) / \mathrm{DW}$ * 100 \\
\hline Dry bulk density $\left(\mathrm{g} \mathrm{cm}^{3}\right)$ & $\mathrm{DW} / \mathrm{V}$ \\
\hline $\begin{array}{l}\text { Ash - free bulk density/ organic matter density }(\mathrm{g} \\
\left.\mathrm{cm}^{3}\right)\end{array}$ & Bulk density * Organic Matter \% \\
\hline
\end{tabular}

\subsubsection{2: Carbon:Nitrogen Analysis}

Carbon:nitrogen (C:N) analyses were conducted for two reasons: (i) so that the carbon dataset could constrain higher resolution carbon content estimates, within the peat zone, and (ii) to use the $\mathrm{C}: \mathrm{N}$ ratio as a palaeovegetation index throughout the sequence, including the lower, 
inorganic, zones (Burrows et al., 2014; Shriller et al., 2014). See Figure 3.15 to see how the C:N was sampled and Table 3.1 for sampling resolution and justification.

Before measuring the carbon and nitrogen content of every sample, it is standard protocol to check for the presence of carbonates (Chambers et al., 2011). This is done to determine whether any of the carbon being detected is inorganic carbon. If no carbonates are detected then it is assumed that the carbon measured is just organic carbon, but if carbonates are detected then this would need to be removed using a pre-treatment before analysis. This provides certainty that resulting carbon readings are the total organic carbon percentage (TOC) content. To check for the presence of carbonates, tests were carried out on several samples, from each lithological zone, in all cores, using the methods of Harris et al., (2001) (see appendices). The findings of the carbonate tests suggest that no inorganic carbonates were present, and this is consistent with the non-carbonate geology for all sites (Figs.3.16-3.18, also see appendices). Consequently, the remaining samples were not pre-treated prior to analysis, with certainty that the carbon content measured was TOC. The carbon and nitrogen values for the rest of the samples were obtained following the same methods that were used for the control samples, as explained above.

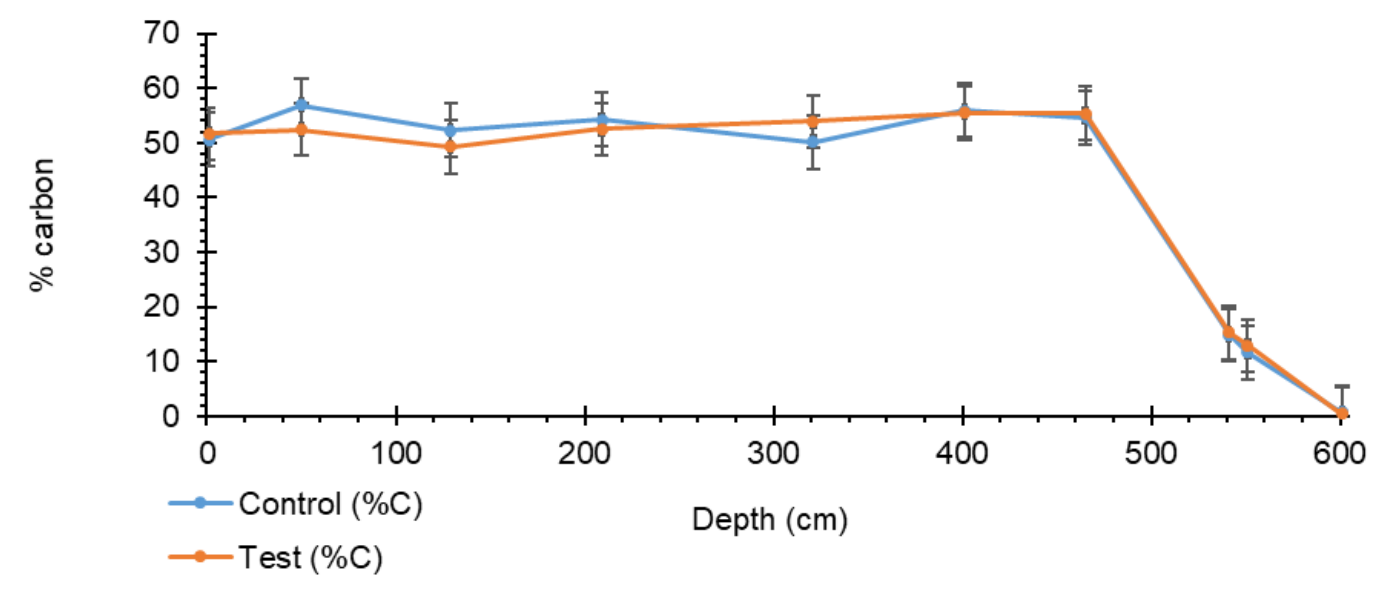

Figure 3:16: Carbonate test results plotted against depth for Pyllau Cochion. 


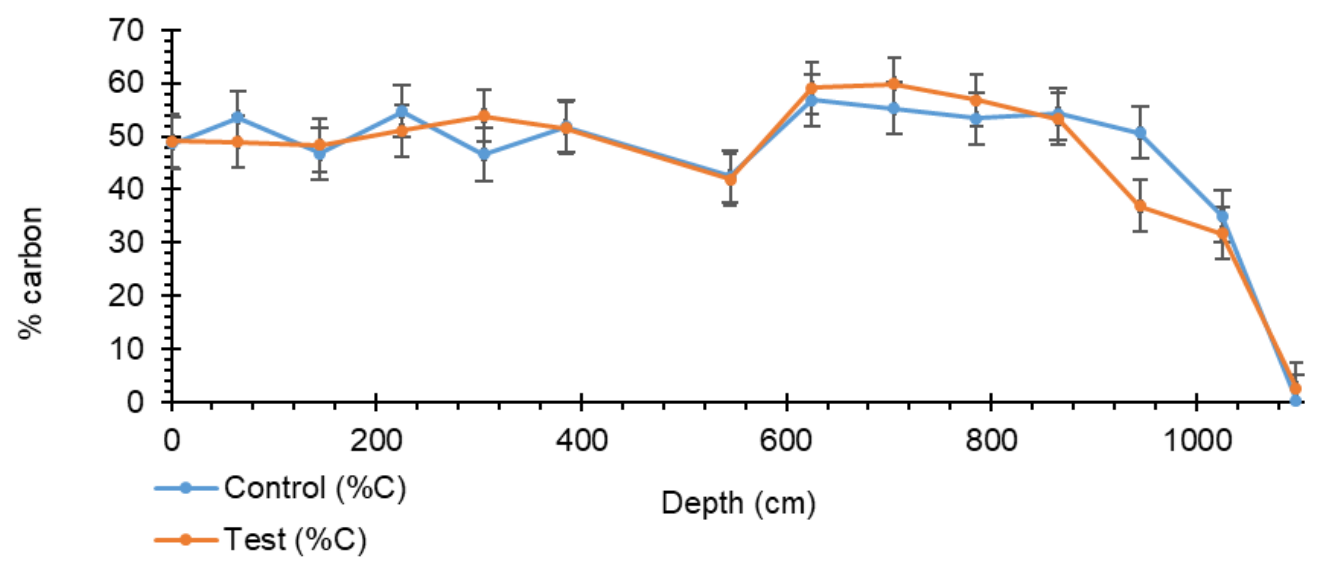

Figure 3:17: Carbonate test results plotted against depth for Figyn Common.

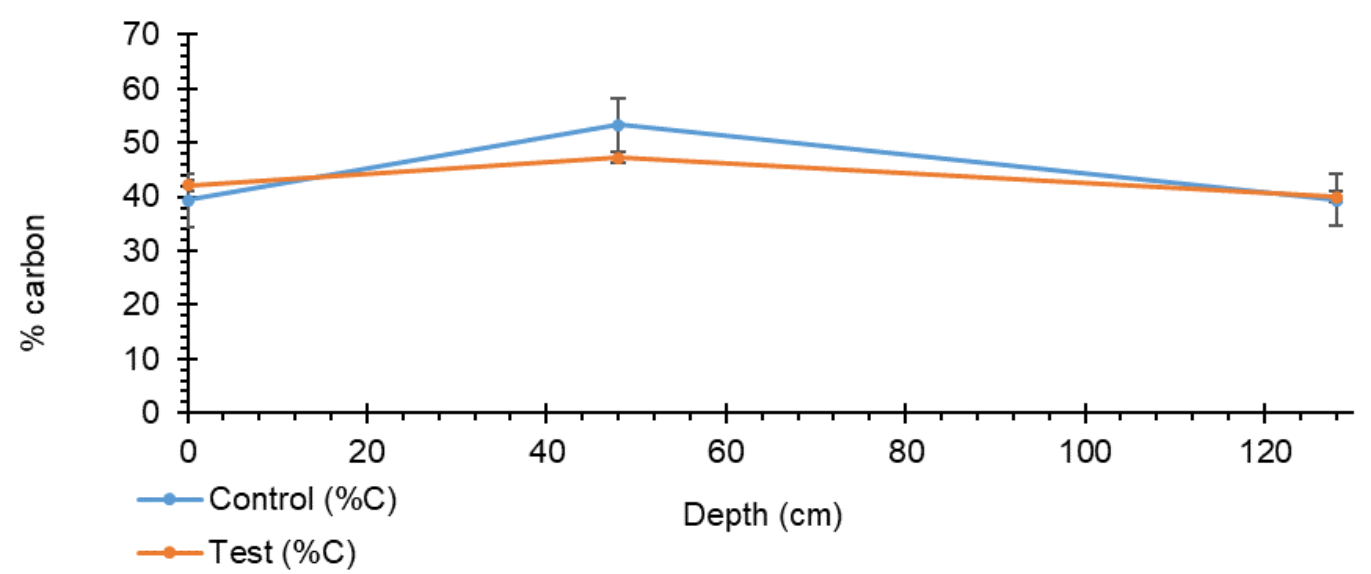

Figure 3:18: Carbonate test results plotted against depth for Mynydd Bach.

\subsection{4: Humification}

Humification analysis was conducted to provide a record of bog surface wetness (BSW). Humification was chosen as the BSW proxy as it could be carried out at a high resolution (every $2 \mathrm{~cm}$ ) within the time limits, and the expertise for other BSW proxies were not available at the university. The fen sections/cores were not analysed for Humification. This includes the full Mynydd Bach core, and the underlying fen peat sections for Pyllau Cochion and Figyn Common. The humification work was done on the uppermost 'bog peat' sections for Figyn 
Common and Pyllau Cochion (see Figure 3.15 and Table 3.1 to see the sampling strategy, resolution, and justification, all $2 \mathrm{~cm}$ samples were homogenised).

The fen peat sections were not analysed because of potential methodological and interpretative issues. To elaborate, conducting humification in more minerogenic peat can be problematic because some mineral material can pass through during the filtering stage (see method described below) (Payne and Blackford, 2008). Furthermore, fen peat is not typically used for palaeoclimatic analysis, like humification, because unlike bogs (that are solely rain fed), fens receive water from other sources, such as ground water and runoff, in addition to precipitation inputs (Barber and Charman, 2005). Therefore, it is difficult to underpin the causes of wetness shifts in the fen record, from say, anthropogenic forest clearance, that increased surface runoff, to climatic changes that influenced 'effective precipitation' (Barber and Charman, 2005). As a result of these potential methodological complications and interpretative unknowns, the humification analysis was done only on the bog peat core sections.

Humification analyses were conducted following the procedures of Chambers et al., (2011). For each contiguous sample, $0.2 \mathrm{~g}$ of dry peat was ground, homogenised and boiled in an $8 \%$ $\mathrm{NaOH}$ solution, at $95{ }^{\circ} \mathrm{c}$, for an hour. The samples were then filtered using filter paper (Whatman No.1) and the extract was diluted with distilled water. Following this, the diluted sample was pipetted into cuvettes and the amount of light transmission (\%) was measured using a spectrophotometer that was programmed to $540 \mathrm{~nm}$. Three different measurements were taken for each sample and the mean reading was calculated to give the final, raw, humification result.

Once the raw humification results had been determined they were subjected to two corrections. The first of which was to correct the dataset for any mineral content present, as this could cause the results to be misleading. To do this, each data point was divided by the organic proportion 
of the LOI (\%) for that sample, as in Payne and Blackford (2008(a)). After the results had been corrected for any mineral content, they were detrended to ensure that any long-term patterns, that could be due to autogenic peatland development were removed (Blackford and Chambers, 1995). The results were detrended using a linear regression and positive residuals indicate wetter intervals whilst lower residuals show drier periods (Swindles et al., 2012).

\subsection{5: Macrofossils}

Macrofossil analysis was performed as a supplementary proxy on a small number of strategically selected samples for PCC2, FGC1 and MBC1. This analysis was carried out to help better determine the vegetational composition of the different lithological zones and to test the reliability of the humification record for Pyllau Cochion and Figyn Common, as a BSW proxy. The reliability of the humification record was tested in order to mitigate the potential concerns, addressed by Hughes et al., (2012) about using humification analysis, on its own, to reconstruct BSW changes. Macrofossils can be used to assess the reliability of the humification record as they are also a proxy of BSW and therefore should depict the same wetness scenario (Blundell et al., 2016; Hughes et al., 2012). To exemplify, a high light transmission reading (indicating a wet period in the humification record) should be mirrored by the macrofossil composition found at the equivalent depth i.e., species indicative of a high bog surface wetness, and vice versa. Therefore, by comparing the results from the two different proxies, the reliability of the humification record can be assessed.

\section{Sample selection}

With the two aforementioned objectives for macrofossil work in mind a sample from each lithological zone was selected for all three sites (Tables 3.3-3.5). The samples selected for 
Pyllau Cochion and Figyn Common also represented either a high, low, or mean humification value for Pyllau Cochion and Figyn Common.

Table 3:3: Sample depths chosen for macrofossil analysis at Pyllau Cochion and the sampling rationale according to lithological zone and humification value.

\begin{tabular}{|l|c|l|}
\hline Core: PCC2 & & $\begin{array}{l}\text { Humification data: } \\
\text { Mean: } 39.76 \quad \text { Range: } 65.93-25.61\end{array}$ \\
& $\begin{array}{c}\text { Lithological } \\
\text { zone }\end{array}$ & Humification justification \\
\hline $32-34$ & $3-80$ & Low value: 27.36 \\
\hline $136-138$ & $80-210$ & Mean value: 39.27 \\
\hline $216-218$ & $210-253$ & High value: 53.4 \\
\hline $264-266$ & $253-323$ & Low value: 31.81 \\
\hline $350-352$ & $323-365$ & High value: 65.93 \\
\hline $392-400$ & $\begin{array}{c}365-520 \\
\text { (Fen peat } \\
\text { zone) }\end{array}$ & $\begin{array}{l}\text { N/A (humification analyses not done in } \\
\text { fen peat) }\end{array}$ \\
\hline
\end{tabular}

Table 3:4: Sample depths chosen for macrofossil analysis at Figyn Common and the justification for it being chosen in terms of the lithological zone it represents and the humification value.

\begin{tabular}{|l|c|l|}
\hline Core: FGC1 & & $\begin{array}{l}\text { Humification data: } \\
\text { Mean: } 48.54 \text { Range: } 74.67-28.83\end{array}$ \\
Sample depth chosen $\mathbf{( c m )}$ & $\begin{array}{c}\text { Lithological } \\
\text { zone }\end{array}$ & Humification Justification \\
\hline $48-50$ & $2-78$ & Low value: 30.67 \\
\hline $120-122$ & $78-164$ & High value: 64 \\
\hline $208-210$ & $164-228$ & High value: 74.68 \\
\hline $272-274$ & $228-298$ & Low value: 32.06 \\
\hline $400-402$ & $392-484$ & Mean value: 47.14 \\
\hline $512-514$ & $484-527$ & High value: 61.94 \\
\hline $592-594$ & $\begin{array}{c}585-1020 \\
\text { (Fen peat } \\
\text { zone) }\end{array}$ & $\begin{array}{l}\text { N/A (humification analyses not done in } \\
\text { fen peat) }\end{array}$ \\
\hline
\end{tabular}

Table 3:5: Sample depths chosen for macrofossil analysis at Mynydd Bach and the justification for it being chosen in terms of the lithological zone it represents.

\begin{tabular}{|l|c|}
\hline $\begin{array}{l}\text { Core: MBC1 } \\
\text { Sample depth chosen }(\mathbf{c m})\end{array}$ & Lithological zone \\
\hline $0-2$ & $0-9$ \\
\hline $24-26$ & $9-36$ \\
\hline $64-66$ & $36-120$ \\
\hline $128-130$ & $120-130$ \\
\hline
\end{tabular}




\section{Training set}

Before starting the macrofossil analysis, a 'training set' of modern plants was collected and carefully studied. This training set was collected to gain more familiarity with looking at the different plant components under the microscope, and to build a reference collection that could be used to identify plant remains found in the peat record. The training set consisted of 25 cuttings of plants currently living on Figyn common, 23 of which were identified in the field, using the field study identification guides by Jones and Roberts (2002); Gardner and Roberts (2010); O'Reilly et al., (2012); Godfrey (2014). The plant cuttings were brought back into the laboratory, dissected to macrofossil scale, and studied under the microscope.

\section{Sample preparation}

Once the training set had been studied the selected samples for macrofossil analysis were prepared following the procedures outlined by Mauquoy et al., (2011) and Greiser (2011). A $5 \mathrm{~cm}^{3}$ sample was taken from each selected depth increment, and warmed (at $60{ }^{\circ} \mathrm{C}$ ), in a $5 \%$ potassium hydroxide $(\mathrm{KOH})$ solution, for 30 minutes. The samples were then sieved at 125 $\mu \mathrm{m}$. Whilst sieving, the sample was kept underneath the water surface to avoid damaging macrofossils and charcoal shards.

\section{Counting and identification}

The macrofossil composition or peat components percentage for each sample, was determined using the first half of the Quadrat and Leaf Count (QLC) method (Barber et al., 1994), as described by Mauquoy et al., (2011). Only the quadrat count part of the QLC method was used because it gives the percentage abundance of species $\left(\mathrm{cm}^{3}\right)$ for the given depth studied and time constraints meant that it was not feasible to do the second part of the of the QLC method, the leaf count (assessing 100 Sphagnum leaves under high power microscopy). However, the quadrat counts provide enough information about the relative species compositions in each 
sample and whether they accumulated in a relatively high or low BSW scenario, and therefore address the research questions.

To estimate the percentage abundance of macrofossil species each sample was placed into several petri dishes and suspended in distilled water (Mauquoy et al., 2011). Once the sample was in the petri dish the remains in each dish were assessed under a stereo microscope. Any seeds/fruits present were identified and totalled and the macrofossils within 15 , randomly selected, different viewpoints were analysed at x10 magnification. For each of the 15 viewpoints, the macrofossils present were identified, and the percentage abundance of each macrofossil was estimated. The results from the 15 viewpoints were then averaged to give the overall percentage species abundance/peat components for that sample.

Plant macrofossils were identified using peat macrofossil identification guides (Katz et al., (1965); Grosse-Brauckmann (1972); Daniels and Eddy, (1990); Mauquoy and Van Geel (2007); Birks (2007)) and the training set. The macrofossils found were allocated into one of the following categories, herbaceous plants (dwarf shrubs, grasses and trees), Sphagnum mosses, other mosses, herbaceous plant tissue remains, algal mud and unidentified organic matter (U.O.M). After this, as many as possible of the species within each category were identified. Herbaceous plants were more easily identifiable due to them being larger and there often being several parts of them present (flower heads, leaves, seeds etc.). However, although time was spent trying to identify Sphagnum down to a sub-species level (where intact remains, with stems and branches still attached, were present), it was decided that confident sub-species could only be made by conducting the second part of Barber et al., (1994) QLC method, the leaf counts, and as mentioned above, time restraints inhibited this. Therefore, the Sphagnum found was not identified at a sub-species level. 


\section{Converting macrofossils to Bog Surface Wetness}

The macrofossils results were converted into a measure of relative BSW using the 'Dupont Hydroclimatic Index (DHI)' that was developed by Dupont (1986) (Daley and Barber, 2012). This index was chosen because it is the most reliable indicator of BSW in long peat core records (Daley and Barber, 2012). The DHI determines relative BSW by assigning weightings to species based on the modern BSW conditions that they are associated with, lower DHI's are associated with wetter conditions and a higher DHI is associated with drier settings (Daley and Barber, 2012). The DHI species weightings, used in this study were taken and adapted from Daley and Barber (2012) and are listed in Table 3.6. A DHI was produced for each sample by taking the percentage species abundances and multiplying them against the weighting for each species (Dupont, 1986):

$D H I=\left(s^{1} / 100 * x^{1}\right)+\left(s^{2} / 100 * x^{2}\right)+\ldots\left(s^{n} / 100 * x^{n}\right)$

$\mathrm{S}=$ Species abundance $(\%)$

$\mathrm{X}=$ DHI Species weighting

Table 3:6: listing the DHI species weightings as in Daley and Barber (2012). The DHI weighting for Sphagnum moss was calculated as an average of the weights given for 6 different sub-species of Sphagnum.

\begin{tabular}{|l|c|}
\hline Species & DHI weighting \\
\hline Wood & 8 \\
\hline Betula & 8 \\
\hline Erica tetralix & 8 \\
\hline Culluna vulgaris & 8 \\
\hline Unidentified organic matter (UOM) & 8 \\
\hline Ericaceae & 8 \\
\hline Eriophorum vaginatum & 7 \\
\hline Monocots undifferentiated & 7 \\
\hline Trichophorum cepitosum & 6 \\
\hline Racomitrium lanuginosum & 6 \\
\hline
\end{tabular}




\begin{tabular}{|l|l|}
\hline Aulacomnium palustre & 6 \\
\hline Other moss undifferentiated & 6 \\
\hline Rhynchospora & 3 \\
\hline Sphagnum & 3 \\
\hline Eriophorum angustifolium & 2 \\
\hline Algal muds & 1 \\
\hline
\end{tabular}

\subsection{6: Charcoal Record}

Fire history was reconstructed at all three sites (see Figure 3.15 and Table 3.1 to see the sampling strategy, resolution, and justification). This reconstruction was done to see whether burning, evident at Pyllau Cochion and Figyn Common today, has been a recurrent feature at the sites, and within the surrounding landscape in pre-modern periods. Macrocharcoal and charred macrofossil plant remains were analysed and these two proxies were chosen because they provide a local, and 'on-site', history of fire. Charcoal fragments between 125-500 $\mu \mathrm{m}$ give a record of fires within a $7 \mathrm{~km}$ radius (Whitlock and Millspaugh, 1996) and both charcoal fragments above $500 \mu \mathrm{m}$, and charred macrofossil plant remains, provide strong eevidence of 'on-site' fires (Magnan et al., 2012; Ohlson and Tryterud, 2000).

\section{Sample preparation}

All the sub-samples for macrocharcoal analysis were sampled, and pre-treated, using the same sample preparation method described for macrofossil analysis (see macrofossil methods). This was done so that some of these sub-samples could be used for both analyses. This methodological approach was deemed to be appropriate because a sub-sample volume of $5 \mathrm{~cm}^{3}$ is suited to charcoal analysis in a $2 \mathrm{~cm}$ depth increment (Whitlock and Larsen, 2001) and $\mathrm{KOH}$ is used as a deflocculant in several charcoal analysis studies e.g., Remy et al., (2018); Magnan et al., (2012), Hörnberg, (1995). 


\section{Counting and identification}

To identify and count the macrocharcoal fragments the contents of each sample were poured into several petri dishes and assessed under a stereoscope microscope. Charcoal fragments were identified following the identification protocols in Whitlock and Larsen (2001). For both sites two size fractions were counted $-125-500 \mu \mathrm{m}$ and $>500 \mu \mathrm{m}$. The 125-250 $\mu \mathrm{m}$ and 250-500 $\mu \mathrm{m}$ were not done separately as the record between these two size classes has been found to depict a similar fire history (Froyd, 2006). Following counting, the charcoal totals were divided by 5 to give the concentration of charcoal shards per $2 \mathrm{~cm}^{3}$. These concentration values were then divided by 2 to give the average per $\mathrm{cm}$ concentration for that $2 \mathrm{~cm}$ depth increment (and this value was assigned to both centimetres in that sample). These per $\mathrm{cm}$ concentrations were then converted into charcoal accumulation rates (CHAR) using the equation below (Froyd, 2006):

Charcoal concentration (per $\mathrm{cm}^{3}$ )/number of years in the given depth (as specified by the age-depth model)

\subsection{7: Radiocarbon Dating}

Radiocarbon dating is the most suitable method for dating organic rich sediments, like peat, spanning the Holocene (Charman, 2002).

\section{General Sampling strategy}

The depths selected for radiocarbon dating were chosen to constrain the timings of key events, but also to maximise the potential of building a robust age-depth model, which would provide a chronological framework throughout the full peat sections. Given these factors, the depths selected were chosen because they represented one, or more, of the following three criteria: 1) 
a basal date at peat inception; 2) a point of lithological or proxy interest; 3) a 'gap-filler' to provide regular spacing of dates, needed to constrain the age-depth model. Furthermore, the number submitted per site was informed by the length of the record whereby a date was sampled at approximately each metre, which typically equates to $c a .1000$ years in peat accumulations (Loisel et al., 2014). A total of 19 samples were sent off for dating, 10 for Pyllau Cochion, 9 for Figyn Common and 1 for Mynydd Bach. The full sampling strategy, including the sample depths, the rationale for that depth, and the material dated for each site are given in the results chapters.

The radiocarbon analysis for Pyllau Cochion was performed by Beta Analytic, as the Carmarthenshire Bogs Project funding stipulations required the dates within a very short timeframe, and Beta Analytic had the quickest analysis time. The other 10 dates, 9 for Figyn and 1 for Mynydd Bach, were produced by the Scottish Universities Environmental Research Centre (SUERC).

\section{Laboratory preparation}

Once the depths had been chosen, they were sub sampled and prepared for dating. The samples were prepared following the protocols of Piotrowska et al., (2011) whereby macrofossils of above-ground plants were sampled where possible, to provide the most reliable radiocarbon ages. However, at several depths' macrofossils were completely absent or the minimum sample weight was not achieved, even after repeated re-sampling attempts. As such, bulk samples were dated for those depths (see Tables 4.3, 5.3 and 6.3 in results chapters).

As mentioned above, the samples were prepared following the protocols of Piotrowska et al., (2011). Peat samples were sieved at $125 \mu \mathrm{m}$, with distilled water only, and macrofossils were picked under a stereomicroscope using watch-maker forceps. Where the peat was very humified and no identifiable terrestrial macrofossils were present, a bulk sediment sample was 
sent for dating. The bulk samples were carefully taken from the centre of the cores using a scalpel.

At both SUERC, and Beta Analytic, plant macrofossil samples were pre-treated using the acidbase-acid method (ABA) (also known as the acid/alkali/acid method (AAA)) (Beta Analytic, 2019 (a); Dunbar et al., 2016). The plant material was heated in a 0.1M hydrochloric acid (HCL) solution, then in a $0.1 \mathrm{M}$ sodium hydroxide solution $(\mathrm{NaOH})$, and then again, in $0.1 \mathrm{M}$ HCL. Each acid/alkali wash was done for two hours, and the samples were thoroughly rinsed with distilled water, in between washes, and after all washes were completed. The treated plant material was then dried.

The bulk sediment samples were handled differently by the two labs, in accordance with their standard protocols. Beta Analytic were confident that a reliable age would be retrieved by dating the organic bulk fraction. To obtain the bulk organic fraction, the sediment material below $180 \mu \mathrm{m}$ was soaked for 90 minutes in a $0.25 \mathrm{M}$ HCL solution to remove any carbonates. The material was then rinsed repeatedly, with de-ionized water, until it was at a neutral $\mathrm{pH}$ (Beta Analytic, 2019 (a)). However, SUERC prefer to date the humic acid fraction of a bulk sediment sample (Dunbar et al., 2016). To do this, the sample is placed in a 0.5M HCL solution and heated for two hours, and the extract, containing fulvic acids, is discarded. Following this, the sample is heated for two hours, in $\mathrm{NaOH}(0.5 \mathrm{M})$ and left to cool so that all the solid material settles before the extract is filtered. This sodium hydroxide stage was done twice to make sure that all the humic acid fraction was extracted. To separate the humic acid fraction, from the $\mathrm{NaOH}$, a 4M HCL solution was added to it and it was heated for an hour. The mixture was then left to cool so that the solid material could settle, this solid material is the humic acid fraction. The humic acid fraction was washed thoroughly and freeze dried (Dunbar et al., 2016). 
Once the bulk and macrofossil samples had been treated, they were converted into graphite, so that their radiocarbon $\left({ }^{14} \mathrm{C}\right)$ concentrations could be measured via Accelerator Mass Spectrometry (AMS), at both laboratories. To convert the treated sample into graphite at Beta Analytic, each sample was put into a sealed chemistry line and combusted in oxygen, to produce $\mathrm{CO}_{2}$ which was converted into graphite following the procedures of Manning and Reid (1977) (Beta Analytic Inc, 2019 (b)). At SUERC, the conversion was done using the approach developed by Vandeputte et al., (1996). The sample was combusted in a closed quartz tube, with copper oxide and silver foil (Dunbar et al., 2016). The samples were then ready for their radiocarbon $\left({ }^{14} \mathrm{C}\right)$ concentration to be measured.

At SUERC and Beta Analytic, a high precision Accelerator Mass Spectrometer was used to measure the ${ }^{14} \mathrm{C}$ concentration of the graphite samples. Background, and known-age reference samples (Oxalic acid - NIST4990C) were also measured at the same time for quality assurance and later radiocarbon determination. In addition, the delta carbon thirteen $\left(\delta^{13} \mathrm{C}\right)$ (the ratio of ${ }^{13} \mathrm{C} /{ }^{12} \mathrm{C}$ ) was measured, from a portion of the $\mathrm{CO}_{2}$ produced before graphitisation, using a mass spectrometer (Beta Analytic Inc., 2019 (b) and Dunbar et al., 2016). To obtain the conventional radiocarbon age (BP), the raw ${ }^{14} \mathrm{C}$ measurements were corrected in accordance with the reference samples and amounts of isotopic fractionation, by using the $\delta^{13} \mathrm{C}$ readings (Beta Analytic Inc., 2019 (b) and Dunbar et al., 2016). All obtained radiocarbon ages (BP) were then calibrated, to calendar ages (cal yrs. BP), using the Intcal20 calibration curve (Reimer et al.,2020) on Oxcal software (version 4.3) (Bronk Ramsey, 2009 (a)).

A contemporary date was assigned to the top of the cores that represented the time when they were sampled (2018 for Pyllau Cochion; and 2019 for Figyn Common and Mynydd Bach). This was necessary so that the age-depth models would have an upper limit, however, it is possible that the uppermost peat is not of contemporary age. The top of the core might not be contemporary because of peat cutting or a slowdown / hiatus in accumulation. To determine 
accurate ages the uppermost peat would need to be dated via SCP's or Lead210 (Oldfield, 1995; Swindles, 2010). The date of when the sites were cored therefore only provides crude age estimates for the peatland surfaces.

\section{5: Age-depth Modelling}

An age-depth model was constructed for each site using Bayesian statistics (Bronk Ramsey, 2008). This approach gives rise to probable ages for undated core sections by interpolating between the dated depths (Blaauw and Christen, 2005). When deciding which age-depth model to use it was important to choose a model that would accommodate for some randomness in rates of deposition. This is because, even though peat accumulates at an 'approximately constant' rate (Bronk Ramsey, 2008) there can be periods of rapid accumulation and hiatuses (Blaauw and Christen, 2005). For this reason, the P-Sequence, created by Bronk Ramsey (2008)) was chosen. The P-Sequence considers deposition to be a Poisson process (in which changes in accumulation are fundamentally random) (Bronk Ramsey, 2008). Consequently, the sequence incorporates some random deviation, from the approximated uniform rate of deposition, into the model (Bronk Ramsey, 2008). This was deemed as the most appropriate age-depth model to use to simulate conditions that were as close as possible to real deposition scenarios in a peat bog. The P-Sequence age-depth model was carried out following the instructions of Bronk Ramsey (2008) on Oxcal software (version 4.42, 2020) (Bronk Ramsey, 2009a) using the Intcal20 calibration curve (Reimer et al., 2020).

Each model was set with the following parameters:

\section{- An interpolation rate of 1}

$\circ$ to provide an estimated age for each $1 \mathrm{~cm}$ depth so that proxies fluxes can be estimated a $1 \mathrm{~cm}$ resolution. 
- A variable K value of (1, U (-2,2)) (Bronk Ramsey and Lee, 2013)

O The $\mathrm{K}$ value dictates the rigidity of the P-Sequence. A variable $\mathrm{K}$ value was used as it lets Oxcal dictate the optimal rigidity for each model, and for different points within it, from figures between $100 \mathrm{x}$ and $0.01 \mathrm{x}$ the original value (Bronk Ramsey and Lee, 2013). This means that the $K$ value chosen will be best suited to the depositional context and should produce a robust age-depth model (Bronk Ramsey and Lee, 2013).

- A general outlier analysis model - '('General', T(5), U(0,4), 't')' (Bronk Ramsey, 2009 (b))

- To ensure that any anomalous values do not influence the overall trend. This model sets the outlier posterior probability at $5 \%$, thus any value that is detected above that outlier range will be down-weighted accordingly within the P-sequence (Bronk Ramsey, 2009 (b)).

\section{6: Carbon Accumulation}

\subsection{1: Carbon Content}

The total organic carbon (TOC) was directly measured every $16 \mathrm{~cm}$ using a mass spectrometer (see section above). Higher resolution measurements could not be obtained due to budget restrictions. Therefore, to derive carbon values at a $2 \mathrm{~cm}$ resolution the carbon content was estimated following the methods of Dean (1974) and Loisel et al., (2014), whereby a regression analysis is used to determine the statistical relationship between the TOC and OM values (Fig.3.19) (see Appendix 2). By using the quantified relationship, between TOC and OM 
measurements, more reliable carbon datum should be produced than if the $50 \%$ of OM carbon assumption were used (Chambers et al., 2011). The regression equation stipulated the percentage of OM that is likely to be carbon at each site (see appendices). These percentages are 56\%, 54\% and 52\% for Figyn Common, Pyllau Cochion and Mynydd Bach (respectively) and these were used to derive carbon values for the three sites (Fig.3.19) (see appendices).

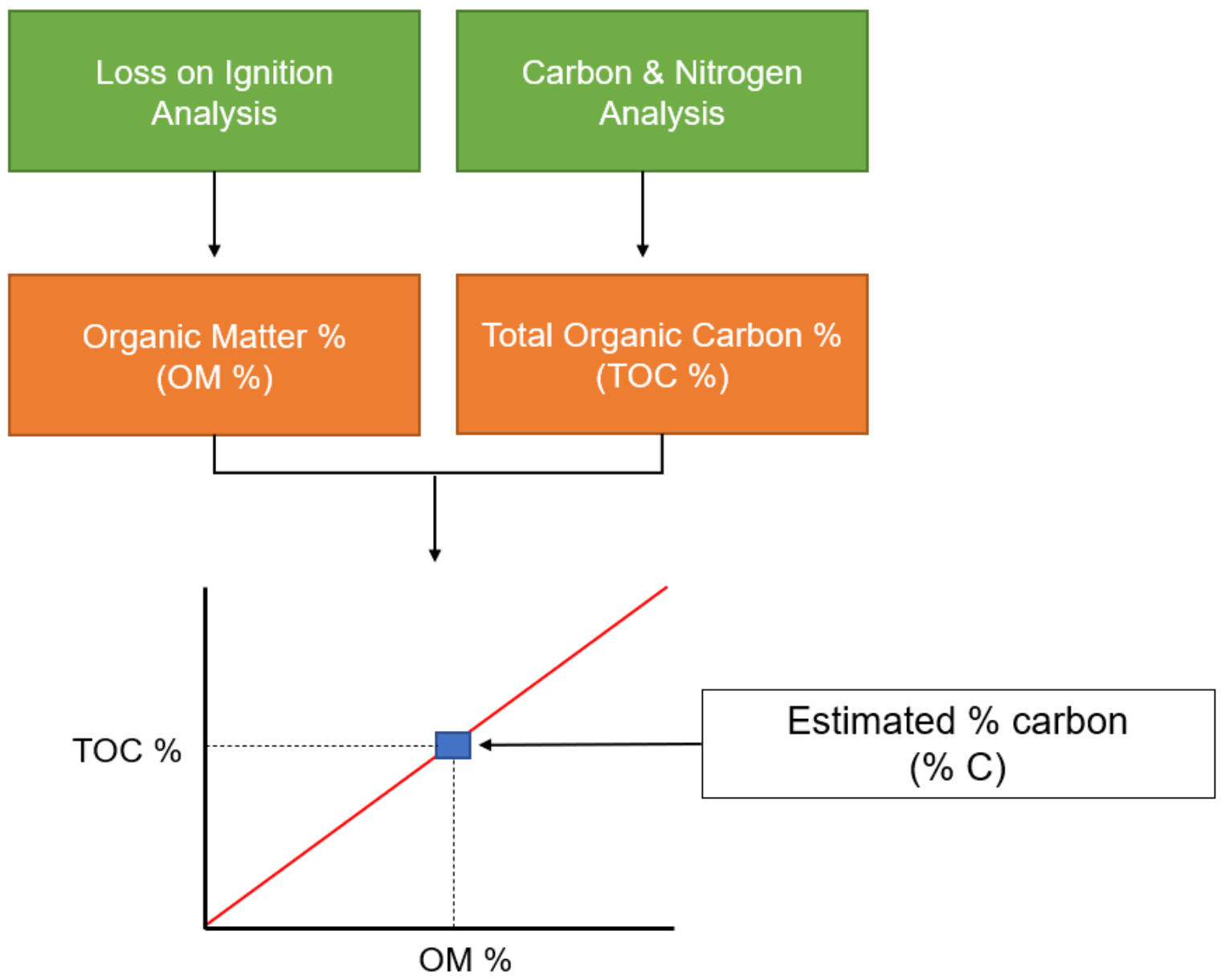

Figure 3:19: Schematic demonstrating how the relationship between TOC and OM is used to predict the amount of carbon from OM values.

\subsection{2: Peat Accumulation Rates, Carbon Density, LARCA and CARs}

Peat accumulation rates $(\mathrm{cm} / \mathrm{yr})$ were determined by dividing the depth of the respective section by its age (cal yrs. BP) (Turunen et al., 2002). The average peat accumulation rates $\left(\mathrm{cm} \mathrm{yr}^{-1}\right)$ 
were calculated for all catotelm peat, fen catotelm peat, bog catotelm peat, and acrotelm peat, at each site. The carbon density (the mass of carbon held within a given volume of peat) was calculated by multiplying the bulk density $\left(\mathrm{g} \mathrm{cm}^{3}\right)$ by the carbon content $(\mathrm{g})$ for each $2 \mathrm{~cm}$ increment (Packalen and Finklestein, 2014; Charman et al., 2013). The value for the $2 \mathrm{~cm}$ increment was taken as an average value for that depth and both centimetres were assigned that figure to produce CARs at a $1 \mathrm{~cm}$ resolution.

The 'long-term (apparent) rate of carbon accumulation (LARCA)' was determined by multiplying the mean catotelm accumulation rate by the average carbon density. Temporal Carbon Accumulation Rates (CARs) were calculated by dividing the per cm carbon density ( $\mathrm{g}$ $\mathrm{cm}^{3}$ ) by the amount of time (cal yrs. BP) in every $1 \mathrm{~cm}$ sample, as specified by the age-depth model (Ratcliffe et al., 2018; van de Linden et al., 2014; Loisel and Yu, 2013). CARs and LARCA figures were multiplied by 10,000 to be presented in metres squared (Turunen et al., 2002). Acrotelm peat was excluded from LARCA and CAR calculations. This was excluded because rates in the catotelm cannot be compared to the acrotelm zone because it has undergone less decomposition (Young et al., 2019). The acrotelm boundary was placed where there was a step-change to lower bulk density values close to the top of the peat profile (Clymo, 1983) or, if this was not present, at $50 \mathrm{~cm}$ depth, as this is a reasonable cut-off for it (Ratcliffe et al., 2018). The age-depth models were used to assign an age to this boundary at all sites. The carbon accumulation rates in the acrotelm zone were calculated as Recent Rates of Carbon Accumulation (RERCA's). An average RERCA was determined by multiplying the mean accumulation rate by carbon density (Tolonen and Turunen, 1996). And temporal RERCA's were calculated by dividing the carbon density by the age in each $1 \mathrm{~cm}$ increment, as with the CARs (Beaulne et al., 2021).

The carbon accumulation rates presented in this study are 'apparent' as slow rates of catotelmic decay have not been considered. This was deemed to be sufficient because this thesis is 
concerned with divergence from the overall growth trend and relative differences in carbon accumulation that are likely to be the result of climatic variations or human interference and apparent rates are frequently used to depict such shifts (Mauquoy et al., 2002; Yu et al., 2009; Loisel and Garneau, 2010; van Bellen et al., 2011; Loisel et al., 2014; van de Linden et al., 2014; Ratcliffe et al., 2018; Beaulne et al., 2021). 


\section{Chapter 4: Pyllau Cochion Results}

The full dataset for Pyllau Cochion is available in appendix 4.

\section{1: Lithostratigraphy and Sediment Composition Data}

The lithology at Pyllau Cochion (PC) is presented in Figure 4.1 and Table 4.1, alongside organic matter content \% $(\mathrm{OM})$, bulk density $(\mathrm{BD})$ and the carbon: nitrogen ratio $(\mathrm{C}: \mathrm{N})$ which are all employed to define and describe the lithological units. The basic macrofossil results shown in Table 4.2 are also used to aid the lithological descriptions.

An $816 \mathrm{~cm}$ core was retrieved from Pyllau Cochion. The corer hit bedrock beneath this point. The lowermost $241 \mathrm{~cm}$ of the core is a clay unit (PC1) (between 816-575 cm) with a low typical OM content of $4.36 \%$ and $\mathrm{C}: \mathrm{N}$ ratio of $6.44 \%$, but a relatively high $\mathrm{BD}$ at $1.14 \mathrm{~g} \mathrm{~cm}^{3}$ (Table 4.1 Fig.4.1). Overlying the clay unit is zone PC2 (Fig.4.1), within which three sub-units are defined (Table 4.1). The first of these sub-units is PC2a, a $2.5 \mathrm{~cm}$ band of silty clay that has an OM content of $6.46 \%$ and BD of $0.77 \mathrm{~g} \mathrm{~cm}^{3}$ (Table 4.1). Above this there is a small silt deposit, PC2b with a slightly higher OM content and $\mathrm{BD}$, at $7.08 \%$ and $0.81 \mathrm{~g} \mathrm{~cm}^{3}$ (respectively) (Table 4.1). The uppermost sub-unit (PC2c) is a $5 \mathrm{~cm}$ clay unit, the mean $\mathrm{BD}$ is lower in this deposit $\left(0.68 \mathrm{~g} \mathrm{~cm}^{3}\right)$, but the OM content is higher $(9.37 \%)$ (Table 4.1). At $564-520 \mathrm{~cm}$ there is a sharp transition into a silt unit that is present until $520 \mathrm{~cm}$ (PC3). Within PC3 the mean OM content increases to $37.06 \%$ and the bulk density reduces to around $0.23 \mathrm{~g} \mathrm{~cm}^{3}$ (Table 4.1; Fig.4.1). The average $\mathrm{C}: \mathrm{N}$ ratio for this silt zone is $15.81 \%$ (Table 4.1: Fig.4.1). Between 520 and 365 $\mathrm{cm}$ a deposit of Substantia humosa is present (PC4) (Table 4.1; Fig.4.1). Substantia humosa is a totally disintegrated organic deposit that is blackish in colour (Birks and Birks, 1980). This unit is thought to be a fen peat due to the high mineral content of 13\% (Lindsay et al., 2014; Rydin and Jeglum, 2006) and C:N ratio of $21.81 \%$, which is indicative of 


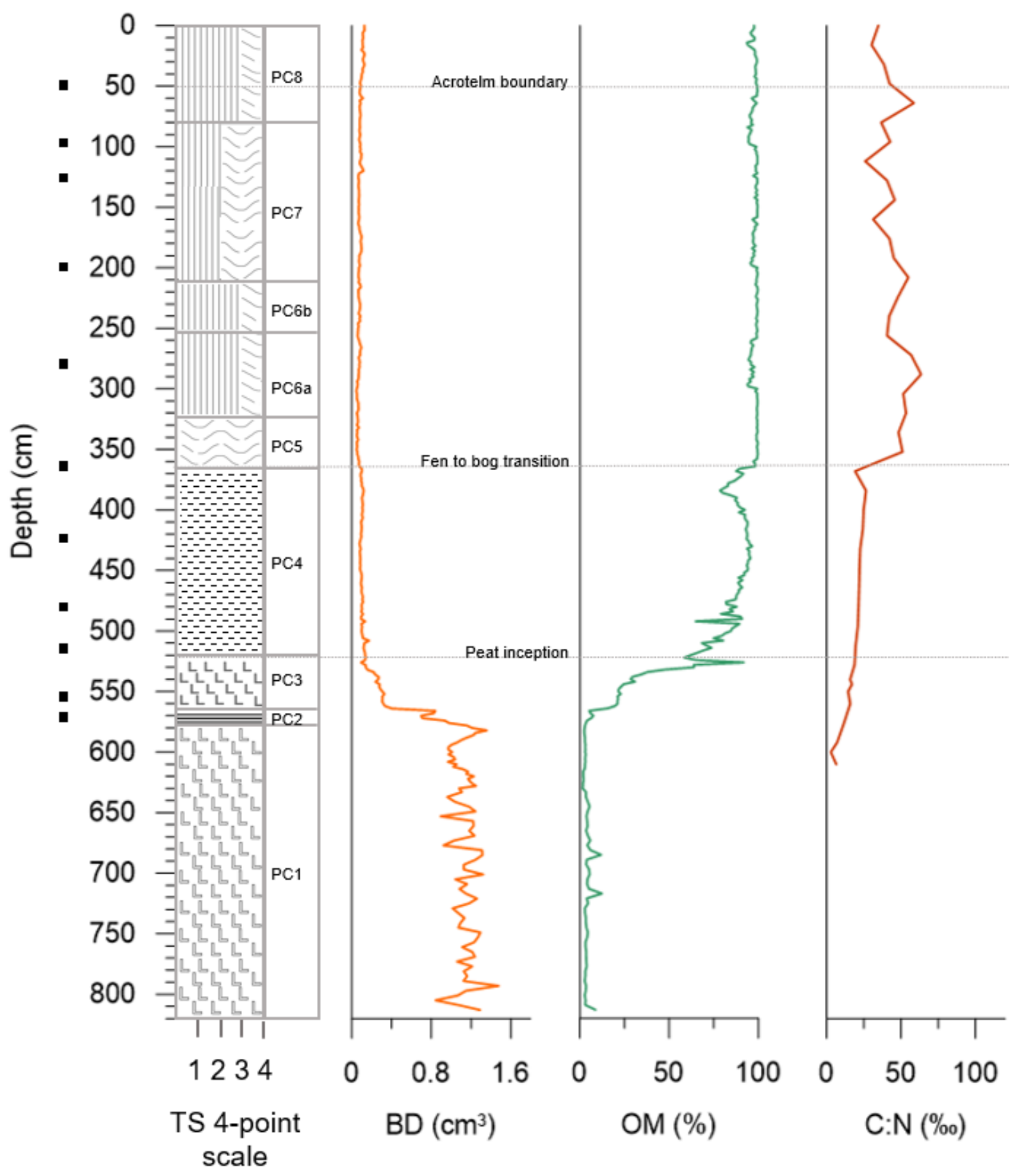

\begin{tabular}{|c|c|}
\hline $\begin{array}{l}\text { Turfa Herbacea } \\
\text { (Herbaceous peat) }\end{array}$ & \\
\hline $\begin{array}{l}\text { Turfa bryophytica } \\
\text { (Sphagnum peat) }\end{array}$ & \\
\hline Substantia humosa & \\
\hline $\begin{array}{l}\text { Argilla granosa } \\
\text { (Silt) }\end{array}$ & \\
\hline $\begin{array}{l}\text { Argilla steatodes } \\
\text { (Clay) }\end{array}$ & \\
\hline
\end{tabular}

Figure 4:1: $P C$ lithostratigraphy including from left to right: lithology, bulk density (BD), organic matter (OM) percentage and carbon:nitrogen ratio $(\mathrm{C}: \mathrm{N})$. Black boxes show the location of radiocarbon dates. 
immediate fen environments (see Figure 2.10 in lit review) (Table 4.1; Fig.4.1). In addition, 42 Chironomid head capsules were found at a depth of 392-394 cm (Table 4.2), typical of fen environments (Wrubleski et al., 1987). Given these observations, PC4 is classified as a fen peat deposit and the peat inception boundary is placed at the base of the unit (Fig.4.1).

At the top of the fen peat there is a short-lived reduction in OM \% between 393-368 $\mathrm{cm}$ where values decline from $\sim 90 \%$ to as low as $78 \%$ (Fig.4.1). A drop in C:N at $368 \mathrm{~cm}$, from ratios of around $22 \%$ to $18 \%$ is also observed at the transition between PC4 and PC5.

Above the fen peat unit is a Sphagnum peat (Turfa bryophitica) (PC5) between $365-232 \mathrm{~cm}$ (Table 4.2). Within this zone the OM content increases to $99.49 \%$, BD decreases from 0.09 to $0.05 \mathrm{~g} \mathrm{~cm}^{3}$ and the $\mathrm{C}: \mathrm{N}$ increases by $\sim 30$ to typical values of $51.37 \%$ (Table 4.1: Fig.4.1). A high presence of Sphagnum moss (91.53\% abundance) was also detected at a depth of 350-352 $\mathrm{cm}$ (Table 4.2) and visible Sphagnum mosses were present throughout the unit. This zone also had a relatively higher elasticity at 2 (Table 4.1). These features are typical of a bog peat (Lindsay et al., 2014; Rydin and Jeglum, 2006) (Fig.4.1; Table 4.1). Furthermore, the mean $\mathrm{C}: \mathrm{N}$ ratio (51.37 \%o) for PC5 implies that this peat was deposited in a terrestrial, oligotrophic, peat bog (See Figure 2.10 in literature review). Consequently, the base of this deposit $(365 \mathrm{~cm})$ is marked as the fen to bog transition (Fig.4.1).

Overlying PC5 is PC6, a deposit that is three-parts herbaceous peat and one part Sphagnum peat between 323-210 cm (Fig.4.1; Table 4.1). This deposit is comprised of two sub-units, PC6a and PC6b (Table 4.1; Fig.4.1). In PC6a the OM is $2 \%$ lower at $97.68 \%$, BD is $1 \mathrm{~g} \mathrm{~cm}^{3}$ higher $\left(0.06 \mathrm{~g} \mathrm{~cm}^{3}\right)$ and $\mathrm{C}: \mathrm{N}$ increases by $2 \%$ to $52.58 \%$ (Table 4.1 ; Fig.4.1). The visual assessment of this unit revealed that it was more humified than PC5 (Table 4.1) and unidentified organic matter (UOM) (52.53\%), Sphagnum (18.93\%) and Eriophorum vaginatum (12.47\%) were found to have the highest abundance at 264-266 cm (Table 4.2). PC6b was 
found to be less humified than the sub-unit immediately below but had a higher OM content ( 99\%) and lower C:N ratio (47.76\%). At one depth within this unit (216-218 cm) Eriophorum vaginatum was found to be more abundant at $48.6 \%$ (Table 4.2 ).

PC7 is an herbaceous/Sphagnum peat, and this is present from 210-80 cm (Fig.1; Table 1). This deposit has a higher proportion of visible Sphagnum peat than the unit below and this is supported by the 71\% Sphagnum abundance at 136-138 cm (Fig.4.1; Table 4.1; Table 4.2). BD in this unit is slightly higher at $0.07 \mathrm{~g} \mathrm{~cm}^{3}$, OM content reduces to $\sim 98 \%$ and $\mathrm{C}: \mathrm{N}$ is $7 \%$ lower at $40.04 \%$.

The uppermost unit (PC8) is Turfa herbacea (herbaceous peat) and this is present between 80$0 \mathrm{~cm}$ (Table 4.1; Fig.4.1). This unit is very stiff and compact to the touch, with an elasticity of 0 (Table 4.1). There are also lots of visible herbaceous plants remains throughout. Macrofossil analysis at 32-34 cm revealed that Sphagnum and UOM were most abundant, with $33.60 \%$ and $35.27 \%$ (respectively) but Calluna vulgaris and Drepanocladus aduncus were also both around $\sim 11 \%$ abundant (Table 4.2 ). Visible at the top of this unit was a $3 \mathrm{~cm}$ band of unidentified black material. This band is likely to be charcoal as signs of burning were observed at the site when the core was being collected and macroscopic charcoal is found at this depth (see Figure 4.12)

\section{Acrotelm boundary}

Lithological indicators are typically used to identify the likely depth of the acrotelm boundary (Clymo, 1983). A decrease in bulk density towards the top of the profile is normally indicative of the accumulation of fresh non-compact acrotelm peat (Clymo, 1983). However, this was not observed at Pyllau Cochion. The uppermost unit (PC8) is marginally more compact (Fig.4.1; Table 4.1). As such, an indicative acrotelm boundary was placed at $50 \mathrm{~cm}$, based on other approaches in the literature, where an acrotelm boundary is not clearly defined (e.g., Ratcliffe et al., 2018). 
Table 4:1: Lithostratigraphy for PC described using the Troels-Smith System (1955) (as outlined in Birks and Birks (1980)) and mean bulk density (BD), organic matter (OM), and carbon:nitrogen ratio (C:N) for each unit. Th= Turfa Herbacea (Herbaceous peat), Tb = Turfa bryophytica (Sphagnum peat), Ti $=$ Turfa lignosa (Wood peat), $\mathrm{Sh}=$ Substantia humosa, Ag = Argilla granosa (Silt), As= Argilla steatodes (Clay). The superscript numbers next to the dominant sediment type represent the degree of humification, with 4 being the most humified. Nig= darkness, sicc $=$ dryness, Elas $=$ Elasticity, Strf $=$ Stratification.

\begin{tabular}{|c|c|c|c|c|c|}
\hline Depth (cm) & Troels-Smith description & $\begin{array}{l}\text { Lithology zone } \\
\text { codes }\end{array}$ & Mean BD $\left(\mathrm{g} \mathrm{cm}^{3}\right)$ & Mean OM (\%) & Mean C: $\mathrm{N}$ ratio (\%o) \\
\hline $0-80$ & $\begin{array}{c}\mathrm{Th}^{2} 3, \mathrm{~Tb} 1 \\
\mathrm{Nig}=3 ; \text { Strf=0; Elas=0; Sicc }=2\end{array}$ & PC8 & 0.09 & 97.99 & 41.84 \\
\hline $80-210$ & $\begin{array}{c}\mathrm{Th}^{2} 2, \mathrm{~Tb} 2 \\
\mathrm{Nig}=3 ; \mathrm{Strf}=0 ; \text { Elas }=1 ; \text { Sicc }=2\end{array}$ & PC7 & 0.07 & 98.31 & 40.04 \\
\hline $210-253$ & $\begin{array}{c}\text { Th222, Tb1 }+ \text { Th } \\
\text { Nig=3; Strf=0; Elas }=1 ; \text { Sicc }=2\end{array}$ & PC6b & 0.06 & 99.56 & 47.76 \\
\hline $210-323$ & $\begin{array}{c}\mathrm{Th}^{3} 3, \mathrm{~Tb} 1+\mathrm{Th} \\
\mathrm{Nig}=3 ; \text { Strf }=0 ; \text { Elas }=1, \text { Sicc }=2\end{array}$ & PC6a & 0.06 & 97.68 & 52.58 \\
\hline $323-365$ & $\begin{array}{c}\mathrm{Tb}^{1} \\
\mathrm{Nig}=2.5 ; \mathrm{Strf}=0 ; \text { Elas=2; Sicc=2 }\end{array}$ & PC5 & 0.05 & 99.49 & 50.37 \\
\hline $365-520$ & $\begin{array}{c}\text { Sh4 }+ \text { TI+Th } \\
\mathrm{Nig}=4 ; \text { Strf }=0 ; \text { Elas }=0 ; \text { Sicc }=3\end{array}$ & PC4 & 0.09 & 87.48 & 21.81 \\
\hline $520-564$ & $\begin{array}{c}\mathrm{Ag} \\
\mathrm{Nig}=2.5 ; \text { Strf }=0 ; \text { Elas }=0 ; \text { Sicc }=3.5\end{array}$ & PC3 & 0.23 & 37.06 & 15.81 \\
\hline $564-569$ & $\begin{array}{c}\text { As } \\
\mathrm{Nig}=1.5 ; \text { Strf }=0 ; \text { Elas }=0 ; \text { Sicc }=3.5\end{array}$ & PC2C & 0.68 & 9.37 & No C:N data \\
\hline $569-572.5$ & $\begin{array}{c}\mathrm{Ag} \\
\mathrm{Nig}=2.5 ; \text { Strf }=0 ; \text { Elas }=0 ; \mathrm{Sicc}=3.5\end{array}$ & $\mathrm{PC} 2 \mathrm{~b}$ & 0.81 & 7.08 & No C:N data \\
\hline $572.5-575$ & $\begin{array}{c}\text { As2; Ag2. } \\
\mathrm{Nig}=2 ; \text { Strf=0; Elas=0; Sicc=3.5 }\end{array}$ & $\mathrm{PC} 2 \mathrm{a}$ & 0.77 & 6.46 & No C:N data \\
\hline $575-816$ & $\begin{array}{c}\text { As } \\
\mathrm{Nig}=1.5 ; \text { Strf }=0 ; \text { Elas=0; Sicc }=3.5\end{array}$ & PC1 & 1.14 & 4.36 & $\begin{array}{c}(6.44) \\
\text { Between 609-576 cm }\end{array}$ \\
\hline
\end{tabular}


Table 4:2: Basic macrofossil analysis results for selected depths at PC. The species abundance/peat components (\%) are averaged over 15 quadrat counts for each sample (see methodology).

\begin{tabular}{|c|c|c|c|c|c|c|c|c|c|c|c|c|}
\hline \multirow{2}{*}{$\begin{array}{l}\text { Depth } \\
\text { (cm) }\end{array}$} & \multirow{2}{*}{$\begin{array}{l}\text { Lithology } \\
\text { Zone }\end{array}$} & \multicolumn{11}{|c|}{ Peat Components (\%) } \\
\hline & & Sphagnum & $\begin{array}{c}\text { Erica } \\
\text { tetralix }\end{array}$ & $\begin{array}{l}\text { Calluna } \\
\text { vulgaris }\end{array}$ & $\begin{array}{c}\text { Molina } \\
\text { caerulea }\end{array}$ & $\begin{array}{l}\text { Drepano- } \\
\text { cladus } \\
\text { aduncus }\end{array}$ & $\begin{array}{c}\text { Eriophorum } \\
\text { vaginatum }\end{array}$ & $\begin{array}{c}\text { Aulacomnium } \\
\text { palustre }\end{array}$ & $\begin{array}{l}\text { Juncus } \\
\text { effusus }\end{array}$ & $\begin{array}{l}\text { No } \\
\text { macros } \\
\text { present }\end{array}$ & UOM & $\begin{array}{l}\text { Seeds and } \\
\text { other }\end{array}$ \\
\hline $32-34$ & PC8 & 33.60 & 3.87 & 11.20 & 4.40 & 11.67 & & & & & 35.27 & $\begin{array}{l}\text { Erica tetralix } \\
\text { seeds: } 3 ; \text { Acari } \\
\text { oribatida: } 2\end{array}$ \\
\hline 136-138 & PC7 & 71.53 & 3.87 & 1.87 & 1.27 & & & & & & 21.47 & $\begin{array}{l}\text { Sphagnum } \\
\text { spores: 4; } \\
\text { Acari oribatida: } \\
\text { 3; Unidentified } \\
\text { seed: } 2\end{array}$ \\
\hline $216-218$ & PC6b & 28.20 & 2.93 & & & & 48.60 & & & & 20.27 & $\begin{array}{l}\text { Erica tetralix } \\
\text { seeds: } 2 ; \\
\text { Unidentified } \\
\text { seed: } 1\end{array}$ \\
\hline $264-266$ & PC6a & 18.93 & 8.07 & & & & 12.47 & 8.00 & & & 52.53 & $\begin{array}{l}\text { Acari oribatida: } \\
\text { 7; Eriophorum } \\
\text { vaginatum } \\
\text { fruit: } 3 \text {; } \\
\text { Chironomid } \\
\text { head: } 1\end{array}$ \\
\hline $350-352$ & PC5 & 91.53 & & & & & & 6.73 & & & 1.73 & $\begin{array}{l}\text { Acari oribatida: } \\
14\end{array}$ \\
\hline 392-394 & PC4 & 4.67 & & & & & & & 2.07 & 33.80 & 59.47 & $\begin{array}{l}\text { Chironomid } \\
\text { heads: } 42 ; \\
\text { Juncus effusus } \\
\text { type seeds: } 16\end{array}$ \\
\hline
\end{tabular}




\section{2: Chronology}

\subsection{1: Radiocarbon dating}

Ten samples were selected for radiocarbon dating and an additional age from Holder (2015) for the depth of $520 \mathrm{~cm}$ is included in the age-model (Table 4.3). No dates were obtained for the clay part of the record, due to the lack of dateable material and the primary focus on the Holocene period. The justification for the selection of depths to be dated and the material analysed are detailed in Table 4.3, alongside the radiocarbon and calibrated calendar ages (cal yrs. BP). The initial goal was to date macrofossil fragments; however, these sub-fossils were absent at several depths, or the minimum sample weight was not achieved, even after repeated re-sampling attempts. As such, 6 of the samples are bulk samples (Table 4.3).

When calibrated as individual ages, 7 of the 11 dates have probability distribution ranges that are $<250$ years (Table 4.3). However, four of the calibrated dates have probability distribution ranges that exceed 250 years. These are 520, 360, 202 and $127 \mathrm{~cm}$ (Figs. 4.2-4.5) (Table 4.3). These dates intersect with a pronounced plateau within the Intcal20 calibration curve. 
Table 4:3: Radiocarbon results for PC, including one date sourced from Holder (2015): Rationale for sample selection; the sample type dated; Laboratory codes; Radiocarbon ages; calibrated ages. The radiocarbon age (BP) was calibrated to calibrated years (BP) on Oxcal v4.42, 2020 (Bronk Ramsey, 2009a) using the Intcal20 calibration curve (Reimer et al., 2020).

\begin{tabular}{|c|c|c|c|c|c|c|}
\hline $\begin{array}{l}\text { Depth } \\
(\mathrm{cm})\end{array}$ & Justification & $\begin{array}{l}\text { Sample type } \\
\text { dated }\end{array}$ & $\begin{array}{l}\text { Laboratory } \\
\text { code }\end{array}$ & $\begin{array}{l}\text { Radiocarbon } \\
\text { Age BP }\end{array}$ & $\begin{array}{l}\text { Calibrated Age Range (cal yrs. BP) } \\
(2 \sigma(95.4 \% \text { probability }))\end{array}$ & $\begin{array}{c}\text { Range } \\
\text { (cal yrs. } \\
\text { BP) }\end{array}$ \\
\hline 50 & Suspected peat cutting above & $\begin{array}{l}\text { Organic bulk } \\
\text { fraction }\end{array}$ & $\begin{array}{l}\text { Beta- } \\
581343\end{array}$ & $1900 \pm 30$ & $1888-1725$ & 163 \\
\hline 95 & $\begin{array}{l}\text { Lithological interest: shortly before the onset of a } \\
\text { different lithological zone. }\end{array}$ & $\begin{array}{l}\text { Macrofossil } \\
\text { (mixed seeds) }\end{array}$ & $\begin{array}{l}\text { Beta- } \\
450138\end{array}$ & $2290 \pm 40$ & $2356-2155$ & 201 \\
\hline 127 & $\begin{array}{l}\text { Proxy interest: to chronologically constrain charcoal } \\
\text { peak identified by Holder (2015). }\end{array}$ & $\begin{array}{l}\text { Macrofossil } \\
\text { (Calluna vulgaris) }\end{array}$ & $\begin{array}{l}\text { Beta } \\
450139\end{array}$ & $2440 \pm 30$ & $2700-2357$ & 343 \\
\hline 202 & $\begin{array}{l}\text { Proxy interest: to chronologically constrain } \\
\text { reduction in tree pollen identified by Watkins (2015). }\end{array}$ & $\begin{array}{l}\text { Macrofossil } \\
\text { (Calluna vulgaris) }\end{array}$ & $\begin{array}{l}\text { Beta- } \\
450140\end{array}$ & $3390 \pm 30$ & $3812-3513$ & 299 \\
\hline 281 & Gap filler & $\begin{array}{l}\text { Macrofossil } \\
\text { (wood) }\end{array}$ & $\begin{array}{l}\text { Beta- } \\
450141\end{array}$ & $3740 \pm 30$ & $4226-3984$ & 242 \\
\hline 360 & Lithological interest: Close to Fen-Bog transition & $\begin{array}{l}\text { Macrofossil } \\
\text { (Sphagnum) }\end{array}$ & $\begin{array}{l}\text { Beta- } \\
450142\end{array}$ & $4080 \pm 30$ & $4806-4441$ & 365 \\
\hline 420 & Gap filler & $\begin{array}{l}\text { Organic bulk } \\
\text { fraction }\end{array}$ & $\begin{array}{l}\text { Beta- } \\
450143\end{array}$ & $6190 \pm 30$ & $7235-6988$ & 247 \\
\hline 481 & $\begin{array}{l}\text { Proxy interest: to chronologically constrain charcoal } \\
\text { peak identified by Holder (2015). }\end{array}$ & $\begin{array}{l}\text { Organic bulk } \\
\text { fraction }\end{array}$ & $\begin{array}{l}\text { Beta- } \\
450144\end{array}$ & $7750 \pm 30$ & $8594-8430$ & 164 \\
\hline 520 & Date from Holder (2015) & $\begin{array}{l}\text { Organic bulk } \\
\text { fraction }\end{array}$ & $\begin{array}{l}\text { Beta- } \\
417645\end{array}$ & $8770 \pm 30$ & $9903-9560$ & 343 \\
\hline 555 & Lithological interest: to time silt zone & $\begin{array}{l}\text { Organic bulk } \\
\text { fraction }\end{array}$ & $\begin{array}{l}\text { Beta- } \\
450145\end{array}$ & $9370 \pm 30$ & $10687-10505$ & 182 \\
\hline 569 & $\begin{array}{l}\text { Lithological interest: transition from a clay into a } \\
\text { band of more organic silt }\end{array}$ & $\begin{array}{l}\text { Organic bulk } \\
\text { fraction }\end{array}$ & $\begin{array}{l}\text { Beta- } \\
450146\end{array}$ & $10830 \pm 40$ & $12827-12728$ & 99 \\
\hline
\end{tabular}




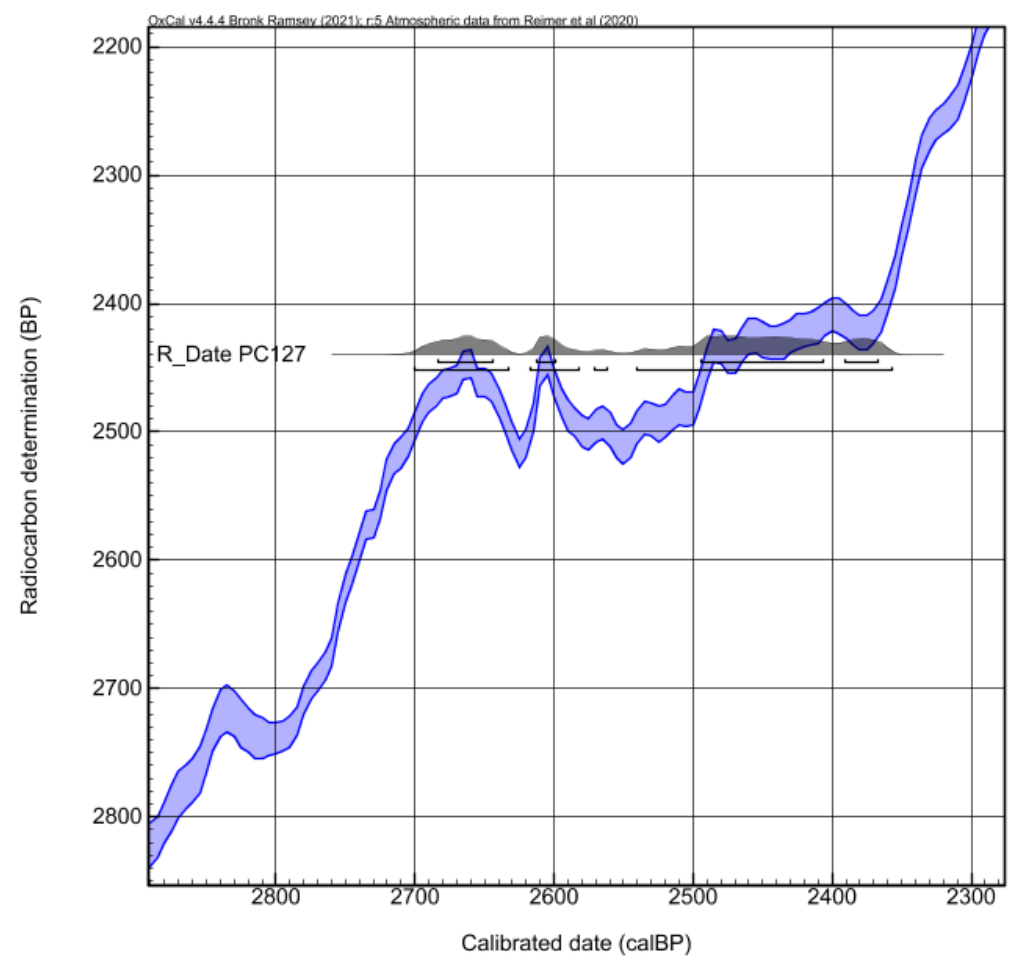

Figure 4:2:The radiocarbon date at $127 \mathrm{~cm}$ at PC on the Intcal20 calibration curve (Reimer et al., 2020)

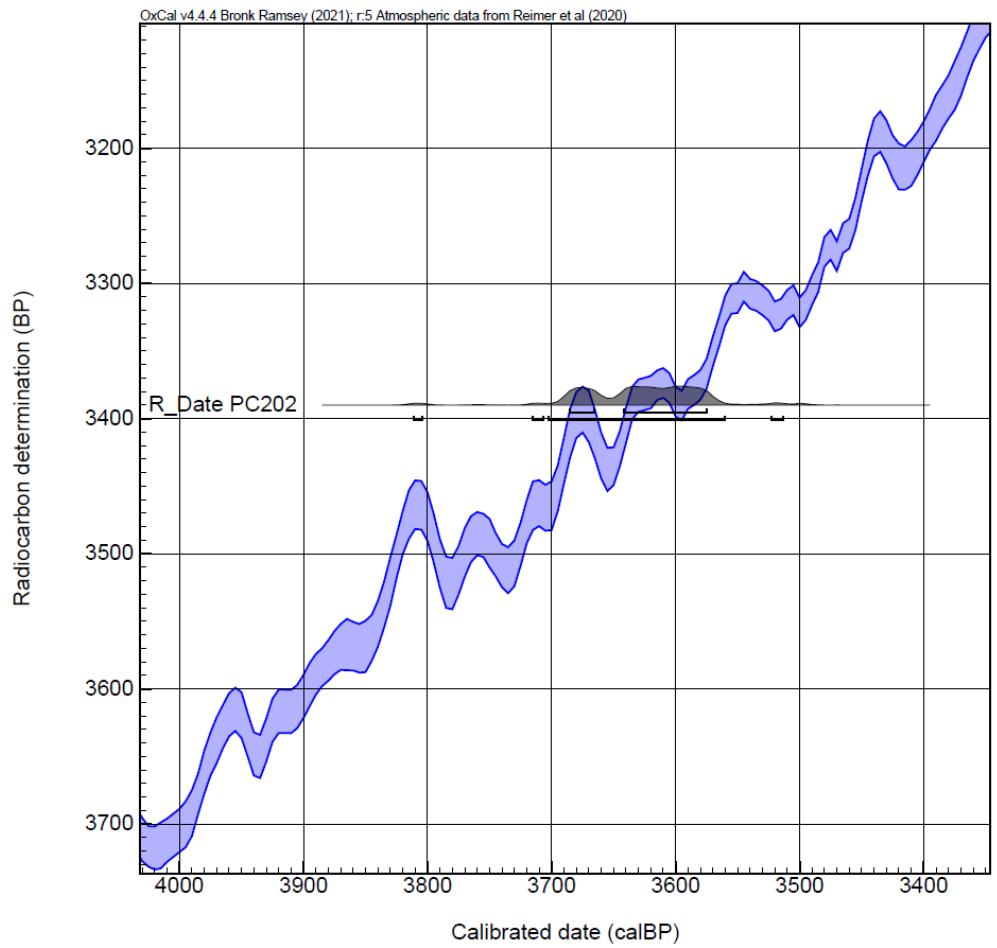

Figure 4:3: The radiocarbon date at $202 \mathrm{~cm}$ at PC on the Intcal20 calibration curve (Reimer et al., 2020). 


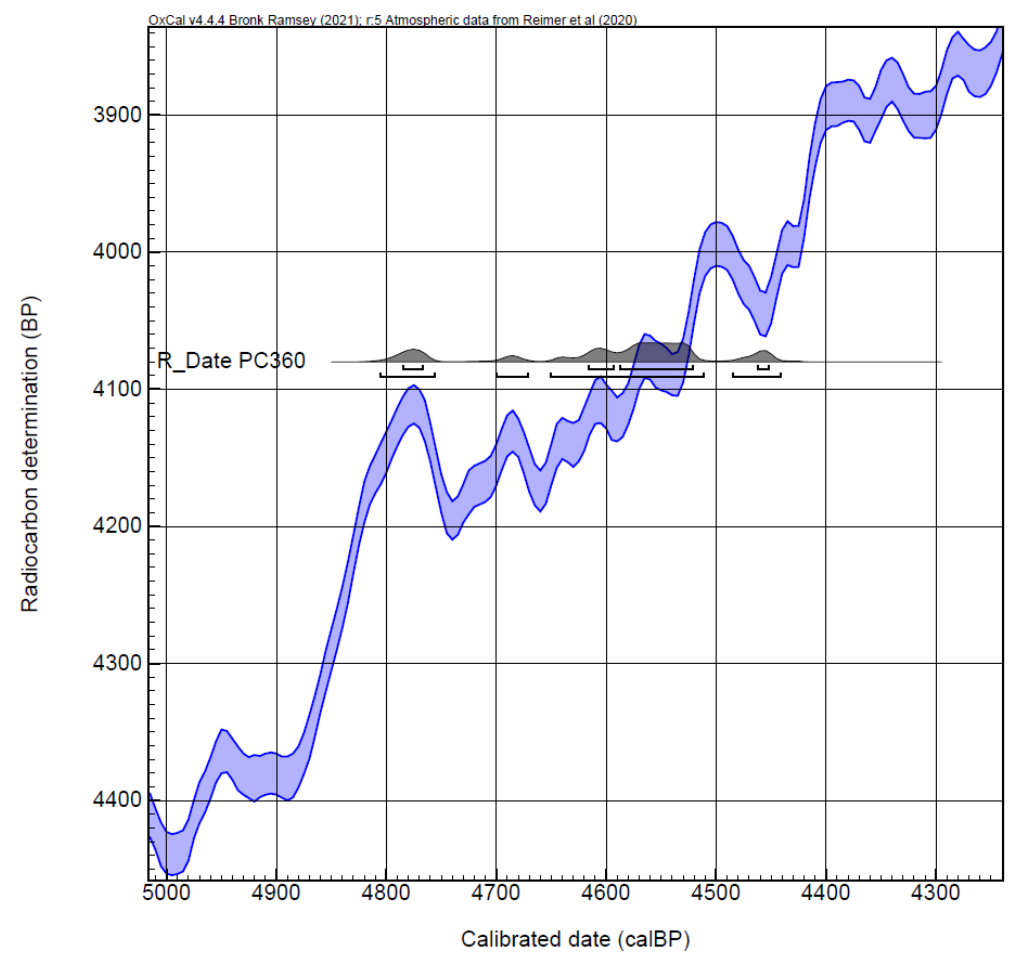

Figure 4:4: The radiocarbon date at $360 \mathrm{~cm}$ at PC on the Intcal20 calibration curve (Reimer et al., 2020).

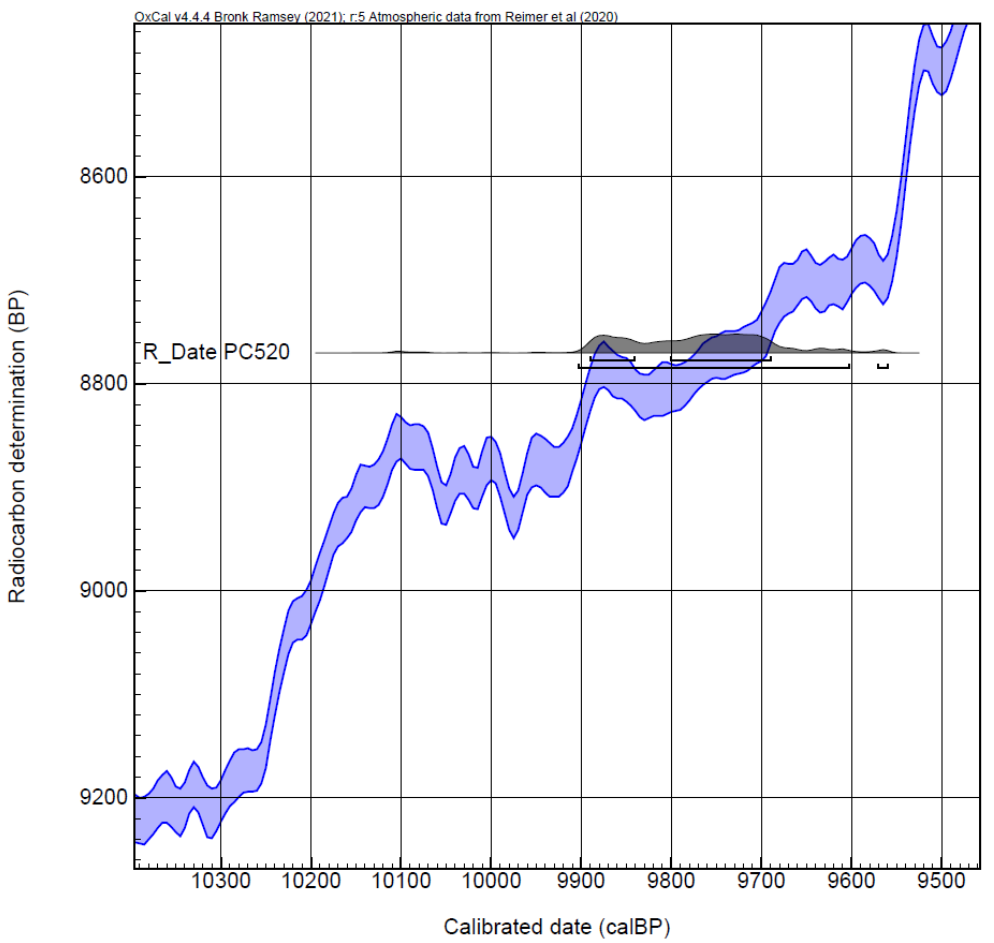

Figure 4:5: The radiocarbon date at $520 \mathrm{~cm}$ at PC (Holder, 2015) on the Intcal20 calibration curve (Reimer et al., 2020). 


\subsection{2: Age-depth model}

The eleven dates detailed in Table 4.3 are used to construct a Bayesian age-depth model that gives modelled ages for all centimeter depths and the associated age uncertainties at $95.4 \%$ probability (2-sigma) (Fig.46a). There are no age reversals in the dates and the age uncertainties in the model range from 3 years at $0 \mathrm{~cm}$ to 2592 years at $600 \mathrm{~cm}$ (Fig.46a).

Age uncertainties for the Bayesian age-depth model are constrained to between 394-519 years between, 127-50 $\mathrm{cm}$ and 202-360 $\mathrm{cm}$ (Table 4.4: Fig.46a). However, there are larger age uncertainties between the depths of $600-360 \mathrm{~cm}$ and $50-0 \mathrm{~cm}$ (Fig.4.6a; Table 4.4). The uncertainty is largest between $569-600 \mathrm{~cm}$ (1604 years), $555-569 \mathrm{~cm}$ (2166 years), 50-0 cm (1436 years), and 481-520 cm (1135 years) (Fig.46a). These larger age ranges are the product of major sedimentation changes between these depths (Staff, 2017) which can be seen in Figure 4.6b, that uses only simple linear interpolation between the dates. Here you can see that the deposition rate is very slow and variable around the dates with larger age uncertainties (Fig.4.6b) and these variations in sedimentation help explain the large errors in the Bayesian model from 600-481 cm and 50-0 cm (Fig.4.6a).

The large uncertainty at $520 \mathrm{~cm}$ causes significant problems for the generated ages for every 1 $\mathrm{cm}$ (Table 4.5) where the age-depth model produces an age that is older for $519 \mathrm{~cm}$ than 520 $\mathrm{cm}$. This peculiarity arises because the radiocarbon age range at $520 \mathrm{~cm}$ (344 years) is smaller than the age range at $519 \mathrm{~cm}(664)$ and this results in generating a mid-point date for $520 \mathrm{~cm}$ that is younger than the centimetre above it (Table 4.5). The age range at $520 \mathrm{~cm}$ is smaller because it is constrained by a radiocarbon date at this depth (Table 4.3). This peculiarity is problematic because it also generates a negative Figure in the 'years per $\mathrm{cm}$ ' dataset that is used to calculate proxy fluxes (Table 4.5). Resultantly no proxy fluxes were calculated for 519 $\mathrm{cm}$. 

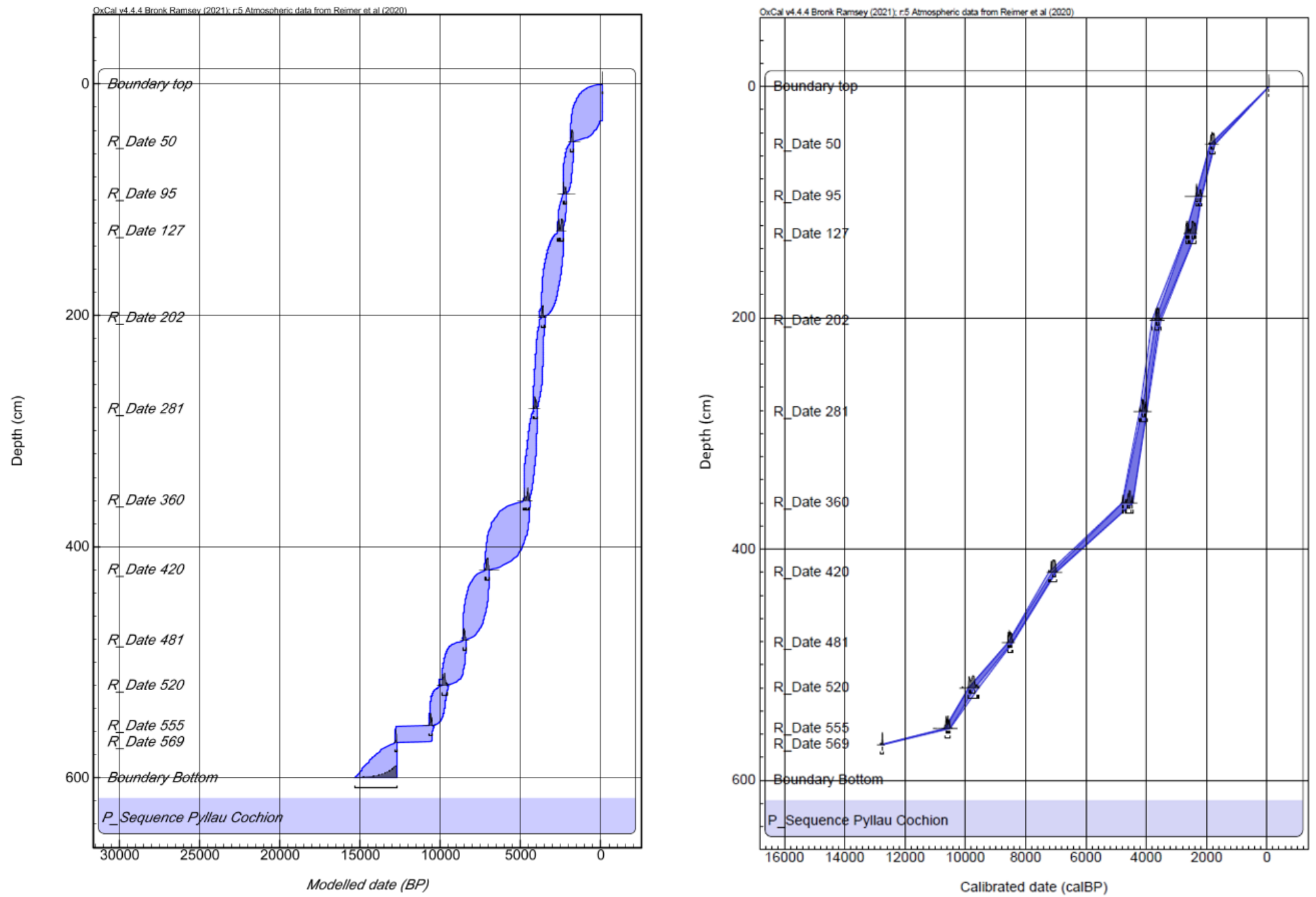

Figure 4:6: PC (A) (left plot) Bayesian age-depth model with modelled ages at a $95.4 \%$ probability; (B) (right plot) simple linear interpolation between individually calibrated radiocarbon dates plotted against depth. Constructed on Oxcal v4.42, 2020 (Bronk Ramsey, 2009a) using the Intcal20 calibration curve (Reimer et al., 2020). 
Table 4:4: PC mean accumulation rates inferred from linear interpolation between dates as presented in Figure 4.6 (b). These sedimentation rates help to explain fluctuations in the Bayesian age-depth model (Fig.4.6 (a)). The mean age uncertainty between dates from the Bayesian model (Fig.4.6(a)) are presented in the right column.

\begin{tabular}{|c|c|c|}
\hline Depth (cm) & $\begin{array}{c}\text { Mean accumulation rate } \\
\text { (cm/yr.) }\end{array}$ & $\begin{array}{c}\text { Mean modelled age uncertainty } \\
\mathbf{9 4 . 5 \%} \text { (2-sigma) probability }\end{array}$ \\
\hline $0-50$ & 0.03 & 1436 \\
\hline $50-95$ & 0.10 & 460 \\
\hline $95-127$ & 0.12 & 394 \\
\hline $127-202$ & 0.07 & 893 \\
\hline $202-281$ & 0.18 & 432 \\
\hline $281-360$ & 0.15 & 519 \\
\hline $360-420$ & 0.02 & 1911 \\
\hline $420-481$ & 0.04 & 1108 \\
\hline $481-520$ & 0.03 & 1135 \\
\hline $520-555$ & 0.04 & 786 \\
\hline $555-569$ & 0.01 & 2166 \\
\hline $569-600$ & 0.02 & 1604 \\
\hline & & \\
\hline $0-600$ & 0.07 & 990 \\
\hline
\end{tabular}

Table 4:5: PC Bayesian age-depth model ages (Fig.4.6 (a)) between $522-518 \mathrm{~cm}$. Showing the large age ranges and uncertainties around and the problematic ages between $522-518 \mathrm{~cm}$.

\begin{tabular}{|c|c|c|c|c|c|}
\hline Depth (cm) & \multicolumn{2}{|c|}{$\begin{array}{c}\text { Age depth model age } \\
\text { range (cal yrs. BP) }\end{array}$} & $\begin{array}{c}\text { Age } \\
\text { uncertainty }\end{array}$ & $\begin{array}{c}\text { Mid-point of modelled } \\
\text { age (cal yrs. BP) }\end{array}$ & $\begin{array}{c}\text { Years } \\
\text { per cm }\end{array}$ \\
\hline 518 & 10113 & 9205 & 908 & 9659 & 121 \\
\hline 519 & 10112 & 9448 & 664 & 9780 & -48 \\
\hline 520 & 9904 & 9560 & 344 & 9732 & 103 \\
\hline 521 & 10114 & 9556 & 558 & 9835 & 25 \\
\hline 522 & 10164 & 9556 & 608 & 9860 & 50 \\
\hline
\end{tabular}


Aside from the problems around $519 \mathrm{~cm}$, the Bayesian age depth model (Fig.4.6a) produces likely ages (95.4\% probability / 2 sigma) for each centimeter and the mid-points of the modelled age ranges (as shown in Figure 4.7) are used to give a date to each centimeter. These ages are rounded to the nearest ten when reported in the text. The proxies, that were sampled at a $2 \mathrm{~cm}$ contiguous resolution, are plotted against the mid-point of the sampled depth and a carbon and charcoal flux value is given for each centimeter within that depth increment (see methodology).

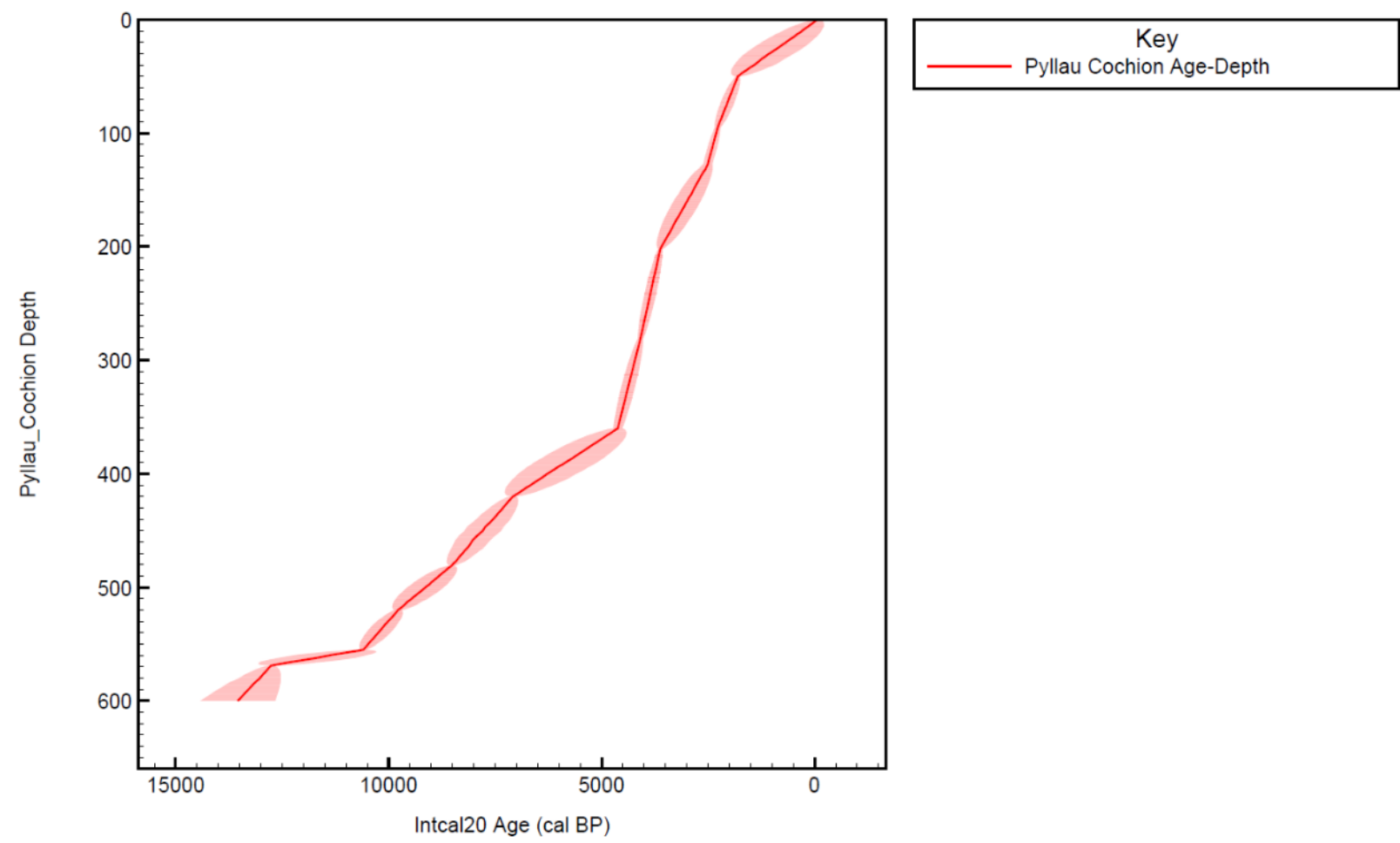

Figure 4:7: A simplified plot of the age-depth model for PC (Fig.4.6). This plot depicts the middle point (red line) that is used to assign an age to each proxy data mid-point.

The lowermost modelled depth at $600 \mathrm{~cm}$ has a modelled age of $c a .14030$ ( \pm 1296$)$ cal yrs. $\mathrm{BP}$ and is thought to be deposited in a cold climate, possibly the Dimlington Stadial. The age of the transition into a more organic silty clay (PC2a) is placed at $c a .13160( \pm 443)$ cal. yrs. $\mathrm{BP}$ and is thought to be from the Windemere Interstadial, although this age is younger than the transition seen at other UK sites (Abrook et al., 2020; Palmer et al., 2021). The overlying clay 
unit (PC2c) is constrained according to the age model to between $c a .12780( \pm 47)$ and 11670 $( \pm 1159)$ cal yrs. BP. Despite the wide age uncertainties, these ages are typical for Loch Lomond Stadial deposits seen at other sites (Abrook et al., 2020; Palmer et al., 2021). The shift to organic sedimentation is consistent with the beginning of the Holocene, at ca. 11670 ( \pm $1159)$ cal yrs. BP and fen peat inception is dated to the early Holocene at $c a .9730( \pm 172)$ cal yrs. BP (Fig. 46a).

\section{3: Peat Accumulation}

Peat accumulation rates were calculated using the ages stipulated by the Bayesian age-depth model. The mean accumulation rate for the catotelm is $0.06 \mathrm{~cm} / \mathrm{yr}$. (Table 4.6). This is lower than the typical peat accumulation rate for temperate peatlands of $0.1 \mathrm{~cm} / \mathrm{yr}$. (Lindsay, 2010). The highest rates of peat accumulation are observed in the bog section, at $0.10 \mathrm{~cm} / \mathrm{yr}$. (Table 4.6).

\section{4: Carbon Accumulation}

\subsection{1: Carbon Content and Density}

The carbon content was calculated for every $2 \mathrm{~cm}$ using the regression equation (see methodology). The carbon content ranges from $1.05-54 \%$ in the full core sequence. The mean carbon content for the catotelm is $51.38 \%$ but it is lower in fen peat $(47.4 \%)$ than the bog peat (53.17\%) in both the bog and acrotelm zone (52.69\%) (Table 4.6). The mean carbon density in the catotelm peat is $0.04 \mathrm{~g} \mathrm{~cm}^{3}$ and $0.05 \mathrm{~g} \mathrm{~cm}^{3}$ for the acrotelm (Table 4.6). These values, along with the peat accumulation rates, feed into the long-term averages and temporal carbon accumulation calculations. 
Table 4:6: Mean peat accumulation rates (calculated via the Bayesian age-depth model (4.6 (a)), carbon content, carbon density and average long-term carbon accumulation (LARCA and RERCA) for different core sections at PC.

\begin{tabular}{|c|c|c|}
\hline Zone & Depth (cm) & Mean accumulation rates $(\mathrm{cm} / \mathrm{yr}$.) \\
\hline Acrotelm Peat & $0-50$ & 0.03 \\
\hline Bog Catotelm Peat & $50-365$ & 0.10 \\
\hline Fen Catotelm Peat & $365-520$ & 0.03 \\
\hline All Catotelm peat & $50-520$ & 0.06 \\
\hline Zone & Depth (cm) & Mean carbon content (\%) \\
\hline Acrotelm Peat & $0-50$ & 52.69 \\
\hline Bog Catotelm Peat & $50-365$ & 53.17 \\
\hline Fen Catotelm Peat & $365-520$ & 47.4 \\
\hline All Catotelm peat & $50-520$ & 51.38 \\
\hline Zone & Depth (cm) & Mean carbon density $\left(\mathrm{g} \mathrm{cm}^{3}\right)$ \\
\hline Acrotelm Peat & $0-50$ & 0.05 \\
\hline All Catotelm peat & $50-520$ & 0.04 \\
\hline Zone & Depth (cm) & $\begin{array}{l}\text { Average long term carbon accumulation rate } \\
\left(\mathrm{g} \mathrm{C} \mathrm{m}^{-2} \mathrm{yr}^{-1}\right)\end{array}$ \\
\hline Acrotelm Peat & $0-50$ & RERCA = 15.52 \\
\hline All Catotelm peat & $50-520$ & LARCA $=23.71$ \\
\hline
\end{tabular}

\subsection{2: LARCA and RERCA}

An average long term carbon accumulation rate (LARCA) of $23.71 \mathrm{~g} \mathrm{C} \mathrm{m}^{-2} \mathrm{yr}^{-1}$ was calculated for the full catotelm peat section at Pyllau Cochion (Table 4.6). This is comparable to rates reported in the literature with temperate LARCA values of 14-16 $\mathrm{g} \mathrm{C} \mathrm{m}^{-2} \mathrm{yr}^{-1}$ (Carless, 2015), $16.3 \mathrm{~g} \mathrm{C} \mathrm{m}^{-2} \mathrm{yr}^{-1}$ (Ratcliffe et al., 2018) and 15-72.5 $\mathrm{g} \mathrm{C} \mathrm{m}^{-2} \mathrm{yr}^{-1}$ (Anderson, 2002). 
A mean recent carbon accumulation rate (RERCA) of $15.52 \mathrm{~g} \mathrm{C} \mathrm{m}^{-2} \mathrm{yr}^{-1}$ was determined for the acrotelm peat (Table 4.6) which is much lower than temporal RERCAs that range between 6-73 $\mathrm{g} \mathrm{C} \mathrm{m}^{-2} \mathrm{yr}^{-1}$ and 9-127 $\mathrm{g} \mathrm{C} \mathrm{m}^{-2} \mathrm{yr}^{-1}$ for a Northern Irish and English bog, respectively, reported by Young et al., (2019) over the last ca. 1000 cal yrs. BP. Ratcliffe et al., (2018) also reported RERCAs between $20-40 \mathrm{~g} \mathrm{C} \mathrm{m}^{-2} \mathrm{yr}^{-1}$ for a Scottish bog.

\subsection{3: Temporal Carbon Accumulation Rates}

The temporal carbon accumulation rates (CARs) are displayed in Figure 4.8. One value is missing at $c a .9780$ cal yrs. BP, just above peat inception, due to the erroneous age produced by this centimeter $(519 \mathrm{~cm})$. This missing value is not incorporated into the moving average. CAR fluctuates between $0.26-244 \mathrm{~g} \mathrm{C} \mathrm{m}^{-2} \mathrm{yr}^{-1}$ throughout the catotelm peat section, and the mean CAR is $44.51 \mathrm{~g} \mathrm{C} \mathrm{m}^{-2} \mathrm{yr}^{-1}$ (Fig.4.8). The values are comparable to those reported at three peatlands in South Wales (between 0-120 $\mathrm{g} \mathrm{C} \mathrm{m}^{-2} \mathrm{yr}^{-1}$ ) but they differ from some other values observed at other temperate sites. For example, a mean of 17.9 and $21.3 \mathrm{~g} \mathrm{C} \mathrm{m}^{-2} \mathrm{yr}^{-1}$ for various Scottish peatlands (Anderson, 2002; Ratcliffe et al., 2018).

CAR is highly variable throughout the sequence. Such variability is found in the comparable studies aforementioned (Anderson, 2002; Carless, 2015; Ratcliffe et al., 2018). The start of the CAR record is characterised by values around $6 \mathrm{~g} \mathrm{C} \mathrm{m}^{-2} \mathrm{yr}^{-1}$ until $c a .12780$ cal. yrs. BP (Fig.4.8). From this point, until ca. 10600 cal yrs. BP there is very little carbon accumulation except for the peculiar large peak between 11680-11650 cal yrs. BP where values reach $182 \mathrm{~g}$ $\mathrm{C} \mathrm{m}^{-2} \mathrm{yr}^{-1}$ (Fig.4.8). During the period from ca. 10600-9840 cal yrs. BP CARs increase to typical values of $30.70 \mathrm{~g} \mathrm{C} \mathrm{m}^{-2} \mathrm{yr}^{-1}$ and are particularly high at $c a .10,200$ at 62.76 $\mathrm{g} \mathrm{C} \mathrm{m}^{-2} \mathrm{yr}^{-1}$ (Fig.4.8) 
From peat inception at $c a .9730 \mathrm{cal}$ yrs. BP to the fen to bog transition at $c a .5120 \mathrm{cal}$ yrs. BP the mean CAR is $27.02 \mathrm{~g} \mathrm{C} \mathrm{m}^{-2} \mathrm{yr}^{-1}$ but rates fluctuate from periods of higher and lower CARs (Fig.4.8). At the start of this interval there is an increase in CAR between $c a$. 9240-8950 cal yrs. BP, with typical values around $53.27 \mathrm{~g} \mathrm{C} \mathrm{m}^{-2} \mathrm{yr}^{-1}$ and a pronounced peak of 184 $\mathrm{g} \mathrm{C} \mathrm{m}^{-2} \mathrm{yr}^{-1}$ at ca. 9240 cal yrs. BP (Fig.4.8).

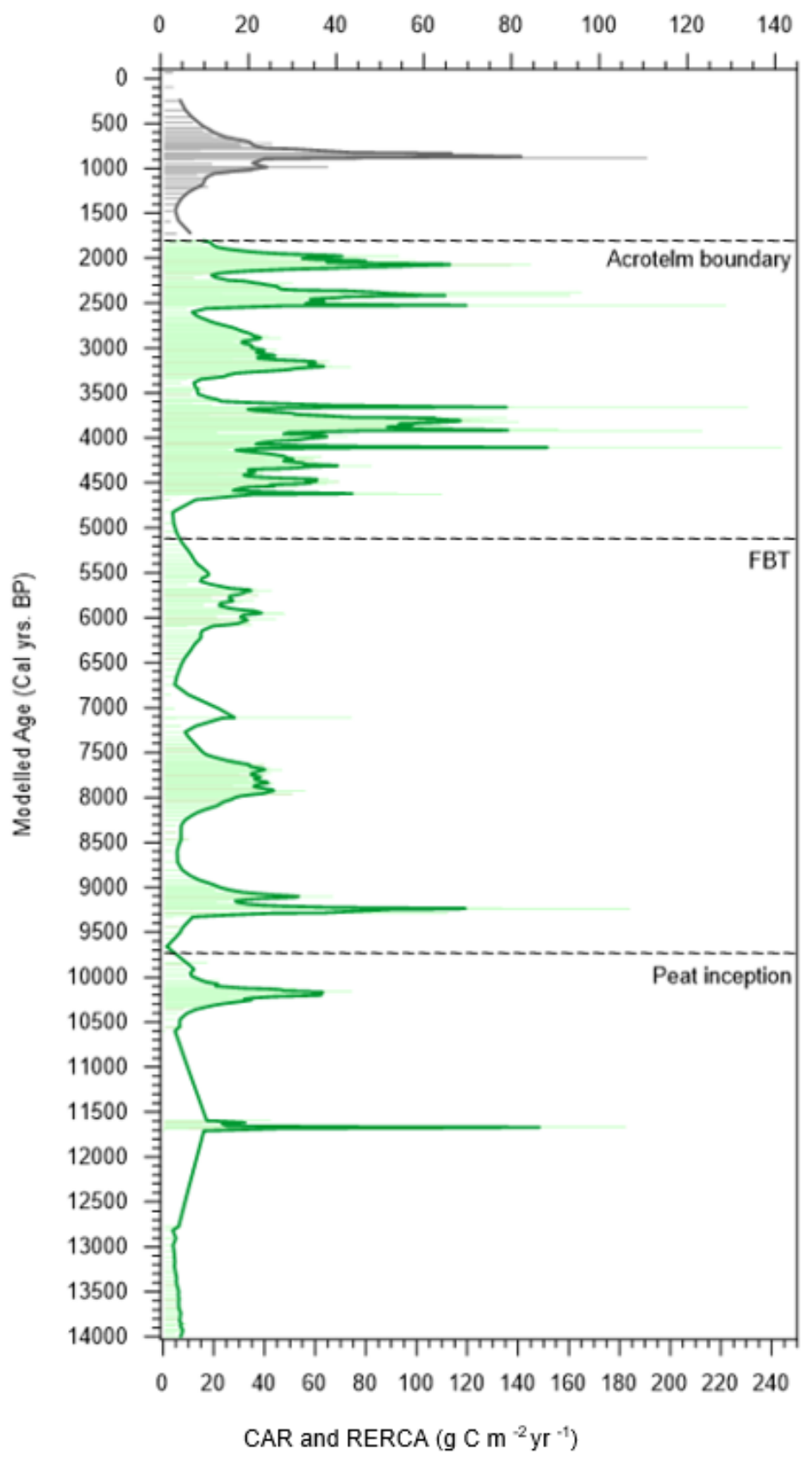

Figure 4:8: PC carbon accumulation rates (CARs) (green) and recent rates of carbon accumulation (RERCAs) (grey) with triangulated 3-point moving averages. 
Between ca. 8950-8250 there is a period of stable lower CARs (mean $6.53 \mathrm{~g} \mathrm{C} \mathrm{m}^{-2} \mathrm{yr}^{-1}$ ). Above this point, carbon accumulation increases to around $40 \mathrm{~g} \mathrm{C} \mathrm{m}^{-2} \mathrm{yr}^{-1}$ for around $c a .1000 \mathrm{cal}$ yrs. BP (Fig.4.8). From ca. 7520-6210 cal yrs. BP CAR slows down to an average rate of 12.41 $\mathrm{g} \mathrm{C} \mathrm{m}^{-2} \mathrm{yr}^{-1}$ (Fig.4.8). This reduction is interrupted by a short-lived peak to 74.33 $\mathrm{g} \mathrm{C} \mathrm{m}^{-2} \mathrm{yr}^{-1}$ at $c a .7110 \mathrm{cal}$ yrs. BP (Fig.4.8). CARs are higher (typically around $25.98 \mathrm{~g} \mathrm{C} \mathrm{m}$ ${ }^{-2} \mathrm{yr}^{-1}$ ) between $c a .6180-5470$ cal yrs. BP but start to fall at $c a .5440$ cal yrs. BP to values as low as $2.6 \mathrm{~g} \mathrm{C} \mathrm{m}^{-2} \mathrm{yr}^{-1}$ at (Fig.4.8).

From $c a .4620-3650$ cal yrs. BP there is a step change to higher CAR values that fluctuate at a greater magnitude (Fig.4.8). During this interval the mean rate of carbon accumulation is 68.20 $\mathrm{g} \mathrm{C} \mathrm{m}^{-2} \mathrm{yr}^{-1}$ and there are three pronounced peaks: i) at $c a .4110 \mathrm{cal}$ yrs. BP with the highest CAR of the record at $244 \mathrm{~g} \mathrm{C} \mathrm{m}^{-2} \mathrm{yr}^{-1}$, ii) an increase $c a .3920$ cal yrs. BP to a rate of 212.66 $\mathrm{g} \mathrm{C} \mathrm{m}^{-2} \mathrm{yr}^{-1}$ and, iii) a CAR of $230.66 \mathrm{~g} \mathrm{C} \mathrm{m}^{-2} \mathrm{yr}^{-1}$ at $c a .3656 \mathrm{cal}$ yrs. BP (Fig.4.8).

CARs decrease between $c a$. 3630-3280 cal yrs. BP to $\sim 18 \mathrm{~g} \mathrm{C} \mathrm{m}^{-2} \mathrm{yr}^{-1}$ and then rise to typical values of $42.21 \mathrm{~g} \mathrm{C} \mathrm{m}^{-2} \mathrm{yr}^{-1}$ from 3270-2800 cal yrs. BP (Fig.4.8). This is followed by ca. 300 year decrease in rates to typical CARs of $18.15 \mathrm{~g} \mathrm{C} \mathrm{m}^{-2} \mathrm{yr}^{-1}$ (Fig.4.8). Above this there is a sharp increase in CARs between $c a$. 2530-1950 cal yrs. BP (Fig.4.8) Mean CAR within this period is $67.64 \mathrm{~g} \mathrm{C} \mathrm{m}^{-2} \mathrm{yr}^{-1}$. There are 4 notable points in the CAR record during this period: the peaks at $c a .2530,2410$ and 2080 cal yrs. BP, with rates of 222, 160.33 and 137.33 $\mathrm{g} \mathrm{C} \mathrm{m}^{-2} \mathrm{yr}^{-1}$ (respectively) and the short-lived reduction in carbon accumulation between $c a$. 2210-2190 cal yrs. BP where CARs fall to $12.19 \mathrm{~g} \mathrm{C} \mathrm{m}^{-2} \mathrm{yr}^{-1}$ (Fig.4.8). From ca. 1940 cal yrs. BP CARs start to fall and this decline continues into the acrotelm (Fig.4.8).

Recent rates of carbon accumulation (temporal RERCAs) for the acrotelm are displayed in grey at the top of Figure 4.8. RERCAs are characterised by low values of $\sim 6 \mathrm{~g} \mathrm{C} \mathrm{m}^{-2} \mathrm{yr}^{-1}$ between 
ca.1730-1230 cal yrs. BP. From ca. 1200 there is an increasing trend in RERCAs to a peak of $191 \mathrm{~g} \mathrm{C} \mathrm{m}^{-2} \mathrm{yr}^{-1}$ at $c a .880 \mathrm{cal}$ yrs. BP (Fig.4.8). The values then display a steady decrease to a carbon accumulation rate of $4.02 \mathrm{~g} \mathrm{C} \mathrm{m}^{-2} \mathrm{yr}^{-1}$ at the surface (Fig.4.8).

\section{5: Humification}

\subsection{1: Light Transmission Data}

Humification analyses were only undertaken for the bog peat (above $362 \mathrm{~cm}$ ) for reasons explained in the methodology. The mean light transmission value is $39.76 \%$, and the values range from 25.61-65.93\% (Fig.4.9). The transmission data demonstrates an overall trend towards lower values (Fig.4.9), which is the opposite of the typical trend observed in peatlands (Blackford and Chambers, 1995). The long-term trend was removed via linear regression because it could be the result of autogenic development and would not reflect relative changes in wetness (Blackford and Chambers, 1995) (Fig.4.10). The humification results are plotted as residuals (Fig.4.10; Fig.4.11).

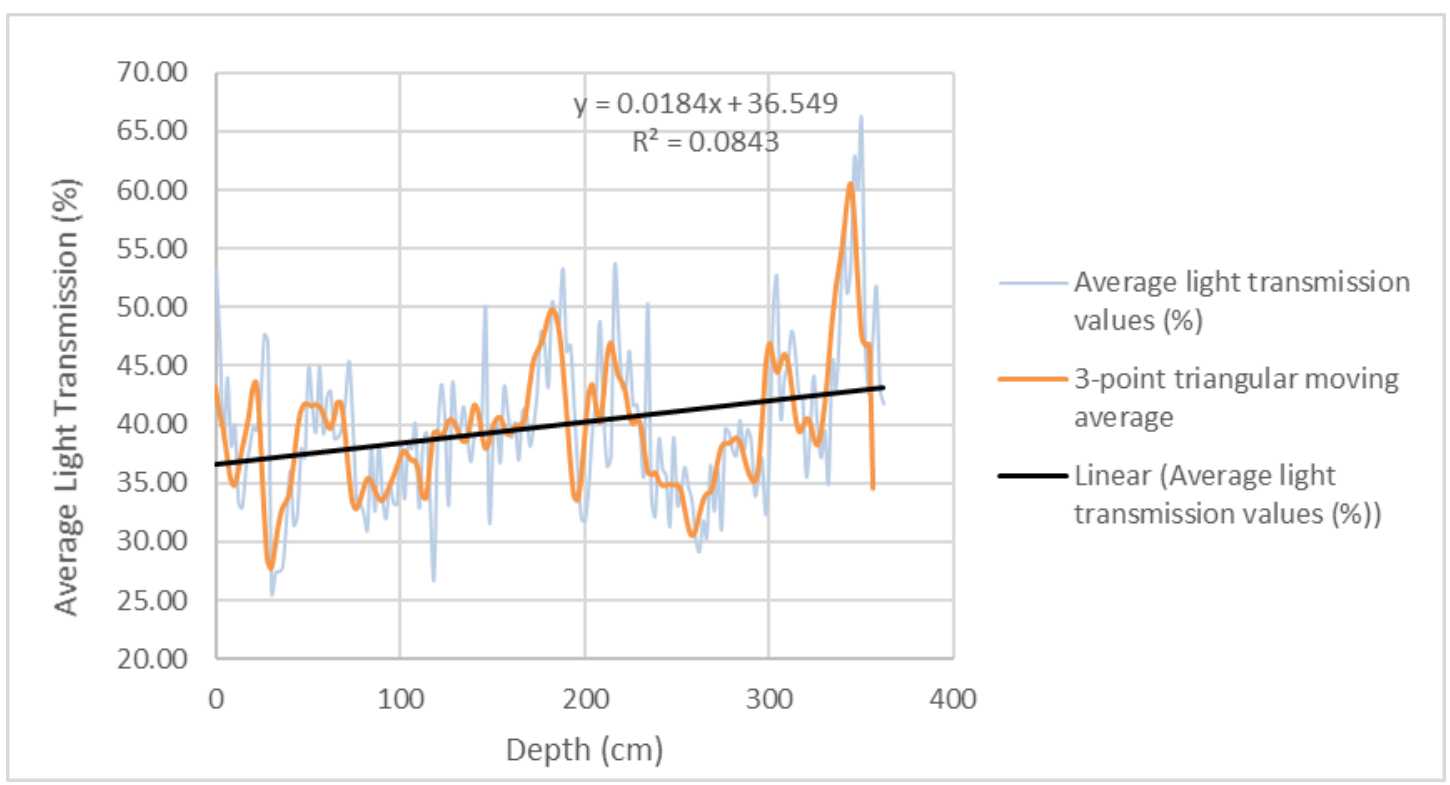

Figure 4:9: PC average light transmission data (\%) plotted against depth 


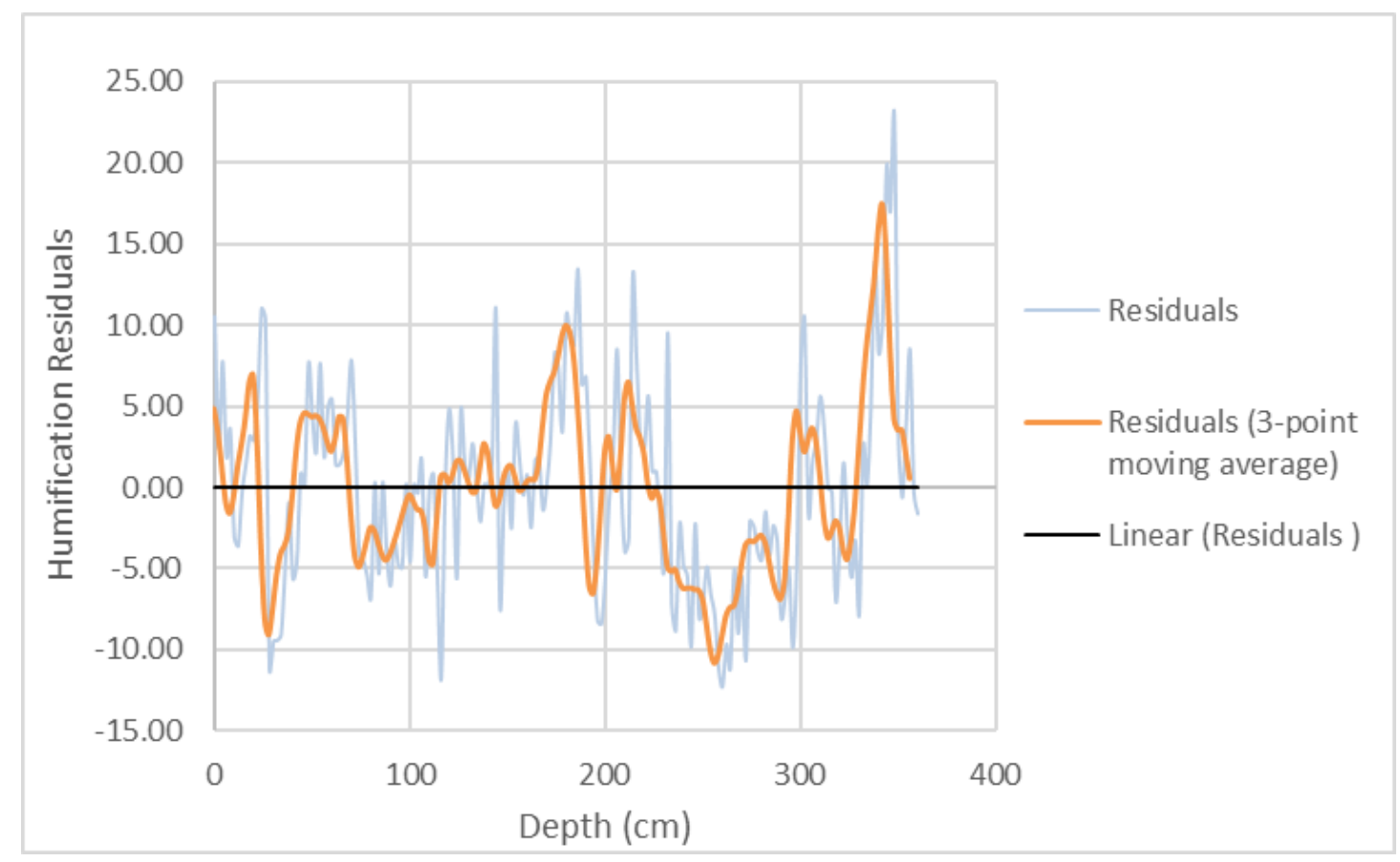

Figure 4:10: PC humification residuals plotted against depth

\subsection{2: Humification Residuals}

Humification residuals are plotted against modelled age to provide qualitative information on relatively wetter or drier periods in the bog peat section (Fig.4.11). Values above zero depict relatively wetter scenarios and values below zero indicate drier intervals. The residuals range from -12.22 to 22.78 (Fig.4.11). A dry interval is identified where the values are below zero and a wet shift is when the values are above zero (Fig.4.11).

At the base of the sequence, a dry interval is observed from $c a$. $4950-4690$ cal yrs. BP (Fig.4.11). This interval comprises residuals from -1.6 to -0.31 (Fig.4.11). A wetter period follows from ca.4630-4470 cal yrs. BP with typical residuals of 8.83 and the highest point of the record, 22.78, observed at ca. 4560 cal yrs. BP (Fig.4.11). Above this, a 120-year dry period is observed between $c a$. 4460-4340 cal yrs. BP with mean residuals of -3.55 (Fig.4.11). This interval is succeeded by a short-lived wet zone between $c a$. $4320-4260$ cal yrs. BP where residuals reach 10.39 (Fig.4.11). 


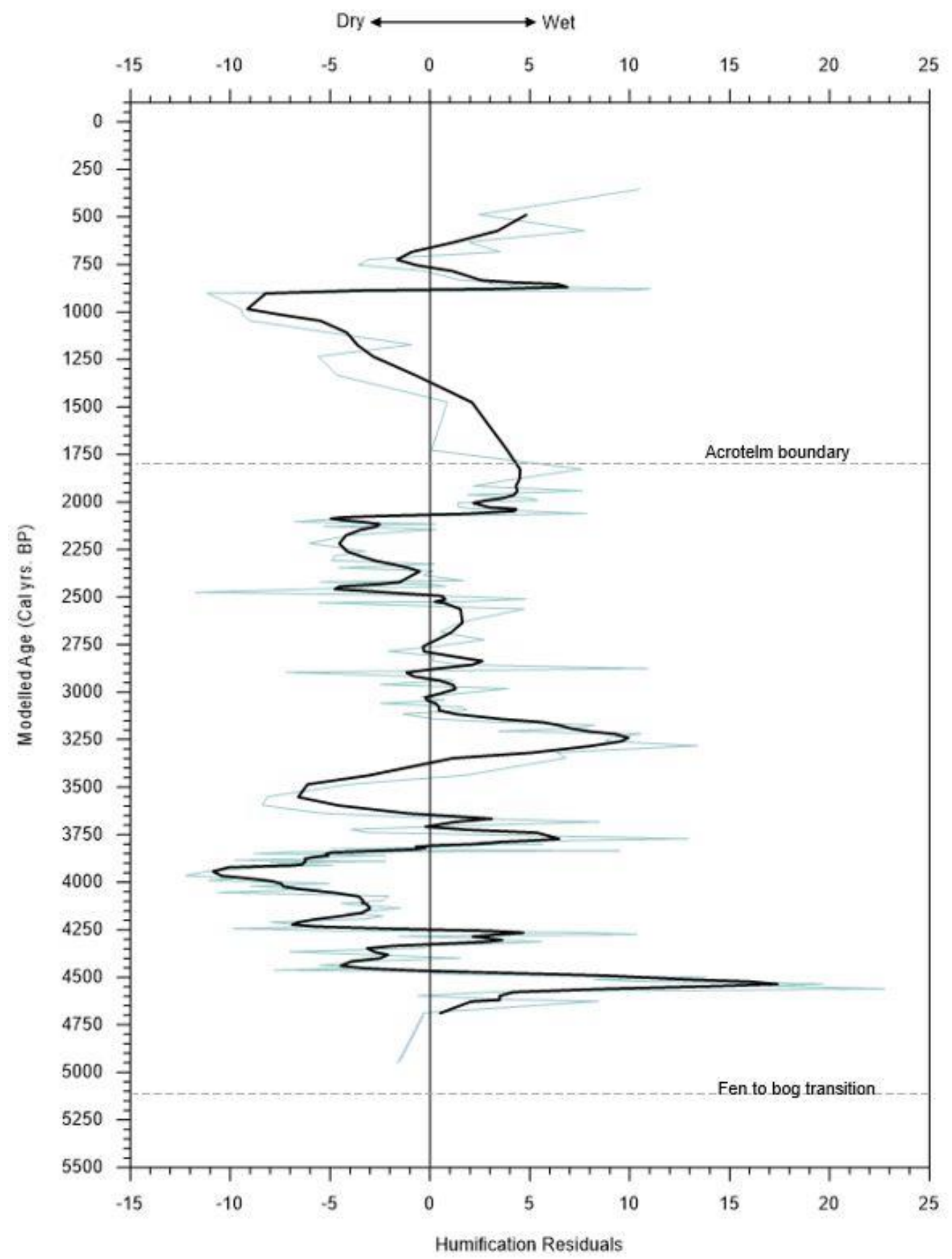

Figure 4:11: PC humification residuals and a 3-point triangulated moving average plotted against modelled age.

There is a pronounced dry period from ca.4250 cal yrs. BP to ca. 3840 cal yrs. BP (Fig.4.11). Within this period residuals are around -6.27 , and the lowest value of the sequence is present 
at $c a .3960$ cal yrs. BP (Fig.4.11). There is a wet shift between $c a .3830-3660$ cal yrs. BP where residuals are as high as 12.92 , but it is punctuated by a short-lived fall in residuals at $c a .3730$ cal yrs. BP (Fig.4.11). From ca. 3660-3480 cal yrs. BP a dry shift is present with mean residuals of -5.30 (Fig.4.11).

A 1000-year long interval with predominantly wet residuals is present between $c a$. 3430-2490 cal yrs. BP, but this zone is characterised by variability (Fig.4.11). During this time, a typical residual value is 2.55 with a pronounced wetter interval in the first 300 years, peaking at 13.42 around $c a .3280$ cal yrs. BP (Fig.4.11). After this, there is a distinct dry shift from $c a .2470$ until $c a$. 2080 cal yrs. BP. Here values fall to a mean of -3.30 and are particularly low (-11.75) at 2470 cal yrs. BP (Fig.4.11).

The record is characterised by wetter residuals between $c a$. 2070-1470 cal yrs. BP, typically around 3.67 (Fig.4.11). This wet shift is followed by a pronounced $c a$. 500-year dry period from $c a$. 1400-900 cal yrs. BP (Fig.4.11). Residuals during this period average at -6.08 and are as low as -11.16 around $c a$. cal yrs. BP (Fig.4.11). Above this there is a short-lived wetter period between $c a$. 890-790 cal yrs. BP where residuals reach 11.04 and a brief drier period from ca. $780-721$ cal yrs. BP with humification residuals falling to -3.58 (Fig.4.11). The uppermost part of the residual record displays an increasing trend of positive, wetter, residuals, from 3.53 to 10.52 over the last 700 years (Fig.4.11). The wet and dry intervals are summarised in Table 4.7.

The residual record does not give the value for the surface; however, the progressively wetter trend is present in the uppermost sample if the light transmission data are considered (Fig.4.9). The 3-point moving average does not continue into the uppermost peat, after ca. $500 \mathrm{cal}$ yrs. $\mathrm{BP}$, because the sedimentation rate is so slow here that there are only two values for this depth. 
Table 4:7: PC wet and dry shifts inferred by the humification record. SL represents short lived shifts $(<100$ years).

\begin{tabular}{|c|c|}
\hline \multicolumn{2}{|c|}{ PC Wet and Dry Shifts (cal yrs. BP) } \\
\hline Wet & Dry \\
\hline $4630-4470$ & $4950-4690$ \\
\hline $4320-4260(\mathrm{SL})$ & $4460-4340$ \\
\hline $3830-3660$ & $4250-3840$ \\
\hline $3430-2490$ & $3660-3480$ \\
\hline $2070-1470$ & $2470-2080$ \\
\hline $890-790(\mathrm{SL})$ & $1400-900$ \\
\hline $680-350$ & $780-720(\mathrm{SL})$ \\
\hline
\end{tabular}

\subsection{3: Comparing DHI and Humification}

The basic macrofossil results were converted in a DHI (Dupont Hydroclimatic Index), and these values are compared against the humification light transmission values to see if they depict similar wetness scenarios. A low DHI indicates a relatively wetter scenario and a high DHI suggests a drier setting. The opposite, however, is the case for the light transmission data i.e., a high value indicates wet conditions, and a low value is indicative of dry conditions. The DHIs and corresponding humification values are presented in Table 4.8.

In most cases, the DHI values are consistent with the humification values in relation to wet/ and dry conditions (Table 4.8). The low (drier) light transmission values at $32-34 \mathrm{~cm}$ and 264$266 \mathrm{~cm}$, both have corresponding high DHI's of 6.028 and 6.7249 (respectively) that also indicate a drier scenario (Table 4.8). The mean transmission value of $39.27 \%$ at $136-138 \mathrm{~cm}$ is matched by a DHI of 4.40 that is around the middle of the DHI values obtained and at $350-352$ $\mathrm{cm}$ the high transmission value $(65.93 \%)$ is matched by a low DHI (Table 4.8). However, the value at $216-218 \mathrm{~cm}$, which is also relatively high (wet) has a DHI value that depicts a drier scenario (Table 4.8). 
Table 4:8: Humification and DHI (Dupont Hydroclimatic Index) values for selected depths. Note that a higher $\mathrm{DHI}$ value indicates a relatively drier scenario and a lower $\mathrm{DHI}$ depicts a wetter scenario. A high $\mathrm{DHI}$ should correspond with lower humification and a low DHI should be mirrored by higher humification.

\begin{tabular}{|l|l|l|}
\hline Core: PCC2 & $\begin{array}{l}\text { Humification data: } \\
\text { Mean: 39.76 Range: 65.93-25.61 }\end{array}$ & \\
Sample depth (cm) & Humification justification & DHI Value \\
\hline $32-34$ & Low value: 27.36 & 6.028 \\
\hline $136-138$ & Mean value: 39.27 & 4.4037 \\
\hline $216-218$ & High value: 53.4 & 6.1008 \\
\hline $264-266$ & Low value: 31.81 & 6.7249 \\
\hline $350-352$ & High value: 65.93 & 3.2872 \\
\hline
\end{tabular}

\section{6: Charcoal Accumulation Record}

The charcoal accumulation records for both size fractions, 125-500 $\mu \mathrm{m}$ and $>500 \mu \mathrm{m}$, are displayed in Figure 4.12.

\section{$125-500 \mu m$}

In the $125-250 \mu \mathrm{m}$ fraction the maximum charcoal shard count is 131 . Charcoal accumulation (CHAR) ranges from 0-2.7 particles $\mathrm{cm}^{-2} \mathrm{yr}^{-1}$ and mean CHAR is 0.06 particles $\mathrm{cm}^{-2} \mathrm{yr}^{-1}$ (Fig.4.12). In this finer size class charcoal is first detected at $c a .10180$ cal yrs. BP where there is a low accumulation rate of 0.01 particles $\mathrm{cm}^{-2} \mathrm{yr}^{-1}$ (Fig.4.12). Between this point and ca. 8000 cal yrs. BP very small amounts of charcoal are observed and CHAR ranges from 0.0030.05 particles $\mathrm{cm}^{-2} \mathrm{yr}^{-1}$ when detected (Figure 4.12). 


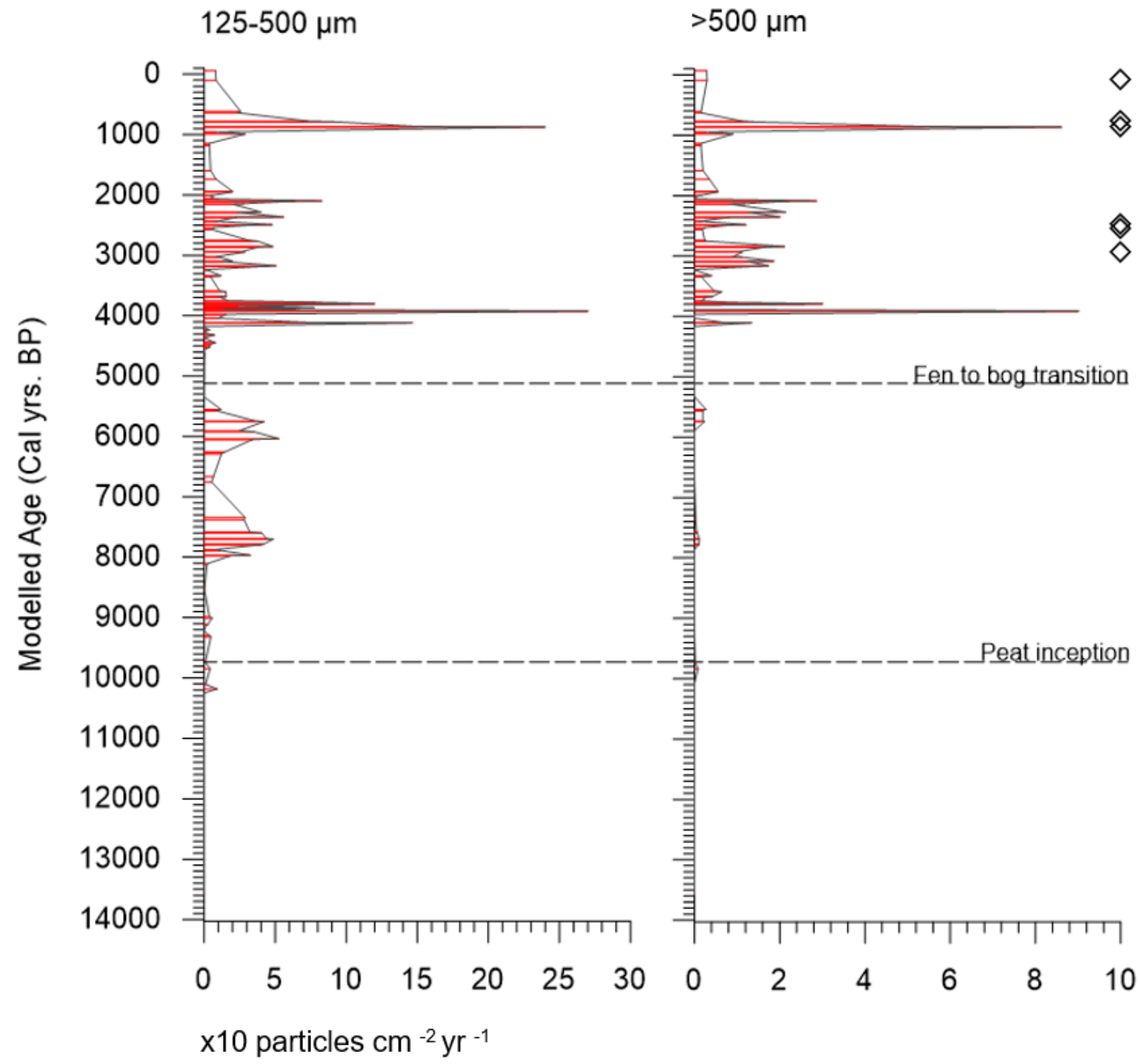

Figure 4:12: Charcoal accumulation rates (CHAR) against modelled age for the two size classes analysed. Diamond shapes show instances where charred plant remains were observed.

Charcoal accumulation increases between $c a$. 7970-7568 cal yrs. BP with typical CHARs of 0.31 particles $\mathrm{cm}^{-2} \mathrm{yr}^{-1}$ and at $c a .7370-7330 \mathrm{cal} \mathrm{yrs}$. BP there is a further peak in carbon accumulation to 0.28 particles $\mathrm{cm}^{-2} \mathrm{yr}^{-1}$ (Fig.4.12). Charcoal is next detected at $\mathrm{ca} .6750 \mathrm{cal}$ yrs. BP in small quantities of 0.06 particles $\mathrm{cm}^{-2} \mathrm{yr}^{-1}$ (Fig.4.12). Between ca. 6280-5540 cal yrs. BP charcoal accumulation is higher and reaches 0.52 particles $\mathrm{cm}^{-2} \mathrm{yr}^{-1}$ at $c a .6040 \mathrm{cal}$ yrs. BP (Fig.4.12). Charcoal is then absent until ca. 4690 cal yrs. BP (Fig.4.12). 
From ca. 4100-3750 cal yrs. BP a step change is observed whereby CHARs are considerably higher and more frequent, with values around 0.44 particles $\mathrm{cm}^{-2} \mathrm{yr}^{-1}$ (Fig.4.12). CHAR is particularly high at three instances: ii) at ca, $3970 \mathrm{cal} \mathrm{yrs}$. BP (with 0.15 particles $\mathrm{cm}^{-2} \mathrm{yr}^{-1}$, ii) around $c a .3910$ cal yrs. BP where the highest CHARs in the record -2.7 particles $\mathrm{cm}^{-2} \mathrm{yr}^{-1}$ and, iii) at $c a .3890$ cal yrs. BP when charcoal accumulation is 0.16 particles $\mathrm{cm}^{-2} \mathrm{yr}^{-1}$ (Fig.4.12). This is followed by a 700-year reduction in CHAR (Fig.4.12).

Between $c a$. 3170-2090 cal yrs. BP charcoal accumulation fluctuates around 0.29 particles $\mathrm{cm}^{-2} \mathrm{yr}^{-1}$ and is highest at the end of this interval at 0.82 particles $\mathrm{cm}^{-2} \mathrm{yr}^{-1}$ (Fig.4.12). Above this, the record is characterised by lower charcoal accumulation values that average at 0.1 particles $\mathrm{cm}^{-2} \mathrm{yr}^{-1}$ until $c a .870 \mathrm{cal}$ yrs. BP where there is a pronounced peak to 2.4 particles $\mathrm{cm}^{-2} \mathrm{yr}^{-1}$ (Fig.4.12). In the uppermost samples, charcoal is detected at four instances, at $c a$.

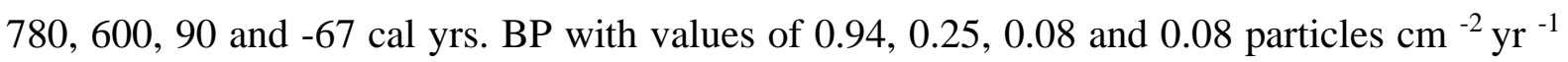
(respectively) (Fig.4.12).

\section{$500 \mu m$}

In the coarser size group, the maximum charcoal shard count is 45 . CHAR ranges from 0-0.9 particles $\mathrm{cm}^{-2} \mathrm{yr}^{-1}$ with a mean of 0.01 particles $\mathrm{cm}^{-2} \mathrm{yr}^{-1}$ (Fig.4.12). Charcoal is first detected at $c a .9840 \mathrm{cal}$ yrs. BP in very low quantities of 0.008 particles $\mathrm{cm}^{-2} \mathrm{yr}^{-1}$ and between $c a .7780$ 7570 cal yrs. BP with a comparable accumulation rate of $0.005-0.009$ particles $\mathrm{cm}^{-2} \mathrm{yr}^{-1}$ (Fig.4.12). From ca. 5740-5540 cal yrs. BP there are two small peaks in CHAR both with rates of 0.02 particles $\mathrm{cm}^{-2} \mathrm{yr}^{-1}$ (respectively) (Fig.4.12). No further charcoal is observed in this size class until ca. 4100 cal yrs. BP (Fig.4.12).

From $c a .4,100-3580$ cal yrs. BP there is shift in the record to higher charcoal accumulation rates and there are two pronounced peaks within this period: One at $c a .3910$ cal yrs. BP, with the highest CHAR in the record at 0.9 particles $\mathrm{cm}^{-2} \mathrm{yr}^{-1}$ and another at $c a .3800$ cal yrs. BP 
of 0.25 particles $\mathrm{cm}^{-2} \mathrm{yr}^{-1}$ (Fig.4.12). Charcoal flux increases again between $c a$. 3170-2840 cal yrs. BP with a mean CHAR of 0.14 particles $\mathrm{cm}^{-2} \mathrm{yr}^{-1}$ (Fig.4.12). This is followed by a 350-year reduction in CHAR and a return to comparable values between ca. 2480-2090 cal yrs. BP (Fig.4.12).

From $c a$. 2080-948 cal yrs. BP accumulation of shards $>500 \mu \mathrm{m}$ is low, typically around 0.3 particles $\mathrm{cm}^{-2} \mathrm{yr}^{-1}$ (Fig.4.12). There is a marked increase in charcoal accumulation between ca. 950-770 cal yrs. BP that is highest $\left(0.86\right.$ particles $\left.\mathrm{cm}^{-2} \mathrm{yr}^{-1}\right)$ at $c a .890 \mathrm{cal} \mathrm{yrs}$. BP (Fig.4.12). Above this, charcoal is observed at $c a .600,90$ and -67 cal yrs. BP with small rates of accumulation $-0.01,0.02,0.02$ particles $\mathrm{cm}^{-2} \mathrm{yr}^{-1}$ (respectively) (Fig.4.12).

In this coarser size class charred plant remains are observable within 7 samples and these results are presented in Table 4.9 (Fig.13). Although abundances are low, the highest number of charred plant fragments is found at ca. 90 cal yrs. BP and ca. 2920 cal yrs. BP (Table 4.9).

Table 4:9: charred plant remains observed in the $>500 \mu \mathrm{m}$ charcoal counts

\begin{tabular}{|c|c|c|}
\hline $\begin{array}{c}\text { Charred plant } \\
\text { remains (n) }\end{array}$ & $\begin{array}{c}\text { Age (ca. cal yrs. } \\
\text { BP) }\end{array}$ & Likely species \\
\hline 18 & 90 & Calluna vulgaris \\
\hline 1 & 780 & Unknown \\
\hline 2 & 870 & unknown \\
\hline 3 & 2490 & Erica tetralix \\
\hline 2 & 2560 & Erica tetralix \\
\hline 4 & 2920 & Erica tetralix \\
\hline 1 & 3790 & unknown \\
\hline
\end{tabular}




\section{7: Pyllau Cochion Site Summary}

A synthesis of proxy data for Pyllau Cochion is presented in Figure 4.13. The lowermost depth at $600 \mathrm{~cm}$ has a modelled age of $14030( \pm 1296)$ cal yrs. BP and is thought to be deposited in a cold climate, possibly the Dimlington Stadial. The sequence of alternating units of clay and organic silty clay (PC2) is thought to be Late-glacial in age. The age of the transition into a more organic silty clay (PC2a) is placed at $c a .13162( \pm 443)$ cal. yrs. BP, within the Windermere Interstadial, although this age is younger than the transition at other UK sites (Abrook et al., 2020; Palmer et al., 2021). The overlying clay unit (PC2c) is constrained according to the age depth model to between ca. $12775( \pm 47)$ and $11670( \pm 1159)$ cal yrs. BP

(Fig.4.13). Despite the wide age uncertainties, these ages are typical for the Loch Lomond Stadial deposits seen at other sites (Abrook et al., 2020; Palmer et al., 2021). The shift to organic sedimentation is consistent with the beginning of the Holocene, at $c a .11670( \pm 1159)$ cal yrs. BP.

Fen peat inception is dated to the early Holocene at $c a .9730( \pm 172)$ cal yrs. BP at the base of PC4. Peat inception is marked by an increase in $\mathrm{OM}$ from $37 \%$ to $87 \%$ and a reduction in BD of $12 \mathrm{~g} \mathrm{~cm}^{3}$ (Fig.4.13). Within the fen zone, carbon accumulation is relatively low but fluctuates, $\mathrm{C}: \mathrm{N}$ is also low but stable and charcoal accumulation is highest after $c a .8000 \mathrm{cal}$ yrs. BP (Fig.4.13).

At the top of the fen peat, between $c a .5870$ to $c a .5120$ cal yrs. BP, the proxy indicators signify a period of change lasting for 750 years. This period is marked by variable OM and BD and a reduction in carbon accumulation (Fig.4.13). At the end of this period, at ca. $5120( \pm 689)$ cal yrs. BP, there is marked shift in the lithology to a Sphagnum-dominated unit (PC5). In PC5 OM increases (from $87 \%$ to $99 \%$ ) and so does C:N (from $22 \%$ to $50 \%$ ). Furthermore, BD decreases by $0.04 \mathrm{~g} \mathrm{~cm}^{3}$, to $0.05 \mathrm{~g} \mathrm{~cm}^{3}$ (Fig.4.13). These indicators are typical of a bog peat 
and therefore this point is believed to signify the fen to bog transition at $c a .5120( \pm 689)$ cal yrs. BP. The 750-year period of variability prior is thought to possibly represent the development of a raised bog catotelm before the transition (see literature review).

The bog peat comprises the end of the Middle Holocene and Late Holocene. Within the bog peat the $\mathrm{C}: \mathrm{N}$, carbon accumulation and charcoal accumulation are higher and more variable (Fig.4.13). CAR is highest between $c a .4620$ to 3650 and ca. 2530-1950 cal yrs. BP (Fig.4.13). There is a step change to larger charcoal accumulation rates at $c a .4100$ cal yrs. BP, and a notable peak around $c a .900 \mathrm{cal}$ yrs. BP, in both of the size classes. The humification record is characterised by wet shifts at $c a .4630,4320$ 3830, 3430, 2070, 890 and 680 cal yrs. BP and dry shifts at 4950, 4460, 4250, 3660, 2470, 1400 and 780 cal yrs. BP.

Comparison between the proxy records implies an intermittent relationship between wetness and carbon accumulation, whereby higher carbon accumulation is associated with wet shifts and drier intervals are accompanied with reductions in CAR. For example, at $c a .3200$ and $c a$. 2000 cal yrs. BP, wet shifts are associated with higher CARs and between $c a$. 2470-2080 cal yrs. BP drier conditions are accompanied with lower carbon accumulation (Fig.4.13). Higher charcoal accumulation rates also appear to be associated with dryness, for instance at the aforementioned dry shift, $c a .2470$ cal yrs. BP and between $c a .4100-3750$ cal yrs. BP. The relationship between CHAR and CAR is not considered because both are based are peat accumulation rates. 


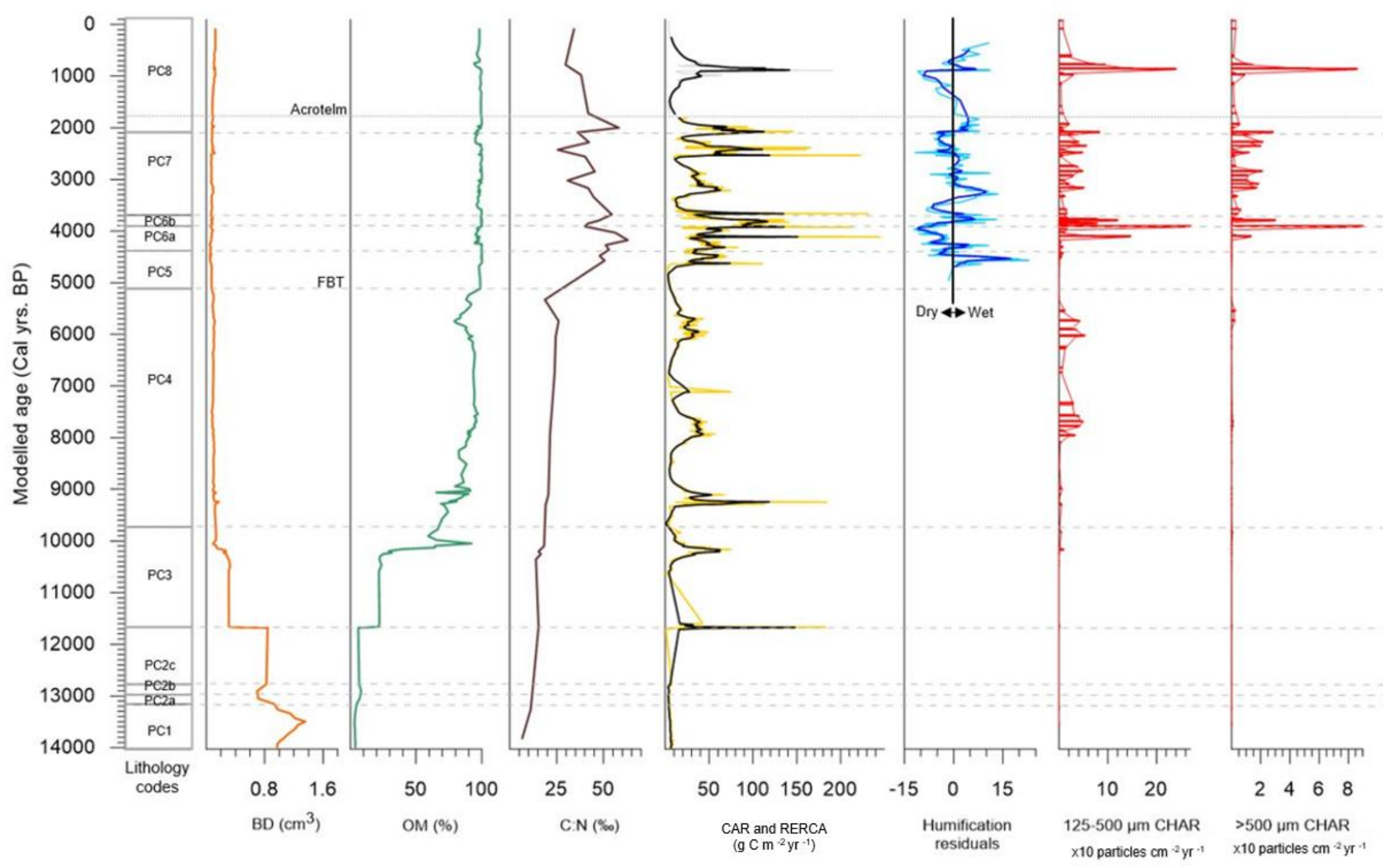

Figure 4:13: PC Proxy synthesis: From left to right: PC Lithostratigraphy; Bulk Density (BD); Organic Matter (OM); carbon:nitrogen ratio (C:N); Carbon Accumulation Rate (CAR) and Recent Accumulation Rates (RERCA) above the acrotelm; Humification residuals; Charcoal accumulation rate (CHAR) for $125-500 \mu \mathrm{m}$ and $>500 \mu \mathrm{m}$. 


\section{Chapter 5: Figyn Common Results}

The full dataset for Figyn Common is available in appendix 5.

\section{1: Lithostratigraphy and Sediment Composition Data}

A core sequence of $1100 \mathrm{~cm}$ was retrieved from Figyn Common (FG) (Fig.5.1). The resistance from the corer indicated that there is bedrock beneath this point. The lowermost unit recovered, above the bedrock is a thin blueish-grey clay unit $(1100-1085 \mathrm{~cm})$ containing small black clasts (zone FG1) (Fig.5.1; Table 5.1). FG1 has a high mean bulk density (BD) $\left(1.26 \mathrm{~g} \mathrm{~cm}^{3}\right)$ and a very low average organic matter content $(\mathrm{OM})(2.81 \%)$ and carbon:nitrogen ratio $(\mathrm{C}: \mathrm{N})(6 \%)$ (Fig.5.1; Table 5.1). The clay unit is overlain by a silt deposit between 1085-1040 cm (zone FG2). In the lowermost $36 \mathrm{~cm}$ of the silt the BD decreases from values of $1.52 \mathrm{~g} \mathrm{~cm}^{3}$ to $0.24 \mathrm{~g}$ $\mathrm{cm}^{3}$, but it rises to $0.54 \mathrm{~g} \mathrm{~cm}^{3}$ shortly before the transition into the overlaying zone (Fig.5.1). Similarly, OM increases from $1085-1047 \mathrm{~cm}$ from $~ 3-30 \%$ but then falls to $20 \%$ at $1045 \mathrm{~cm}$ (Fig.5.1). There is then a sharp transition into the overlying zone at $1040 \mathrm{~cm}$ (FG3) (Fig.5.1).

FG3 is a large unit of highly humified, dark black, Subtantia humosa that is observed between 1040-552 cm (Table 5.1; Fig.5.1). At the base of this unit there is a reduction in BD from values of $0.40 \mathrm{~g} \mathrm{~cm}^{3}$ to $0.11 \mathrm{~g} \mathrm{~cm}^{3}$ by $975 \mathrm{~cm}$ (Fig.5.1). Similarly, OM shows an increasing trend from values of $\sim 25 \%$ to $\sim 90 \%$ at $900 \mathrm{~cm}$ but this increase is more gradual and variable, (Fig.5.1). This unit (FG3) is classified as a fen peat for several reasons. First, the unit is characterised by high OM $(83.31 \%)$ indicative of a peat, but a higher mineral content $(\sim 17 \%)$ than a bog peat (Lindsay et al., 2014; Rydin and Jeglum, 2006). Secondly, the unit also has a mean C:N of 22 $\%$ which are values typically associated with a semi aquatic, mesotrophic, intermediate fen environment (see Figure 2.10 in literature review). The discovery of 7 chironomid heads between 592-594 cm (Table 5.2) also supports this interpretation. 


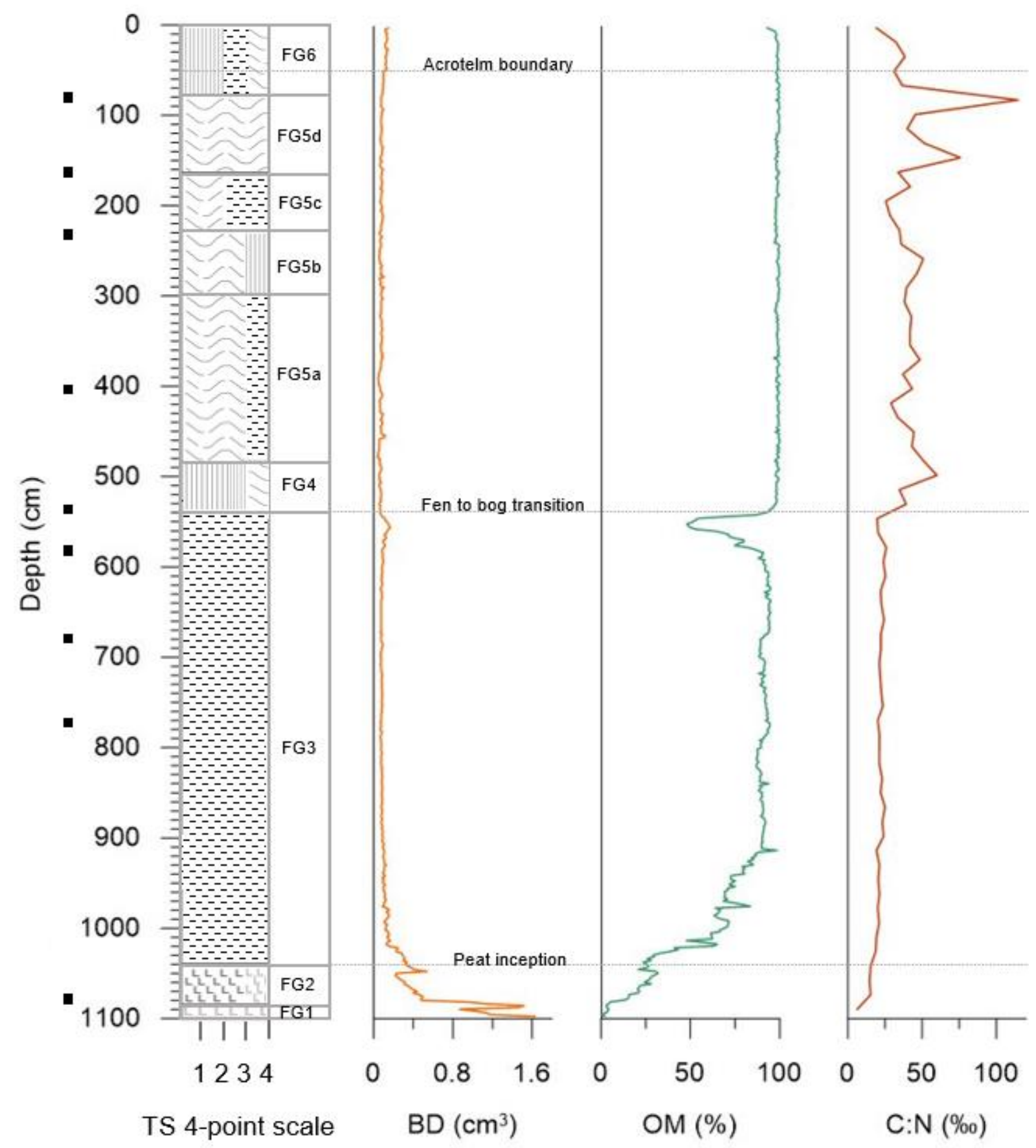

\begin{tabular}{|c|c|}
\hline $\begin{array}{l}\text { Turfa Herbacea } \\
\text { (Herbaceous peat) }\end{array}$ & \\
\hline $\begin{array}{l}\text { Turfa bryophytica } \\
\text { (Sphagnum peat) }\end{array}$ & \\
\hline Substantia humosa & \\
\hline $\begin{array}{l}\text { Argilla granosa } \\
\text { (Silt) }\end{array}$ & \\
\hline $\begin{array}{l}\text { Argilla steatodes } \\
\text { (Clay) }\end{array}$ & \\
\hline
\end{tabular}

Figure 5:1: Lithostratigraphy for FG including from left to right lithology, bulk density (BD), organic matter (OM) percentage and carbon:nitrogen ratio $(\mathrm{C}: \mathrm{N})$. Black boxes show the location of radiocarbon dates. 
These factors suggest that this sediment was deposited under minerotrophic conditions in an intermediate fen. The base of FG3 is therefore marked as the point of fen peat inception.

At the top of the fen peat deposit there is some marked variability in the $\mathrm{BD}$ and $\mathrm{OM}$ (Fig.5.1).BD rises from typical values of $0.1 \mathrm{~g} \mathrm{~cm}^{3}$ to $0.15 \mathrm{~g} \mathrm{~cm}^{3}$, and the OM drops from an average of $85 \%$ to as low as $48 \%$ (Fig.5.1). This change is present between $575-539 \mathrm{~cm}$ and above 538 values sharply increase to a mean of $\sim 98 \%$ (Fig.5.1).

Overlying FG3 is a deposit of Turfa herbacea (herbaceous peat) (FG4) (539-484 cm) (Fig.5.1). FG4 is characterized by a mean OM of $98.56 \%$ (> 15\% higher than the mean for FG3), BD is typically $<0.07 \mathrm{~g} \mathrm{~cm}^{3}$ (Fig.5.1; Table 5.1), and Sphagnum remains are detected at 512-514 cm (Table 5.2). These are indicators of a typical bog peat (Lindsay et al., 2014; Rydin and Jeglum, 2006) (Fig.5.1; Table 5.1). Furthermore, this deposit has a mean C:N of 47 \%o which suggests that this peat was deposited in a terrestrial, oligotrophic, peat bog (see Figure 2.10 literature review). Consequently, the base of this deposit $(539 \mathrm{~cm})$ is marked as the fen to bog transition (Fig.5.1).

A thick deposit of Turfa bryophytica (Sphagnum peat) (FG5) overlies FG4 and 4 sub-units are identified within this unit: FG5a-d. Throughout FG5 the C:N is highly variable, and it fluctuates between $19 \%$ and $114 \%$, this variability is particularly pronounced in sub-unit FG5d (Fig.5.1).

The first sub-unit of FG5 is observed from $484 \mathrm{~cm}$ to $298 \mathrm{~cm}$ (FG5a) (Fig.5.1; Table 5.1). Sphagnum, unidentified organic matter (UOM) and Carex rostrata (sedge) are dominant at 400-402 cm (Table 5.2). BD values are similar to the underlying unit, but OM increases slightly to $99.07 \%$ and $\mathrm{C}: \mathrm{N}$ decreases by around $6 \%$ (Fig.5.1; Table 5.1). Above this deposit, between $298-228 \mathrm{~cm}$, is a further unit of Sphagnum peat (FGb). This sub-unit is similar in all respects but observably less humified and with a higher proportion of herbaceous bog peat (Fig.5.1; 
Table 5.1). The macrofossils at one depth within this sub-unit $(272-274 \mathrm{~cm})$ also indicate the dominance of Sphagnum, UOM and Eriophorum vaginatum (Table 5.2). The FG5c sub-unit (228-164 cm) overlies FG5b and is comprised of a highly humified, Sphagnum peat. Fewer visible herbaceous plant remains are observed in FG5c and the BD increases marginally, to a mean of $0.08 \mathrm{~g} \mathrm{~cm}^{3}$, and the average $\mathrm{OM}$ is $1 \%$ lower. The most notable changes are observed in the C:N values which fall significantly by $10 \%$ to $32.38 \%$. Sphagnum and UOM are dominant at 208-210 cm (Table 5.2).

The uppermost sub-unit FGd $(164-78 \mathrm{~cm})$ is rich in visible Sphagnum but is typically less humified and has high elasticity, in contrast to FGc (Table 5.1). Microscopic examination of the macrofossils reveals a dominance of Sphagnum (94.27\%) at 120-122 cm (Table 5.2). BD and $\mathrm{OM}$ are comparable to the sub-unit below, but the $\mathrm{C}: \mathrm{N}$ increases substantially by $\sim 27 \%$, to a mean of $59.85 \%$ and there is a noticeable peak at $49 \mathrm{~cm}$ to $114 \%$ (Fig.5.1; Table 5.1).

The uppermost unit $(78-0 \mathrm{~cm})(\mathrm{FG} 6)$ is an herbaceous peat characterized by a substantially lower percentage of Sphagnum $(16.13 \%$ at $48-50 \mathrm{~cm}$ ) (Table 5.2). In addition, this unit has a higher mean $\mathrm{BD}\left(0.11 \mathrm{~cm}^{3}\right)$ and the average $\mathrm{C}: \mathrm{N}$ ratio drops to $32.31 \%$ (Fig.5.1; Table 5.1). The peat here is very stiff and compact, with an elasticity of 0 (Table 5.1), and large amounts of visible herbaceous matter are present. Furthermore, there is a visible $1.5 \mathrm{~cm}$ black band at the top. This band is likely to be charcoal because there were signs of burning at the site when the core was being collected and a macroscopic charcoal peak is found at this depth (see Figure 5.9).

\section{Acrotelm boundary}

As explained in the PC results chapter, lithological indicators are typically used to identify the likely depth of the acrotelm boundary, namely a decrease in BD towards the top that signifies the acrotelm transition (Clymo, 1983). However, this was also not present at Figyn. Instead, 
the uppermost unit (FG6) is marginally more compact (Fig.5.1; Table 5.1). As such, an indicative acrotelm boundary was placed at $50 \mathrm{~cm}$, based on other approaches in the literature, where an acrotelm boundary is not clearly defined (Fig.5.1) (e.g., Ratcliffe et al.,2018). 
Table 5:1: Lithostratigraphy for FC described using the Troels-Smith System (1955) (as outlined in Birks and Birks (1980)) and mean bulk density (BD), organic matter $(\mathrm{OM})$, and carbon:nitrogen ratio $(\mathrm{C}: \mathrm{N})$ for each unit. Th= Turfa Herbacea (Herbaceous peat), Tb $=$ Turfa bryophytica (Sphagnum peat), Ti $=$ Turfa lignosa (Wood peat), $\mathrm{Sh}=$ Substantia humosa, $\mathrm{Ag}=$ Argilla granosa (Silt), As= Argilla steatodes (Clay). The superscript numbers next to the dominant sediment type represent the degree of humification, with 4 being the most humified. Nig= darkness, sicc $=$ dryness, Elas $=$ Elasticity, Strf $=$ Stratification.

\begin{tabular}{|c|c|c|c|c|c|}
\hline $0-78$ & $\begin{array}{c}\text { Th.1.52, Tb1, Sh1 } \\
\text { Nig: } 2.5 \text {, Elas: } 0 \text {, Strf: } 1, \text { Sicc: } 3\end{array}$ & FG6 & 0.11 & 98.66 & 31.31 \\
\hline $164-228$ & $\begin{array}{c}\mathrm{Tb}^{3} 2, \mathrm{Sh} 2, \mathrm{Th}+ \\
\text { Nig: } 2-5, \text { Elas: } 2, \text { Strf:0, Sicc: } 3\end{array}$ & FG5c & 0.08 & 98.37 & 32.38 \\
\hline $228-298$ & $\begin{array}{c}\text { Tb23, Th1 }^{2} \\
\text { Nig: } 2-5, \text { Elas: } 2 \text {, Strf:0, Sicc: } 3\end{array}$ & FG5b & 0.07 & 99.21 & 42.95 \\
\hline $484-539$ & $\begin{array}{c}\text { Th}^{3} 3, \text { Tb1 } \\
\text { Nig: } 3 \text {, Elas: } 2 \text {, Strf: } 0, \text { Sicc: } 3\end{array}$ & FG4 & 0.07 & 98.56 & 47.07 \\
\hline $539-1040$ & $\begin{array}{c}\text { Sh4, Ti+ (fen peat) } \\
\text { Nig: 4, Elas: 0, Strf:0, Sicc: } 3\end{array}$ & FG3 & 0.1 & 83.31 & 22.25 \\
\hline $1040-1085$ & $\begin{array}{c}\text { Ag3, As1 } \\
\text { Nig: 2, Elas: 0, Strf:0, Sicc: } 3\end{array}$ & FG2 & 0.44 & 21.2 & 14.69 \\
\hline
\end{tabular}


Table 5:2: Basic macrofossil analysis results for selected depths at FG. The species abundance/peat components (\%) are averaged over 15 quadrat counts for each sample (see methodology).

\begin{tabular}{|c|c|c|c|c|c|c|c|c|c|c|c|}
\hline $\begin{array}{l}\text { Depth } \\
\text { (cm) }\end{array}$ & $\begin{array}{l}\text { Lithology } \\
\text { zone }\end{array}$ & $\begin{array}{c}\text { Erica } \\
\text { tetralix }\end{array}$ & $\begin{array}{l}\text { Vaccinium } \\
\text { oxycoccos }\end{array}$ & $\begin{array}{l}\text { Calluna } \\
\text { vulgaris }\end{array}$ & $\begin{array}{c}\text { Other moss } \\
\text { undiff. }\end{array}$ & $\begin{array}{c}\text { Eriophorum } \\
\text { vaginatum }\end{array}$ & $\begin{array}{c}\text { Monocot } \\
\text { undiff. }\end{array}$ & Sphagnum & $\begin{array}{c}\text { Carex } \\
\text { rostrata }\end{array}$ & UOM & Seeds and other \\
\hline $48-50$ & FG6 & 4.67 & 3.60 & 2.80 & 3.60 & & & 16.13 & & $\begin{array}{c}69.2 \\
0\end{array}$ & $\begin{array}{l}\text { Unidentified seed: } \\
1 ; \\
\text { unidentified black } \\
\text { spores: } 115 ; \\
\text { Acari orbatida: } 6 ; \\
\text { Erica tetralix seed: } \\
1\end{array}$ \\
\hline $120-122$ & FG5d & & & & & & & 94.27 & & 5.73 & $\begin{array}{l}\text { Acari orbatida: } 21 \\
\text { Unidentified seed :1 }\end{array}$ \\
\hline $208-210$ & FG5c & 3.20 & & & & 3.20 & & 75.53 & & $\begin{array}{c}17.5 \\
3\end{array}$ & Acari orbatida: 18 \\
\hline $512-514$ & FG4 & & & & 22.00 & & & 75.47 & & 2.53 & Sphagnum spore: 2 \\
\hline $592-594$ & FG3 & & & & 0.80 & & 6.00 & 1.80 & & $\begin{array}{c}91.4 \\
0\end{array}$ & $\begin{array}{l}\text { Chironomid head: } \\
\text { 7; Juncus seed: } 6\end{array}$ \\
\hline
\end{tabular}




\section{2: Chronology}

\subsection{1: Radiocarbon Dating}

Nine depths were selected for radiocarbon dating. The criteria for the selection of these depths and the material dated is detailed in Table 5.3. The overall aim was to submit only macrofossil remains for dating. However, macrofossils were completely absent at several depths, or the minimum sample weight was not achieved, even after repeated re-sampling attempts. As such, 6 of the samples are bulk material (Table 5.3). Radiocarbon and calibrated calendar ages (cal yrs. BP) are presented in Table 5.3. The radiocarbon dates increase in age with depth i.e., no apparent age reversals. When calibrated singularly the age ranges at a 2 -sigma probability distribution are lower than 250 years for all dates (Table 5.3). These nine dates are used to construct a Bayesian $P_{\_}$sequence age-depth model (Figure 5.2a). 
Table 5:3: Radiocarbon results for FC: Rationale for sample selection; the sample type dated; Laboratory codes; Radiocarbon ages; calibrated ages. The radiocarbon age (BP) was calibrated to calibrated years (BP) on Oxcal v4.42, 2020 (Bronk Ramsey, 2009a) using the Intcal20 calibration curve (Reimer et al., 2020).

\begin{tabular}{|c|c|c|c|c|c|c|}
\hline Depth (cm) & Justification & $\begin{array}{l}\text { Sample type } \\
\text { dated }\end{array}$ & $\begin{array}{l}\text { Laboratory } \\
\text { code }\end{array}$ & $\begin{array}{l}\text { Radiocarbon } \\
\text { Age BP }\end{array}$ & $\begin{array}{c}\text { calibrated Age Range (cal yrs. BP) } \\
(2 \sigma(95.4 \% \text { probability }))\end{array}$ & $\begin{array}{c}\text { Range } \\
\text { (cal yrs. BP) }\end{array}$ \\
\hline 81 & $\begin{array}{l}\text { Lithological interest: close to change into } \\
\text { a new lithological zone }\end{array}$ & $\begin{array}{l}\text { Macrofossil } \\
\text { (Sphagnum) }\end{array}$ & $\begin{array}{l}\text { SUERC-84315 } \\
\text { (GU50037) }\end{array}$ & $1132 \pm 24$ & $1176-958$ & 218 \\
\hline 166 & Gap filler & $\begin{array}{l}\text { Macrofossil } \\
\text { (Sphagnum) }\end{array}$ & $\begin{array}{l}\text { SUERC-84316 } \\
\text { (GU50038) }\end{array}$ & $1532 \pm 24$ & $1515-1349$ & 166 \\
\hline 238 & $\begin{array}{l}\text { Lithological interest: shortly before the } \\
\text { onset of a different lithological zone. }\end{array}$ & $\begin{array}{l}\text { Macrofossil } \\
\text { (Sphagnum) }\end{array}$ & $\begin{array}{l}\text { SUERC-84320 } \\
\text { (GU50039) }\end{array}$ & $2368 \pm 21$ & $2464-2341$ & 123 \\
\hline 405 & $\begin{array}{l}\text { Gap filler and lithological interest: within } \\
\text { a period of lower BD }\left(\mathrm{g} \mathrm{cm}^{3}\right)\end{array}$ & $\begin{array}{l}\text { Humic acid } \\
\text { fraction }\end{array}$ & $\begin{array}{l}\text { SUERC-87431 } \\
\text { (GU51720) }\end{array}$ & $3075 \pm 30$ & $3370-3209$ & 161 \\
\hline 532 & $\begin{array}{l}\text { Lithological interest: close to onset of } \\
\text { bog peat. Peat here is more bog like. }\end{array}$ & $\begin{array}{l}\text { Humic acid } \\
\text { fraction }\end{array}$ & $\begin{array}{l}\text { SUERC-84322 } \\
\text { (GU50042) }\end{array}$ & $3614 \pm 21$ & $3890-3847$ & 43 \\
\hline 584 & $\begin{array}{l}\text { Lithological interest: start of the } \\
\text { transitional zone into bog peat }\end{array}$ & $\begin{array}{l}\text { Humic acid } \\
\text { fraction }\end{array}$ & $\begin{array}{l}\text { SUERC-84323 } \\
\text { (GU50043) }\end{array}$ & $4814 \pm 24$ & $5594-5477$ & 117 \\
\hline 682 & $\begin{array}{l}\text { Gap filler and lithological interest: } \\
\text { increase in OM (\%) and decline in BD ( } \mathrm{g} \\
\mathrm{cm}^{3} \text { ) }\end{array}$ & $\begin{array}{l}\text { Humic acid } \\
\text { fraction }\end{array}$ & $\begin{array}{l}\text { SUERC-84324 } \\
\text { (GU50044) }\end{array}$ & $6586 \pm 23$ & $7561-7428$ & 133 \\
\hline 778 & $\begin{array}{l}\text { Gap filler and lithological interest: } \\
\text { increase in OM (\%) }\end{array}$ & $\begin{array}{l}\text { Humic acid } \\
\text { fraction }\end{array}$ & $\begin{array}{l}\text { SUERC-84325 } \\
\text { (GU50045) }\end{array}$ & $7625 \pm 24$ & $8452-8375$ & 77 \\
\hline 1080 & $\begin{array}{l}\text { Basal date: shortly before the onset of } \\
\text { fen peat }\end{array}$ & $\begin{array}{l}\text { Humic acid } \\
\text { fraction }\end{array}$ & $\begin{array}{l}\text { SUERC-84326 } \\
\text { (GU50046) }\end{array}$ & $9743 \pm 25$ & $11232-11114$ & 118 \\
\hline
\end{tabular}




\subsection{2: Age-Depth Model}

The nine dates detailed in Table 5.3 are used to construct a Bayesian age-depth model that gives modelled ages for all centimeter depths and the associated age uncertainties at $95.4 \%$ probability (2-sigma) (Fig.5.2a). There are no age reversals in the dates and the age uncertainties in the model range from 4-1371 years (Fig.5.2a). The age ranges are particularly small between the base of the sequence and $1080 \mathrm{~cm}$ (mean 374 years) and between the dates at $405-238 \mathrm{~cm}$ and $81-166 \mathrm{~cm}$, at averages of 349 and 254 years (respectively) (Fig.5.2a; Table 5.4). There are large age uncertainties between the depths of 682-405 cm (Fig.5.2a; Table 5.4). These larger age ranges appear to be the product of major sedimentation changes between these depths (Staff, 2017). This is best observed on Figure $5.2 \mathrm{~b}$ that uses linear interpolation between the dates. Here the changes in sedimentation and the variations shown in Figure 5.2b help to explain the large errors in the Bayesian model around this region (Fig.5.2a).

Figure $5.2 \mathrm{~b}$ implies that above $682 \mathrm{~cm}$ the accumulation rate reduces by half to $0.05 \mathrm{~cm} / \mathrm{yr}$. until $584 \mathrm{~cm}$ (Table 5.4). This reduction in deposition represents a divergence from the overall sedimentation trend (Fig.5.2b) and consequently the age-depth model has wider age errors between these depths (853 years) (Fig.5.2a; Table 5.4). Furthermore, the reduction in sedimentation is even more pronounced in the overlying depths (between $584 \mathrm{~cm}$ to 532 ) where the rate of deposition falls to $0.03 \mathrm{~cm} / \mathrm{yr}$, much slower than the mean core rate of 0.10 cm/yr. (Table 5.4; Fig.52b). Above this, from 532-405 $\mathrm{cm}$ the sedimentation increases significantly to $0.22 \mathrm{~cm} / \mathrm{yr}$. These changes in deposition rate cause a marked kink in the sedimentation trend (red circle in Figure 5.2b). This kink creates large uncertainties in the Bayesian age-depth model, between 584-532 cm (1027 years) and 532-405 (792 years) (Table 5.4; Fig.5.2a). The age probabilities are particularly wide around the date at $532 \mathrm{~cm}$, reaching 1371 years (Table 5.5; Fig.5.2a). 

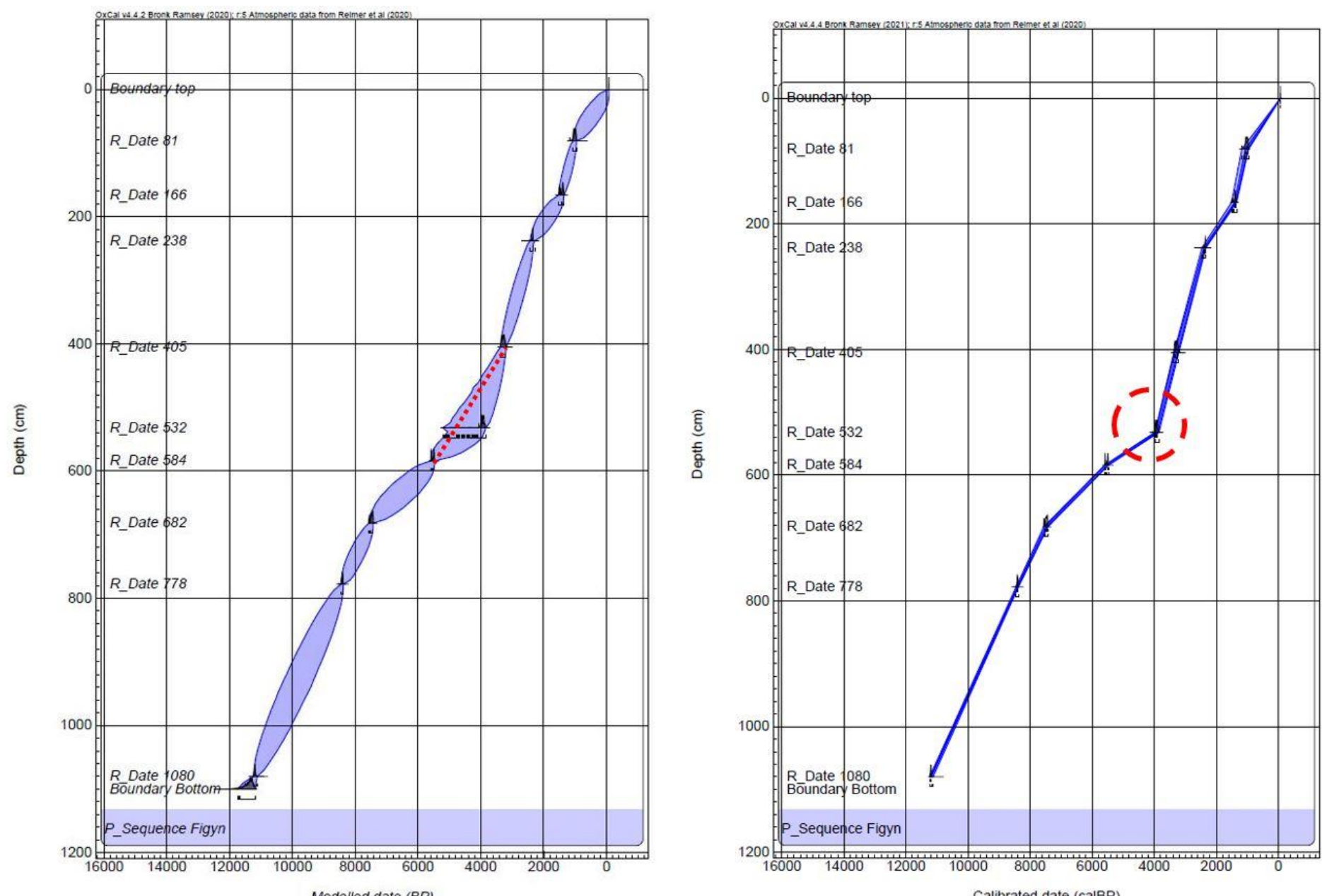

Figure 5:2: FG (A) (left plot) the Bayesian age-depth model with modelled ages at a $95.4 \%$ probability against depth (the red dotted line exemplifies how the model is trying to follow the overall deposition trend). (B) (right plot) linear interpolation between radiocarbon dates plotted against depth (the red dashed circle shows the kink in the deposition trend). Constructed on Oxcal v4.42, 2020 (Bronk Ramsey, 2009a) using the Intcal20 calibration curve (Reimer et al., 2020). 
These large uncertainties are produced because the Bayesian age-depth model, that considers the overall deposition trend and the radiocarbon dates, deems it possible that the date at 532 cm could be erroneously young and might follow the expected deposition trend (red line on Fig.5.2a). It therefore allows for the possibility of older ages, that fit the trend, as well as the younger ages that align with the date at $532 \mathrm{~cm}$, and hence the wide age uncertainties (Fig.5.2a).

The large age ranges around $532 \mathrm{~cm}$ are problematic because they cause the ages from 538 528 to be modelled as becoming older up core (Table 5.5). This is because as it gets closer to the date at $532 \mathrm{~cm}$ the age errors become bigger, creating a kink in the age-depth errors (Fig.5.3) and allowing for the mid-point of modelled ages to be erroneously older (Table 5.5; Fig.5.3; Fig.5.2a). This results in minus values for the 'years between centimetres' which would lead to inaccurate proxy fluxes (Table 5.5). Considering the arrangement of the dates it is unlikely that this reflects the true sedimentation rate, and instead, it is a result of the model's disagreement with the date at $532 \mathrm{~cm}$. Therefore, the calculated years between centimetres for these depths $(538-528 \mathrm{~cm})$ will not be used for proxy fluxes and no data will be presented for these depths.

Aside from the problems at the date around $532 \mathrm{~cm}$, the Bayesian age depth model (Fig.5.2a) produces likely ages (95.4\% probability / 2 sigma) for each centimeter. The mid-point of the model age ranges (as shown in Figure 5.4) are used to give a date to each centimeter. These ages are rounded to the nearest ten when reported in the text. The proxies, that were sampled at a $2 \mathrm{~cm}$ contiguous resolution, are plotted against the mid-point of the sampled depth and a carbon and charcoal flux value is given for each centimeter within that depth increment (see methodology). 
Table 5:4: FG mean accumulation rates inferred from the linear interpolation between dates as presented in Figure 5:2 (b) These sedimentation rates help to explain fluctuations in the Bayesian age-depth model (Fig.5:2 (a)). The mean age uncertainty between dates from the Bayesian model (Fig.5:2 (a)) are presented in the right column.

\begin{tabular}{|c|c|c|}
\hline Depth (cm) & $\begin{array}{c}\text { Mean accumulation rates } \\
\text { (cm/yr.) inferred from Figure 2a }\end{array}$ & $\begin{array}{c}\text { Mean modelled age uncertainties } \\
\text { from Figure 2b } \\
\mathbf{9 4 . 5 \% / 2 - s i g m a ~ p r o b a b i l i t y ) ~}\end{array}$ \\
\hline $0-81$ & 0.08 & 501 \\
\hline $81-166$ & 0.23 & 254 \\
\hline $166-238$ & 0.07 & 477 \\
\hline $238-405$ & 0.19 & 349 \\
\hline $405-532$ & 0.22 & 792 \\
\hline $532-584$ & 0.03 & 1027 \\
\hline $584-682$ & 0.05 & 853 \\
\hline $682-778$ & 0.10 & 420 \\
\hline $778-1080$ & 0.11 & 731 \\
\hline $1080-1100$ & 0.07 & 374 \\
\hline & & \\
\hline $0-1100$ & 0.10 & 577.8 \\
\hline
\end{tabular}

Table 5:5: FG Bayesian modelled ages (Fig.5:2(a)) between 539-530 cm. Showing the large age ranges and uncertainties around these depths and the problematic dates ages between 532-538 $\mathrm{cm}$.

\begin{tabular}{|c|c|c|c|c|c|}
\hline Depth (cm) & \multicolumn{2}{|c|}{$\begin{array}{c}\text { Age depth model age- } \\
\text { range (cal yrs. BP) }\end{array}$} & $\begin{array}{c}\text { Age } \\
\text { uncertainty }\end{array}$ & $\begin{array}{c}\text { Mid-point of modelled } \\
\text { age (cal yrs. BP) }\end{array}$ & $\begin{array}{c}\text { Years } \\
\text { per cm }\end{array}$ \\
\hline 527 & 5063 & 3767 & 1296 & 4415.00 & 22.5 \\
\hline 528 & 5093 & 3782 & 1311 & 4437.50 & 22 \\
\hline 529 & 5122 & 3797 & 1325 & 4459.50 & 22.5 \\
\hline 530 & 5152 & 3812 & 1340 & 4482 & 22 \\
\hline 531 & 5182 & 3826 & 1356 & 4504 & 22.5 \\
\hline 532 & 5212 & 3841 & 1371 & 4526.5 & -8.5 \\
\hline 533 & 5188 & 3848 & 1340 & 4518 & -9 \\
\hline 534 & 5164 & 3854 & 1310 & 4509 & -8.5 \\
\hline 535 & 5140 & 3861 & 1279 & 4500.5 & -9 \\
\hline 536 & 5116 & 3867 & 1249 & 4491.5 & -8.5 \\
\hline 537 & 5092 & 3874 & 1218 & 4483 & -8.5 \\
\hline 538 & 5068 & 3881 & 1187 & 4474.5 & 1 \\
\hline 539 & 5063 & 3888 & 1175 & 4475.5 & 11 \\
\hline
\end{tabular}




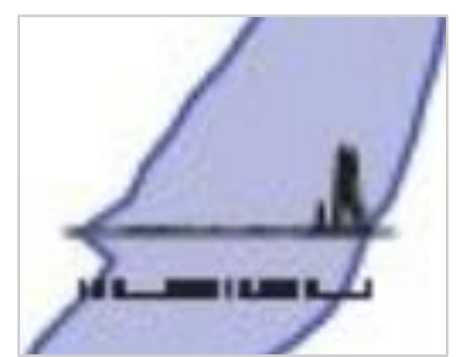

Figure 5:3: Zoomed in screenshot of the age-depth model (Fig.52(a)) around the date at $532 \mathrm{~cm}$. Showing how the age-uncertainty increases between $538-528 \mathrm{~cm}$ and produces the age reversals shown in Table 5.5.
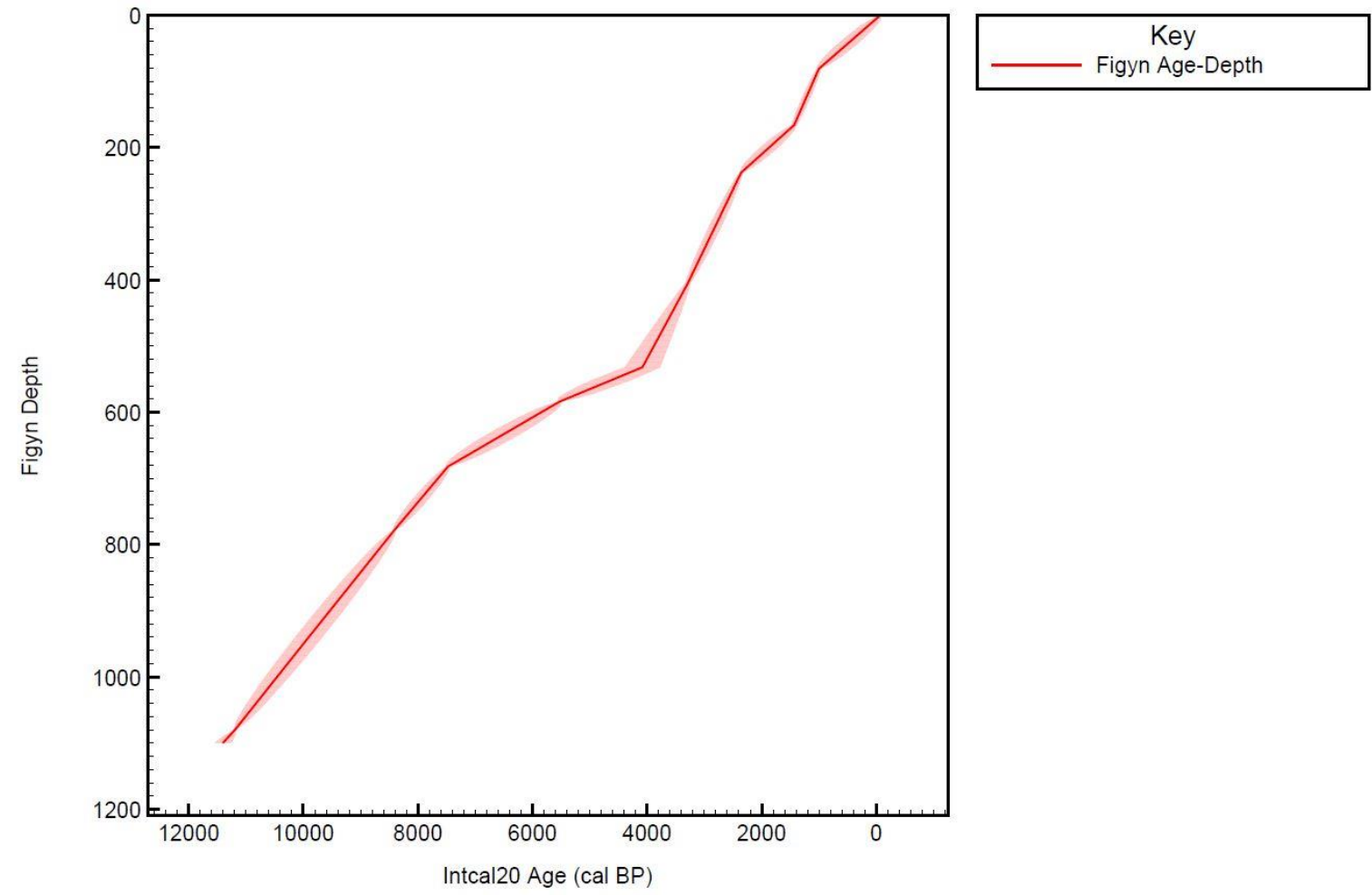

Figure 5:4: A simplified plot of the age-depth model for FG (Fig.5.2 (a)). This plot depicts the middle point (red line) that is used to assign an age to each proxy data mid- point.

The base of the clay unit (FG1) is modelled to be $c a .11450$ cal yrs. BP old (Fig.). However, the sediment chemistry implies that it was deposited in a cold environment and therefore it could be of Loch Lomond age (Fig.5.2a). The transition into a more organic silt is radiocarbon dated to the Early Holocene ca. 11270 cal yrs. BP and fen peat inception is placed at $c a .10800$ cal yrs. BP (Fig.5.2a). 


\section{3: Peat Accumulation}

Peat accumulation rates were derived using the ages in the Bayesian age-depth model. The average accumulation rate for all peat within the catotelm is $0.1 \mathrm{~cm} / \mathrm{yr}$. (Table 5.6). This is a typical peat accumulation rate for temperate peatlands (Lindsay, 2010). The rate of peat addition is $0.04 \mathrm{~cm} / \mathrm{yr}$. higher in the bog section than the fen and acrotelm rate (Table 5.6).

Table 5:6: Mean peat accumulation rates (as inferred by the Bayesian age-depth model (Fig.5:2 (a)) carbon content, carbon density and long-term carbon accumulation (LARCA and RERCA) for different core sections at FG.

\begin{tabular}{|c|c|c|}
\hline Zone & Depth (cm) & Mean accumulation rates $(\mathrm{cm} / \mathrm{yr}$.) \\
\hline Acrotelm Peat & $0-50$ & 0.08 \\
\hline Bog Catotelm Peat & $50-539$ & 0.12 \\
\hline Fen Catotelm Peat & $539-1040$ & 0.08 \\
\hline All Catotelm peat & $50-1040$ & 0.10 \\
\hline Zone & Depth (cm) & Mean carbon content (\%) \\
\hline Acrotelm Peat & $0-50$ & 55.08 \\
\hline Bog Catotelm Peat & $50-539$ & 54.84 \\
\hline Fen Catotelm Peat & $539-1040$ & 46.77 \\
\hline All Catotelm peat & $50-1040$ & 50.86 \\
\hline Zone & Depth (cm) & Mean carbon density $\left(\mathrm{g} \mathrm{cm}^{3}\right)$ \\
\hline Acrotelm Peat & $0-50$ & 0.072 \\
\hline All Catotelm peat & $50-1040$ & 0.045 \\
\hline Zone & Depth (cm) & $\begin{array}{l}\text { Average long term carbon accumulation rate } \\
\left(\mathrm{g} \mathrm{C} \mathrm{m}^{-2} \mathrm{yr}^{-1}\right)\end{array}$ \\
\hline Acrotelm Peat & $0-50$ & RERCA = 59.81 \\
\hline All Catotelm peat & $50-1040$ & LARCA $=42.55$ \\
\hline
\end{tabular}




\section{4: Carbon Accumulation}

\subsection{1: Carbon Content and Density}

To determine the rates of carbon accumulation, carbon content was calculated for every 2 $\mathrm{cm}$ using the regression equation (see methodology). The carbon content ranges from $0.03 \%$ to $56 \%$ in the full core sequence. In the peat section $(1040-0 \mathrm{~cm})$ it varies between $13-56 \%$ with an average carbon percentage of $50.86 \%$ (Table 5.6). Carbon content is higher in the bog peat zone (typically 54.84\%) compared to the fen peat section with a mean value of $46.77 \%$ (Table 5.6). However, the average carbon density is the same in both the fen and bog peat sections at $0.045 \mathrm{~g} \mathrm{~cm}^{3}$, but it is higher in the acrotelm, at $0.07 \mathrm{~g} \mathrm{~cm}^{3}$ (Table 5.6). Carbon density ranges between $0.022-0.083 \mathrm{~g} \mathrm{~cm}^{3}$ in the peat section $(1040-0 \mathrm{~cm})$. These values, along with the peat accumulation rates, feed into the long-term average, and temporal, carbon accumulation calculations.

\subsection{2: LARCA and RERCA}

An average long term carbon accumulation rate (LARCA) of $42.55 \mathrm{~g} \mathrm{C} \mathrm{m}^{-2} \mathrm{yr}^{-1}$ was calculated for the full catotelm peat section at Figyn Common (Table 5.6). This rate is high when compared with LARCA Figures from other temperate peatlands which are typically between 14-16 $\mathrm{g} \mathrm{C} \mathrm{m}^{-2} \mathrm{yr}^{-1}$ (Carless, 2015) and $16.3 \mathrm{~g} \mathrm{C} \mathrm{m}^{-2} \mathrm{yr}^{-1}$ (Ratcliffe et al., 2018). However, Anderson (2002) reports LARCA's ranging from 15-72.5 $\mathrm{g} \mathrm{C} \mathrm{m}^{-2} \mathrm{yr}^{-1}$ from three Scottish bogs.

A mean recent carbon accumulation rate (RERCA) of $59.81 \mathrm{~g} \mathrm{C} \mathrm{m}^{-2} \mathrm{yr}^{-1}$ was determined for the acrotelm peat (Table 5.6). A comparable mean RERCA for temperate peatlands has not been found because averages are not reported, but temporal recent rates of carbon presented by Young et al., (2019) for a Northern Irish and English bog, over the last $c a$. 1000 cal yrs. BP, range between 6-73 $\mathrm{g} \mathrm{C} \mathrm{m}^{-2} \mathrm{yr}^{-1}$ and 9-127 $\mathrm{g} \mathrm{C} \mathrm{m}^{-2} \mathrm{yr}^{-1}$ (respectively). 


\subsection{3: Temporal Carbon Accumulation Rates}

Temporal carbon accumulation rates (CARs) and recent carbon accumulation rates (RERCAs) are displayed in Figure 5.5. There are no calculated values between $538-528 \mathrm{~cm}$ because of the erroneous age-depth modelled ages around these depths. The missing data is represented by the grey bar in Figure 5.5. The mean CAR is $52.04 \mathrm{~g} \mathrm{C} \mathrm{m}^{-2} \mathrm{yr}^{-1}$ and these rates fluctuate between $0-145 \mathrm{~g} \mathrm{C} \mathrm{m}^{-2} \mathrm{yr}^{-1}$ in the catotelm peat (Fig.5.5).

The CAR record is characterised by lower values (typically around $15 \mathrm{~g} \mathrm{C} \mathrm{m}^{-2} \mathrm{yr}^{-1}$ ) from ca. $11420-11180$ cal yrs. BP. Between 11700 and 7490 cal yrs. BP higher CAR values of $\sim 49.46 \mathrm{~g} \mathrm{C} \mathrm{m}^{-2} \mathrm{yr}^{-1}$ are observed (Fig.5.5). However, within this period there are four notable variations: i) a short-lived carbon peak of $96.5 \mathrm{~g} \mathrm{C} \mathrm{m}^{-2} \mathrm{yr}^{-1}$ at ca.10850, ii) two small periods where no carbon accumulated ( $c a .8960$ and 8750 cal yrs. BP) and iii) a prolonged drop in carbon accumulation between $c a .8500$ to $c a .8250$ cal yrs. BP (Fig.5.5). In this longer reduction of carbon accumulation, values fall to around $32 \mathrm{~g} \mathrm{C} \mathrm{m}^{-2} \mathrm{yr}^{-1}$.

From ca.7490 - 4580 cal yrs. BP there is a sustained interval of lower, relatively stable, carbon accumulation with mean rates of $21.83 \mathrm{~g} \mathrm{C} \mathrm{m}^{-2} \mathrm{yr}^{-1}$ (Fig.5.5). This reduction in CAR is particularly pronounced between $c a$. $5670-5280 \mathrm{cal}$ yrs. BP with values as low as 10.06 $\mathrm{g} \mathrm{C} \mathrm{m}^{-2} \mathrm{yr}^{-1}$ (Fig.5.5). Between $c a .4530-3710 \mathrm{cal}$ yrs. BP CARs are higher, more variable and fluctuate between 18.51 to $54.32 \mathrm{~g} \mathrm{C} \mathrm{m}^{-2} \mathrm{yr}^{-1}$ with an average of $36.51 \mathrm{~g} \mathrm{C} \mathrm{m}^{-2} \mathrm{yr}^{-1}$. There is a short-lived peak around $c a .3650 \mathrm{cal}$ yrs. BP, and the record then displays a step change in carbon accumulation to rates of around $59 \mathrm{~g} \mathrm{C} \mathrm{m}^{-2} \mathrm{yr}^{-1}$ until ca.3170 yrs. BP (Fig.5.5). 


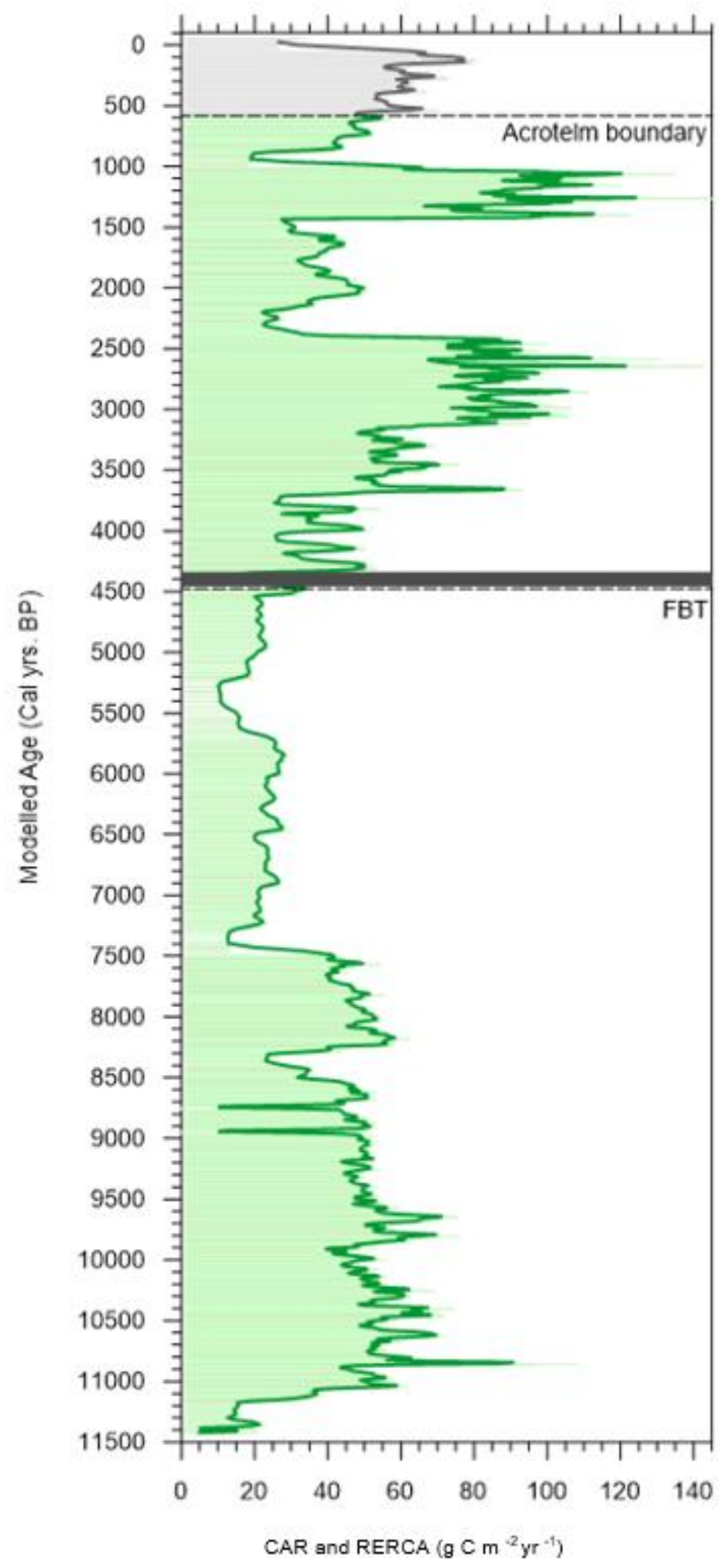

Figure 5:5: FG carbon accumulation rates (CARs) (green) and recent rates of carbon accumulation (RERCAs) (grey) with triangulated 3-point moving averages. The dark grey rectangle around ca. 4,400 cal yrs. BP indicates the missing values in the dataset between $528-538 \mathrm{~cm}$. 
Between $c a$. 3160-2420 cal yrs. BP carbon accumulates at a faster rate than the depths below and CARs fluctuate more frequently (Fig.5.5). The average CAR value for this period is $84.36 \mathrm{~g} \mathrm{C} \mathrm{m}^{-2} \mathrm{yr}^{-1}$ with some particularly high values around ca. $2650 \mathrm{cal}$ yrs. BP of 128 $142 \mathrm{~g} \mathrm{C} \mathrm{m}^{-2} \mathrm{yr}^{-1}$. This period of increased CAR is followed by a period of around 1000 years where carbon accumulation rates are lower at $50 \mathrm{~g} \mathrm{C} \mathrm{m}^{-2} \mathrm{yr}^{-1}$, until ca. $1440 \mathrm{cal} \mathrm{yrs}$. BP. There is then a 400-year period (ca. 1430-1040 cal yrs. BP) with very high CARs, averaging at $93.74 \mathrm{~g} \mathrm{C} \mathrm{m}^{-2} \mathrm{yr}^{-1}$ (Fig.5.5). Within this interval CARs are highest around $c a$. 1260 cal yrs. BP and $c a .1070$ cal yrs. BP (Fig.5.5). At the former carbon accumulation reaches the highest point in the record at $145 \mathrm{~g} \mathrm{C} \mathrm{m}^{-2} \mathrm{yr}^{-1}$ and the latter has CARs of 120 $\mathrm{g} \mathrm{C} \mathrm{m}^{-2} \mathrm{yr}^{-1}$ (Fig.5.5). At ca. 990 cal yrs. BP rates decline to $19 \mathrm{~g} \mathrm{C} \mathrm{m}^{-2} \mathrm{yr}^{-1}$ and then steadily increase towards the acrotelm boundary at ca. $580 \mathrm{cal}$ yrs. BP (Fig.5.5).

Carbon accumulation beyond the designated acrotelm boundary is expressed as temporal RERCAs (grey in Figure 5.5). The average temporal RERCA is $58.27 \mathrm{~g} \mathrm{C} \mathrm{m}^{-2} \mathrm{yr}^{-1}$ and values range from 26.46-80.46 $\mathrm{g} \mathrm{C} \mathrm{m}^{-2} \mathrm{yr}^{-1}$ (Fig.5.5). RERCAs show an overall increasing trend between $c a$. 580 to $c a .100$ cal yrs. BP up to $80.46 \mathrm{~g} \mathrm{C} \mathrm{m}^{-2} \mathrm{yr}^{-1}$ (Fig.5.5). In the most recent 100 years of the record RERCAs decline to around $30 \mathrm{~g} \mathrm{C} \mathrm{m}^{-2} \mathrm{yr}^{-1}$ (Fig.5.5).

\section{5: Humification}

\subsection{1: Light Transmission Data}

Humification analyses were only undertaken for the bog peat above $527 \mathrm{~cm}$ for reasons explained in the methodology. The average light transmission (\%) value was $48.46 \%$, and the values ranged from 28.83-74.67\% (Fig.5.6). The light transmission data demonstrates a slight increasing trend towards the top of the core (Fig.5.6). This long-term trend is likely 
the result of autogenic changes and was therefore removed via linear regression and converted into humification residuals (Fig.5.7) (Blackford and Chambers, 1995).

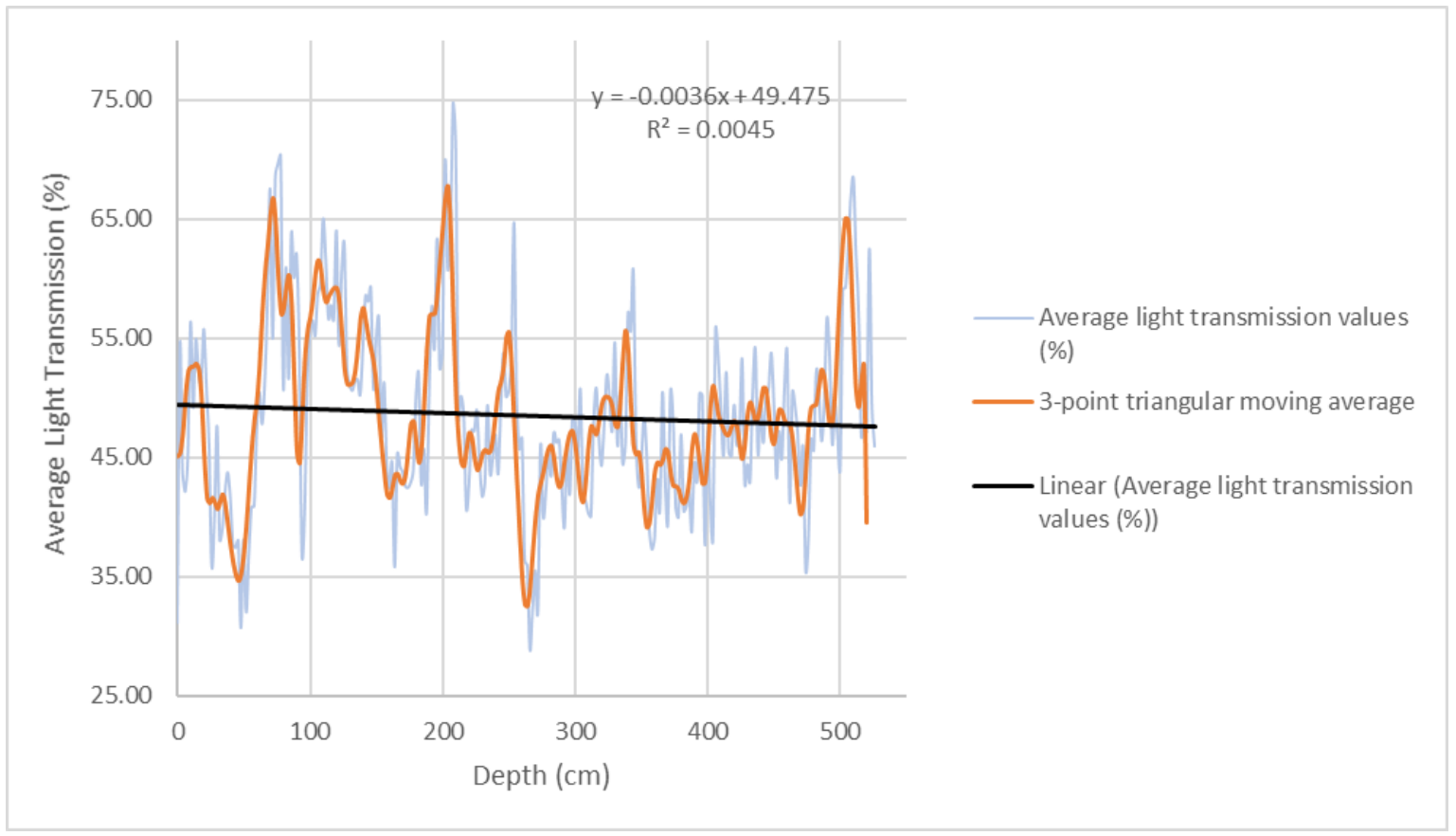

Figure 5:6: FG average light transmission data (\%) plotted against depth.

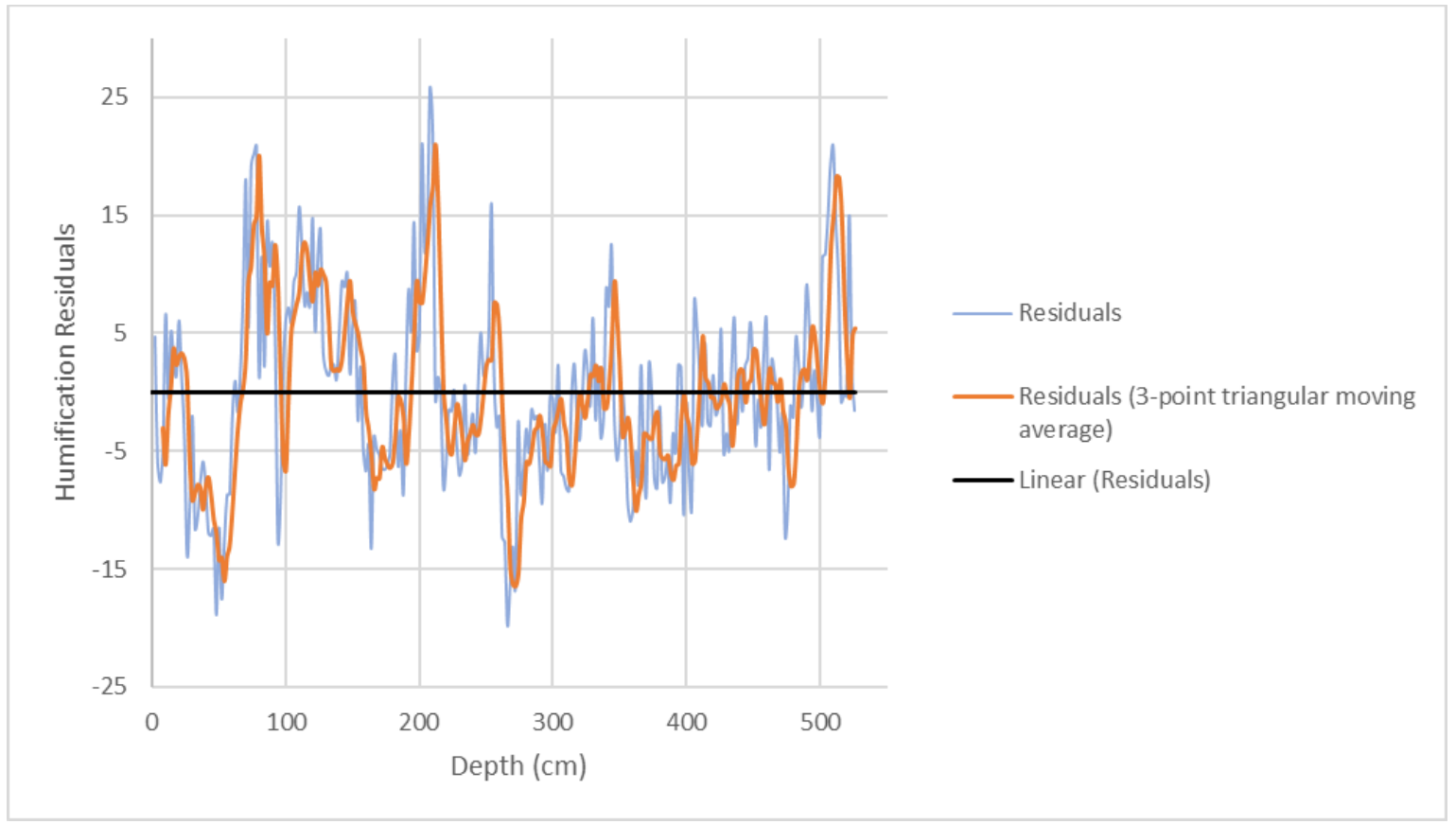

Figure 5:7: FG humification residuals plotted against depth. 


\subsection{2: Humification Residuals}

The humification residuals are plotted against modelled age to see temporal changes in wetness (Fig.5.8). These humification residuals provide qualitative information on relatively wetter or drier periods in the bog peat section (Fig.5.8). Values above zero can depict relatively wetter scenarios and values below zero indicate drier intervals. The residuals range from -19.79 to 25.83 . Here, a dry zone is identified as a period where most of the values are below zero and a wet zone is classed as an interval with most values above zero (Fig.5.8).

An interval with mostly wet residuals is observed at the base of the sequence between $c a$. 4350-3900 cal yrs. BP (Fig. 5.8). This interval is characterised by two wetter shifts, between ca. 4350-4100 cal yrs. BP, with residuals as high as 20.84 , and second smaller peak from ca. 4010-3900 cal yrs. BP (Fig.5.8).

From $c a .3890$ cal yrs. BP, until ca. 2000 cal yrs. BP the values are close to zero, with a mean of -2.43 . This indicates that between $c a$. 3890-2000 cal yrs. BP the peatland experienced comparatively drier conditions (Fig.5.8). However, there is variability within this period. There are dry shifts at $c a$. 3890-3800, 3280-2950, 2780-2490, 2400-2000 cal yrs. BP, with residuals as low as $-12.21,-10.93,-19.76,-8.08$ (respectively) (Fig.5.8). The drop to -19.76 at $c a .2490$ is the lowest point of the record. In addition to the dry shifts, there are some shorter-lived wet intervals, the most notable of which are the residual peaks at $c a$. 2,950 cal yrs. BP and ca. 2,480 cal yrs. BP to 16 (Fig.5.8).

A 250-year wet interval is then observed from $c a$. 1970-1750 cal yrs. BP, with residual values around 12 (Fig.5.8). The largest residual observed in the record of 25.83 is within this zone at $c a .1960$ cal yrs. BP. Between $c a .1730$ cal yrs. BP and $c a .1370$ cal yrs. BP there is a drier period with mean residuals of -4.53 (Fig.5.8). Above this, there is a $~ 700$ year wet shift (ca. 1360 and $c a .740$ cal yrs. BP) with residuals around 7.43 (Fig.5.8). This 
wet period is punctuated by a short-lived change to drier conditions at 1080 cal yrs. BP (Fig.5.8).

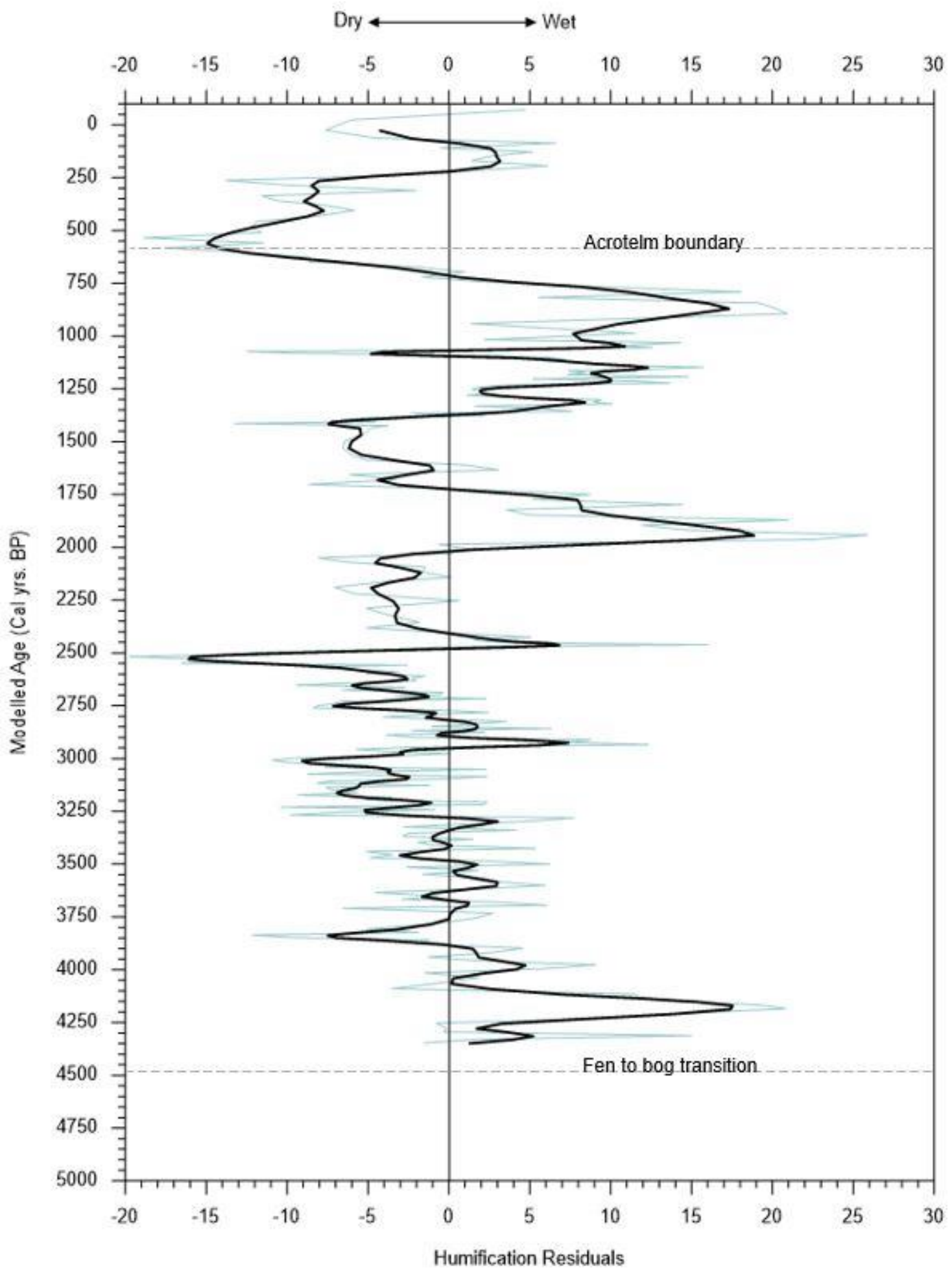

Figure 5:8: FG humification residuals and a 3-point triangulated moving average plotted against modelled age. 
Overlying this is a pronounced dry shift ( $c a$. 740-240 cal yrs. BP). Average residuals in this zone are -0.91 , and they are lowest around $c a .580$ cal yrs. BP, the designated acrotelm boundary (Fig.5.8). The uppermost zone comprises a series of 5 wetter values (between $c a$. 230-140 cal yrs. BP) and a shift into declining values around ca. 76 cal yrs. BP (Fig.5.8). The wet and dry shifts are summarised in Table 5.7.

Table 5:7: FG wet and dry shifts inferred by the humification record. SL represents short lived shifts $(<100$ years).

\begin{tabular}{|c|c|}
\hline \multicolumn{2}{|c|}{ FG Wet and Dry Shifts (cal yrs. BP) } \\
\hline Wet & Dry \\
\hline $4350-4100$ & $3890-3800(\mathrm{SL})$ \\
\hline $4010-3900$ & $3280-2950$ \\
\hline $2950-2920(\mathrm{SL})$ & $2780-2490$ \\
\hline $2480-2420(\mathrm{SL})$ & $2400-2000$ \\
\hline $1970-1750$ & $1730-1370$ \\
\hline $1360-740$ & $730-250$ \\
\hline $230-140(\mathrm{SL})$ & $76-2$ \\
\hline
\end{tabular}

\subsection{3: Comparing Humification and DHI}

The basic macrofossil results were converted in a DHI (Dupont Hydroclimatic Index), and these values are compared against the humification light transmission values to see if they depict similar wetness scenarios. A low DHI indicates a relatively wetter scenario and a high DHI suggests a drier setting. Whereas for the light transmission data it is the other way around, and a high value is wet, and a low value is dry. The DHIs and corresponding humification values are presented in Table 5.8.

Generally speaking, the DHI and humification values depict similar wetness scenarios (Table 5.8). The dry conditions depicted by the humification record are accompanied by a very high DHI. The high humification values at $120-122,208-210,512-514 \mathrm{~cm}$ have a corresponding low DHI value that is indicative of a wetter scenario. Furthermore, the mean transmission reading at $400-402 \mathrm{~cm}$ aligns well with a DHI value of 5.24 as this sits between 
the highest and lowest DHI figures produced (Table 5.8). The only anomaly is at 272-274 $\mathrm{cm}$ where the humification reading depicts a drier scenario than the DHI (Table 5.8).

Table 5:8: Humification and DHI (Dupont Hydroclimatic Index) values for selected depths. Note that a higher $\mathrm{DHI}$ value indicates a relatively drier scenario and a lower $\mathrm{DHI}$ depicts a wetter scenario. A high DHI should correspond with low humification values and a low $\mathrm{DHI}$ should be mirrored by higher humification.

\begin{tabular}{|l|l|l|}
\hline Core: FGC1 & $\begin{array}{l}\text { Humification data: } \\
\text { Mean: } 48.54 \quad \text { Range: } 74.67-28.83\end{array}$ & \\
\hline Sample Depth (cm) & Humification Value & DHI Value \\
\hline $48-50$ & Low value: 30.67 & 7.09 \\
\hline $120-122$ & High value: 64 & 3.29 \\
\hline $208-210$ & High value: 74.68 & 4.19 \\
\hline $272-274$ & Low value: 32.06 & 4.86 \\
\hline $400-402$ & Mean value: 47.14 & 5.24 \\
\hline $512-514$ & High value: 61.94 & 3.78 \\
\hline $592-594$ & $\begin{array}{l}\text { N/A (humification analyses not done in fen } \\
\text { peat) }\end{array}$ & 3.39 \\
\hline
\end{tabular}

\section{6: Charcoal Accumulation Record}

\section{5-500 $\mu m$}

The charcoal accumulation rates (CHAR) for the two size fractions are displayed in Figure 5.9. In the smaller size class $(125-500 \mu \mathrm{m})$ charcoal is detected frequently throughout the record, whereas coarser-grained charcoal particles are only observed in significant amounts in peat younger than $c a .5250$ cal yrs. BP (Fig.5.9).

Within the fine-grained fraction, the maximum charcoal shard count is 89 . The mean CHAR is 0.14 particles $\mathrm{cm}^{-2} \mathrm{yr}^{-1}$ and it ranges from $0-1.26$ particles $\mathrm{cm}^{-2} \mathrm{yr}^{-1}$. Charcoal is found first at ca. 11000 cal yrs. BP and CHAR varies temporally throughout the record (Fig.5.9). 


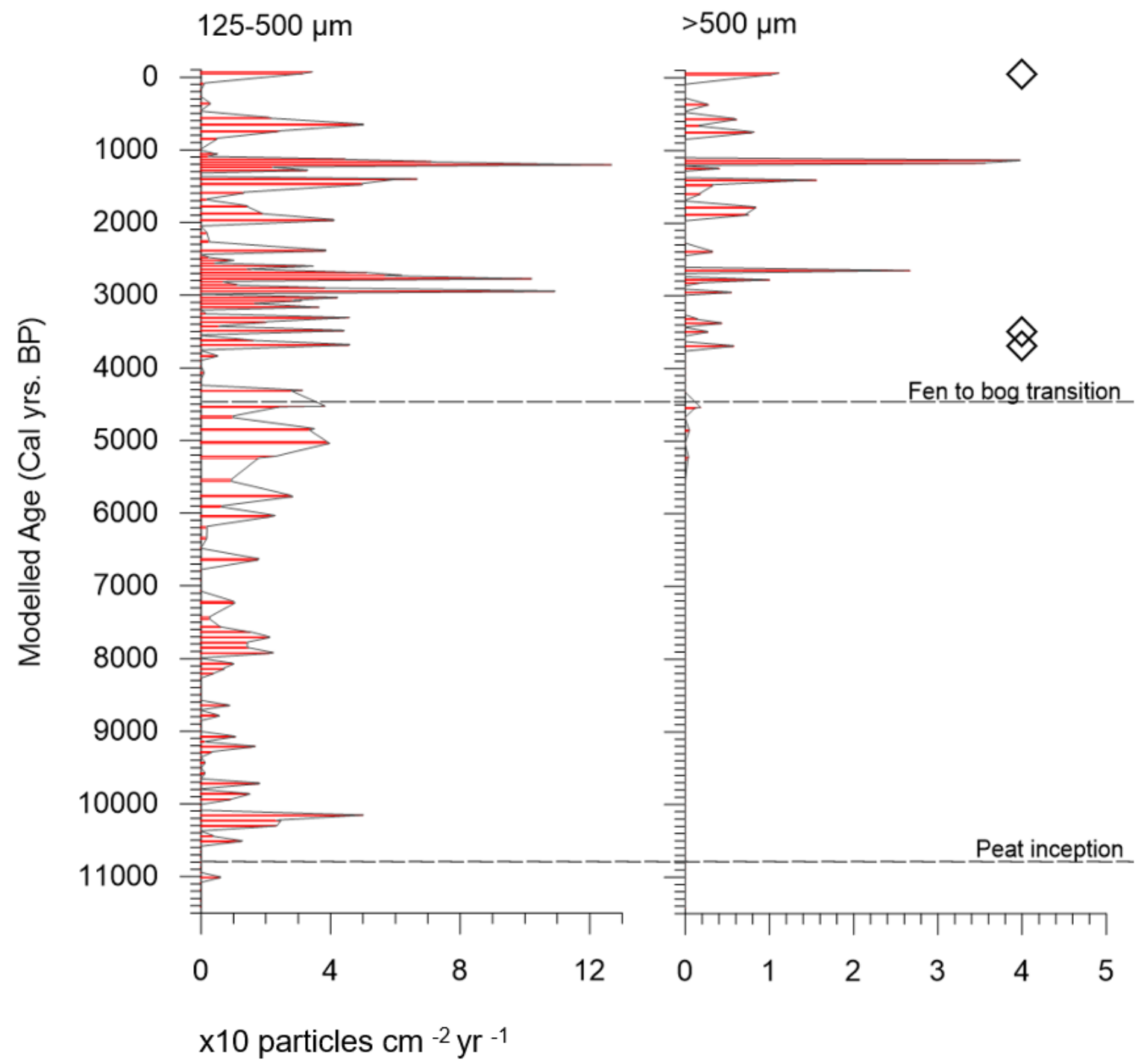

Figure 5:9: Charcoal accumulation rates (CHAR) against modelled age for the two size classes analysed. Diamond shapes show instances where charred plant remains were observed.

Between $c a$. 11020-7060 cal yrs. BP charcoal accumulation is relatively low, with values around 0.07 particles $\mathrm{cm}^{-2} \mathrm{yr}^{-1}$ (Fig.5.9). There is a notable peak in CHAR at $c a .10170 \mathrm{cal}$ yrs. BP to 0.47 particles $\mathrm{cm}^{-2} \mathrm{yr}^{-1}$ (Fig.5.9). From $\mathrm{ca}$. 6650-4070 cal yrs. BP charcoal flux is higher, around 0.13 particles $\mathrm{cm}^{-2} \mathrm{yr}^{-1}$ (Fig.5.9). Within this time period there are four distinct peaks in CHAR: at $c a .5040$ cal yrs. BP $\left(0.39\right.$ particles $\left.\mathrm{cm}^{-2} \mathrm{yr}^{-1}\right), c a .4850$ cal yrs. BP $\left(0.34\right.$ particles $\left.\mathrm{cm}^{-2} \mathrm{yr}^{-1}\right), c a .4550$ cal yrs. BP $\left(0.38\right.$ particles $\left.\mathrm{cm}^{-2} \mathrm{yr}^{-1}\right)$ and $c a .4310$ cal yrs. BP (0.31 particles $\left.\mathrm{cm}^{-2} \mathrm{yr}^{-1}\right)$. There is a reduction in CHAR from 4240-3780 cal yrs. BP (Fig.5.9). From ca. 3690-2380 cal yrs. BP CHAR is high (mean 0.24 particles 
$\mathrm{cm}^{-2} \mathrm{yr}^{-1}$ ) (Fig.5.9). There are two large peaks in the record during this interval: at $c a .2950$ cal yrs. BP and 2770 cal yrs. BP where CHAR increases to 1.09 particles $\mathrm{cm}^{-2} \mathrm{yr}^{-1}$ and 1.02 particles $\mathrm{cm}^{-2} \mathrm{yr}^{-1}$ (respectively) (Fig.5.9). From $2450 \mathrm{cal}$ yrs. BP to 1300 cal yrs. BP, charcoal fluctuates between 0.01-0.66 particles $\mathrm{cm}^{-2} \mathrm{yr}^{-1}$ (Fig.5.9). Above this (ca. 13001100 cal yrs. BP) there is a sharp increase in charcoal accumulation and the highest rate in the record (1.26 particles $\left.\mathrm{cm}^{-2} \mathrm{yr}^{-1}\right)$ is at $c a .1210 \mathrm{cal}$ yrs. BP (Fig.5.9). Within the last $c a$. 1000 years there is a peak in CHAR at $c a .660$ cal yrs. BP and at ca -70 cal yrs. BP (the uppermost sample) with rates of 0.5 and 0.33 particles $\mathrm{cm}^{-2} \mathrm{yr}^{-1}$ (Fig.5.9).

\section{$>500 \mu m$}

The CHAR counts in the $>500 \mu \mathrm{m}$ group are less frequent in this record and are of a smaller magnitude with a mean CHAR of 0.015 particles $\mathrm{cm}^{-2} \mathrm{yr}^{-1}$ and a range from 0-0.4 particles $\mathrm{cm}^{-2} \mathrm{yr}^{-1}$ (Fig.5.9). The maximum shard charcoal count was 25.

Charcoal in this size class is not detected until $c a .5250$ cal yrs. BP where there is a small peak in CHAR of 0.003 particles $\mathrm{cm}^{-2} \mathrm{yr}^{-1}$ (Fig.5.9). Above this there is another very low peak at $c a .4850 \mathrm{cal}$ yrs. BP $\left(0.004\right.$ particles $\left.\mathrm{cm}^{-2} \mathrm{yr}^{-1}\right)$ and a slightly larger peak at $c a .4530$ cal yrs. BP (0.02 particles $\left.\mathrm{cm}^{-2} \mathrm{yr}^{-1}\right)$ (Fig.5.9). These early detections correspond with some peaks in the fine-grained record e.g., at $c a .4850 \mathrm{cal}$ yrs. BP to 0.34 particles $\mathrm{cm}^{-2} \mathrm{yr}^{-1}$ (Fig.5.9). Charcoal is next detected at $c a .3,700$ cal yrs. BP (Fig.5.9). Between this time and ca. 3300 cal yrs. BP, there are four peaks in CHAR with values around 0.05 particles $\mathrm{cm}^{-2} \mathrm{yr}^{-1}$ (Fig.5.9). From $c a .2950$ cal yrs. BP to $c a .2,640$ cal yrs. BP there are three increases in carbon accumulation, the most notable is the high CHAR at ca. 2,770 cal yrs. $\mathrm{BP}$ with a value of 0.09 particles $\mathrm{cm}^{-2} \mathrm{yr}^{-1}$ (Fig.5.9). Above this there is only one interval with charcoal, around ca. 2380 cal yrs. BP until ca. 1900 cal yrs. BP (Fig.5.9). In the period from $c a$. 1900-1,050 cal yrs. BP CHAR is at its highest with a mean charcoal accumulation 
rate of 0.02 particles $\mathrm{cm}^{-2} \mathrm{yr}^{-1}$. Within this interval the largest CHAR of 0.4 particles $\mathrm{cm}^{-2} \mathrm{yr}^{-1}$

is observed at ca. $1130 \mathrm{cal}$ yrs. BP (Fig.5.9). After this interval charcoal is detected on four further occasions, at ca. 750, 650, 560 and -70 cal yrs. BP (the surface sample) (Fig.5.9). The largest of these charcoal detections is that at $c a$. -70 with 0.11 particles $\mathrm{cm}^{-2} \mathrm{yr}^{-1}$.

Charred plant remains are identified at 3 points in the record (Table 5.9). The greatest number of charred plant fragments are found at ca. $3680 \mathrm{cal} \mathrm{yrs.} \mathrm{BP} \mathrm{(Table} \mathrm{5.9).}$

Table 5:9: charred plant remains observed in the $>500 \mu \mathrm{m}$ charcoal counts

\begin{tabular}{|c|c|c|}
\hline $\begin{array}{c}\text { Charred plant } \\
\text { remains (n) }\end{array}$ & $\begin{array}{c}\text { Age (ca. cal yrs. } \\
\text { BP) }\end{array}$ & Likely species \\
\hline 1 & -70 & unknown \\
\hline 6 & 4400 & Calluna vulgaris \\
\hline 9 & 3680 & Calluna vulgaris \\
\hline
\end{tabular}

\section{7: Site Summary Figyn Common}

All of the proxy data for Figyn Common, are presented against modelled age in Figure 5.10. The base of the $15 \mathrm{~cm}$ clay unit (FG1) is modelled to be $11450 \mathrm{cal}$ yrs. BP old (Fig.5.10). However, the sediment chemistry implies that it was deposited in a cold environment and therefore it could be of Loch Lomond age (Fig.5.10). The transition into a more organic silt is radiocarbon dated to the Early Holocene ca. 11270 cal yrs. BP and fen peat inception is placed at $c a .10800$ cal yrs. BP (Fig.5.10).

The onset of fen peat is characterised by a gradual increase in OM during the first thousand years, from values of around $20 \%$ to $80 \%$ OM that stabilise thereafter (Fig.5.10). In addition to this BD decreases from $0.44 \mathrm{~g} \mathrm{~cm}^{3}$ to $0.1 \mathrm{~g} \mathrm{~cm}^{3}$ (Fig.5.10). Carbon accumulation is 
relatively low and stable in the fen zone and from ca.7490-4480 cal yrs. BP there is a sustained interval of notably lower CARs (Fig.5.10). Charcoal in the finer size class is present throughout the fen zone but in the coarser record $(>500 \mu \mathrm{m})$ charcoal is not detected until ca. $5250 \mathrm{cal}$ yrs. BP (Fig.5.10).

At the top of the fen peat there is a reduction in OM, to as low as $48 \%$ and BD increases by $0.05 \mathrm{~g} \mathrm{~cm}^{3}$ (Fig.5.10). These changes are observable for 710 years, between $c a .5190-4480$ cal yrs. BP. At the end of this period OM and C:N increase to $98 \%$ and $47 \%$ and BD drops by $0.08 \mathrm{~g} \mathrm{~cm}^{3}$ to $0.07 \mathrm{~g} \mathrm{~cm}^{3}$. This change is thought to indicate the stabilisation of a raised bog, and therefore the FBT is placed at $c a .4480( \pm 587)$ cal yrs. BP. The 710-year period of variability leading up to the transition is believed to possibly represent the development of an impermeable raised bog catotelm layer (see literature review).

Within the bog peat section, C:N, carbon accumulation, and charcoal occurrence are higher and more variable. CARs are particularly high at ca. 3160-2420 and ca. 1430-1040 cal yrs. BP (Fig.5.10). Accumulation of $125-250 \mu \mathrm{m}$ charcoal is highest at $c a .2950,2770$ and 1210 cal yrs. BP and in the coarser record $(>500 \mu \mathrm{m})$ it is greatest at $c a .2770$ and 1130 cal yrs. BP (Fig. 5.10). The bog peat wetness record is characterised by wet shifts at $c a$. 4350, 4010, 2950, 2480, 1970, 1360 and 230 cal yrs. BP. and dry shifts at ca. 3890, 3280, 2780, 2400, 1730, 730 and 76 cal yrs. BP (Fig.5.10).

The proxy synthesis demonstrates an intermittent relationship between carbon accumulation and wetness in the Late Holocene, whereby lower carbon accumulation in some instances is associated with dry shifts and higher CARs are within wetter intervals. Examples of where this association is observable include, ca. 2400 and $1400 \mathrm{cal}$ yrs. BP (Fig.5.10). In addition to this, charcoal variation also appears to be related to wetness fluctuations. This relationship is most apparent between $c a$. 3690-2600 cal yrs. BP where frequent burning is accompanied 
by a period of relatively dry residuals (Fig.5.10). The relationship between CHAR and CAR is not considered because both are based are peat accumulation rates. 


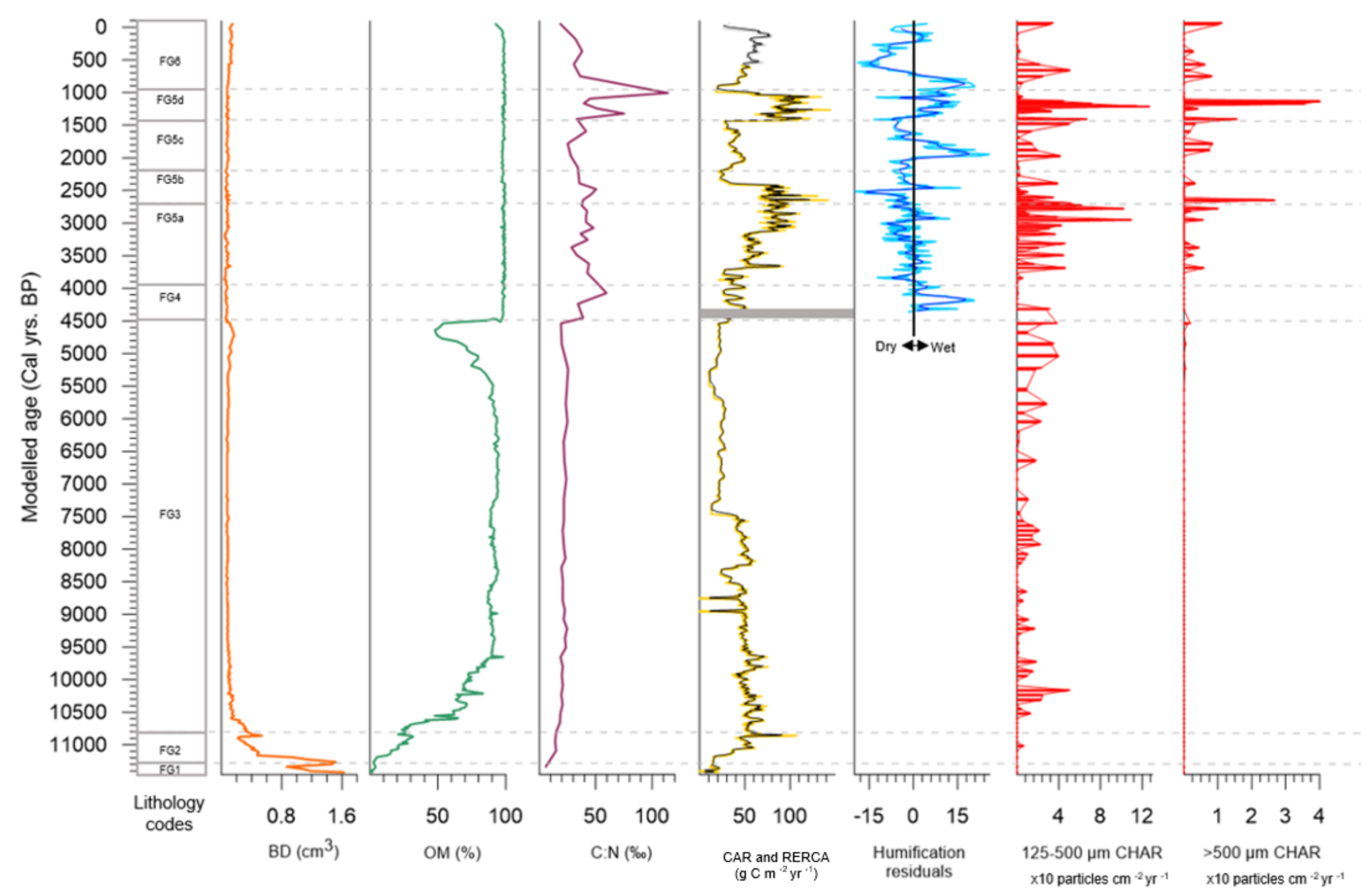

Figure 5:10: FG proxy synthesis. From left to right: FG Lithostratigraphy; Bulk Density (BD); Organic Matter (OM); carbon:nitrogen ratio (C:N); Carbon Accumulation Rate (CAR) and Recent Accumulation Rates (RERCA) above the acrotelm (the grey bar represents the missing CAR values between 538-532 $\mathrm{cm})$; Humification residuals; Charcoal accumulation rate (CHAR) for $125-500 \mu \mathrm{m}$ and $>500 \mu \mathrm{m}$. 


\section{Chapter 6: Mynydd Bach Results}

The full dataset for Mynydd Bach is available in appendix 6.

Mynydd Bach was analysed as a supplementary site. This was done because Dyfed Archaeological Trust wanted to obtain additional information about the site, to add context to its archaeology, and because it could provide supplementary information about the history of the Carmarthenshire bogs, such as the timing of peat initiation. However, there were a lack of funds available for Mynydd Bach and resultantly, it only has one basal radiocarbon date. This means that there are substantial limitations in its analysis and large age errors associated with the age-depth model (discussed in the age-depth model section below). Therefore, there is great uncertainty around the timings of the proxy reconstructions at this site.

\section{1: Lithostratigraphy and Sediment Composition Data}

A $130 \mathrm{~cm}$ core sequence was retrieved from Mynydd Bach and there was bedrock beneath this point. The lithostratigraphy and sediment composition data are presented in Figure 6.1 and Table 6.1, with basic macrofossil results to aid the description of lithological zones (Table 6.2). At the base of this sequence, a $10 \mathrm{~cm}$ unit of Substantia humosa is observed between 130-120 cm (MB1) (Fig.6.1; Table 6.1). MB1 has a mean bulk density (BD) of $0.22 \mathrm{~g} \mathrm{~cm}^{3}$, an average organic matter content $(\mathrm{OM})$ of $67.73 \%$ and a carbon:nitrogen ratio $(\mathrm{C}: \mathrm{N})$ of $23.26 \%$ (Fig.6.1; Table 6.1). This sediment is dark brown, highly humified and has a very low elasticity (Table 6.1). Basic macrofossil analysis at $128-130$ shows that $81.73 \%$ of the peat is comprised of unidentified organic matter (UOM) (Table 6.2). 
Overlying MB1 is another zone of Substantia humosa (MB2) but it is less humified and has some Turfa herbacea (herbaceous peat) (Fig.6.1; Table 6.1). At 64-66 the dominant peat components are UOM (79.93\%) and Juncus conglomeratus (17.47\%). Within MB2 the mean OM and C:N increases, to $84.39 \%$ and $32.55 \%$ (respectively) and typical BD decreases to 0.19 $\mathrm{g} \mathrm{cm}^{3}$. However, there is some variability within this zone at three instances: i) at $65 \mathrm{~cm}$ the C:N increases from around $32 \%$ to $42.92 \%$, ii) between 70-36 cm BD increases and values fluctuate around $0.03 \mathrm{~g} \mathrm{~cm}^{3}$, and iii) there is a pronounced decrease in $\mathrm{OM}$ at the top of $\mathrm{MB} 2$ (49-37 cm) where values drop as low as 65\% (Fig.6.1). 


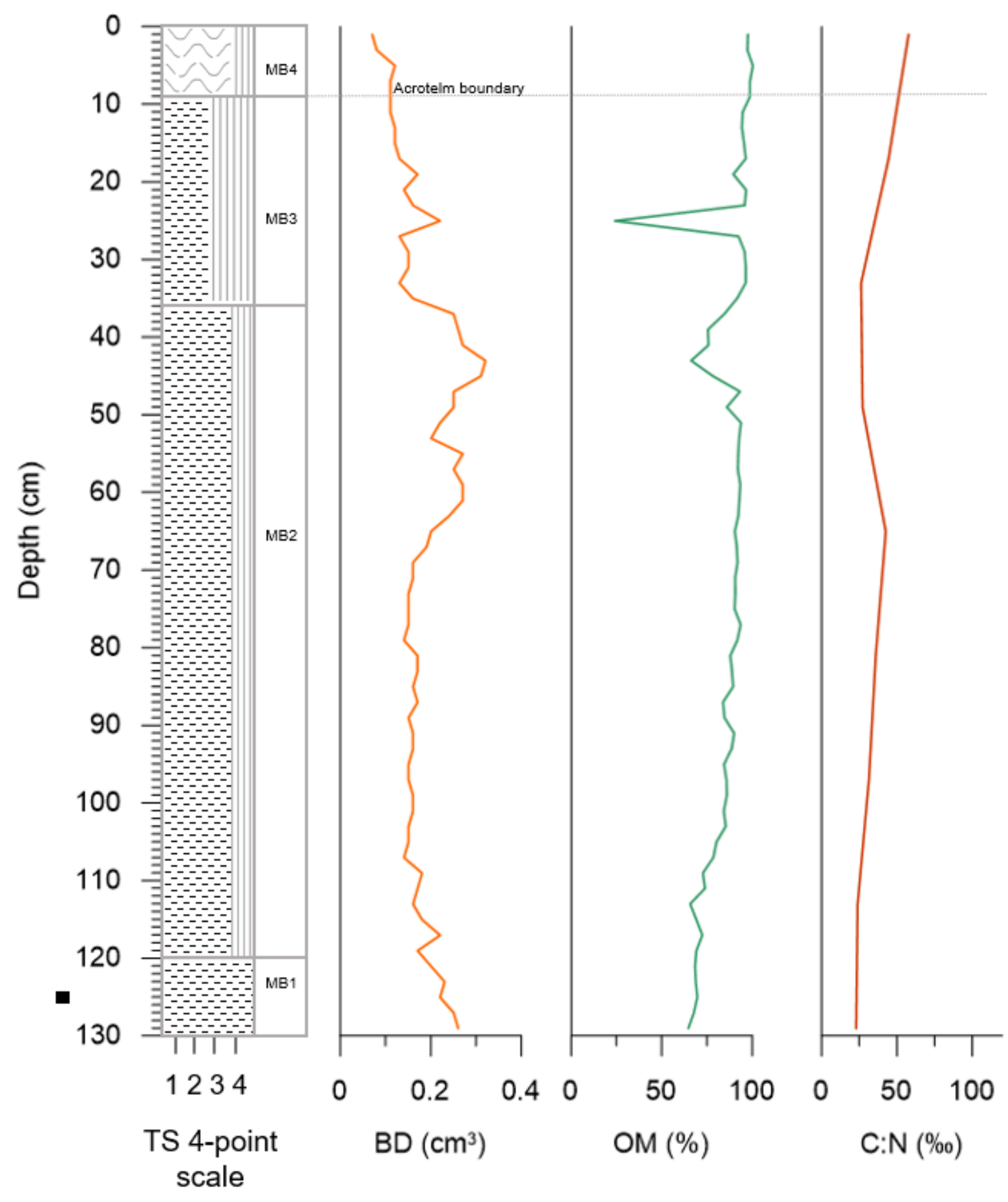

Turfa Herbacea (Herbaceous peat)

Turfa bryophytica (Sphagnum peat)

Substantia humosa
Figure 6:1: MB Lithostratigraphy from left to right: lithology, bulk density (BD), organic matter percentage $(\mathrm{OM})$ and carbon:nitrogen ratio $(\mathrm{C}: \mathrm{N})$. The Black box shows the location of the radiocarbon date. 
Above MB2 there is a Turfa herbacea/Substantia humosa deposit between $36-9 \mathrm{~cm}$ (MB3) (Fig.6.1; Table 6.1). This zone is less humified than the one below, with visible herbaceous plant remains. At $24-26 \mathrm{~cm}$ undifferentiated monocots were found to be the most dominant macrofossil (71.4\% abundant; Table 6.2). Within MB3 BD is lower $\left(0.14 \mathrm{~g} \mathrm{~cm}^{3}\right)$, and mean $\mathrm{OM}$ and $\mathrm{C}: \mathrm{N}$ are generally higher, $88.79 \%$ and $35.68 \%$ (respectively), but there is some fluctuation (Fig.6.1). At $25 \mathrm{~cm}$ a short-lived decrease is evident in OM and C:N displays an increasing trend from $32 \mathrm{~cm}$ towards the surface (Fig.6.1).

The uppermost zone (MB4) is identified from 9-0 cm (Fig.6.1; Table 6.1). This unit is distinct from the underlying unit and is comprised of non-humified, densely packed Sphagnum and herbaceous rootlets and is very spongy and relatively light in colour. This visual assessment was supported by macrofossil analyses from the surface sample $(0-2 \mathrm{~cm})$ that contained $62.07 \%$ Sphagnum and $24.87 \%$ Eriophorum vaginatum (Table 6.2 ). In this unit mean OM is $\sim 10 \%$ higher, $\mathrm{C}: \mathrm{N}$ increases by more than $20 \%$ and BD falls to $0.10 \mathrm{~g} \mathrm{~cm}^{3}$ (Fig.6.1; Table 6.1). The nature of this zone aligns well with what would be expected for the acrotelm zone i.e., lower BD and freshly accumulated Sphagnum (Lindsay, 2010; Clymo, 1983) and therefore the base of MB4 was set as the acrotelm boundary (Fig.6.1).

The fen to bog transition was not apparent at Mynydd Bach. For the lowermost $121 \mathrm{~cm}$ of the core sequence the sediment characteristics, highly humified Substantia humosa, C:N between $\sim 30 \%$, and $\mathrm{OM} \%$ values around $85 \%$, are characteristic of a poor fen environment (Lindsay et al., 2014; Rydin and Jeglum, 2006; Succow and Joosten, 2001). 
Table 6:1: Lithostratigraphy for Figyn Common described using the Troels-Smith System (1955) (as outlined in Birks and Birks (1980)) and mean bulk density (BD), organic matter (OM), and carbon:nitrogen ratio (C:N) for each unit. Th= Turfa Herbacea (Herbaceous peat), Tb = Turfa bryophytica (Sphagnum peat), Ti $=$ Turfa lignosa (Wood peat), $\mathrm{Sh}=$ Substantia humosa, $\mathrm{Ag}=$ Argilla granosa (Silt), As= Argilla steatodes (Clay). The superscript numbers next to the dominant sediment type represent the degree of humification, with 4 being the most humified. Nig= darkness, sicc $=$ dryness, Elas $=$ Elasticity, Strf $=$ Stratification.

\begin{tabular}{|c|c|c|c|c|c|}
\hline Depth (cm) & Troels-Smith description & $\begin{array}{l}\text { Lithology zone } \\
\text { codes }\end{array}$ & Mean BD $\left(\mathrm{g} \mathrm{cm}^{3}\right)$ & Mean OM (\%) & Mean C: $\mathrm{N}$ ratio $(\%)$ \\
\hline $0-9$ & $\begin{array}{c}\mathrm{Tb}^{0}, \text { Th1 } \\
\mathrm{Nig}=1.5 ; \text { Strf }=0 ; \text { Elas }=4 ; \text { Sicc }=2\end{array}$ & MB4 & 0.10 & 98.13 & 57.99 \\
\hline 9-36 & $\begin{array}{c}\mathrm{Th}^{2}, \mathrm{Sh} 2, \mathrm{Ti}+ \\
\mathrm{Nig}=2.5 ; \mathrm{Strf}=0 ; \text { Elas=2; Sicc=3 }\end{array}$ & MB3 & 0.14 & 88.79 & 35.68 \\
\hline $36-120$ & $\begin{array}{c}\mathrm{Sh}^{3}, \mathrm{Th} 1,+\mathrm{Tb},+\mathrm{Ti} \\
\mathrm{Nig}=3 ; \text { Strf=0; Elas=0; Sicc=3 }\end{array}$ & MB2 & 0.19 & 84.39 & 32.55 \\
\hline $120-130$ & $\begin{array}{c}\mathrm{Sh}^{4},+\mathrm{Tb},+\mathrm{Th} \\
\mathrm{Nig}=3.5 ; \mathrm{Strf}=0 ; \text { Elas=0; Sicc=3 }\end{array}$ & MB1 & 0.22 & 67.73 & 23.26 \\
\hline
\end{tabular}

Table 6:2: Basic macrofossil analysis results for selected depths at Mynydd Bach. The species abundance/peat components (\%) are averaged over 15 quadrat counts for each sample (see methodology).

\begin{tabular}{|c|c|c|c|c|c|c|c|c|c|c|c|c|}
\hline \multirow{2}{*}{$\begin{array}{l}\text { Depth } \\
\text { (cm) }\end{array}$} & \multirow{2}{*}{$\begin{array}{l}\text { Lithology } \\
\text { zone }\end{array}$} & \multicolumn{11}{|c|}{ Peat Components (\%) } \\
\hline & & $\begin{array}{c}\text { Eriophorum } \\
\text { vaginatum }\end{array}$ & Sphagnum & $\begin{array}{c}\text { Aulacomnium } \\
\text { palustre }\end{array}$ & $\begin{array}{l}\text { Other } \\
\text { moss } \\
\text { undiff. }\end{array}$ & $\begin{array}{c}\text { Juncus } \\
\text { conglomeratus }\end{array}$ & $\begin{array}{c}\text { Betula } \\
\text { nana }\end{array}$ & Wood & $\begin{array}{l}\text { Monocot } \\
\text { Undiff. }\end{array}$ & $\begin{array}{c}\text { Mineral } \\
\text { Fragments }\end{array}$ & UOM & $\begin{array}{l}\text { Seeds and } \\
\text { other }\end{array}$ \\
\hline $0-2$ & MB1 & 24.87 & 62.07 & 7.87 & & & & & & & 5.20 & $\begin{array}{l}\text { Eriophorum } \\
\text { fruit: } 1 \\
\text { Acari } \\
\text { Oribatida: } 8\end{array}$ \\
\hline
\end{tabular}




\begin{tabular}{|l|c|c|c|c|c|c|c|c|c|c|c|}
\hline 24-26 & MB2 & & & & 7.80 & & & 0.8 & 71.4 & \multicolumn{1}{|c|}{$\begin{array}{l}\text { Juncus } \\
\text { conglomeratus } \\
\text { seed: } 14\end{array}$} \\
\hline $64-66$ & MB3 & & 2 & & & 17.47 & & 0.6 & & $\begin{array}{l}79.93 \\
\text { Juncus } \\
\text { conglomeratus } \\
\text { seed: } 24\end{array}$ \\
\hline $128-130$ & MB4 & & 4.47 & & & 1.87 & 5.13 & & $\begin{array}{l}\text { Juncus } \\
\text { conglomeratus } \\
\text { seed: } 131\end{array}$ \\
\hline
\end{tabular}

Table 6:3: Radiocarbon result for Mynydd Bach: Rationale for sample selection; the sample type dated; laboratory code; radiocarbon age; calibrated age. The radiocarbon age (BP) was calibrated to calibrated years (BP) on Oxcal v4.42, 2020 (Bronk Ramsey, 2009a) using the Intcal20 calibration curve (Reimer et al., 2020).

\begin{tabular}{|c|c|c|c|c|c|c|}
\hline Depth (cm) & Justification & $\begin{array}{c}\text { Sample type } \\
\text { dated }\end{array}$ & Laboratory code & $\begin{array}{c}\text { Radiocarbon } \\
\text { Age BP }\end{array}$ & $\begin{array}{c}\text { calibrated Age Range (cal yrs. } \\
\text { BP) } \\
(2 \sigma(95.4 \% \text { probability }))\end{array}$ & $\begin{array}{c}\text { Range } \\
\text { (cal yrs. BP) }\end{array}$ \\
\hline 125 & To get an age close to the base of the core & $\begin{array}{l}\text { Humic acid } \\
\text { fraction }\end{array}$ & $\begin{array}{c}\text { SUERC-87432 } \\
\text { (GU51721) }\end{array}$ & $6850 \pm 30$ & $7750-7610$ & 140 \\
\hline
\end{tabular}




\section{2: Chronology}

\subsection{1: Radiocarbon Dating and Age-depth Model}

One radiocarbon date was obtained at Mynydd Bach at a depth of $125 \mathrm{~cm}$ to chronologically constrain the base of the sequence (Table 6.3). Funds were not available for additional dates. The material dated and the radiocarbon and calibrated age range are displayed in Table 6.3. The calibrated age for $125 \mathrm{~cm}$ has a range of 140 years and is dated to $7750-7610 \mathrm{cal} \mathrm{yrs}$. BP at a $95.4 \%(2 \sigma)$ probability.

This date was used to construct a simple Bayesian age-depth model that produces a date for each centimeter in the $130 \mathrm{~cm}$ core sequence (Fig.6.2). The mean modelled age range is 405 years between $130-125 \mathrm{~cm}$ and the age range increases to an average of 1780 years between $125-0 \mathrm{~cm}$ (Fig.6.2). The age uncertainty is large because the model is only constrained by one radiocarbon date.

The mid-points of the model age range (as shown in Figure 6.3) are used to give a date to each centimeter and the ages are rounded to the nearest ten when reported in the text. The proxies, that were taken at a $2 \mathrm{~cm}$ contiguous resolution, are plotted against the mid-point of the sampled depth and a carbon and charcoal flux value are given for each centimeter within that depth increment (see methodology).

The age depth model implies that peat sedimentation began in the Middle Holocene at $c a .7960$ $( \pm 333)$ cal yrs. BP. Furthermore, the transition into a less humified peat (MB2) is dated to $c a$. $7340( \pm 360)$ and the base of MB3 is placed at $2170( \pm 1011)$ cal yrs. BP. 


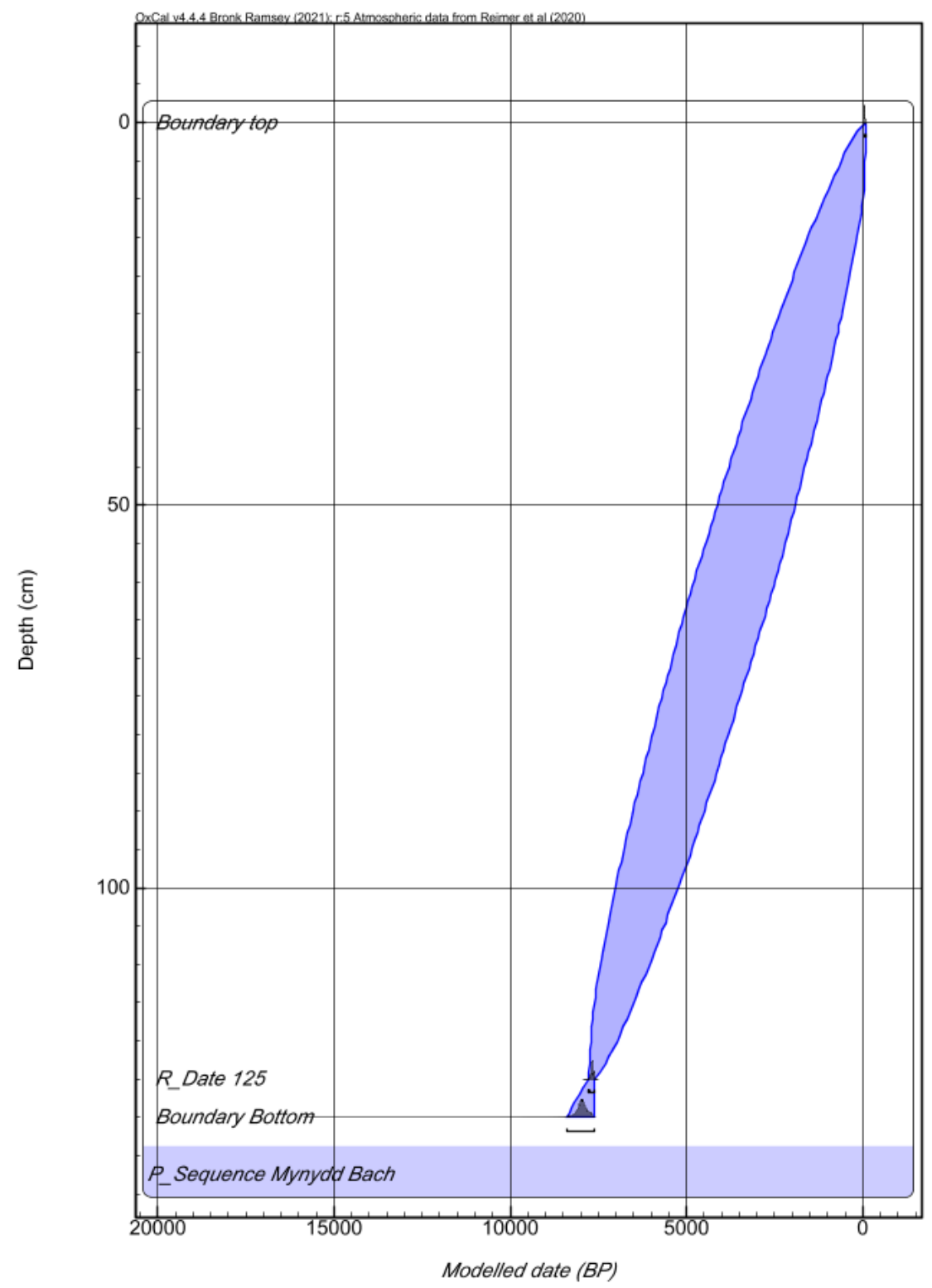

Figure 6:2: Bayesian age-depth model with modelled ages at a $95.4 \%$ probability against depth. Constructed on Oxcal v4.42, 2020 (Bronk Ramsey, 2009a) using the Intcal20 calibration curve (Reimer et al., 2020). 


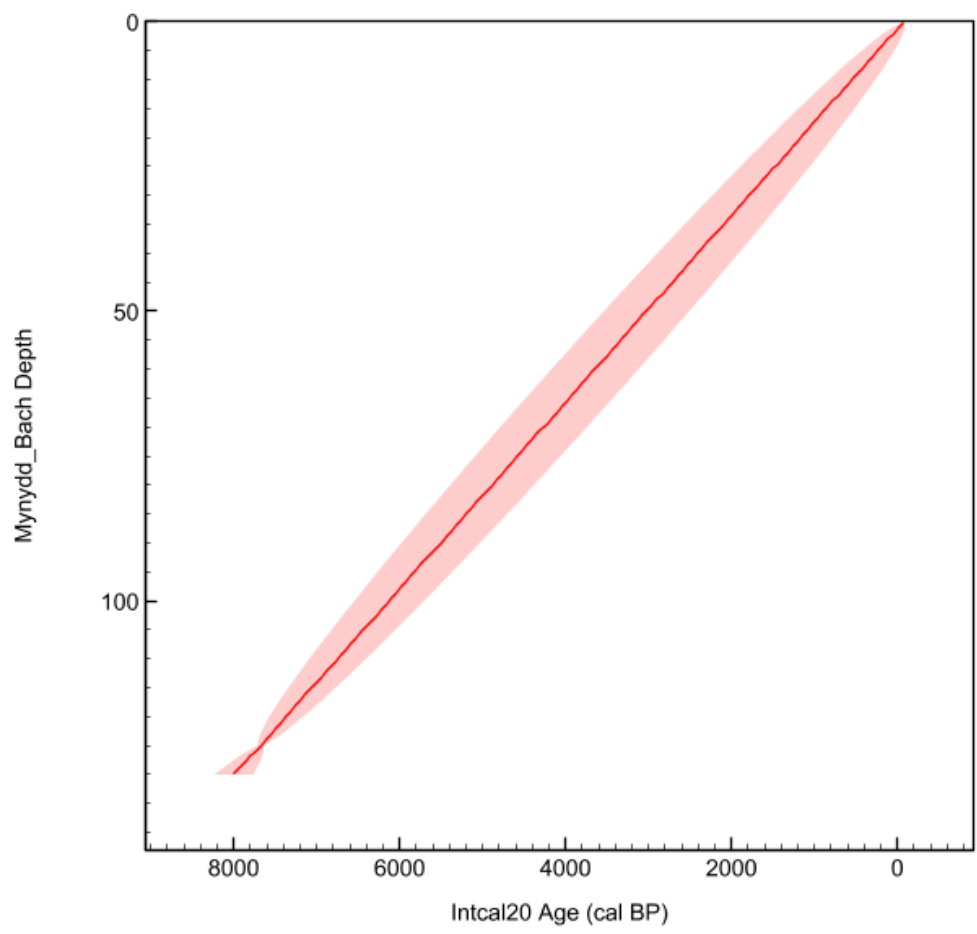

Figure 6:3: A simplified plot of the age-depth model for Mynydd Bach (Fig.2). This plot depicts the middle point (red line) that is used to assign an age to each proxy data mid-point.

\section{3: Peat Accumulation}

The mean rate of peat accumulation is the same in the catotelm and acrotelm zones (Table 6.4). This is unusual as higher peat accumulation rates are typically observed in the acrotelm peat (Clymo, 1983).

\section{4: Carbon Accumulation}

\subsection{1: Carbon Content and Density}

To determine the carbon accumulation rate, carbon content was calculated every $2 \mathrm{~cm}$ using the regression equation (see methodology chapter). The carbon content ranges from $12.36 \%$ to $51.97 \%$. Mean carbon content is higher for the acrotelm, at $51.01 \%$, than the catotelm with a carbon content of $43.65 \%$ (Table 6.4). The mean carbon density in the catotelm peat is $0.08 \mathrm{~g}$ 
$\mathrm{cm}^{3}$ and it is $0.05 \mathrm{~g} \mathrm{~cm}^{3}$ for the acrotelm (Table 6.4). These values, along with the peat accumulation rates, feed into the long term and temporal carbon accumulation calculations (Table 4).

Table 6:4: Mean peat accumulation rates (as inferred by the Bayesian age-depth model (Fig.5:2 (a)) carbon content, carbon density and long-term carbon accumulation (LARCA and RERCA) for different core sections at MB.

\begin{tabular}{|l|l|l|}
\hline Zone & Depth (cm) & Mean accumulation rate (cm/yr.) \\
\hline Acrotelm peat & $0-9$ & 0.02 \\
\hline Catotelm peat & $9-130$ & 0.02 \\
\hline Zone & Depth (cm) & Mean carbon content (\%) \\
\hline Acrotelm peat & $0-9$ & 51.01 \\
\hline Catotelm peat & $9-130$ & 43.65 \\
\hline Zone & Depth (cm) & Mean carbon density (g cm $\left.{ }^{3}\right)$ \\
\hline Acrotelm peat & $0-9$ & 0.05 \\
\hline Catotelm peat & $0-130$ & 0.08 \\
\hline Zone & Depth (cm) & $\begin{array}{l}\text { Average long term carbon accumulation rate } \\
\left(\mathbf{g ~ C ~} \mathbf{m}^{-2} \mathbf{y r}^{-1} \text { ) }\right.\end{array}$ \\
\hline Acrotelm peat & $0-09$ & RERCA = 9.12 \\
\hline Catotelm peat & $0-130$ & LARCA $=13.09$ \\
\hline & &
\end{tabular}

\subsection{2: LARCA and RERCA}

An average long term carbon accumulation rate (LARCA) of $13.09 \mathrm{~g} \mathrm{C} \mathrm{m}^{-2} \mathrm{yr}^{-1}$ was calculated for the full catotelm peat section at Mynydd Bach (Table 6.4). This sits at the lower end of some rates reported in the literature with temperate LARCA values of $14-16 \mathrm{~g} \mathrm{C} \mathrm{m}^{-2} \mathrm{yr}^{-1}$ (Carless, 2015), $16.3 \mathrm{~g} \mathrm{C} \mathrm{m}^{-2} \mathrm{yr}^{-1}$ (Ratcliffe et al., 2018) and 15-72.5 $\mathrm{g} \mathrm{C} \mathrm{m}^{-2} \mathrm{yr}^{-1}$ (Anderson, 2002). 
A mean recent carbon accumulation rate (RERCA) of $9.12 \mathrm{~g} \mathrm{C} \mathrm{m}^{-2} \mathrm{yr}^{-1}$ was determined for the acrotelm peat (Table 6.4). A similar mean RERCA from a temperate region was not found in the literature, but this Figure is much lower than temporal RERCA's reported by Young et al., (2019) over the last ca. $1000 \mathrm{cal}$ yrs. BP, that range between 6-73 $\mathrm{g} \mathrm{C} \mathrm{m}^{-2} \mathrm{yr}^{-1}$ and 9-127 $\mathrm{g} \mathrm{C} \mathrm{m}^{-2} \mathrm{yr}^{-1}$ (for a Northern Irish and English bog (respectively)) and by Ratcliffe et al., (2018) who display recent CARs between $20-40 \mathrm{~g} \mathrm{C} \mathrm{m}^{-2} \mathrm{yr}^{-1}$.

\subsection{3: Temporal Carbon Accumulation Rates}

The temporal accumulation rates (CARs) for Mynydd Bach are displayed in Figure 6.4. Rates of accumulation in the acrotelm are presented separately as temporal RERCAs (grey in Fig.6.4). CARs range from $4.11 \mathrm{~g} \mathrm{C} \mathrm{m}^{-2} \mathrm{yr}^{-1}$ to $22.62 \mathrm{~g} \mathrm{C} \mathrm{m}^{-2} \mathrm{yr}^{-1}$ and the mean CAR is 12.99 $\mathrm{g} \mathrm{C} \mathrm{m}^{-2} \mathrm{yr}^{-1}$ (Fig.6.4).

Between ca. 7960-4330 cal yrs. BP CARs are typically around $11.37 \mathrm{~g} \mathrm{C} \mathrm{m}^{-2} \mathrm{yr}^{-1}$ with slightly higher carbon accumulation in the first 100 years of the record $\left(\sim 14 \mathrm{~g} \mathrm{C} \mathrm{m}^{-2} \mathrm{yr}^{-1}\right)$ and at $c a$. 7180 cal yrs. BP ( $\left.15 \mathrm{~g} \mathrm{C} \mathrm{m}^{-2} \mathrm{yr}^{-1}\right)$ (Fig.6.4). From $c a .4270$ cal yrs. BP CARs display an increasing trend and there is a step change to higher values around $20 \mathrm{~g} \mathrm{C} \mathrm{m}^{-2} \mathrm{yr}^{-1}$ at $c a .3840$ cal yrs. BP (Fig.6.4). This increase to larger CARs is observable until $c a .2170$ cal yrs. BP but is punctuated by a period of lower carbon accumulation (typically $16 \mathrm{~g} \mathrm{C} \mathrm{m}^{-2} \mathrm{yr}^{-1}$ ) between ca. 3210-3090 cal yrs. BP (Fig.6.4). At ca. 3000 cal yrs. BP carbon accumulation falls to an average of $10 \mathrm{~g} \mathrm{C} \mathrm{m}^{-2} \mathrm{yr}^{-1}$ (Fig.6.4). Such rates are present until ca. $1550 \mathrm{cal}$ yrs. BP. CARs then decrease to $\sim 4 \mathrm{~g} \mathrm{C} \mathrm{m}^{-2} \mathrm{yr}^{-1}$ for 66 years (Fig.6.4). Between $c a .1360-990$ cal yrs. BP the mean rate of carbon accumulation is $12.14 \mathrm{~g} \mathrm{C} \mathrm{m}^{-2} \mathrm{yr}^{-1}$ and it decreases to typical values of 9 $\mathrm{g} \mathrm{C} \mathrm{m}^{-2} \mathrm{yr}^{-1}$ from $c a .920$ cal yrs. BP to $c a .490$ cal yrs. BP (Fig.6.4). 
Temporal RERCAs (grey in Fig.6.4) range from $3.50 \mathrm{~g} \mathrm{C} \mathrm{m}^{-2} \mathrm{yr}^{-1}$ to $12.59 \mathrm{~g} \mathrm{C} \mathrm{m}^{-2} \mathrm{yr}^{-1}$ and they average at $8.65 \mathrm{~g} \mathrm{C} \mathrm{m}^{-2} \mathrm{yr}^{-1}$ in peat younger than $500 \mathrm{cal}$ yrs. BP (Fig.6.4). This recent record is characterised by an increasing trend for the first 200 years, from rates of 8.4 $\mathrm{g} \mathrm{C} \mathrm{m}^{-2} \mathrm{yr}^{-1}$ to $12.35 \mathrm{~g} \mathrm{C} \mathrm{m}^{-2} \mathrm{yr}^{-1}$, and a reduction from $c a$. 162 cal yrs. BP to 3.5 $\mathrm{g} \mathrm{C} \mathrm{m}^{-2} \mathrm{yr}^{-1}$ at the surface (Fig.6.4).

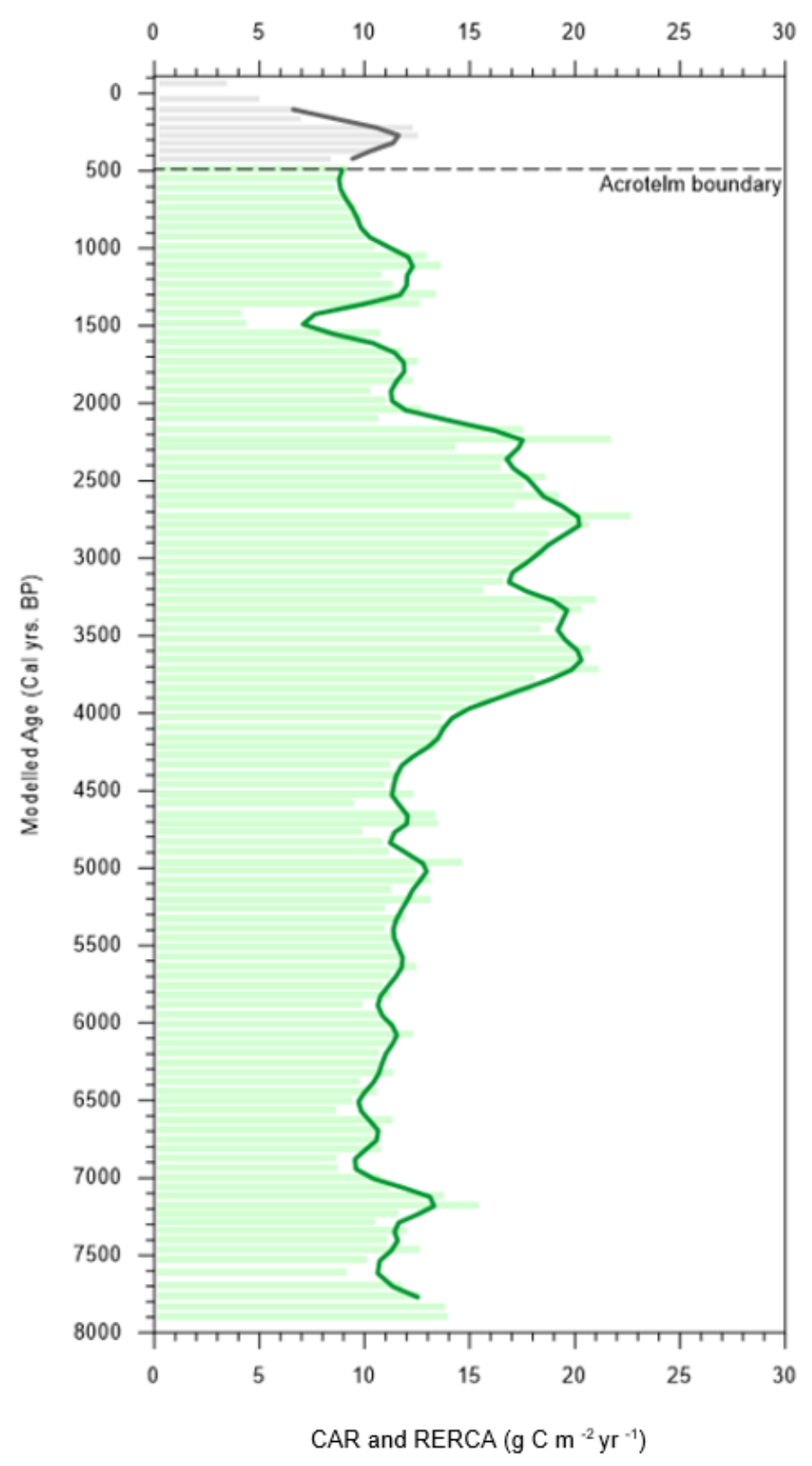

Figure 6:4: MB carbon accumulation rates (CARs) (green) and Recent Rates of carbon accumulation (RERCAs) (grey) with triangulated 3-point moving averages. 


\section{5: Charcoal Accumulation Record}

The charcoal accumulation records for both size classes analysed, 125-500 $\mu \mathrm{m}$ and $>500 \mu \mathrm{m}$ are displayed in Figure 6. The charcoal shard counts were low at MB when compared to the PC and FG. The maximum shard count in the finer size class was 139 and in the coarser charcoal group (>500 $\mu \mathrm{m})$ it was 32 .

\section{5-500 $\mu m$}

In the $125-500 \mu \mathrm{m}$ record charcoal accumulation (CHAR) ranges between 0-0.23 particles $\mathrm{cm}^{-2} \mathrm{yr}^{-1}$ and the mean CHAR is 0.05 particles $\mathrm{cm}^{-2} \mathrm{yr}^{-1}$ (Fig.6.5). Charcoal is present throughout the record and at ca. $7900 \mathrm{cal}$ yrs. BP CHAR is 0.05 particles $\mathrm{cm}^{-2} \mathrm{yr}^{-1}$. Above here it ranges between 0.02-0.03 particles $\mathrm{cm}^{-2} \mathrm{yr}^{-1}$ until ca. $5880 \mathrm{cal}$ yrs. BP (Fig.6.5). At ca. 5390 cal yrs. BP, it increases to 0.085 particles $\mathrm{cm}^{-2} \mathrm{yr}^{-1}$ at and between $c a .4400-3330$ cal yrs. BP it is more stable, typically 0.06 particles $\mathrm{cm}^{-2} \mathrm{yr}^{-1}$ (Fig.6.5).

There is a shift to larger values at $c a .2910$ cal yrs. BP and here charcoal accumulation is 0.13 particles $\mathrm{cm}^{-2} \mathrm{yr}^{-1}$ (Fig.6.5). Above this, a bigger peak is observed at ca. $2350 \mathrm{cal}$ yrs. BP, of 0.23 particles $\mathrm{cm}^{-2} \mathrm{yr}^{-1}$ the highest CHAR in the record (Fig.6.5). The upper part of the sequence is characterised by a small charcoal flux $\left(0.003\right.$ particles $\left.\mathrm{cm}^{-2} \mathrm{yr}^{-1}\right)$ at $c a .1360 \mathrm{cal}$ yrs. BP and a peak of 0.09 particles $\mathrm{cm}^{-2} \mathrm{yr}^{-1}$ at $c a .920$ cal yrs. BP (Fig.6.5).

\section{$500 \mu m$}

In this larger size group charcoal accumulation is lower, and ranges between 0-0.05 particles $\mathrm{cm}^{-2} \mathrm{yr}^{-1}$ with an average CHAR of 0.007 particles $\mathrm{cm}^{-2} \mathrm{yr}^{-1}$ (Fig.6.5).

At the start of this record (ca. 7900-7280 cal yrs. BP) CHAR is between 0.004-0.003 particles $\mathrm{cm}^{-2} \mathrm{yr}^{-1}$ and is higher at $6810 \mathrm{cal} \mathrm{yrs} \mathrm{BP}\left(\sim 0.08\right.$ particles $\left.\mathrm{cm}^{-2} \mathrm{yr}^{-1}\right)$ (Fig.6.5). Between 6500 and 2410 cal yrs BP, charcoal is only detected at two levels: at ca. 5390 cal yrs. BP (0.01 
particles $\left.\mathrm{cm}^{-2} \mathrm{yr}^{-1}\right)$ and at $c a .4400$ cal yrs. BP (0.065 particles $\left.\mathrm{cm}^{-2} \mathrm{yr}^{-1}\right)$ (Fig.6.5). Above these levels, charcoal is not observed until $c a$. 2410 at an influx rate of 0.01 particles $\mathrm{cm}^{-2} \mathrm{yr}^{-1}$ (Fig.6.5). High rates of charcoal accumulation are observed between $c a$. 1420-1360 cal yrs. BP, where CHAR reaches 0.05 particles $\mathrm{cm}^{-2} \mathrm{yr}^{-1}$ (the highest point in this record) and at ca. 920 cal yrs. BP with a rate of 0.02 particles $\mathrm{cm}^{-2} \mathrm{yr}^{-1}$ (Fig.6.5).

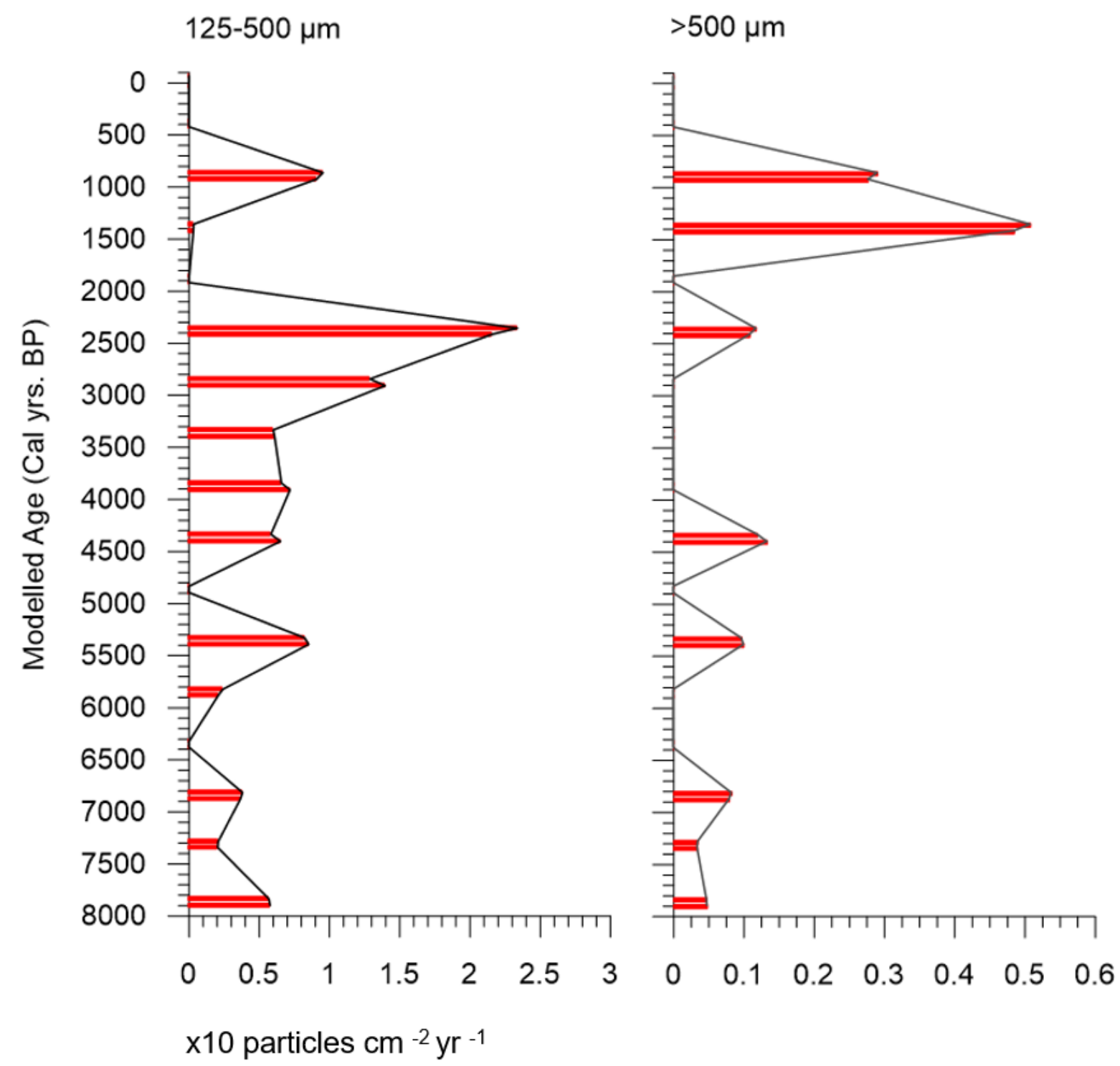

Figure 6:5: MB charcoal accumulation rates (CHAR) against modelled age for the two size classes analysed, $125-500 \mu \mathrm{m}$ and $>500 \mu \mathrm{m}$. 


\section{6: Site Summary Mynydd Bach}

The lithology and proxy data for Mynydd Bach are plotted against modelled age in Figure 6.6. The age-depth model places the start of sedimentation in the Middle Holocene at ca. 7960 ( \pm 333) cal yrs. BP and the base of MB2, and the start of the gradual increase in OM, is dated at ca. $7340( \pm 360)$ cal yrs. BP. Carbon accumulation is relatively low and stable between $c a$. 7960-4330 cal yrs. BP and is highest in the Late Holocene (ca. 4270-2160 cal yrs. BP). This higher carbon accumulation rate is coupled with increased BD (Fig.6.6). After ca. 2170 cal yrs. BP, CARs decline. This decline coincides with a general reduction in BD towards the peat surface. Except at $c a$. $1490 \mathrm{cal}$ yrs. BP where a short-lived increase in BD is accompanied by a reduction in $\mathrm{OM}$ and carbon accumulation (Fig.6.6). Charcoal in both size classes is present throughout the record but the finer fragments are more prevalent. Overall, the charcoal accumulation rate is low when compared to the deeper sites, PC and FG. In the 125-500 $\mu \mathrm{m}$ fraction, the maximum CHAR values are observed at $c a .2910$ and $2350 \mathrm{cal} \mathrm{yrs}$. BP. In the > $500 \mu \mathrm{m}$ flux, charcoal accumulation is greatest at ca. 1420 and 1360 cal yrs. BP. The relationship between CHAR and CAR is not considered because both are based are peat accumulation rates. However, the peak at $c a .1360 \mathrm{cal}$ yrs. BP, is associated with lower carbon accumulation, suggesting that here, the direction of the two fluxes in a not a product of peat accumulation (Fig.6.6). 


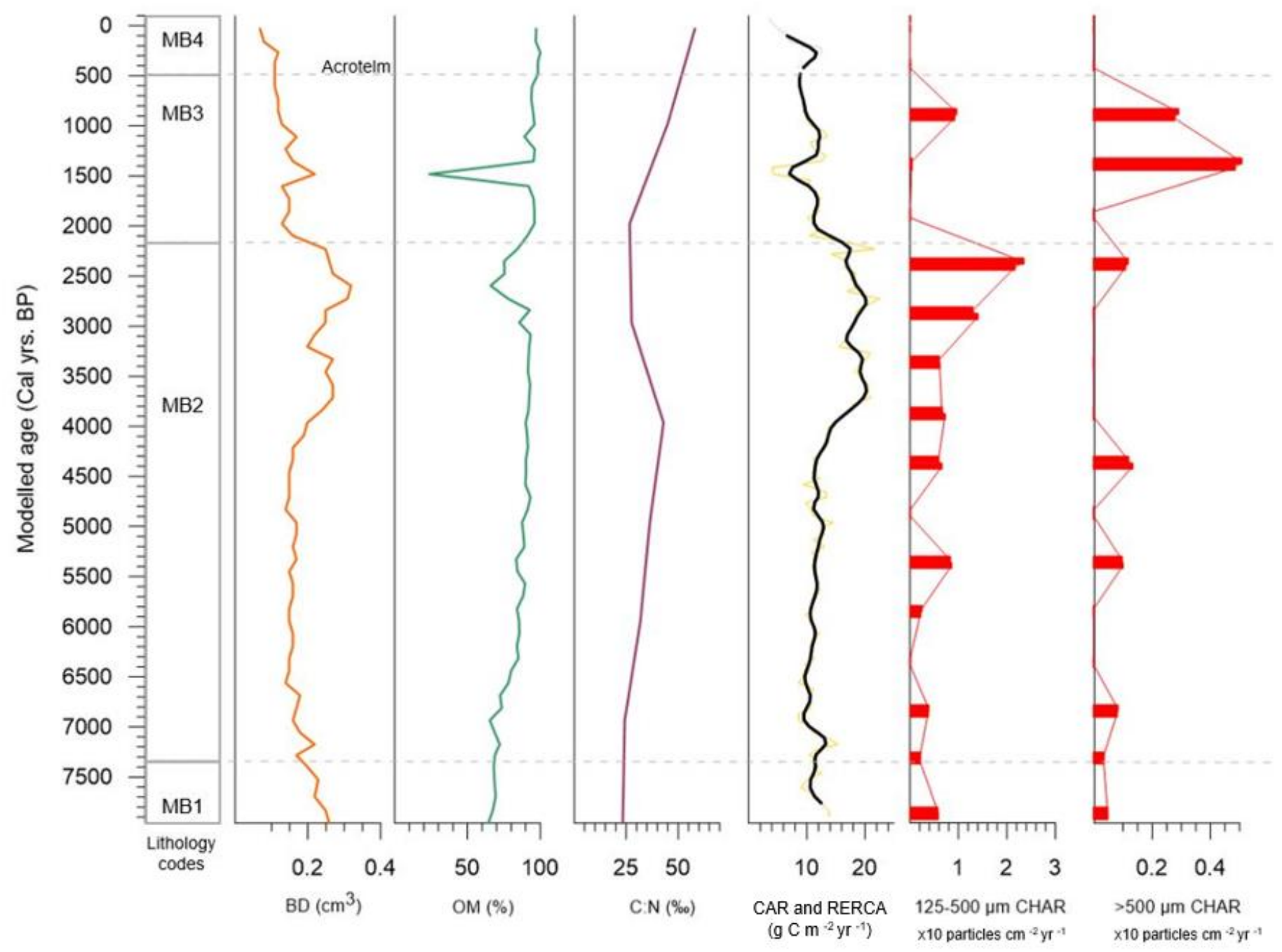

Figure 6:6: MB proxy synthesis. From left to right: MB lithostratigraphy; Bulk Density (BD); Organic Matter (OM); carbon:nitrogen ratio (C:N); Carbon Accumulation Rate (CAR) and Recent Accumulation Rates (RERCA) above the acrotelm; Charcoal accumulation rate (CHAR) for $125-500 \mu \mathrm{m}$ and $>500 \mu \mathrm{m}$. 


\section{Chapter 7: Discussion}

\section{1: Late Glacial to Early Holocene Changes}

The lowermost sediments in the core sequences provide a snapshot of Late-glacial changes and the transition to peat inception in the Carmarthenshire area. Pyllau Cochion (PC) provides the longest record of change where the lowermost unit is at least $c a .14030( \pm 1296)$ cal yrs. BP in age. The oldest age derived for Figyn Common (FG) is ca. $11450( \pm 286)$ cal yrs. BP, whereas sediment accumulation at Mynydd Bach (MB) does not begin until ca. $7960( \pm 333)$ cal yrs. BP.

At the Last Glacial Maximum ( $c a .26000$ cal yrs. BP), it is likely that all of the study sites would have been ice covered. These conditions are most likely to have remained until $c a .19600$ cal yrs. BP, when evidence shows that the Welsh Ice Cap was already beginning to recede (Glasser et al., 2018). It is possible that the basins at PC and FG are ice-scoured basins formed during the glacial period (Macdonald et al., 2006; Gorham et al., 2007).

A thick clay unit is present at the base of PC $(816-575 \mathrm{~cm}, \mathrm{PC} 1)$ and this is overlain by a thin unit of interbedded silts and clays (PC2). The lowermost clay unit is minerogenic, clastic, organic poor and has a $\mathrm{C}: \mathrm{N}$ ratio that is indicative of deposition within a waterlain and cold environment with low productivity (Street-Perrott, 2015). It is likely that this unit includes allochthonous minerogenic material from the surrounding catchment during the deglaciation period. The shift to organic sedimentation (PC2) is dated to $c a .13160$ cal yrs. BP, and small increases in the $\mathrm{OM}$ are indicative of deposition within a period of climatic amelioration most likely the Windermere Interstadial (14700-12900 cal yrs. BP) when summer temperatures were around $12-13{ }^{\circ} \mathrm{C}$ (Palmer et al., 2021). Therefore, this more organic sediment might reflect the establishment of vegetation that led to organic soil formation during this period (Roberts, 2014; Abrook et al., 2020). 
This shift to organic sedimentation is short-lived (from 575-569 cm / ca. 13160-12775 cal yrs. $\mathrm{BP})$ with a return to minerogenic clay (PC2b) in the PC sequence, constrained in age between ca. 12780 to 11670 cal yrs. BP. Sediment composition of PC2b, and the modelled dates, suggest that this clay was deposited during the colder Loch Lomond stadial (ca. 12900-11700 cal yrs. BP), when summer temperatures fell by as much as $5{ }^{\circ} \mathrm{C}$ in Britain (Abrook et al., 2020; Lowe et al., 1994). This clay zone is succeeded by a silt unit that becomes increasingly organic towards the onset of peat (PC3).

The lowermost sediments at Figyn Common (FG) only reflect part of the sequence observed at PC. The clay unit (FG1) at the base is constrained in age to at least $c a$. 11450 cal yrs. BP and in the absence of any underlying organic unit, this is thought to represent deposition during the Loch Lomond Stadial. It is possible that sediments from the Windermere Interstadial were not recovered during the coring process or that local factors may have suppressed the accumulation of organic material during this period. Nevertheless, organic sedimentation at the start of the Holocene in both sites appears to start at a similar time, within the errors of the age-model. At PC, the transition to organic sedimentation is dated to $c a .11670( \pm 1159)$ cal yrs. BP and at FG to $11270( \pm 131)$ cal yrs. BP. Organic sedimentation at this age, is likely in response to the rising temperatures at the start of the Holocene at $11,700 \mathrm{cal}$ yrs. $\mathrm{BP}\left(8^{\circ} \mathrm{C}\right.$ increase in the first 300 years) (Roberts, 2014; Lowe et al., 1994).

Both PC and FG records indicate clay and silt deposition in a limnic environment, likely whilst the basins were occupied by a shallow body of water (Abrook et al., 2020). These lithostratigraphical changes are typical of records found in other Late-glacial sequences around the UK (Brooks et al., 2012; Abrook et al., 2020; Palmer et al., 2021). 


\section{2: Early Holocene Fen Peat Inception}

Fen peat inception occurred at $c a .10800, c a .9730$ and $c a .7960$ cal yrs. BP at FG, PC and MB (respectively). These dates fall within the range of Welsh peat inception ages reported in the literature (e.g., Chambers, 1982; Smith and Cloutman, 1988; Smith and Green, 1995; Hughes and Schulz, 2001; Hughes and Dumayne-Peaty, 2002; Hughes et al., 2007 and references Hughes et al., 2001 within; Carless, 2015). These studies report a large range of $c a .12800$ 3500 cal yrs. BP for peat inception and this transition in the Carmarthenshire bogs falls in the early part of this range.

At PC and FG, the presence of underlying limnic clays and silts, suggests that peat inception took place through the process of terrestrialisation or infilling (see Figure 2.2 in literature review). Infilling is a part of a plant community succession termed the hydrosere (Klinger, 1996). The first stage of this succession takes place when aquatic and terrestrial plants begin to colonise the site (Rotherham, 2020). Once the plants have established at the site, the water body becomes progressively infilled with organic and non-organic material, including dead plant remains (Rydin and Jeglum, 2006; Koster and Favier, 2005; Anderson et al., 2003; Charman, 2002). Infill of material within the water body gives rise to reduced oxygen levels which inhibits the decomposition of the plant remains and so they accumulate as peat, usually on top of formerly deposited lake (limnic) sediments (Rydin and Jeglum, 2006).

The infilling of small water-filled basins, like PC and FG, was a widespread feature following deglaciation in northern Europe and North America (Gorham, 1991; Roberts, 2014) and there is a rapid upsurge of new peatlands reported, between $c a .11,000-9,000 \mathrm{cal}$ yrs. BP (see Figure 2.3 in literature review) (Yu et al., 2010; Macdonald et al., 2006). In the high and mid-latitudes of both hemispheres, this process is thought to have been driven by temperature increase after deglaciation (Morris et al., 2018). More specifically, an increase in the number of days with 
temperatures exceeding $0{ }^{\circ} \mathrm{C}$ during the growing season (Morris et al., 2018). This is thought to have facilitated the establishment of peat-forming vegetation in waterlogged settings and subsequent peat inception (Macdonald et al., 2006; Morris et al., 2018). Peat inception at PC and FG falls within the early Holocene period and is therefore consistent with the widely reported northern initiation dates (e.g., Macdonald et al., 2006).

At $\mathrm{MB}$, no limnic sediment was recovered below the peat and so it is thought that peat accumulation was initiated immediately on top of the mineral substrate (assuming that the corer hit bedrock). This feature indicates that the onset of peat at MB occurred via paludification, where peat forms on a previously drier surface, typically replacing forested land, grassland, or bare rock (see literature review) (Rydin and Jeglum, 2006; Koster and Favier, 2005; Charman, 2002; Clymo, 1991). In order for paludification to take place there must be a change in the local hydrology, or soil permeability, that stimulates conditions of surface waterlogging on once dry land (Charman, 2002). The presence of water-logged conditions promotes the growth of peat forming vegetation, reduces decay and leads to peat accumulation (Rydin and Jeglum, 2006).

Wetter conditions at $\mathrm{MB}$, leading to paludification, could have been facilitated by the pronounced wet shift that is documented around 8300-7800 in Irish and English bog surface wetness records (see Figure 2.11 in the literature review) (Hughes, 1997; Hughes et al., 2000). This wetness shift is tentatively linked to the cold event referred to as the ' 8.2 event' (84008000 cal yrs. BP) when much of the Northern hemisphere was cooler (Alley et al., 1997; Mayewski et al., 2004). It is possible that peat inception at MB could be related to an increase in water availability as a result of the 8.2 event. Furthermore, paludification at MB coincides with a documented widespread upsurge of this process between $c a .8000-5000$ cal yrs. BP resulting in the proliferation of many new peatlands after the 8.2 event, that are thought to be climatically driven (Hughes and Barber, 2004; Gallego-Sala et al., 2015). 
Following peat inception carbon accumulation is relatively low and stable between $c a$. 79604330 cal yrs. BP at MB (Fig. 6.6). Similarly, at both PC and FG the early-mid Holocene is characterised by lower rates of carbon accumulation (Figs 4.13 and 5.10). Burning is present at $\mathrm{PC}, \mathrm{MB}$, and FG throughout the record, but in smaller concentrations when compared to the Late Holocene (Figs. 4.13, 5.10 and 6.6). The carbon and fire history records will be discussed in more detail in the later sections.

\section{3: Fen to Bog Transition}

The fen to bog transition (FBT) is the change from a minerotrophic fen to an ombrotrophic bog. This transition was not apparent at MB. The absence of this could be related to the position of the peatland here. It sits at the bottom of a hill and occupies the area where the landscape flattens out. As a result of this position it has likely been continually subjected to mineral rich overland and ground water flows and therefore may not have become sufficiently nutrient deficient for oligotrophic bog conditions to develop. However, lithostratigraphical and sediment chemistry changes towards the end of the Middle Holocene imply that the FBT took place at $c a .5120( \pm 689)$ and $c a .4480( \pm 587)$ cal yrs. BP, at PC and FG (respectively). The transition is within age errors at both sites.

Leading up to the FBT there is a $\sim 700$-year period of variability in the proxy record at both sites (Figs 7.1 and 7.2). At PC, these fluctuations are present between ca. 5870-5120 cal yrs. BP (Fig.7.1). Within this period there are two distinct shifts to lower organic matter (OM) and higher bulk density (BD): between $c a$. 5870-5700 cal yrs. BP and $c a$. 5400-5250 cal yrs. BP (Fig.7.1). Above this BD decreases and OM increases until they stabilise at $c a .5120$ cal yrs. BP to values typical of a bog peat (Fig.4.13). At FG, 2 comparable increases in BD and reductions in OM are observed between $c a .5190$ to $c a .4480$ cal yrs. BP and at $c a .5040-4910$ cal yrs. BP and a more pronounced shift between $c a$. 4910-4650 cal yrs. BP (Fig.7.2). BD 
reduces and $\mathrm{OM}$ increases beyond this point until $c a .4480$ cal yrs. BP where a step change to sediment characteristics indicative of a bog peat are observed (Fig.5.10). In addition to the changes in sediment chemistry, peat accumulation rate is markedly lower during these periods at both sites (see Figs.4.6 and 5.2).

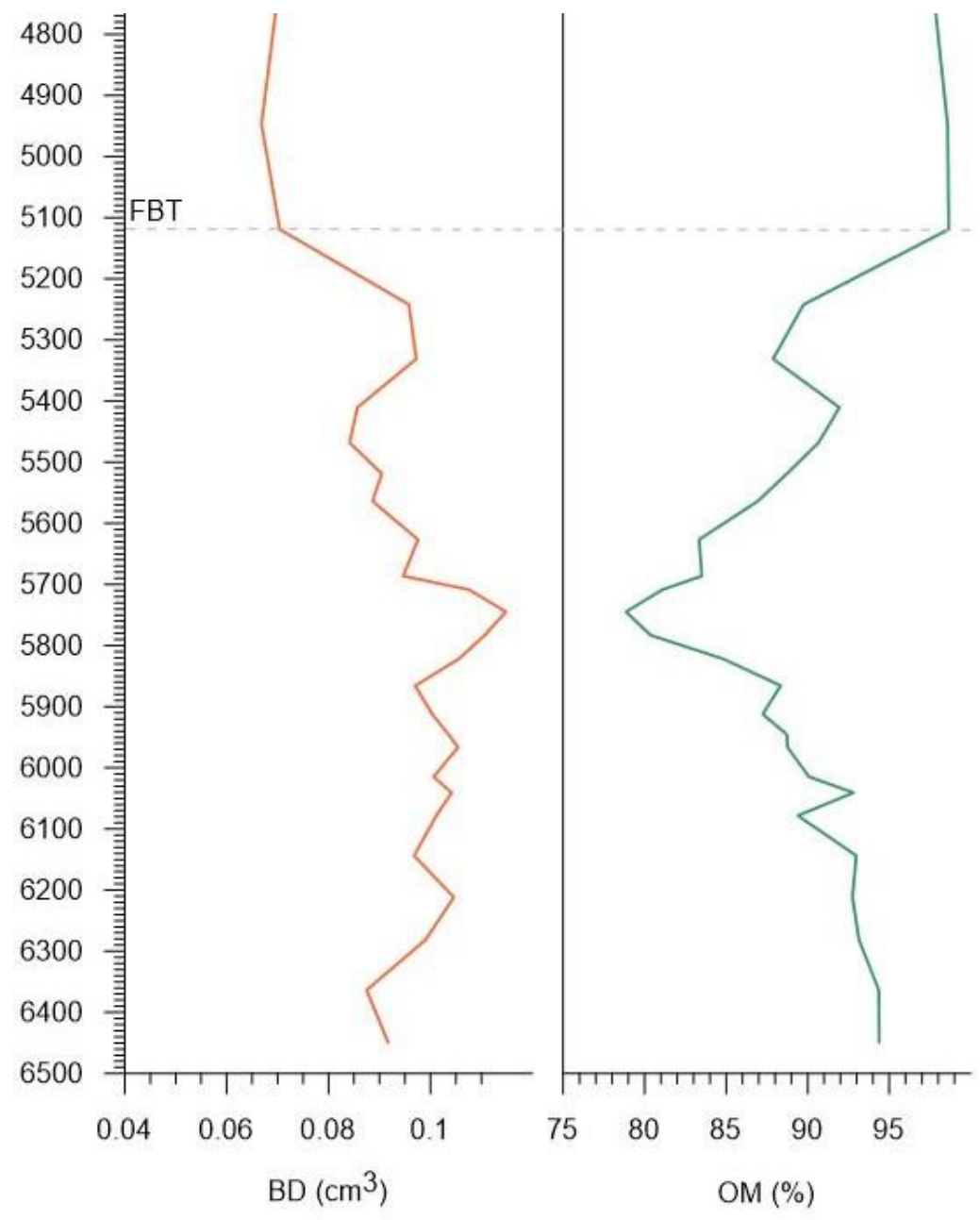

Figure 7:1: Sediment changes leading up to the FBT at PC 


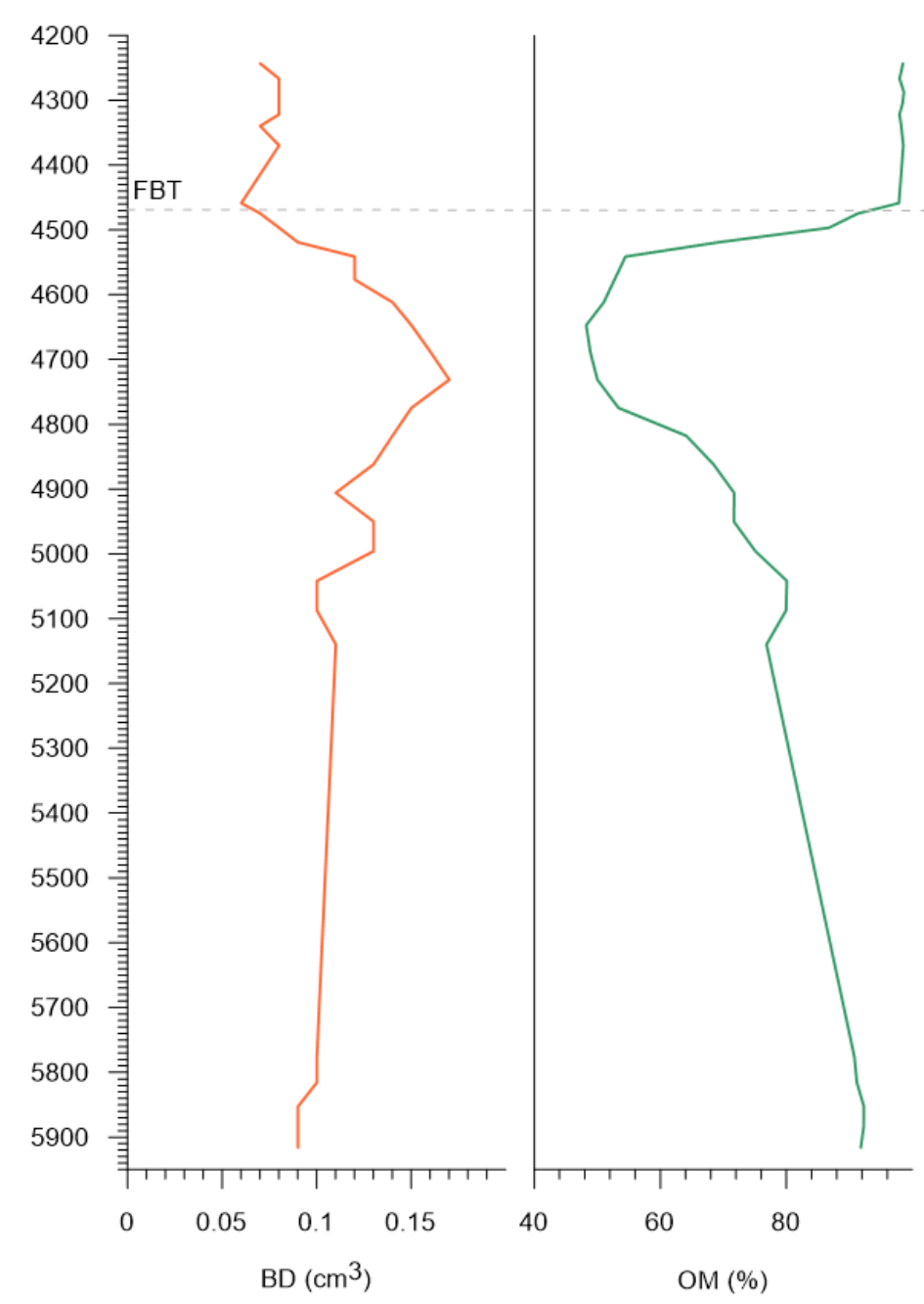

Figure 7:2: Sediment changes leading up to the FBT at FG

The features observed are hypothesized to possibly be the result of a process that has been associated with the FBT at some sites (e.g., Hughes et al., 2000; Hughes and Dumayne-Peaty, 2002). Palaeoecological studies imply that when the FBT begins it does so because the peat has become perched above the ground water table (Belyea, 2009). In some peatlands in England and Wales, this initial raised bog peat was subjected to unstable water tables (Hughes and Barber, 2004; Hughes and Dumayne-Peaty, 2002; Hughes et al., 2000; Hughes, 1997). This variability in the water table is thought to have arisen because a sufficiently deep enough raised catotelm zone has not yet been established and therefore a near surface water table cannot be maintained (Hughes et al., 2000). Under conditions of fluctuating water tables, Calluna and Eriophorum plants establish, and the peat decays rapidly (Hughes et al., 2000). 
This highly decayed material eventually provides a suitably impermeable peat stratum to maintain a raised water table and bog (Hughes and Barber, 2004; Hughes and Dumayne-Peaty, 2002; Hughes et al., 2000; Hughes, 1997).

The changes observed leading up to the FBT at PC and FG could possibly be indicative of the aforementioned process. In particular, the periods of higher BD and lower OM during the intervals leading up to the FBT (ca. 5870-5120 (PC) and ca. 5190-4480 (FG) cal yrs. BP) could be indicative of a more humified peat layer i.e., where a higher degree of drying led to a denser layer, with a lower OM. Yet, it is difficult to say conclusively as humification analysis was not done in the fen peat. However, if these fluctuations in BD and OM did represent the presence of more humified layers, the beginning of the $~ 700$-year period leading up to the FBT could signify the point at which the peat surface first becomes perched above the ground water table and is exposed to aeration. Furthermore, the high BD just before the onset to bog conditions could mark the development of another humified layer of peat, also produced during the unstable pioneer bog stage. But this layer, and the catotelm peat beneath might have then been thick enough to provide an impermeable layer catotelm that facilitated the maintenance of a raised bog above. This seems likely as the sediment characteristics and chemistry imply that ombrotrophic bog conditions stabilise shortly after this point at $c a .5120 \mathrm{cal}$ yrs. BP at PC and around $c a .4480$ at FG.

This theory that the FBT followed the process discussed above (Hughes, 1997; Hughes et al., 2000; Hughes and Barber, 2004) is supported by other lines of evidence. For example, the slower peat accumulation noted above, during the interval leading up to the FBT, suggests that water tables may have fluctuated throughout these periods and resulted in higher decomposition (Anderson, 2002). Additionally, the appearance of charcoal fragments $>500 \mu \mathrm{m}$ during this period imply burning on the peatland surface (Ohlson and Tryterud, 2000; Magnan et al., 2012) and on-site burning is thought to indicate periods when the peatland surface is 
drier (Hughes et al., 2000). Furthermore, the pollen diagram at PC shows that calluna is present during this interval, a plant that is indicative of fluctuating water levels during the FBT (Hughes and Barber, 2004).

To summarise, this hypothesis suggests that the peat surface first became perched above the ground water table at $c a .5870 \mathrm{cal}$ yrs. BP at PC and $c a .5190$ cal yrs. BP at FG and that for around 700 years the water table fluctuated at both sites. This instability eventually led to the creation of a highly humified impermeable raised bog catotelm layer, that facilitated the stabilisation of ombrotrophic bog conditions by $c a .5120$ cal yrs. BP at PC and $c a .4480$ cal yrs. BP at FG. However, additional lines of evidence, including high resolution dating during the transition and a macrofossil Bog Surface Wetness (BSW), are needed to state the nature of the FBT more conclusively at these sites.

\subsection{1: Possible Drivers of the FBT}

It is difficult to state with high confidence what the drivers for the FBT at these sites would have been. The literature suggests that the shift is commonly caused by a combination of autogenic and allogenic factors (Hughes and Dumayne-Peaty, 2002; Loisel and Bunsen, 2020).

One allogenic factor that could have contributed to the FBT at these sites is the peat growing above the water table (Belyea, 2009). PC had accumulated a sediment depth of $428 \mathrm{~cm}$ and Figyn had accumulated $466 \mathrm{~cm}$ of sediment before the start of the FBT. This could have been enough to raise the peat surface above the ground water table, but it's difficult to say without a water table proxy.

Another theory is that the FBT may have been promoted by autogenic factors and increased wetness. Enhanced water availability promotes the FBT by stimulating tussock development, 
and subsequent nutrient leaching, that facilitates the upward growth of Sphagnum lawns (Dumayne-Peaty, 2002; Hughes and Barber, 2004).

Wetness is thought to play a role in the FBT at the study sites because there are several widely documented British wetness shifts during the variable interval leading up to the FBT. For example, the beginning of the FBT at PC, around $c a .5800 \mathrm{cal}$ yrs. BP corresponds with a time of increased water availability depicted in an Irish peatland (Langdon et al., 2003) and the onset of ombrotrophic conditions ( $c a .5120$ cal yrs. BP) aligns with a widely documented wet interval in British BSW records, around ca. 5200 cal yrs. BP (Tipping, 1995; Hughes et al., 2000; Langdon et al., 2003; Mayewski et al., 2004; Daley and Barber, 2012). Interestingly, the later start of the FBT at FG also corresponds with this wetness shift at $c a .5200$ cal yrs. BP and the establishment of a raised bog ( $c a .4470$ cal yrs. BP) is within the duration of the wetter interval reported by Langdon et al., (2003). Furthermore, a widespread shift to ombrotrophication in British peatlands, around $c a .6000 \mathrm{cal}$ yrs. BP, is thought to be associated with the longer-term onset of neoglacial wetter/cooler conditions that prevailed after $c a$. 6000 cal yrs. BP (Barber $e t$ $a l ., 2003)$. These associations suggest that increases in water availability may have acted as tipping points during the FBT at already mature fens. However, there are large age uncertainties surrounding the FBT, so it is difficult to convincingly attribute it to any of these wet shifts.

To summarise, the FBT at both sites is marked by distinct fluctuations in organic matter and bulk density that are present for around 700 years before the bog conditions stabilise (from $c a$. 5870-5120 cal yrs. BP at PC and from ca. 5190-4480 cal yrs. BP at FG). In particular, lower $\mathrm{BD}$ and higher OM characterise the start of the intervals and these shifts are present in the same direction to just before the FBT. Peat accumulation around this time is also slower. This implies that there are sustained changes at the sites for around 700 years before the shift into ombrotrophication. This period could represent the development of an impermeable raised bog surface when the newly raised peat surface was subjected to fluctuating water levels. The FBT 
could have been promoted by allogenic climate forcing, but it is difficult to align the shifts with a given wetter interval because of the large age uncertainties around the transition. However, the age uncertainties for the FBT at both sites means that they occur within the age errors. Therefore, it is possible that the transition happened at a similar time at both sites, possibly in response to climatic forcing. High resolution dating and a macrofossil based BSW record would help to better inform the nature of this shift.

\section{4: Wetness Changes During the Mid to Late Holocene}

Following the establishment of bog peat in the mid-Holocene, humification records from PC and FG give insight into wet-dry shifts (Fig.7.3). The light transmission data for several samples along each sequence were compared to a macrofossil derived Dupont Hydroclimatic Index (DHI) to assess if the two BSW proxies (humification and macrofossils) depicted similar wetness scenarios at selected depths (Tables 4.8 and 5.8). The two bog surface wetness proxies were generally found to yield similar results in 10 out of 12 of the samples. Two samples revealed inconsistent results $(216-218 \mathrm{~cm}(c a .3770-3740 \mathrm{cal} \mathrm{yrs} . \mathrm{BP})$ at PC and 272-274 cm (ca. 2570-2560 cal yrs. BP) at FG). In the former the DHI depicts a drier scenario relative to the light transmission data. This may be because the sample comprises around 50\% Eriophorum Vaginatum and humification analyses can sometimes give erroneously wetter values when herbaceous vegetation is dominant (Hughes et al., 2012). However, in the latter example at Figyn Common, the DHI indicates a wetter scenario whereas the light transmission data suggests dry condition. No clear reason for this observation has been found.

Although, only a small number of samples were analysed for DHI, the overall results support the light transmission data as both of the BSW proxies generally indicate changes in the same direction. 
For both sites, the light transmission values and humification residuals are comparable to those found in the literature at other British sites whereby frequent shifts between relatively dry and wetter conditions are apparent (Anderson, 1998; Ellis and Tallis, 2000, Chambers and Blackford, 2001; Swindles et al., 2012; Turner et al., 2014). This is a common feature of ombrotrophic bogs during the late Holocene (Barber et al., 2003). In Figure 7.3, the humification residuals for both sites are plotted against a similar record from the Brecon Beacons (South Wales) that spans the last ca. 2200 cal yrs. BP (Chambers and Blackford, 2001) and a compilation of Northern English testate amoebae BSW records (Charman et al., 2006).

\subsection{1: Common Wetness Features}

Overall, there is a significant amount of variability between the two study site records, but there are some common features. These are: a dry shift at $c a . \sim 2400$, a return to wet conditions at ca. 2000 cal yrs. BP and a peak in wetness around $c a .850$ cal yrs. BP (Fig.7.3). The wetness shift at $c a .2000$ cal yrs. BP and the dry shift at $c a .2400 \mathrm{cal}$ yrs. BP are associated with higher and lower carbon accumulation (respectively). At PC this dry shift is also associated with increased high fire activity. These relationships will be discussed more in the later sections.

The changes discussed above are also reflected in the Northern English compilation, and to a lesser extent, the Brecon Beacons humification record (Fig.7.3) (Chambers and Blackford, 2001; Charman et al., 2006). Furthermore, a wet shift around ca. 2050 cal yrs. BP is widely documented in the literature (Barber 1981 and 1994; Tipping, 1995; Blackford and Chambers, 1991 and 1995; Hughes et al., 2000). These findings imply that SW Wales was warmer between $\sim c a$. 2400-2000 cal yrs. BP and wetter from $c a .2000$ cal. yrs. BP to at least $c a .1730$ cal yrs. BP. 
The most recent peak to occur simultaneously in all four records is an increase in wetness at ca. 850 cal yrs. BP (Fig.7.3). This is also referenced within other British studies (e.g., Ellis and Tallis, 2000; Barber et al., 2003; Blundell et al., 2008).

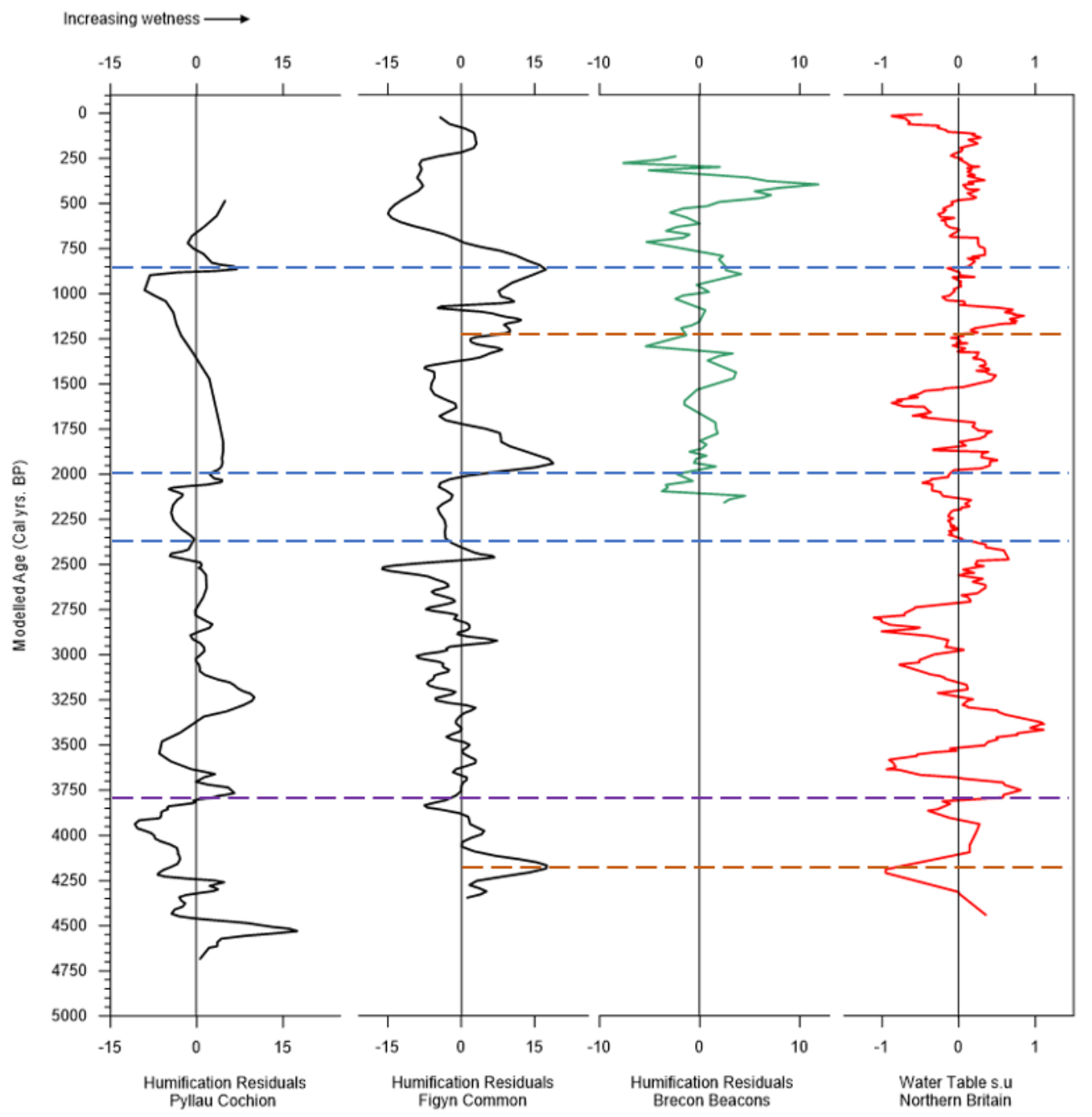

Figure 7:3: left to right; 3-point moving average humification residual curve for PC and FG; Smoothed Humification residuals for a peatland in Brecon Beacons (Chambers and Blackford, 2001); Northern English testate amoebae BSW record (Charman et al., 2006). Blue dashed lines signify common wetness features in all records. Brown dashed lines represents changes apparent only at FG and the comparison records. The purple dashed line indicates a shift that is only present at PC and the northern BSW compilation.

The changes at $c a .2500, c a .2000$ and $c a .850$ cal yrs. BP provide the strongest evidence of climatically induced changes at the sites and give important insights into climate changes in SW Wales during the late Holocene. Several studies link shifts in the British BSW record, including those discussed above, with solar variability, whereby correspondence with changing 
lake levels in France and Switzerland has been suggested (Magny, 2004; Charman et al., 2006; Mauquoy et al., 2008; Swindles et al., 2010). The changes in solar activity alter the westerly storm courses and increase water availability by changing the precipitation to evaporation balance, which is reflected in peat BSW records, including the study sites (Charman et al., 2006).

\subsection{2: Inconsistencies between the surface wetness records}

Despite the correspondence with some wet and dry shifts between sites and reported in the literature, there are also marked differences between the reconstructed wetness records from FG and PC (Fig.7.3). In some instances, only one study site seems to respond in accordance with commonly reported water balance changes in the literature.

For example, at FG there is a pronounced wet shift from $c a .4350-4100$ cal yrs. BP and the wettest values are observed at $c a .4200$ cal yrs. BP. A wet shift centred around $c a .4200$ cal yrs. BP has been reported in other British BSW records (Barber, 1994 and 1981; Tipping, 1995; Hughes et al., 2000; Barber et al., 2003; Langdon et al., 2003; Daley and Barber, 2012) and the northern English testate amoebae compilation (Fig.7.3) (Charman et al., 2006). Furthermore, a cooling event around $c a .4200$ cal yrs. BP, with higher effective precipitation in NW and Central Europe (Charman, 2010) is well documented within peat, as well as other palaeoclimatic proxy records (Mayewski et al., 2004; Charman, 2010; Walker, 2019). However, in the PC record a drier period after $c a .4250$ cal yrs. BP is present. It could be that the earlier short-lived wet period at PC, between $c a .4320-4260$ cal yrs. BP represents the cooling event at $c a .4200$ cal yrs BP because the age errors around this depth $(\sim \pm 300$ years $)$ mean that the ages of the wet shifts at both sites overlap. Therefore, the records could possibly be showing evidence of cooling around $c a .4200$ cal yrs. BP. Isochron dating, such as 
cryptotephra analysis, could help to chronologically constrain the shifts around this time (Turner et a., 2014).

Above this, there are further inconsistencies between the two study site records. Between $c a$. 3750-2400 cal yrs. BP the FG wetness record hovers around zero and does not demonstrate any notable correspondence with PC or the northern compilation record (Fig.7.3). Whereas PC does demonstrate a wetness shift around $c a .3800$ cal yrs. BP, that is also depicted by Charman et al., (2006) (Fig.7.3) in the northern English compilation record. The low responsivity at FG could be the result of the high local and on-site burning that is evident in the charcoal record during this time (see Fig.7.5). This is discussed more in the fire history section.

Between $c a$. 2000 to $c a .900$ cal yrs. BP, it is the PC record that appears less receptive to regionally reported shifts. For instance, the wet period around $c a .1250$ cal yrs. BP that is present in the other three records shown in Figure 7.3, and in many other BSW records, (Chambers and Blackford, 2001; Charman et al., 2006) is not present at PC. This inconsistency, and those previously mentioned, could be because of varying palaeohydrological responses to climatic forcing at the sites, which can be influenced by a multitude of factors, such as: internal hydrology, surface geometry, local environmental factors, autogenic development (e.g., vegetational successions) and peatland resilience (Chambers and Blackford; 2001; Chiverrell, 2001).

Beyond $c a .500$ cal yrs. BP it is difficult to detect a regional signal as the PC record does not continue (see Results). At FG there is a shift around $c a .80$ cal yrs. BP (1870 AD). A change to drier conditions around this time is depicted in the northern English BSW compilation and has been found to be a common feature across many European peatlands, in response to climate warming and summer precipitation reductions (Swindles et al., 2019). However, this dryness 
could also have been worsened by recent drainage at FG (see FG site description in Methodology).

There is also implied drying at PC but on a longer timescale. This is apparent in the raw light transmission data that demonstrates a general drying trend throughout the record (Fig.4.9). This is an interesting feature because usually humification records are characterised by increasing wetness towards the less decomposed peat at the top of the profile (Chambers and Blackford, 2001) but at Pyllau Cochion the opposite is present. It is possible that this overall drying trend is the result of peat cutting at the site, with at least $50 \mathrm{~cm}$ thought to be missing (discussed in the later section about human impacts). This could have left the peat surface bare and open to drying (Waddington et al., 2002; Waddington and Price, 2013). This drying out effect is commonly associated with peatlands that are cut in Ireland (Barber et al., 2003).

\section{5: Holocene Fire History}

Charcoal fragments in the $125-500 \mu \mathrm{m}$ fraction typically provide a record of fires in the surrounding landscape, within a $7 \mathrm{~km}$ radius of a core site (Whitlock and Millspaugh, 1996), whereas charcoal fragments $>500 \mu \mathrm{m}$ in size, and charred macrofossil plant remains, provide strong evidence of 'on-site' fires (Magnan et al., 2012; Ohlson and Tryterud, 2000). As such, charcoal occurrence within the $125-500 \mu \mathrm{m}$ range is used to reconstruct a pattern of local fires and the $>500 \mu \mathrm{m}$ fraction is employed to reconstruct 'on site' fires.

The charcoal concentrations found at the three study sites (Fig.7.4) are similar to other Holocene charcoal records (e.g., Ellis and Tallis, 2001; Turner et al., 2014; Abrook et al., 2020) and the macroscopic charcoal accumulation is comparable with Holocene charcoal accumulation rates (CHARs) in Scottish sequences (Froyd, 2006). However, the CHAR at MB is considerably smaller than the two other study sites (Fig.7.4). This is because MB has a much lower mean accumulation rate at $0.02 \mathrm{~cm} / \mathrm{yr}$. Charred plant remains are only found on some 
occasions at PC and FG and are mostly the remains of dwarf shrubs like Calluna vulgaris or Erica textralix. However, they are not found at all on-site fire peaks. This could be for several reasons, including dwarf shrub vegetation not being present at the time, differences in fire intensity or because the remains are missing in the cores (Fig.7.4). Evidence of local fire is found throughout the Holocene at PC and FG and from the mid- Holocene at MB (Fig.7.4). This demonstrates that fire has been a long-standing feature of the local landscape. On-site burning has been a part of MB's history since peat inception but at the two deeper sites (FG and PC) it does not become an important part of the record until post $c a .4000$ cal yrs. BP (Fig.7.4). Local and regional fire activity throughout the Holocene is also depicted in numerous British palaeofire records (e.g., Smith and Cloutman, 1988; Fyfe et al., 2003; Froyd, 2006; Edwards et al., 2007; Innes et al., 2010 Grant, 2012; Innes et al., 2013; Marlon et al., 2013; Swindles et al., 2021).

\subsection{1: Fire Activity During the Early Holocene}

In this study, fire activity is relatively low in the early Holocene (ca.11000-8200 cal yrs. BP). There is evidence of regular fire in the FG record, but this is less apparent at PC, with 125-500 $\mu \mathrm{m}$ CHAR lower than 0.02 particles $\mathrm{cm}^{-2} \mathrm{yr}^{-1}$ during this interval.

It is difficult to state conclusively the origin of these fires during the Early Holocene. However, some studies imply that they are likely to be caused by climatic forcing. Increases in fire incidence from $c a$. $11300-8000$ cal yrs. BP in a Scottish peatland have been linked to warming temperatures and aridity (Abrook et al., 2020) and Mauquoy et al., (2020) suggest that Early Holocene fires could have been lightning induced. In addition, analysis of the NEEM ice core record demonstrated that fire occurrence between $c a$. 12000-7000 cal yrs. BP closely followed the trend of increasing summer temperatures during this time (Zennaro et al., 2015). Human populations in the early Holocene were small relative to that of central Europe (Marlon et al., 
2013; Bevan et al., 2017) and there is little evidence of extensive human burning before $c a$. 8000 cal yrs. BP (Fyfe et al., 2003; Innes and Blackford, 2003). However, a human trigger cannot be completely discounted. Nonetheless, considering the evidence that is available at present it seems more probable that these Early Holocene fires would have been climatically induced.

\subsection{2: Fire Activity During the Mid-Holocene}

At PC and FG there is a simultaneous increase in local burning close to $c a .8000$ cal yrs. BP and charcoal is detected here at the start of the record at MB (Fig.7.4). Fire is prevalent at all three sites throughout much of the Mesolithic period. There is evidence to suggest that this burning could have been caused by Mesolithic populations. Smith and Cloutman (1988) find evidence of Mesolithic burning for land management in South Wales at ca. 8000 cal yrs. BP, and Grant (2012) finds similar evidence in North Wales. Furthermore, there is widespread evidence of Mesolithic deforestation involving fire in numerous British palaeofire records (Fig.7.4) (e.g., Fyfe et al., 2003; Edwards et al., 2007; Innes et al., 2010; Innes et al., 2013; Swindles et al., 2021). This Mesolithic forest management was thought to be a way to improve animal hunting by providing suitable grazing sites for prey (Fyfe et al., 2003). On the other hand, fires around this period have also been attributed to increases in summer temperatures and insolation, that were highest in the northern hemisphere at $c a .7000$ cal yrs. BP (Zennaro et al., 2015; Marlon et al., 2013). Therefore, there are reasonable arguments for fire activity between $c a$. 8000-6000 cal yrs. BP being attributed to a combination of Mesolithic clearance and the climatic amelioration during this time.

On site burning during the Mesolithic is only found at MB. At PC and FG, it is not commonplace until after $c a .4000 \mathrm{cal}$ yrs. BP (Fig.7.4). This could be because more stable near- 
surface water tables during the minerotrophic fen stage inhibited on site fire activity (Ohlson et al., 2006; Magnan et al., 2012).

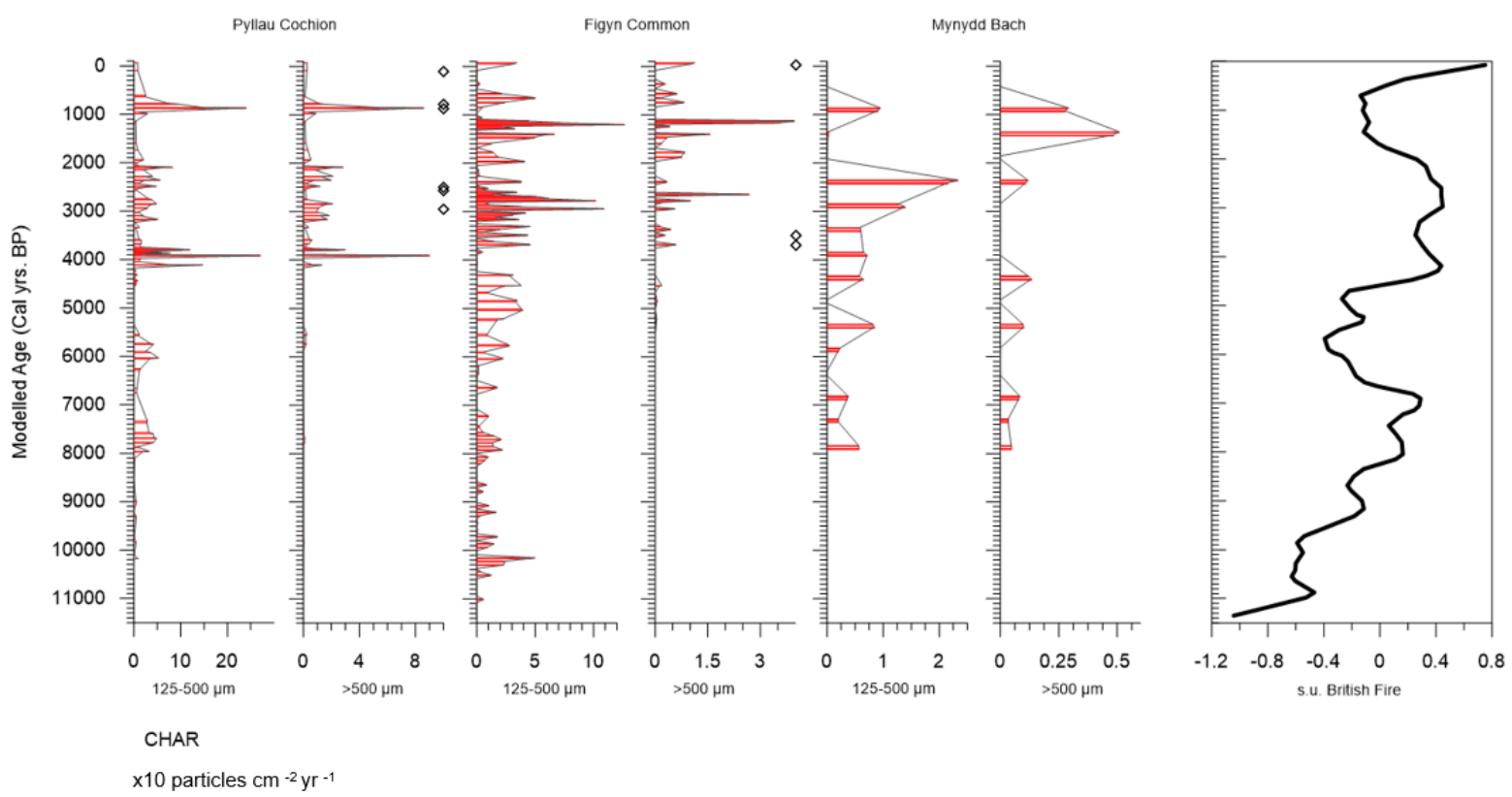

Figure 7:4: left to right; CHAR counts for both size classes analysed (125-500 $\mu \mathrm{m}$ and $>500 \mu \mathrm{m})$ for PC, FG, and MB; 250-year running average of British Isles fire from a compilation of palaeofire records (Marlon et al., 2013). Diamond shapes represent the presence of charred fragments. Note the smaller amounts of charcoal found at MB.

\subsection{3: Fire Activity After ca. 4500 cal yrs. BP}

From $c a .4500-4000$ cal yrs. BP there is a step change to higher local charcoal flux, and on-site burning at all sites (Fig.7.4). In particular, at Mynydd Bach there is recurrent burning between ca. 4400-2350 cal yrs. BP. This fire activity aligns well with the Bronze Age period (44502750 cal yrs. BP (Adkins et al., 2017)). Four burial mounds are present at Mynydd Bach (the Crugiau Round Barrows - Scheduled Ancient Monuments), thought to be from the Bronze Age, implied by dates of similar monuments nearby (Fan barrow, Ceredigion, and Fan Foel Carmarthenshire) (CCC, 2014 (c); Piper, 2021)). The archaeological evidence from these nearby sites suggests that Mynydd Bach was a ritual burial site during the Bronze age (Piper, 
2021). Here, the remains of individuals would have been cremated and buried within the mounds, along with grave offerings, and it would have been very sacred (Piper, 2021). It is possible that evidence of this burning is captured within the increased charcoal levels for MB, between $c a$. 4400-2350 cal yrs. BP. This finding adds context to this archaeologically important site, suggesting that on-site and local burning could play a role in the use of this site and the local area during the Bronze Age.

The higher burning after $c a .4500$ cal yrs. BP at PC and FG, and post Bronze age at MB, may also be attributed to human activity (Fig.7.4). The pollen record at PC shows that from the start of the Bronze age period there is clearance of the landscape by human populations cultivation (see pollen diagram in site description) (Watkins and Froyd, 2017; CCC, 2017). Tree presence declines and shrubs and herbs increase, suggesting deforestation and from ca. 3000-2000 cal yrs. BP. After this, deforestation continues and plant species, indicative of human activity (such as Plantago) increase (CCC, 2017). Furthermore, the consistently high levels of charcoal, as displayed in FG and PC, post $c a .4500$ cal yrs. BP are unlikely to be attributed exclusively to wildfires. As such, some human interference is assumed (Innes and Simmons, 2000; Turner et $a l ., 2014)$. What is more, the northern hemisphere climate for the last $c a .5000$ cal yrs. BP does not explain the increase in fires observed during this period (Zennaro et al., 2015). Therefore, it is likely that the fires at the sites during this time are human induced. This human interference would have likely been associated with the clearance of the landscape for cultivation and to enhance grazing opportunities in the locality and on the sites (Marlon et al., 2013).

There is also some evidence to suggest that Late Holocene fire activity at PC and FG might be related to changes in bog surface wetness. Local and on-site fire peaks, at both sites, appear to coincide with drier intervals (Fig.7.5). At PC, this relationship is most pronounced at ca. 41003750, ca. 2470-2080 cal yrs. BP and ca. 870 cal yrs. BP. The latter is where a fire peak is present at the end of a dry interval. Furthermore, fire occurrence is very low during the 
prolonged wet interval at PC from $c a$. 2070-1470 cal yrs. BP (Fig.7.5). The record at FG also displays a similar link at some points, with the most pronounced increases in fire activity being associated with a prolonged relatively drier period between $c a$. 3690-2600 cal yrs. BP and an increase in CHAR just before a dryness spike at ca. 1080 cal yrs. BP (Fig.7.5). These associations imply that increased fire activity is sometimes related to periods when the water table was lower.

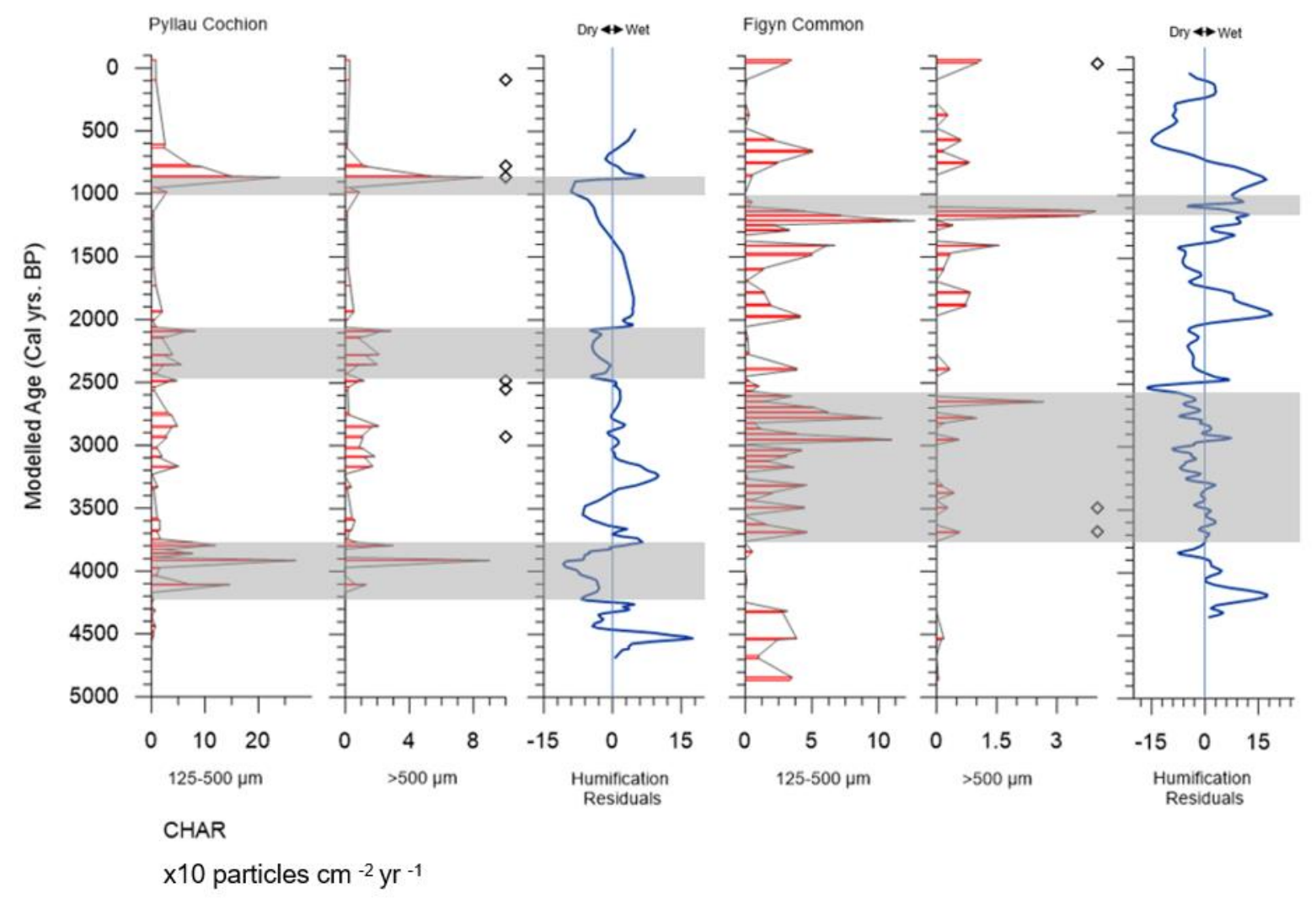

Figure 7:5: left to right; Mid-Late Holocene CHAR counts for both size classes analysed (125-500 $\mu \mathrm{m}$ and $>500 \mu \mathrm{m}$ ) plotted against a 3-point moving average for PC and FG. The grey boxes indicate periods when higher fire activity is associated with dryness in the BSW record.

In the PC record, two of the BSW shifts discussed (ca. 2470 and $c a .2070$ cal yrs. BP) are associated with higher and decreased fire activity (respectively) and are linked with widely reported British wetness changes (Chambers and Blackford, 2001; Charman et al., 2006). This 
suggests that during these periods, fire activity was enhanced directly, or indirectly, by a drier climate. The drier climate may have meant that PC and the surrounding local landscape was more vulnerable to wildfires by enhancing productivity and drying out the available biomass, thus making it more flammable (Zenarro et al., 2015). However, there are limited examples like this to draw on in the record so the relationship between fire and regional climate shifts is tentative. Furthermore, fire, even in the regionally drier intervals, may still have been human induced. Turner et al., (2014) suggest that drier conditions on the peat surface, during the late Holocene, might have made it more suitable for grazing, and therefore burning could have been used to maintain a low-level of vegetation (Turner et al., 2014).

In addition to this, there is a possibility that human fire activity on the sites could have induced the drier conditions. For example, at FG, the high on-site burning between ca. 3690-2600 cal yrs. BP is associated with a relatively dry period in the wetness record, during which FG is less receptive to regionally documented wetness shifts. Therefore, it could be that this burning, the regularity of which suggests a human cause, is contributing towards the dryness observed at FG during this time. This is possible as regular burning has been found to be associated with significant peatland drying (Holden et al., 2004; Marcisz et al., 2015).

Two of the sites (PC and FG) are also known to have been subjected to recent illegal burning and charred vegetation was visible when the sites were cored between 2016-2019 AD. The uppermost centimetre at both sites appeared as a dark black band. The band was not identified to be charcoal at the time, but the high charcoal concentrations in the uppermost $2 \mathrm{~cm}$ samples suggest that it was. The fire presence at the top of PC and FG are therefore thought to be related to this activity and other human-induced burning from at least $1950 \mathrm{AD}$ to present (FG) and during the last 250 years at PC. 
Overall, there is convincing evidence to suggest that burning post $c a .4500$ cal yrs. BP was predominantly caused by human land use practices but may have been amplified directly or indirectly by climate at times. Furthermore, the examples discussed above suggest that burning can lead to peatland dryness, but also that climatic induced dryness can leave a peatland more susceptible to natural burning or better suited to human management through burning.

\subsection{4: Comparison with British Fire History}

The broad pattern of fire activity at the three sites ties in loosely with some of the UK wide fire trends depicted by a compilation of 20 British palaeofire records (Fig.7.4) (Marlon et al., 2013). For example, the Mesolithic increases in fire and the higher fire activity post $c a .4500$ cal yrs. BP (Marlon et al., 2013). However, there are some significant differences. For example, the drop in fire occurrence between $c a$. 5000-6000 cal yrs. BP is only present at PC. This British wide reduction is thought to be related to the Elm decline (Marlon et al., 2013). However, this feature is not present at FG or MB. This could possibly be because the sites, or the surrounding areas, were being more actively managed by humans during this time, and PC was not. The comparison against the British palaeofire compilation demonstrates that the macrocharcoal record does depict some UK wide fire history shifts but local influences may be more important.

\section{6: Carbon Accumulation}

\subsection{1: Long-term Rate of Carbon Accumulation (LARCA)}

LARCA values for the three sites are 23.71, 13.09 and $42.55 \mathrm{~g} \mathrm{C} \mathrm{m}^{-2} \mathrm{yr}^{-1}$ for PC, MB, and FG (respectively). These LARCAs are comparable to other temperate and northern peatland values reported in the literature (see Table 2.4 in literature review). This demonstrates that the study 
sites have been effectively sequestering carbon for most of the Holocene at a rate comparable with other British and Northern peatlands.

The LARCA for PC sits within the middle of these reported values, but FG is at the higher end of the range and MB is at the lower end. The lower LARCA at MB (13.09 $\left.\mathrm{g} \mathrm{C} \mathrm{m}^{-2} \mathrm{yr}^{-1}\right)$ is likely because peat inception did not occur until around $c a .8000 \mathrm{cal}$ yrs. BP, whereas the other two study sites, and many of the sites in the literature, have peat basal dates around $c a .10000$ cal yrs. BP. Therefore, MB has had less time to accumulate carbon. Furthermore, MB is also a fen and fens have been found to accumulate less than bogs in some instances because they experience higher decay rates (Loisel and Bunsen, 2020). This higher decomposition is caused by their mineral-rich water source that promotes microbial activity (Loisel and Bunsen. 2020).

The comparatively high LARCA value at FG $\left(42.55 \mathrm{~g} \mathrm{C} \mathrm{m}^{-2} \mathrm{yr}^{-1}\right)$ is most probably attributed to its very fast peat accumulation rate, of $0.08 \mathrm{~cm} / \mathrm{yr}$. in the fen zone and $0.12 \mathrm{~cm} / \mathrm{yr}$. in the bog peat zone. These rates are much higher than the average rate reported from three Welsh peat bogs $(0.04 \mathrm{~cm} / \mathrm{yr}$. (Carless, 2015)) and a Scottish peat database, with a mean of $0.03 \mathrm{~cm} / \mathrm{yr}$. (Ratcliffe et al., 2018). This implies that FG has been particularly effective at accumulating peat and carbon, throughout the Holocene.

\section{Temporal Carbon Accumulation Rates (CARs)}

Mean CARs are 44.51, 52.04 and $12.99 \mathrm{~g} \mathrm{C} \mathrm{m}^{-2} \mathrm{yr}^{-1}$, for PC, FG, and MB (respectively). The values are comparable to a mean CAR reported from three peatlands in South Wales $(60 \mathrm{~g} \mathrm{C}$ $\mathrm{m}^{-2} \mathrm{yr}^{-1}$ ) but they differ from other reported values (see literature review Table 2.4). For example, a mean of 17.9 and $21.3 \mathrm{~g} \mathrm{C} \mathrm{m}^{-2} \mathrm{yr}^{-1}$ for various Scottish peatlands (Anderson, 2002; Ratcliffe et al., 2018) and $22.9 \mathrm{~g} \mathrm{C} \mathrm{m}^{-2} \mathrm{yr}^{-1}$ for the Northern peatland database (Loisel et al., 2014). CARs at MB are lower than this, and at PC and FG, they are higher. 
The lower value for MB, similarly for the LARCA, could be attributed to it being a fen (Loisel and Bunsen, 2020). The higher numbers for PC and FG could be because of differences in the carbon content between the sites and the aforementioned studies. For example, Ratcliffe et al., (2018) calculate the carbon percentage to be $50 \%$ of OM, whereas, in this study the regression equation between some measured total organic carbon values and organic matter is used to calculate carbon content, resulting in a figure of $56 \%$ for FG and $54 \%$ for PC. This difference could explain the lower CARs reported by Ratcliffe et al., 2018. Furthermore, the mean CAR in the Northern database, that comprises 215 sites, could have been downweighed by sites with particularly low carbon content percentages, such as those in Canada and Alaska, reported to have average carbon contents below 35\% (Loisel et al., 2014). But sites in Western Europe were found to have carbon contents around 55\%, comparable to the study sites (Loisel et al., 2014). These factors could explain the differences between the CARs in this site (FG) and some of those reported in the literature.

The CARs at PC and FG are highly variable throughout the Holocene and this variability is a common feature of CAR records (e.g., Anderson, 2002; Carless, 2015; van der Linden et al., 2014; Ratcliffe et al., 2018). MB is less variable because the sequence is only constrained by one date close to the bottom of the profile and therefore the carbon history is somewhat smoothed over time. To make it easier to see the long-term trends, and compare the CARs against other records, they were placed into 1000-year bins following Yu et al., (2014). The CAR bins are plotted in Figure 7.6 alongside the CAR database for 43 Scottish peatlands (Ratcliffe et al., 2018) and the Northern CAR composite, that comprises over 250 northern peatland sites (Loisel et al., 2014; Yu et al., 2014). 


\subsection{2: Holocene Carbon Accumulation Trends}

At FG, and to a lesser extent PC, carbon accumulation is higher between 1100-9000 cal yrs. BP (Fig.7.6). Higher carbon accumulation during this time is also observed in Scottish and Northern peatlands (Fig. 7.6) (e.g., Yu et al., 2009; Yu et al., 2012; Loisel et al., 2014; Yu et al., 2014; Charman et al., 2015; Ratcliffe et al., 2018). It has been suggested that this may be a response to increasing temperatures, following the end of the Loch Lomond cold period (MacDonald et al., 2006; Yu et al., 2014) but autogenic processes also have a role to play. Typically, the beginning of the fen stage sees faster rates of accumulation because there is a surplus of ground water availability (Yu et al., 2003). Furthermore, higher carbon accumulation rates in the lowermost peats can result from lower decomposition rates and higher productivity shortly after peat inception (Anderson 2002).

At FG there is a clear declining trend in carbon accumulation between ca. 9000-5000 cal yrs. $\mathrm{BP}$ and a similar trend is observed at PC but with more variability (Fig.7.6). This is interesting because a large number of studies on northern peatlands find that the highest CARs are observed during the first half of this interval (ca. 9000-7000 cal yrs. BP), (Fig.7.6) (Yu et al., 2009; Yu et al., 2012; Loisel et al., 2014; Yu et al., 2014). These higher CARs in other studies are attributed to the Holocene thermal maximum (HTM), between $c a .9000-6000$ cal yrs. BP, during which temperatures were increased by as much as $5{ }^{\circ} \mathrm{C}$ (Fig.7.6) (Davis, 2003; Renssen et al. 2009). In Northern, boreal, peatlands this temperature increase led to enhanced carbon accumulation, because it lengthened the growing season, which is a limiting factor for peatland growth in these regions (Yu et al., 2009). However, at PC and FG carbon accumulation appears to continue on a declining trend and are more akin to the Scottish sites (Fig.7.6).

The opposing trend at PC and FG, in comparison to the Northern sites, is potentially because the study sites sit close to the limit of the bioclimatic envelope of peatland formation, in a UK 
context (Gallego-Sala, 2015). At such peatlands moisture is the limiting factor not the length of the growing season (Charman et al., 2015). Therefore, during the HTM the warmer temperatures may have tipped the water balance at these marginal sites to conditions that were unfavourable for peat accumulation and hence the decrease in carbon accumulation. Similar trends were found in more southern peripheral sites during the HTM, by Loisel et al., (2014) and Charman et al., (2015).

PC and FG also experience lower accumulation rates between $c a$. 6000-5000 cal yrs. BP when cooler neoglacial conditions begin (Fig.7.6) (Davis et al., 2003; Renssen et al., 2009; Marcott et al., 2013). However, this lower accumulation rate is most likely responding to the FBT, that was occurring at both sites within this time interval. As discussed in the earlier FBT section, the transition at both sites involves a slow-down in peat accumulation, and this environmental succession is typically associated with marked lower carbon accumulation (Anderson, 2002). Therefore, autogenic factors likely explain this period of lower accumulation. On the other hand, at Mynydd Bach, CAR is typically stable during this period and begins to increase slightly at ca. 6000 cal yrs. BP, possibly in response to the onset of cooler conditions (Fig.7.6).

After ca. 5000 cal yrs. BP, there is an increasing trend in CAR at all three sites and they all demonstrate particularly high carbon accumulation between $c a$. 4000-2000 cal yrs. BP (Fig.7.6). This is the opposite trend of what is observed in the Scottish and Northern peatland databases, where during this period carbon accumulation is at its lowest (Fig.76). In these regions, carbon accumulation is suggested to be low after $c a .5000$ cal yrs. BP, because cooler neoglacial conditions reduced net primary productivity (the limiting factor at these sites) and hindered peat accumulation (Yu et al., 2009; Yu et al., 2012; Loisel et al., 2014; Yu et al., 2014; Charman et al., 2015; Ratcliffe et al., 2018). However, at the study sites where moisture is the limiting factor, the increased wetness during this time may have promoted carbon accumulation, thus explaining this Late Holocene increase (Fig.7.6). 

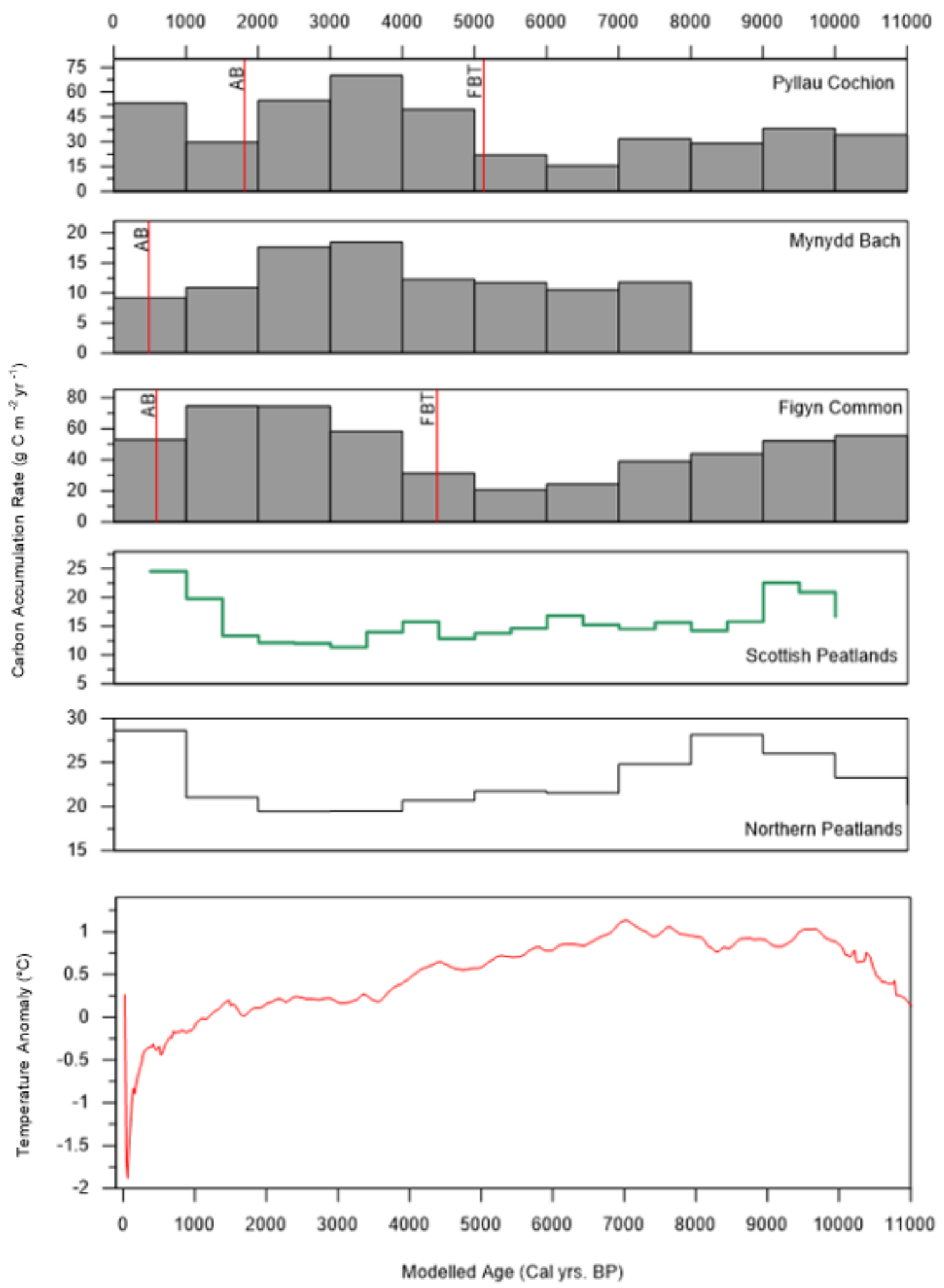

Figure 7:6: From top to bottom; Holocene carbon accumulation rates at PC, MB and FG in 1000-year bins (respectively) (FBT = fen to bog transition, $A B=$ acrotelm boundary); Below that, carbon accumulation records from a Scottish database in 500-year bins (Ratcliffe et al., 2018); the Northern Peatland carbon accumulation database in 1000-year bins (Yu et al., 2014); Northern Hemisphere $\left(>30^{\circ} \mathrm{N}\right)$ temperature reconstruction (Marcott et al., 2013). 
The diverging trend between climate and carbon accumulation that is found between the study sites and the more northern peatlands (at the HTM and during the later Holocene neoglacial cooling) implies that the Carmarthenshire peatlands respond differently to climate changes. This supports the findings of Loisel et al., (2014) and Charman et al., (2015). That is, at northern peatlands, that sit comfortably within the peatland moisture bioclimatic envelope, the impact that past increases in temperature have on lengthening the growing season outweighs reductions in water (Charman et al., 2015). Whereas for peatlands that sit on the southernmost limit close to moisture threshold, like the Carmarthenshire sites, water availability is a more important factor, and therefore any decreases can lead to enhanced decomposition and lower carbon accumulation (Charman et al., 2015). This would explain why the study sites have generally experienced higher accumulation during the wetter conditions associated with the neoglacial cooling after $c a .5000$ cal yrs. BP and lower accumulation during the warmer HTM.

\subsection{3: Short-term Wetness Shifts and Carbon Accumulation}

In addition to the relationship between carbon uptake and longer-term climatic changes, at PC and FG there appears to be an association between shorter-term wetness shifts during the Late Holocene (implied by the humification record) and carbon accumulation (Fig.7.7). Wetter shifts are associated with higher carbon accumulation at some instances and drier intervals correspond with lower CARs, although this relationship is not exclusive (Fig.7.7). Some examples of this association at PC are $c a .3200$ and $c a .2000$ cal yrs. BP where a wetter shift is accompanied by higher CAR and at $c a .3600$ and $c a .2400$ cal yrs. BP, when a dry shift is associated with lower CARs (Fig.7.7) The relationship is less apparent at FG, but there are some convincing examples of CAR being influenced by wetness, at ca. 4200, ca, 2400 and $c a$. 2000 (Fig7.7.). This association between carbon accumulation and wetness suggests that the 
sites sequester more carbon under cooler/wetter scenarios and that carbon accumulation is reduced during warmer/drier times. This is similar to how they seem to have responded to longer term cooling over the Holocene and therefore provides further evidence that increases in wetness at these sites can lead to enhanced carbon accumulation. Furthermore, the lower carbon accumulation experienced during drier times could therefore be the result of the moisture balance being tipped and decay exceeding productivity (Gallego-Sala et al., 2018). This finding further demonstrates the importance of moisture at the Carmarthenshire peatlands, and other southern peripheral sites, and implies that here drying/warming can lead to carbon accumulation reductions.

Overall, the general Holocene responses to longer scale climatic changes and the apparent relationship between short-term wetness shifts and carbon accumulation implies that the sites are likely to experience reduced carbon accumulation in response to projected warming. It therefore has important implications for future projections of peatland carbon. Furthermore, it adds weight to the growing body of research finding that southern marginal peatlands are more at risk of experiencing reductions, and even a cessation, in carbon accumulation in response to projected warming within this century. In contrary to northern peatlands that will experience an increase over the next century (Gallego-Sala et al., 2010; Charman et al., 2013; Charman et al., 2015; Loisel et al., 2014; Yu et al., 2014; Gallego-Sala et al., 2018). 


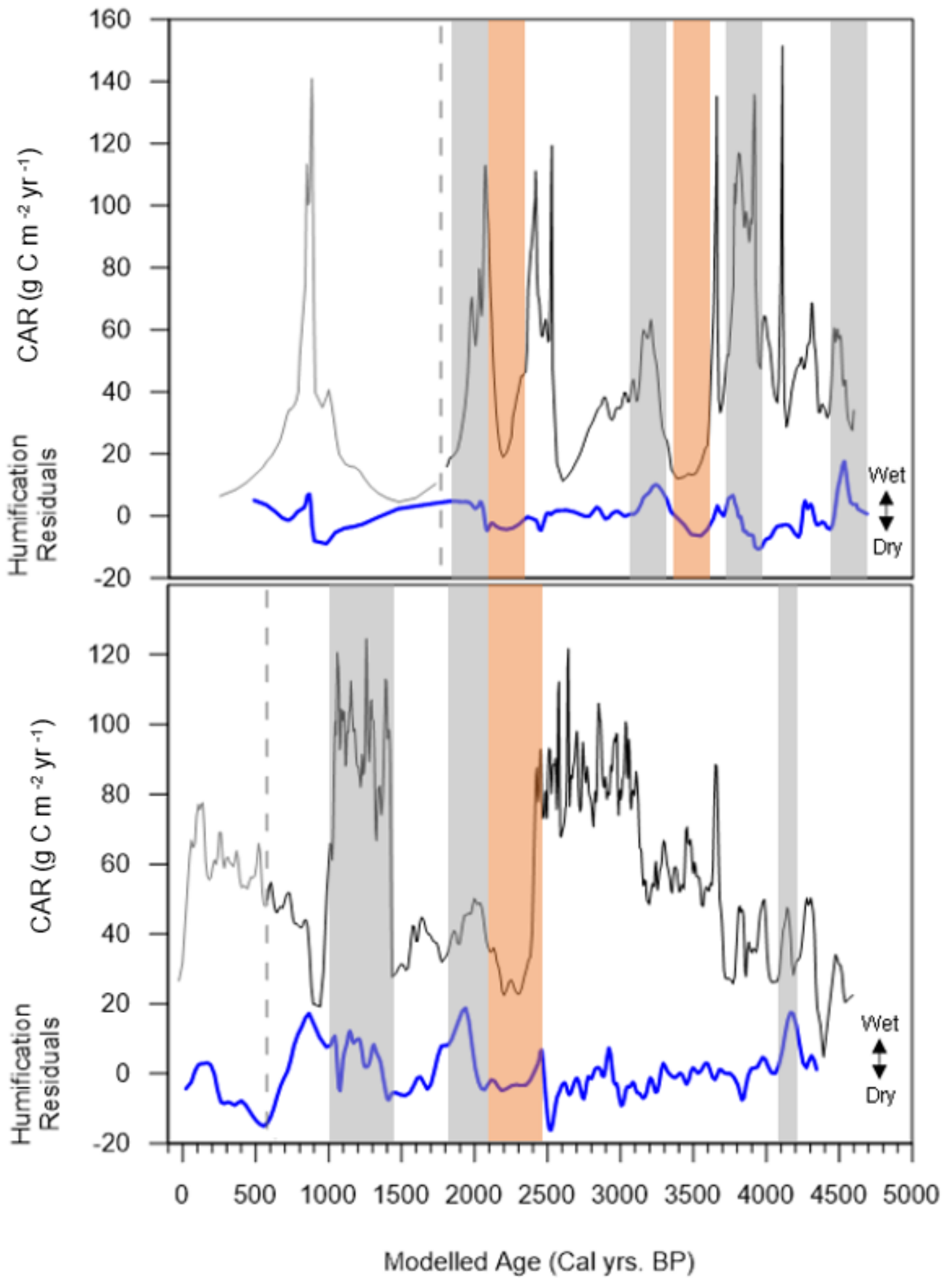

Figure 7:7: Late Holocene carbon accumulation plotted alongside the 3-point moving average humification curve, for PC (top) and FG (bottom). The grey bands indicate examples where a wetter period is associated with higher CAR and the orange bands show some instances where drier intervals are associated with lower CAR. The dashed line signifies the acrotelm boundaries at the two sites. 


\subsection{4: Recent Rates of Carbon Accumulation (RERCAs)}

The RERCAs were calculated for the peat above the designated acrotelm zones (Results). This gave mean RERCAs of 59.81, 15.5 and $9.12 \mathrm{~g} \mathrm{C} \mathrm{m}^{-2} \mathrm{yr}^{-1}$, for FG, PC, and MB (respectively). It is difficult to interpret recent rates of accumulation because it comprises freshly accumulated plant matter that has not yet been fully decayed, referred to as the acrotelm effect (see section 2.2.7.2. in the Literature Review) (Young et al., 2019). However, it can be compared to RERCAs at other peatlands.

Recent carbon accumulation at FG is comparable to RERCAs reported within the literature (see Table 2.4 in literature review). However, the RERCAs at PC and MB are in the lower end of the range, suggesting that they have not accumulated as much carbon in the acrotelm as other temperate and northern peatlands. Furthermore, recent carbon accumulation is typically higher than that in the catotelm (Tolonen and Turunen, 1996). However, at MB and PC RERCAs are lower than catotelm CARs. This loosely implies that carbon accumulation in the recent peat may be much slower than it has been in the past because only $10 \%$ of acrotelm carbon is believed to become incorporated into the catotelm (Clymo, 1983). These features suggest that recent peat accumulation at $\mathrm{MB}$ and $\mathrm{PC}$ is low when compared to other reported RERCAs.

At PC this could be because of peat cutting. Strong evidence of peat removal at this site was suggested by Low (2014) (see PC site description in methodology) and the uppermost date at $50 \mathrm{~cm}(\mathrm{ca} .1800 \mathrm{cal} \mathrm{yrs} . \mathrm{BP})$ is not consistent with the accumulation rate $(0.1 \mathrm{~cm} / \mathrm{yr}$.) beneath this depth. This therefore implies that peat cutting has taken place at some point after $c a .1800$ cal yrs. BP. Peat cutting is known to have occurred in Wales from the late 1700's (Evans, 1800; Slater, 1983...and references Davies, 1814 and Pugh, 1816 therein). At MB, this reduction could be associated with the process of natural fen maturity that sees fen peat growing above the groundwater table height at some point and therefore being subjected to faster 
decomposition. This is reported to occur at fens because, unlike bogs that maintain a perched water table, fens are limited by the groundwater levels (Yu et al., 2003; Loisel and Bunsen, 2020). However, to better understand the impacts of human interference at these sites the uppermost peat ( $<50 \mathrm{~cm}$ depth) would need to be dated using SCPs and Lead210, and even then, it would still be difficult to ascertain the extent to which recent carbon accumulation has been impacted because of the acrotelm effect (see section 2.2.7.2. in Literature Review). 


\section{7: Site Conservation}

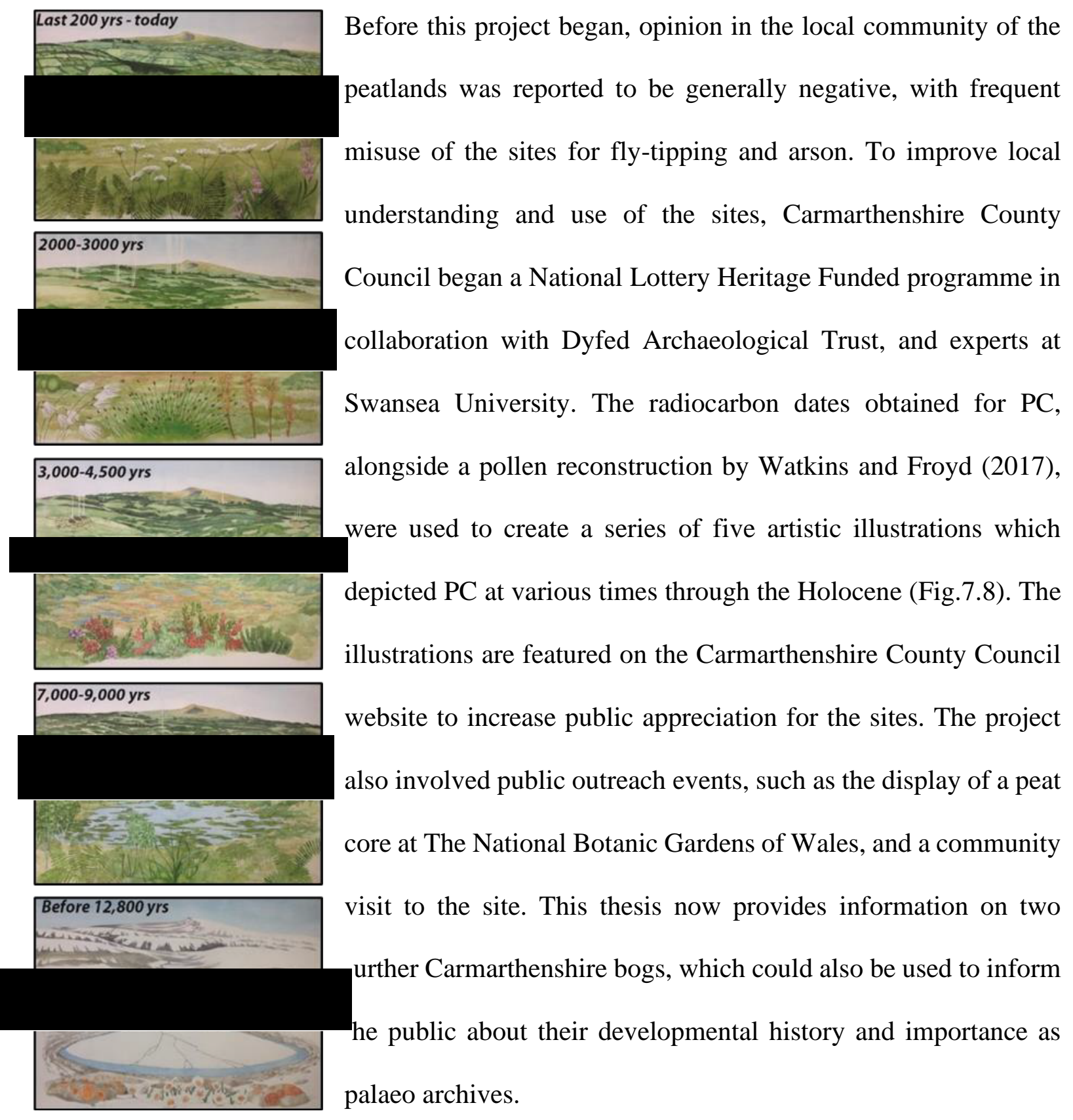

Figure 7:8: Artistic

illustrations of Pyllau

Cochion throughout the

Holocene (Watkins and

Froyd, 2017; CCC, 2021).

Alongside increasing public awareness, the findings of this study may provide some insights into appropriate management strategies for the future. For example, there are concerns about illegal burning on the peatlands (PC and FG) and the literature suggests that fires contribute to 
dryness (Holden et al., 2004; Marcisz et al., 2015). It has therefore been a part of Carmarthenshire County Councils management approach to try and reduce fire activity. This study demonstrates that although fire has been a long-standing feature in this landscape, in some instances it is associated with peatland dryness (see section about this in the fire history discussion). Thereby providing some scientific support behind management strategies that might tackle illegal peat burning. The results from this work also imply that wetter conditions are sometimes related to higher carbon accumulation throughout the Holocene (see section about this in the wetness record discussion). This finding implies that inhibiting drainage could promote greater carbon sequestration in the future. Furthermore, this research suggests that these peatlands are likely to be negatively impacted by projected warming during the next century and therefore their carbon stocks are threatened. This vulnerability to climatic warming at the sites increases the need for a strategy of active management moving forward. 


\section{Chapter 8: Conclusions and Future Recommendations}

\section{1: Conclusions}

- The lowermost sediments observed at Pyllau Cochion are thought to have accumulated during the Late-glacial period. At Figyn, the clay sediments at the base are thought to be of Loch Lomond age. The Late Glacial-Holocene lithostratigraphic changes observed are similar to those found in other Welsh and British records. This provides additional insight into the extent and preservation of Late-Glacial deposits in the Carmarthenshire area.

- Fen peat inception occurred at ca. 10800, ca. 9730 and ca. 7960 cal yrs. BP at Figyn Common, Pyllau Cochion and Mynydd Bach, respectively. These dates correspond with the broad range of Welsh peat inception ages reported in the literature and the process of terrestrialisation or infilling is thought to be at play at FG and PC, likely in response to warmer temperatures at the start of the Holocene. Paludification is the most likely process at Mynydd Bach, possibly triggered by widely reported wetness changes during the $8.2 \mathrm{ka}$ event.

- The fen to bog transition (FBT) is dated to $c a .4480$ cal yrs. BP at Figyn Common and ca. 5120 cal yrs. BP at Pyllau Cochion. The shift is not present at Mynydd Bach, possibly due to its topographic position. At the other two sites, fluctuations in water table are thought to have persisted for around 700 years leading up to the FBT, evidenced by changes in the sediment composition. The transition could have been driven by allogenic forcing including widely documented wetness shifts between $c a$. 6000-5000 cal yrs. BP and the onset of neoglacial cooling after ca. $6000 \mathrm{cal}$ yrs BP.

- In the Late Holocene, wetness records for Figyn Common and Pyllau Cochion provide convincing evidence of regional wet shifts in SW Wales at, ca. 2000 and ca. 850 cal 
yrs. BP and a dry shift at $c a .2400$ cal yrs. BP. These shifts are widely documented in other British BSW records.

- The presence of regionally documented wet/dry shifts at Pyllau Cochion and Figyn Common highlights their potential as palaeoclimatic archives. However, despite some coherence, there are also inconsistencies between the two Carmarthenshire records, for example at $c a .4350-4100$ and $c a .3750-2400$ cal yrs. BP. These inconsistencies could be the result of differences in their reconstructed chronologies, or local factors such as burning.

- The Figyn Common record suggest the persistence of dry conditions at around $c a .80$ cal yrs. BP. The dry shift at $c a .80$ cal yrs. BP is thought to be part of an overall drying trend over the last $\sim 150$ years, possibly in response to climate change and/or ongoing drainage. At Pyllau Cochion a long-term drying out trend is depicted by the raw humification data. This could be the result of peat-cutting or drainage.

- All three sites demonstrate evidence of burning through the Mesolithic period. This burning is thought to be the result of a combination of Mesolithic land clearance and warmer temperatures during the Holocene thermal optimum.

- Evidence for on-site burning increases at all sites after $c a .4500$ cal yrs. BP. In general, there is strong evidence to support the fact that fire activity after $c a .4500 \mathrm{cal}$. yrs BP was human-induced but may have been enhanced indirectly or directly by drier climate at times. At MB, fire activity is linked to Bronze Age ritual practices, and this adds context to the important archaeology of the site. More recent burning is found in the uppermost sample at Pyllau Cochion and Figyn Common and this could be representative of recent arson accounts.

- The broad pattern of fire activity at the three sites ties in with some of the UK wide fire trends and adds new insight into local fire history. 
- There is some evidence to suggest that increased burning activity may have promoted drier bog conditions, for instance at ca. 3690-2600 cal yrs. BP at Figyn Common and ca. 2470-2080 cal yrs. BP at Pyllau Cochion.

- LARCA values for the three sites are 23.71, 13.09 and $42.55 \mathrm{~g} \mathrm{C} \mathrm{m}^{-2} \mathrm{yr}^{-1}$ for Pyllau Cochion, Mynydd Bach, and Figyn Common (respectively). The LARCA values demonstrate that the sites have been effectively sequestering carbon for most of the Holocene at a rate comparable with British and Northern peatlands.

- The LARCA for FG sits at the higher end of the figures reported within the literature implying that FG has been particularly effective at accumulating carbon.

- Mean CARs are 44.51, 52.04 and $12.99 \mathrm{~g} \mathrm{C} \mathrm{m}^{-2} \mathrm{yr}^{-1}$, for Pyllau Cochion, Figyn Common and Mynydd Bach (respectively). The values for Pyllau Cochion and Figyn Common are high in comparison to some studies and this is likely because of the high carbon content percentage found at these sites.

- Carbon accumulation is high in the early Holocene (ca. 1100-9000 cal yrs. BP) at Figyn Common and Pyllau Cochion likely in response to the faster accumulation rates that are associated with early fen stages.

- In contrast to other northern peatlands carbon sequestration at Pyllau Cochion and Figyn Common is lower during the Holocene Thermal Maximum, and at all three sites it is high between $c a$. 4000-2000 cal yrs. BP, when neoglacial cooling persisted. This implies that the sites accumulate more carbon during wetter/cooler conditions and less when it is warmer/drier. Likely because they sit close to the moisture threshold of peatland formation in a UK context.

- An association between shorter-term wet shifts (inferred by the humification record) and higher carbon accumulation is found at several points in the Pyllau Cochion and Figyn Common record, e.g., at ca. 4500 and $c a .2000$ cal yrs. BP (PC) and at $c a .4100$ 
and $c a .2000$ cal yrs. BP (FG). This further demonstrates the importance of moisture at these sites.

- The two aforementioned findings suggest that the sites will likely experience reductions in carbon accumulation in response to projected warming during the $21^{\text {st }}$ century. This adds support to the widely reported theory in the literature that peripheral peatlands will be the first to see losses in their carbon sequestration capacity because of warming.

- Some of the information obtained for this study has been used to enhance public appreciation of the sites, namely by contributing to a series of artistic impressions that depict Pyllau Cochion throughout the Holocene. This study provides information on the history of two other Carmarthenshire bogs that could also be used to promote public awareness.

- The findings of this thesis may provide some insight into appropriate future management strategies, including support towards reducing fire activity and drainage on the sites. It also demonstrates that the carbon stocks at these sites are vulnerable to climate change and therefore need to be actively managed.

\section{2: Future Recommendations}

- To build further on the chronological framework. Including:

o Dating the uppermost sediments using Lead210 and SCPs. This would better inform the timing of peat cutting at Pyllau Cochion and provide more detailed recent carbon accumulation rates at all three sites to assess how the peatlands are responding to current climatic changes.

- Cyptotephra analysis to see if any isochrons are present. These could serve as tools to better correlate the wetness shifts at the two sites and with other peatlands. 
- High resolution dating around the FBT to further constrain the timing of the shift and identify the drivers. This would help to understand the role that allogenic forcing can play in important environmental successions, like the FBT.

- To conduct additional proxy work on the sites. For example, a high-resolution macrofossil analysis could inform vegetation changes around the time of the FBT and in the peat over the last 1000 years. The latter will help to better assess the impacts of human interference. In addition, testate amoebae analysis would strengthen the BSW record. Furthermore, Figyn Common, with its high peat accumulation rate (equating to approximately a metre per 1000 years), would provide an ideal site to conduct high resolution pollen work that could inform centennial scale vegetation changes in the local area.

- Additional proxy work at the sites could then be used to create artistic illustrations for Figyn Common and Mynydd Bach which would further promote their conservation. 


\section{Chapter 9: Appendices}

\section{1: Appendix 1: Pyllau Cochion Core Lithologies}

Table 9:1: Lithological boundaries and depths for the two cores taken at Pyllau Cochion.

\begin{tabular}{|c|c|c|}
\hline PCC1 & PCC2 & Zone description (Troels - Smith (1955) \\
\hline $0-3$ & $0-3$ & $\begin{array}{c}\text { Sh4 } \\
\mathrm{Nig}=4 ; \text { Strf=0; Elas=0; } \text { Sicc }=2\end{array}$ \\
\hline $3-80$ & $3-80$ & $\begin{array}{c}\mathrm{Th}^{2} 3, \mathrm{~Tb} 1 \\
\mathrm{Nig}=3 ; \text { Strf=0; Elas=0; Sicc=2 }\end{array}$ \\
\hline $80-210$ & $80-210$ & $\begin{array}{c}\mathrm{Ti}^{2} 2, \mathrm{~Tb} 2 \\
\mathrm{Nig}=3 ; \text { Strf=0; Elas=1; Sicc=2 }\end{array}$ \\
\hline $210-251$ & $210-253$ & $\begin{array}{c}\text { Ti23, Tb1 }+ \text { Th } \\
\text { Nig=3; Strf=0; Elas }=1 ; \text { Sicc }=2\end{array}$ \\
\hline $251-322$ & $253-323$ & $\begin{array}{c}\mathrm{Ti}^{3} 3, \mathrm{~Tb} 1+\mathrm{Th} \\
\mathrm{Nig}=3 ; \text { Strf=0; } \text { Elas=1, Sicc=2 }\end{array}$ \\
\hline $322-364$ & $323-365$ & $\begin{array}{c}\mathrm{Tb}^{1} \\
\mathrm{Nig}=2.5 ; \mathrm{Strf}=0 ; \text { Elas=2; Sicc=2 }\end{array}$ \\
\hline $364-520$ & $365-520$ & $\begin{array}{c}\text { Sh4 }+ \text { TI }+ \text { Th } \\
\text { Nig=4; Strf }=0 ; \text { Elas=0; Sicc=3 }\end{array}$ \\
\hline $520-562$ & $520-564$ & $\begin{array}{c}\mathrm{Ag} \\
\mathrm{Nig}=2.5 ; \text { Strf }=0 ; \text { Elas }=0 ; \text { Sicc }=3.5\end{array}$ \\
\hline $562-568$ & $564-569$ & $\begin{array}{c}\text { As } \\
\mathrm{Nig}=1.5 ; \text { Strf=0; Elas=0; Sicc=3.5 }\end{array}$ \\
\hline $568-571.5$ & $569-572.5$ & $\begin{array}{c}\mathrm{Ag} \\
\mathrm{Nig}=2.5 ; \text { Strf }=0 ; \text { Elas=0; Sicc }=3.5\end{array}$ \\
\hline $571.5-574$ & $572.5-575$ & $\begin{array}{c}\text { As2; Ag2. } \\
\text { Nig=2; Strf=0; Elas=0; Sicc=3.5 }\end{array}$ \\
\hline $574-816$ & $575-628$ & $\begin{array}{c}\text { As } \\
\mathrm{Nig}=1.5 ; \text { Strf=0; Elas=0; Sicc=3.5 }\end{array}$ \\
\hline
\end{tabular}




\section{2: Appendix 2: Carbonate Testing}

To check for the presence of carbonates, tests were carried out on several samples from each lithological zone in all cores using the methods of Harris et al., (2001). Two samples were taken from each selected depth; one of these samples was treated to remove any carbonate material (test), and the other sample was not treated (control). The test samples were placed in a $0.5 \mathrm{M}$ hydrochloric acid solution for 24 hours and then washed four times using a centrifuge. The treated and untreated samples were then freeze dried, homogenised, weighed using a microbalance, and the carbon and nitrogen content was measured in a mass spectrometer, as in Chambers et al., (2011). The carbon content results of the test and control samples were then compared. This comparison allows for the carbonate content to be indirectly quantified according to the difference between the carbon found in the non-treated samples, and the carbon found in the treated samples, the latter of which have had all potential carbonates removed (Bissuti et al., 2004). A much higher value in the non-treated sample would suggest that carbonates were present and therefore need to be removed.

The carbonate tests revealed that carbon content in the untreated (control) and treated (test) samples were very similar (see Tables 9.2-9.4 and Figs.3.16-3.18 in the methodology). Furthermore, the small differences found between the test and control samples were likely the result of analytical error. This is because the \% $\mathrm{C}$ of the standard used during analysis (acetanilide) has a standard deviation (SD) of 4.89\%: therefore, we know that the results may deviate by this amount. As a result, any two values separated by less than the expected SD range $( \pm 4.89 \%)$ are indistinguishable. For both Pyllau Cochion and Mynydd Bach all \% C values fall within the expected SD range. At Figyn, all but one of the values also fall within the expected range, the exception being at $945 \mathrm{~cm}$. This exception might be because of a different, more minerogenic lithology at this depth, and the test sample might have contained a mineral fragment. Ultimately however, it was not appropriate to treat all samples based on this one 
anomaly. Overall, the findings of the carbonate test suggest that no inorganic carbonates were present, and this is consistent with the non-carbonate geology for all sites.

Table 9:2: Carbonate test results for Pyllau Cochion. Standard deviation range is \pm 4.89 .

\begin{tabular}{|c|c|c|}
\hline Depth cm (mid-point) & Control \% C & Test \% C \\
\hline 1 & 50.53 & 51.62 \\
\hline 50 & 56.94 & 52.44 \\
\hline 129 & 52.29 & 49.31 \\
\hline 209 & 54.18 & 52.46 \\
\hline 321 & 50.17 & 53.88 \\
\hline 401 & 55.92 & 55.48 \\
\hline 465 & 54.60 & 55.39 \\
\hline 541 & 14.84 & 15.30 \\
\hline 551 & 11.65 & 12.86 \\
\hline 601 & 0.71 & 0.46 \\
\hline
\end{tabular}

Table 9:3 Carbonate test results for Figyn Common. Standard deviation range is \pm 4.89 .

\begin{tabular}{|c|c|c|}
\hline Depth cm (mid-point) & Control \% C & Test \% C \\
\hline 1 & 48.69 & 49.14 \\
\hline 65 & 53.57 & 48.95 \\
\hline 145 & 46.72 & 48.30 \\
\hline 225 & 54.73 & 51.08 \\
\hline 305 & 46.58 & 53.85 \\
\hline 385 & 51.87 & 51.57 \\
\hline 545 & 42.45 & 41.94 \\
\hline 625 & 56.81 & 59.15 \\
\hline 705 & 55.20 & 59.84 \\
\hline 785 & 53.35 & 56.85 \\
\hline 865 & 54.18 & 53.23 \\
\hline 945 & 50.60 & 36.91 \\
\hline 1025 & 35.08 & 31.80 \\
\hline 1097 & 0.38 & 2.64 \\
\hline
\end{tabular}


Table 9:4 Carbonate test results for Mynydd Bach. Standard deviation range is \pm 4.89 .

\begin{tabular}{|c|c|c|}
\hline Depth cm (mid-point) & Control \% C & Test \% C \\
\hline 0 & 39.39 & 42.16 \\
\hline 48 & 53.30 & 47.29 \\
\hline 128 & 39.45 & 40.00 \\
\hline
\end{tabular}




\section{3: Appendix 3: Determining Carbon Content}

Regression analyses between TOC\% and OM\% were calculated to estimate carbon content. The result from the regression analysis implies how much carbon (as a percentage) is in each OM measurement at a $2 \mathrm{~cm}$ resolution for each site (see Figure 3.13 in methodology).

For Mynydd Bach, a simple regression analysis was conducted between OM \% and TOC \% (Fig.9.1). However, for the deeper sites (Pyllau Cochion and Figyn Common), the data was first reworked so that it was better suited to a regression analysis (McCarroll, 2016).

The data was reworked because of a cluster of values at the higher end for all sites (Fig.9.2; Fig.9.4). This cluster of values meant that the dataset was not continuous enough for a reliable regression (McCarroll, 2016). To mitigate this issue, the data was ranked. The values that exceeded 88\% OM and 50\% TOC were grouped for Figyn Common, whilst values above 78\% OM and 49\% TOC were grouped for Pyllau Cochion. An average figure for each group was then used for the regression which reduced clustering at the higher end of the dataset ranges so that they were more continuous (Fig.9.3; Fig.9.5). This worked data was used to construct a simple linear regression (Fig.9.3; Fig.9.5).

The linear regression line for all sites gave an $\mathrm{R}^{2}$ value of 0.99 , meaning that $99 \%$ of the variance in TOC is explained by OM (Fig.9.1, 9.3 and 9.5). The regression equation stipulates the percentage of organic matter that is likely to be carbon at each site. These percentages are 56\%, 54\% and 52\% for Figyn Common, Pyllau Cochion and Mynydd Bach (respectively) (Fig.9.1, 9.3 and 9.5).

To ensure that the regression predicted results that were close to the real TOC measurements, the predictions were compared against them (Fig.9.6-9.8). The regression-predicted carbon values for Figyn Common and Pyllau Cochion were close to the range of the actual carbon values (TOC \%). However, they did not predict low values as effectively in some cases 
(Fig.9.6-9.7). Additionally, the 50\% OM prediction gave values that generally underestimated carbon content (Fig.9.6: Fig.9.7). Yet at Mynydd Bach, both assumptions overestimate and underestimate TOC (Fig.9.8).

Overall, both predictors have caveats, but for two of the sites the regression prediction produces values closer to the real TOC \% than the 50\% OM prediction (Fig.9.6-9.7). Furthermore, the regression prediction is likely to provide more accurate values because it is based on some real data (McCarroll, 2016). Therefore, the regression prediction percentages were used to derive carbon content from OM. These percentages are that $56 \%, 54 \%$ and $52 \%$ of OM is carbon for Figyn Common, Pyllau Cochion and Mynydd Bach (respectively).

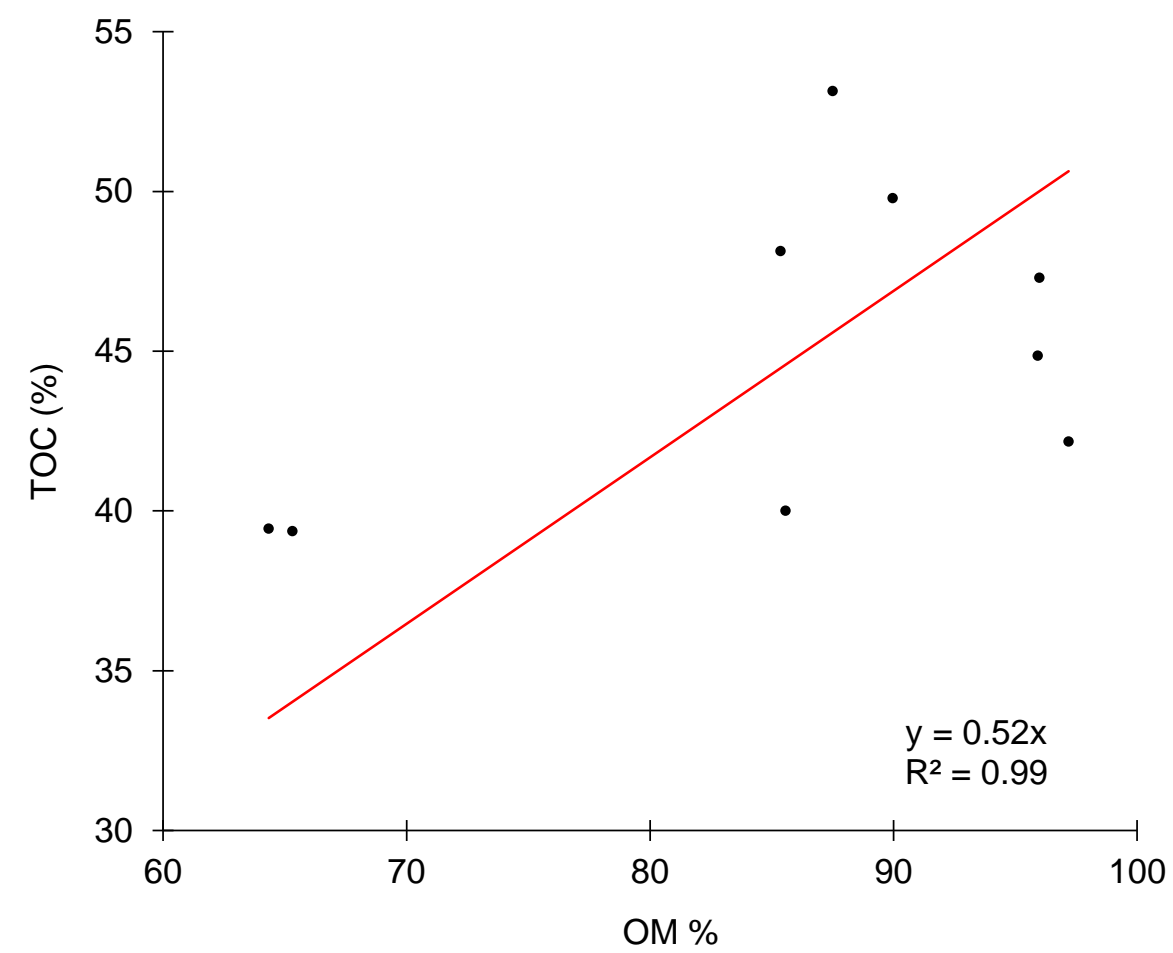

Figure 9:1: Mynydd Bach: scatter plot of unworked TOC \% and OM \%. Data for the regression line is displayed in the right-hand corner. 


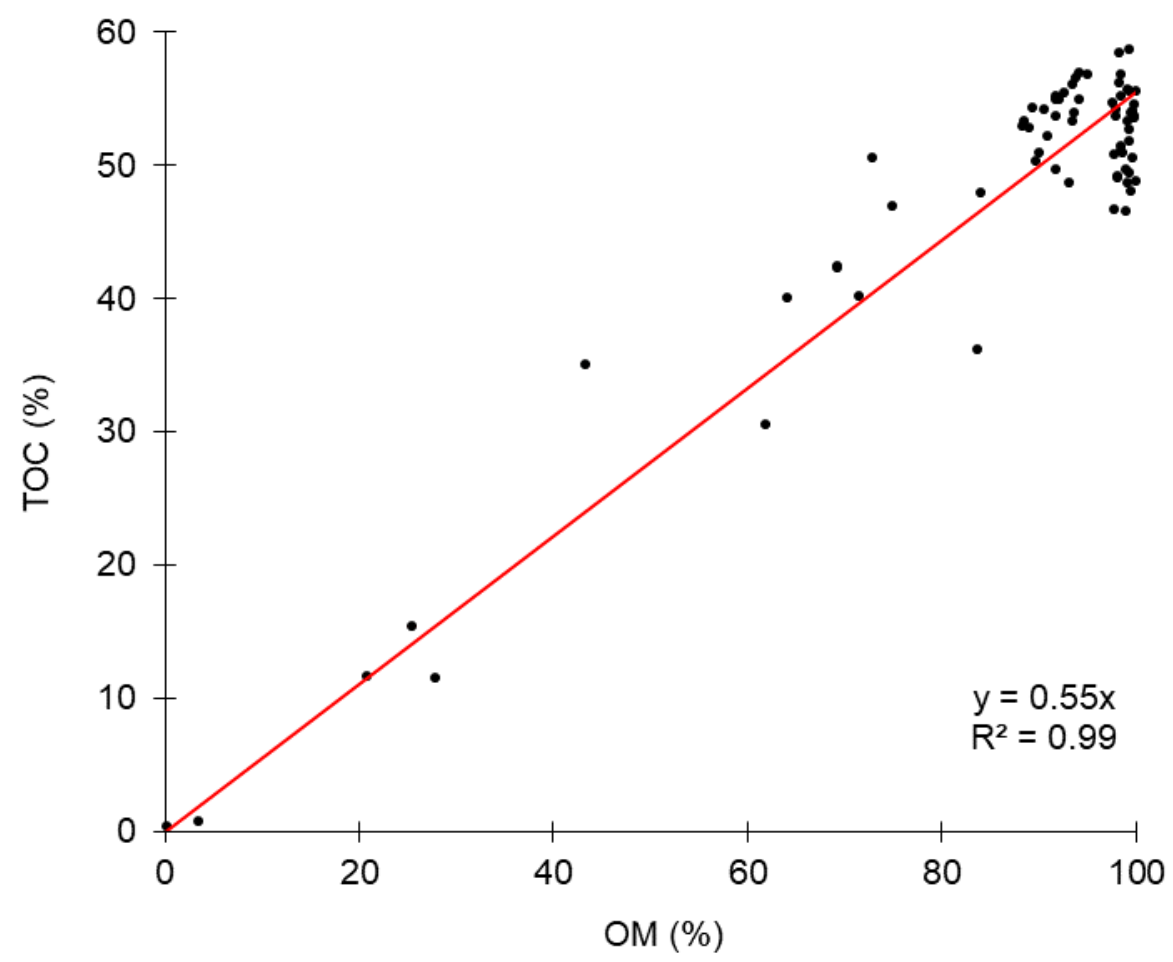

Figure 9:2: Figyn Common: scatter plot of unworked TOC \% and OM \%. Data for the regression line is displayed in the right-hand corner.

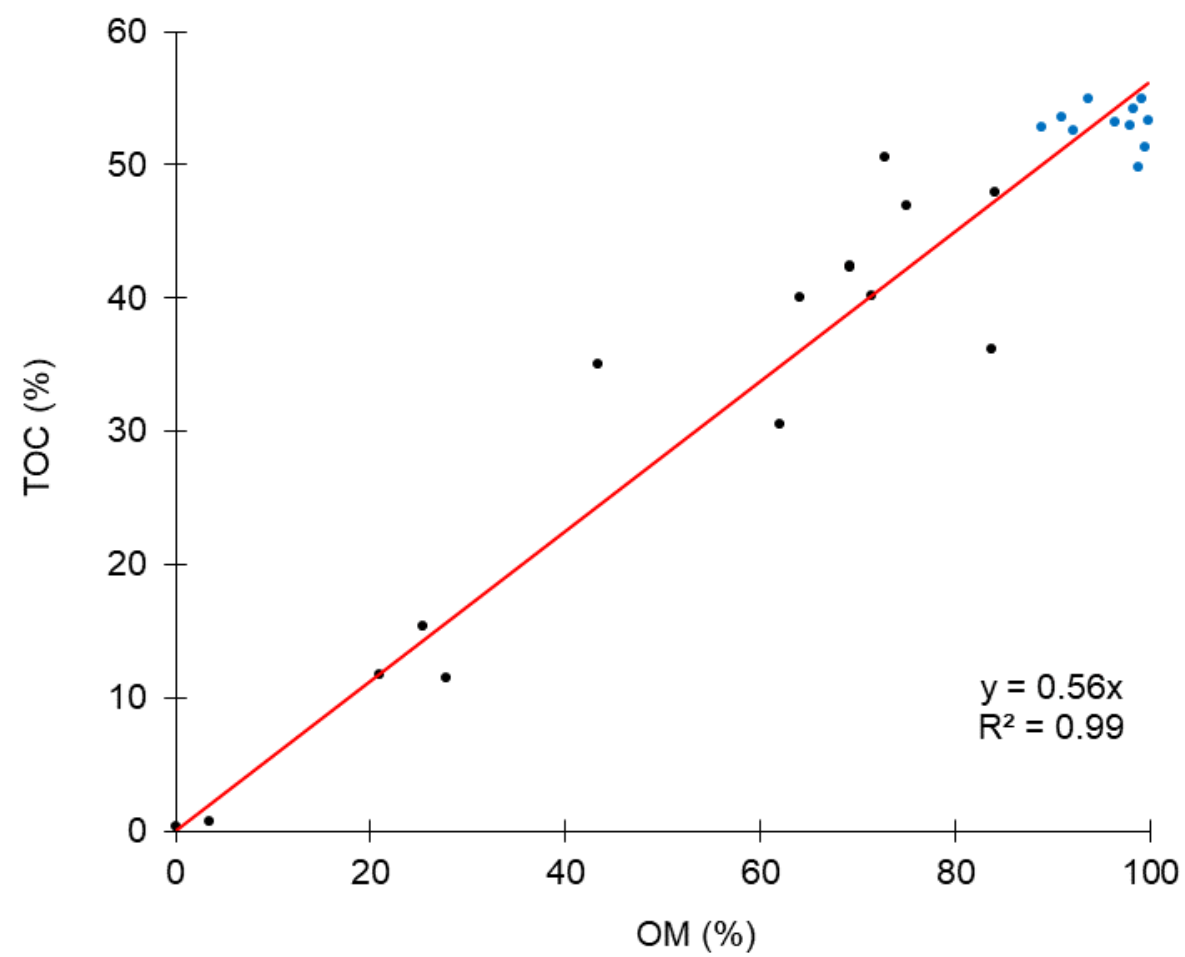

Figure 9:3: Figyn Common: scatter plot of worked TOC \% and OM \% with regression line. Worked data points are in blue. Data for regression line displayed in the right-hand corner. 


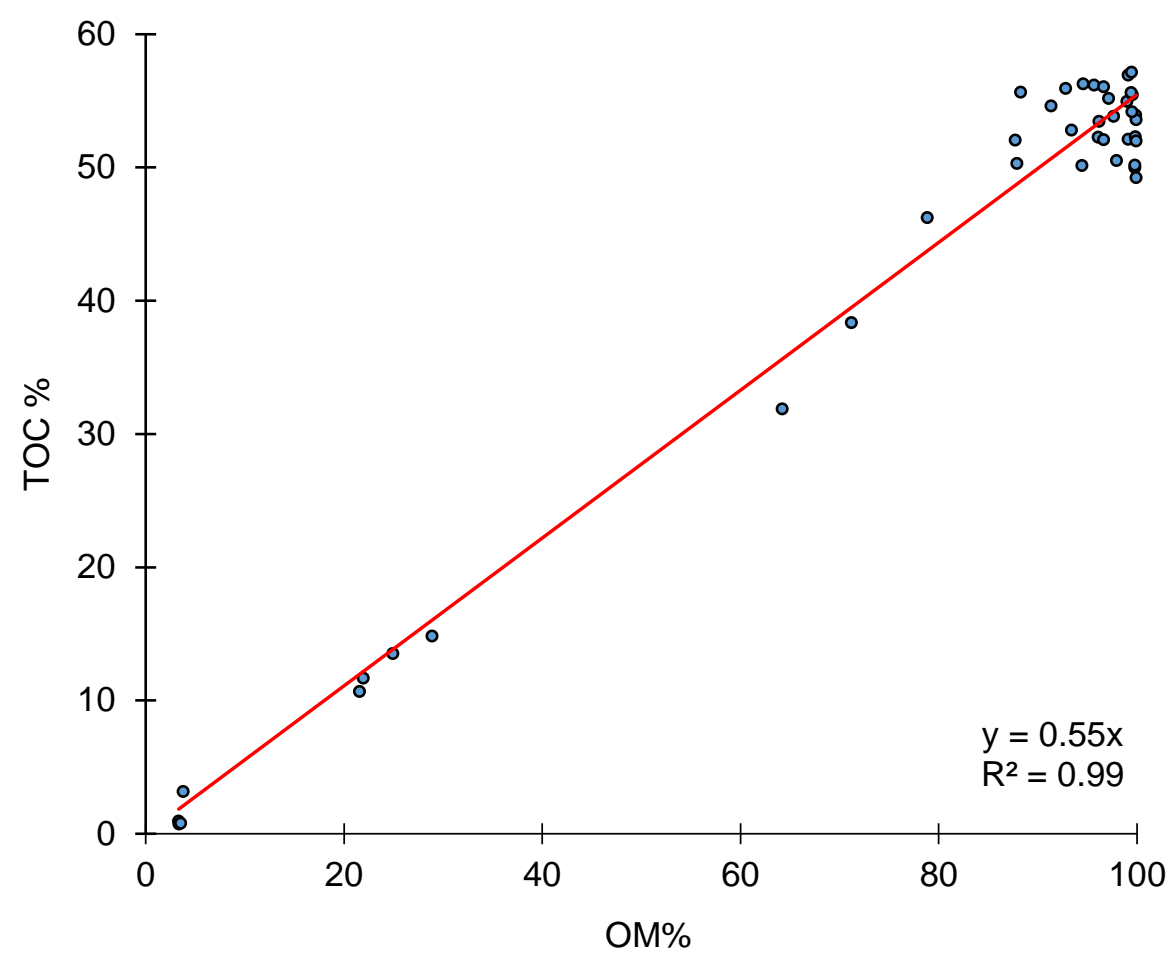

Figure 9:4: Pyllau Cochion: scatter plot of unworked TOC \% and OM \%. Data for the regression line is displayed in the right-hand corner.

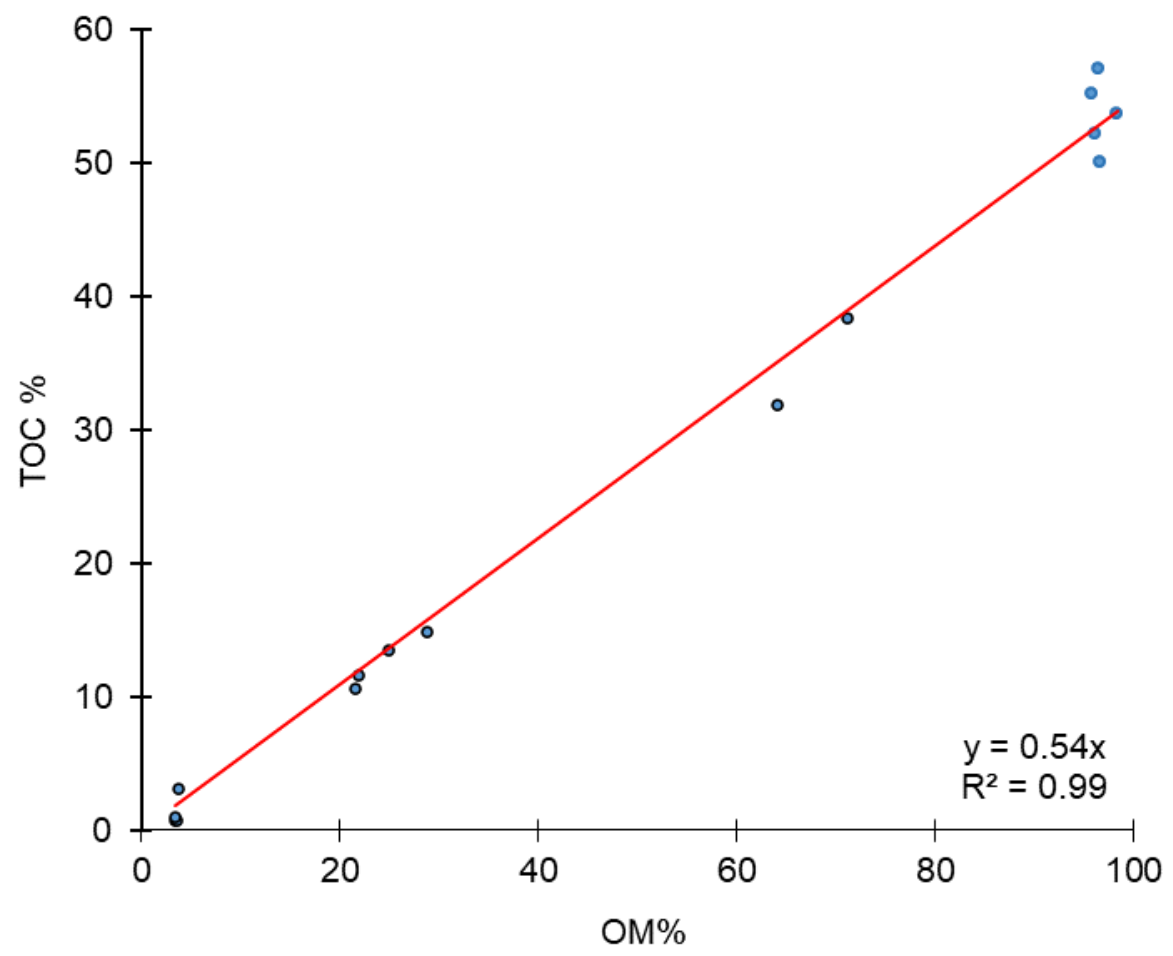

Figure 9:5: Pyllau Cochion: scatter plot of worked TOC \% and OM \% data with regression line. Worked data points are in lighter blue. Data for regression line displayed in the right-hand corner. 


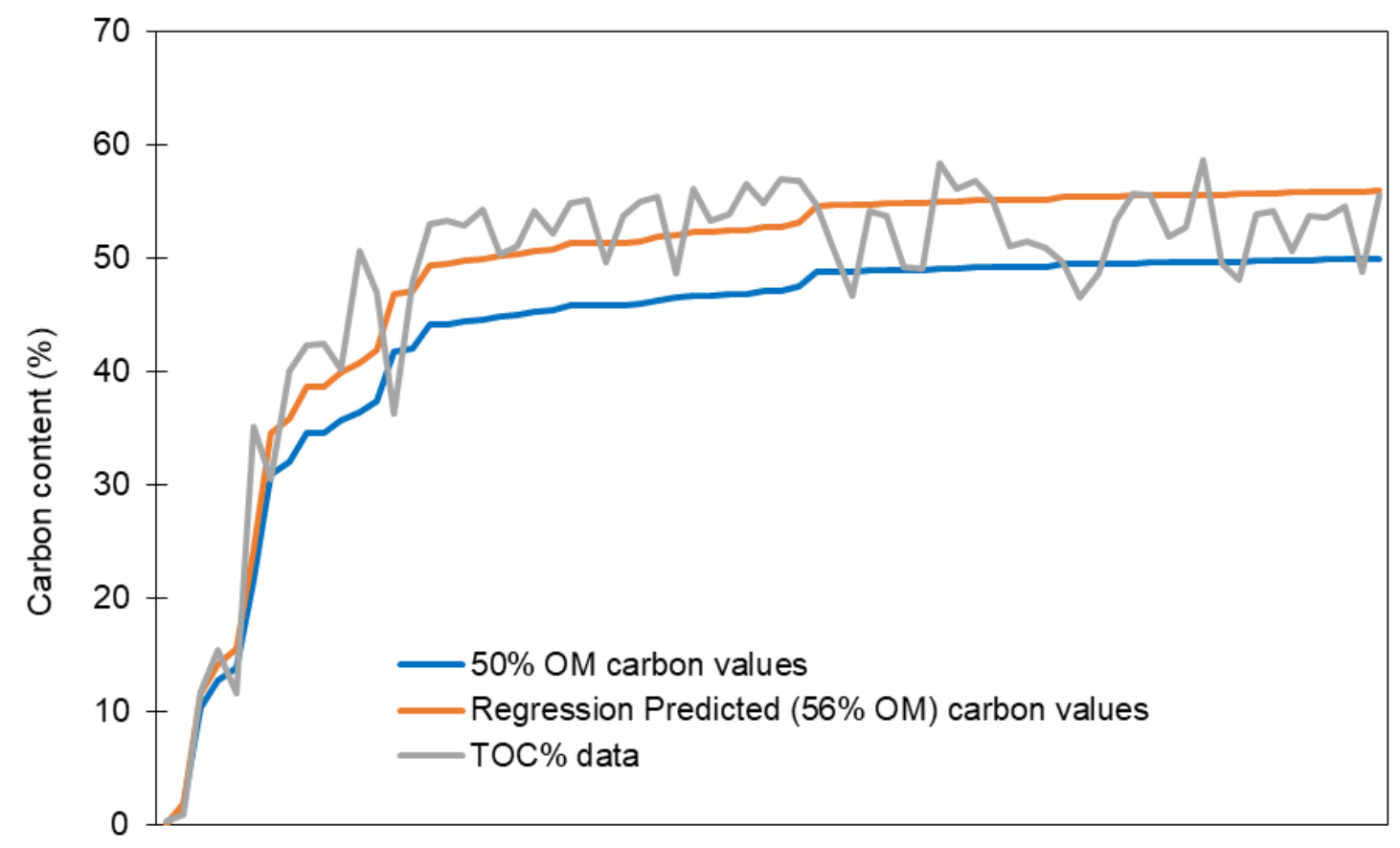

Figure 9:6: Figyn Common: line graph of ranked TOC \%, regression predicted carbon values and OM predicted carbon values.

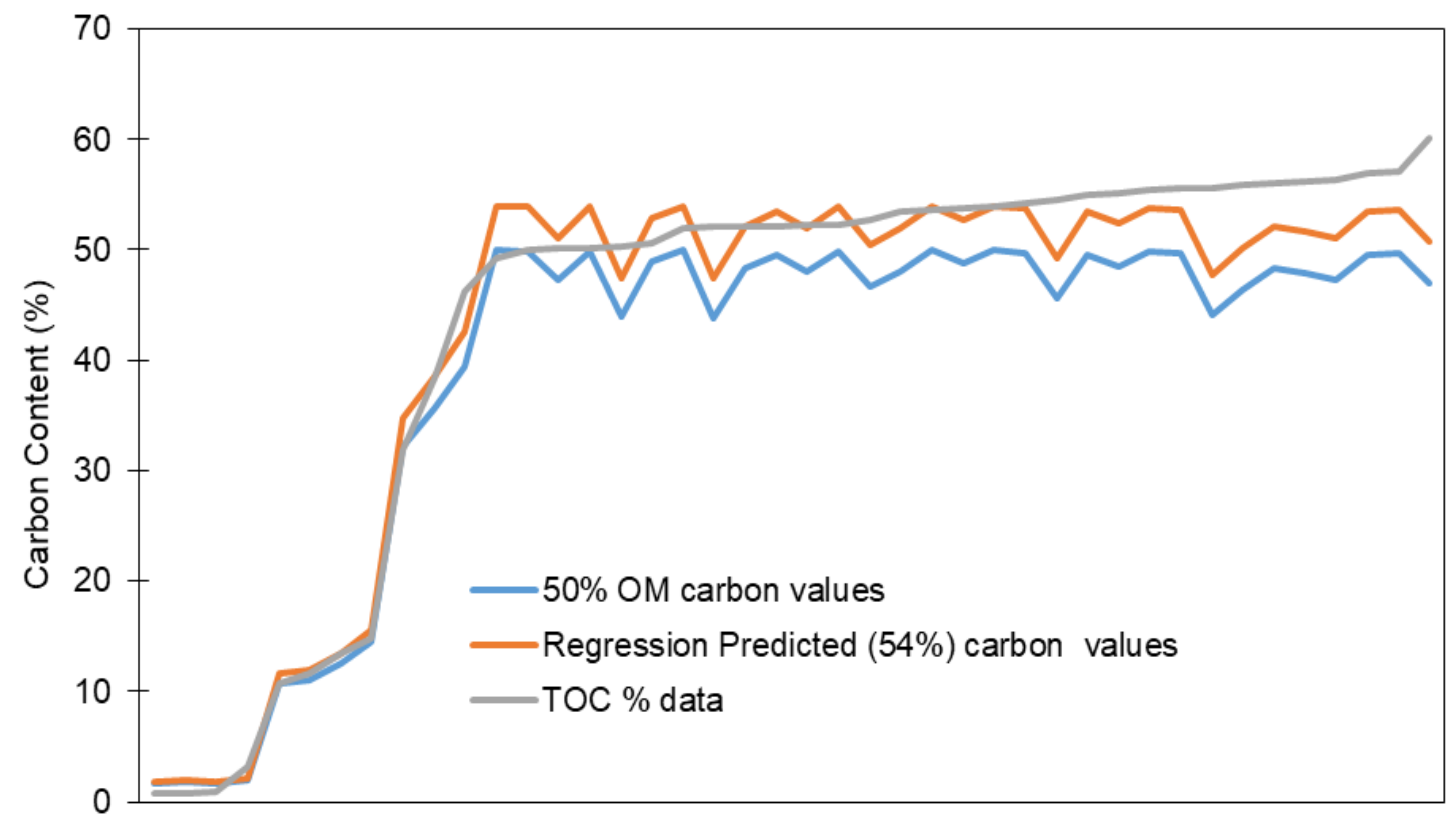

Figure 9:7: Pyllau Cochion: line graph of ranked TOC \%, regression predicted carbon values and OM predicted carbon values. 


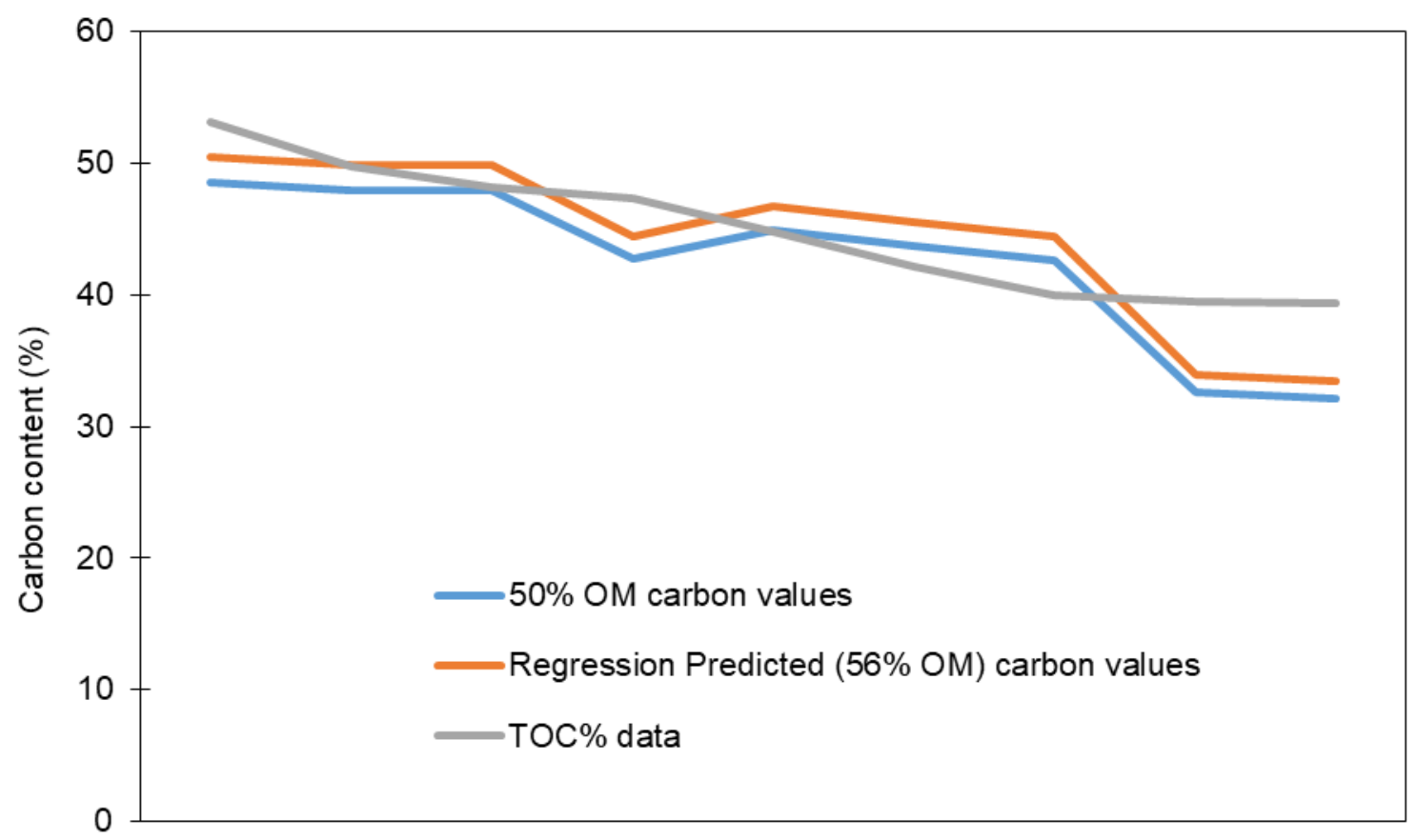

Figure 9:8: Mynydd Bach: line graph of ranked TOC \%, regression predicted carbon values and OM predicted carbon values. 


\section{4: Appendices 4-6: Supplementary Data}

Results tables for Pyllau Cochion, Figyn Common and Mynydd Bach found at:

https://emea01.safelinks.protection.outlook.com/?url=https\%3A\%2F\%2Fswanseauniversitymy.sharepoint.com\%2F\%3Af\%3A\%2Fg\%2Fpersonal\%2F653908_swansea_ac_uk\%2FEslI6 xCW5QFCkcOOEEEGof0BzFbrHbwNVZ7FRYtTzhSGCQ\%3Fe\%3D1KEp0Kanddata=04 \%7C01\%7C\%7C117633e95d574d0ff61b08d93686b941\%7C84df9e7fe9f640afb435aaaaaaaa aaaа\%7C1\%7C0\%7C637600774519335312\%7CUnknown\%7CTWFpbGZsb3d8eyJWIjoiM C4wLjAwMDAiLCJQIjoiV2luMzIiLCJBTiI6Ik1haWwiLCJXVCI6Mn0\%3D\%7C1000ands data=s0hCaiZ1ghuG2ePS0YCNjlhxIp7NpZJm7tk2L14SwPM\%3Dandreserved=0 


\section{Chapter 10: References}

Aaby, B. and Berglund, B.E., (1986). Characterization of peat and lake deposits. In Berglund, B.E., eds., (1986). Handbook of Holocene palaeoecology and palaeohydrology, 231-246.

Aaby, B. and Tauber, H., (1975). Rates of peat formation in relation to degree of humification and local environment, as shown by studies of a raised bog in Deninark. Boreas, 4(1), 1-17.

Aaby, B., (1976). Cyclic climatic variations in climate over the past 5,500 yr reflected in raised bogs. Nature, 263(5575), 281-284.

Abrook, A.M., Matthews, I.P., Candy, I., Palmer, A.P., Francis, C.P., Turner, L., Brooks, S.J., Self, A.E. and Milner, A.M., (2020). Complexity and asynchrony of climatic drivers and environmental responses during the Last Glacial-Interglacial Transition (LGIT) in north-west Europe. Quaternary Science Reviews, 250, 106634.

Adkins, L., Adkins, R. and Leitch, V., (2008). The handbook of British Archaeology. Constable, London.

Adkins, L., Adkins, R., Leitch, V., (2017). The Handbook of British Archaeology. Little Brown Book Group, London.

Aguiar, W., Meissner, K.J., Montenegro, A., Prado, L., Wainer, I., Carlson, A.E. and Mata, M.M., (2021). Magnitude of the $8.2 \mathrm{ka}$ event freshwater forcing based on stable isotope modelling and comparison to future Greenland melting. Scientific reports, 11(1), 1-10.

Alexander, P.D., Bragg, N.C., Meads, R., Padelopoulos, G. and Watts, O. (2008). Peat in horticulture and conservation: the UK response to a changing world. Mires and Peat, 3(8).

Alley, R.B., Mayewski, P.A., Sowers, T., Stuiver, M., Taylor, K.C. and Clark, P.U., (1997). Holocene climatic instability: A prominent, widespread event 8200 yr ago. Geology, 25(6), 483-486.

Anderson, D.E., (2002). Carbon accumulation and C/N ratios of peat bogs in North-West Scotland. Scottish Geographical Journal, 118(4), 323-341.

Anderson, D.E., (1998). A reconstruction of Holocene climatic changes from peat bogs in north-west Scotland. Boreas, 27(3), 208-224.

Anderson, R.L., Foster, D.R. and Motzkin, G., (2003). Integrating lateral expansion into models of peatland development in temperate New England. Journal of Ecology, 91(1), 68-76. 
Bahnson, H (1968). Kolorimetriske betemmelser af humificeringstal i højmosetørv fra Fugls $\varnothing$ mose på Djursland. Hans Reitzel, 1968.

Baird, A.J. and Waldron, S., (2003). Shallow horizontal groundwater flow in peatlands is reduced by bacteriogenic gas production. Geophysical Research Letters, 30 (2043).

Bain, C.G., Bonn, A., Stoneman, R., Chapman, S., Coupar, A., Evans, M., Gearey, B., Howat, M., Joosten, H., Keenleyside, C., Labadz, J., Lindsay, R., Littlewood, N., Lunt, P., Miller, C.J., Moxey, A., Orr, H., Reed, M., Smith, P., Swales, V., Thompson, D.B.A., Thompson, P.S., Van de Noort, R., Wilson, J.D. and Worrall, F., (2011). IUCN UK Commission of Inquiry on Peatlands. IUCN UK Peatland Programme, Edinburgh.

Baker, J . H., (1972). The rate of production and decomposition of Chorisodontiuamci phylum (Hook. f. and Wils.) Broth. British Antarctic Survey Bulletin, 27, 123-129.

Barber, K., Dumayne-Peaty, L., Hughes, P., Mauquoy, D. and Scaife, R., (1998). Replicability and variability of the recent macrofossil and proxy-climate record from raised bogs: field stratigraphy and macrofossil data from Bolton Fell Moss and Walton Moss, Cumbria, England. Journal of Quaternary Science: Published for the Quaternary Research Association, 13(6), 515528.

Barber, K.E., (1981). Peat Stratigraphy and Climate Change: A Palaeoecological Test of the Theory of Cyclic Peat Bog Regeneration. Balkema, Rotterdam.

Barber, K.E., and Charman, D.J., (2014). Holocene Palaeoclimate Records from Peatlands. In Birks, J., Battarbee, R., Mackay, A. and Oldfield, F., eds., (2014). Global change in the Holocene. Routledge, Abingdon, 210-266.

Barber, K.E., Chambers, F.M. and Maddy, D., (2003). Holocene palaeoclimates from peat stratigraphy: macrofossil proxy climate records from three oceanic raised bogs in England and Ireland. Quaternary Science Reviews, 22(5-7), 521-539.

Barber, K.E., Chambers, F.M., Maddy, D., Stoneman, R., and Brew, J.S., (1994). A sensitive high-resolution record of late Holocene climatic change from a raised bog in northern England. The Holocene, 4(2),198-205.

Barber, K.E., Maddy, D., Rose, N., Stevenson, A.C., Stoneman, R. and Thompson, R., (2000). Replicated proxy-climate signals over the last $2000 \mathrm{yr}$ from two distant UK peat bogs: new evidence for regional palaeoclimate teleconnections. Quaternary Science Reviews, 19(6), 481487.

Beaulne, J., Garneau, M., Magnan, G. and Boucher, É., (2021). Peat deposits store more carbon than trees in forested peatlands of the boreal biome. Scientific reports, 11(1), 1-11. 
Belyea, L. R. (2009). Nonlinear Dynamics of Peatlands and Potential Feedbacks on the Climate System. In: Baird, A.J., Belyea, L.R.B., Comas, X., Reeve, A.S. and Slater, L.D. eds., (2009). Carbon cycling in northern peatlands. American Geophysical Union, Washington, DC.

Belyea, L.R. and Malmer, N., (2004). Carbon sequestration in peatland: patterns and mechanisms of response to climate change. Global Change Biology, 10(7), 1043-1052.

Belyea, L.R. and Warner, B.G., (1996). Temporal scale and the accumulation of peat in a Sphagnum bog. Canadian Journal of Botany, 74(3), 366-377.

Berger, A. and Loutre, M.F., (1991). Insolation values for the climate of the last 10 million years. Quaternary Science Reviews, 10(4), 297-317.

Beta Analytic.Inc, (2019 (a)). Beta Analytic Standard Pretreatment Protocols. Accessed online at:> https://www.radiocarbon.com/pretreatment-carbon-dating.htm (Accessed 17/11/2019).

Beta Analytic Inc., (2019 (b)). Introduction to Radiocarbon Determination by the Accelerator Mass Spectrometry Method. Accessible online at:> https://www.radiocarbon.com/PDF/AMSMethodology.pdf (Accessed 21/11/2019).

Bevan, A., Colledge, S., Fuller, D., Fyfe, R., Shennan, S. and Stevens, C., (2017). Holocene fluctuations in human population demonstrate repeated links to food production and climate. Proceedings of the National Academy of Sciences, 114(49), E10524-E10531.

Birks, H. J. B. and Birks, H.H. (1980). Quaternary Palaeoecology. Edward Arnold, London.

Birks, H.H., (2007). Plant macrofossil introduction. In: Elias, S.A., eds., (2007). Encyclopedia of quaternary science 3. Elsevier Science, 2266-2288.

Birks, H.J.B., (1981). Late Wisconsin vegetational and climatic history at Kylen Lake, northeastern Minnesota. Quaternary Research, 16 (3), 322-355.

Bisutti, I., Hilke, I. and Raessler, M., (2004). Determination of total organic carbon-an overview of current methods. TrAC Trends in Analytical Chemistry, 23(10-11), 716-726.

Blaauw, M., and Christen, J.A., (2005). Radiocarbon peat chronologies and environmental change.' Journal of the Royal Statistical Society, 54, (4), 805-816.

Blaauw, M., van der Plicht, J. and van Geel, B., (2004). Radiocarbon dating of bulk peat samples from raised bogs: non-existence of a previously reported 'reservoir effect'?. Quaternary Science Reviews, 23(14-15), 1537-1542. 
Blackford, J.J. and Chambers, F.M., (1991): Proxy records of climate from blanket mires: evidence for a Dark Age (1400 BP) climatic deterioration in the British Isles. The Holocene, $1,63-67$.

Blackford, J.J. and Chambers, F.M., (1995). Proxy climate record for the last 1000 years from Irish blanket peat and a possible link to solar variability. Earth and Planetary Science Letters, 133(1-2), 145-150.

Blundell, A. and Barber, K., (2005). A 2800-year palaeoclimatic record from Tore Hill Moss, Strathspey, Scotland: the need for a multi-proxy approach to peat-based climate reconstructions. Quaternary Science Reviews, 24(10-11), 1261-1277.

Blundell, A. and Holden, J., (2015). Using palaeoecology to support blanket peatland management. Ecological Indicators, 49, 110-120.

Blundell, A., Charman, D.J. and Barber, K., (2008). Multiproxy late Holocene peat records from Ireland: towards a regional palaeoclimate curve. Journal of Quaternary Science: Published for the Quaternary Research Association, 23(1), 59-71.

Blundell, A., Holden, J., and Turner, T.E., (2016). Generating multi-proxy Holocene palaeoenvironmental records from blanket peatlands. Palaeogeography, Palaeoclimatology, Palaeoecology, 443, 216-229.

Blytt, A., (1876). Essay on the immigration of the Norwegian flora during alternating rainy and dry periods. Kristiana, Cammermeyer.

Bond, G., Showers, W., Cheseby, M., Lotti, R., Almasi, P., DeMenocal, P., Priore, P., Cullen, H., Hajdas, I. and Bonani, G., (1997). A pervasive millennial-scale cycle in North Atlantic Holocene and glacial climates. Science, 278(5341), 1257-1266.

Booth, R.K., Lamentowicz, M. and Charman, D.J., (2010). Preparation and analysis of testate amoebae in peatland palaeoenvironmental studies. Mires and Peat, 7.

Bronk Ramsey, C., and Lee, S., (2013). Recent and Planned Developments of the Program Oxcal. Radiocarbon, 55(2), 720-730.

Bronk Ramsey, C., (2008). Deposition models for chronological records. Quaternary Science Reviews, 27(1-2), 42-60.

Bronk Ramsey, C., (2009 (a)). Bayesian analysis of radiocarbon dates. Radiocarbon, 51(1), 337-360.

Bronk Ramsey, C., (2009 (b)). Dealing with outliers and offsets in radiocarbon dating. Radiocarbon, 51(3), 1023-1045. 
Brooks, S.J., Matthews, I.P., Birks, H.H. and Birks, H.J.B., (2012). High resolution Lateglacial and early-Holocene summer air temperature records from Scotland inferred from chironomid assemblages. Quaternary Science Reviews, 41, 67-82.

Bunsen, M.S. and Loisel, J., (2020). Carbon storage dynamics in peatlands: Comparing recentand long-term accumulation histories in southern Patagonia. Global Change Biology, 26(10), 5778-5795.

Burrows, M., Fenner, J. and Haberle, S., (2014). Testing peat humification analysis in an Australian context: Identifying wet shifts in regional climate over the past 4000 years. Mires and Peat, 4 (5), 1-19.

Carless, D., (2015). Carbon Storage in Organic Soils: Carbon stocks and accumulation rates in raised bogs of the Brecon Beacons National Park (BBNP), South Wales. PhD thesis, Swansea University, 2015.

Carmarthenshire County Council (CCC) (2014 (a)). Pyllau Cochion management plan. Carmarthenshire Council report, available on request.

Carmarthenshire County Council (CCC) (2014 (b)). Figyn Common management plan. Carmarthenshire Council report, available on request.

Carmarthenshire County Council (CCC) (2014 (c)). Mynydd Bach Common management plan. Carmarthenshire Council report, available on request.

Carmarthenshire County Council (CCC) (2017). The Carmarthenshire Bogs Project Evaluation Report. National Lottery Evaluation report - project number OH-14-08960.

Carmarthenshire County Council (CCC) (2021). The Carmarthenshire Bogs Project. Available at:> https://www.carmarthenshire.gov.wales/home/council-services/planning/biodiversity/hlfbogs-project/\#.YNg3U-hKiUk (Accessed 27/06/2021).

Chambers, F.M. and Blackford, J.J., (2001). Mid-and late-Holocene climatic changes: a test of periodicity and solar forcing in proxy-climate data from blanket peat bogs. Journal of Quaternary Science: Published for the Quaternary Research Association, 16(4), 329-338.

Chambers, F.M., (1982). Two radiocarbon-dated pollen diagrams from high-altitude blanket peats in South Wales. The Journal of Ecology, 70(2), 445-459.

Chambers, F.M., Barber, K.E., Maddy, D. and Brew, J., (1997). A 5500-year proxy-climate and vegetation record from blanket mire at Talla Moss, Borders, Scotland. The Holocene 7, 391-99. 
Chambers, F.M., Bielman, D.W. and Yu., Z., (2011). Methods for determining peat humification and for quantifying peat bulk density, organic matter, and carbon content for palaeostudies of climate and peatland carbon dynamics. Mires and Peat, 7, 1-10.

Chambers, F.M., Booth, R.K., De Vleeschouwer, F., Lamentowicz, M., Le Roux, G., Mauquoy, D., Nichols, J.E. and Van Geel, B., (2012). Development and refinement of proxyclimate indicators from peats. Quaternary International, 268, 21-33.

Chambers, F.M., Mauquoy, D., Cloutman, E.W., Daniell, J.R.G. and Jones, P.S., (2007). Recent vegetation history of Drygarn Fawr (Elenydd SSSI), Cambrian Mountains, Wales: implications for conservation management of degraded blanket mires. Biodiversity and Conservation, 16(10), 2821-2846.

Charman, D., (2002). Peatlands and Environmental Change. John Wiley and Sons, Chichester.

Charman, D.J. (1990). Origins and development of the flow country blanket mire, northern Scotland, with particular reference to patterned fens. Unpublished PhD thesis, University of Southampton, 1990.

Charman, D.J. and Garnett, M.H., (2005). Chronologies for recent peat deposits using wigglematched radiocarbon ages: problems with old carbon contamination. Radiocarbon, 47(1), 135145 .

Charman, D.J., (2008). Peatlands and Past Climate Change. In: Parish, F., Sirin, A., Charman, D., Joosten, H., Minayeva, T., Silvius, M. and Stringer, L., eds., (2008). Assessment on Peatlands, Biodiversity and Climate Change: Main Report. Global Environment Centre, Kuala Lumpur and Wetlands International, Wageningen. 39-59.

Charman, D.J., (2010). Centennial climate variability in the British Isles during the mid-late Holocene. Quaternary Science Reviews, 29(13-14), 1539-1554.

Charman, D.J., Amesbury, M.J., Hinchliffe, W., Hughes, P.D., Mallon, G., Blake, W.H., Daley, T.J., Gallego-Sala, A.V. and Mauquoy, D., (2015). Drivers of Holocene peatland carbon accumulation across a climate gradient in northeastern North America. Quaternary Science Reviews, 121, 110-119.

Charman, D.J., Barber, K.E., Blaauw, M., Langdon, P.G., Mauquoy, D., Daley, T.J., Hughes, P.D. and Karofeld, E., (2009). Climate drivers for peatland palaeoclimate records. Quaternary Science Reviews, 28(19-20), 1811-1819.

Charman, D.J., Beilman, D.W., Blaauw, M., Booth, R.K., Brewer, S., Chambers, F.M., Christen, J.A., Gallego-Sala, A., Harrison, S.P., Hughes, P.D. and Jackson, S.T., (2013). Climate-related changes in peatland carbon accumulation during the last millennium. Biogeosciences, 10(2), 929-944. 
Charman, D.J., Blundell, A., Chiverrell, R.C., Hendon, D. and Langdon, P.G., (2006). Compilation of non-annually resolved Holocene proxy climate records: stacked Holocene peatland palaeo-water table reconstructions from northern Britain. Quaternary Science Reviews, 25(3-4), 336-350.

Chimner, R. A., D. J. Cooper, and W. J. Parton., (2002). Modeling carbon accumulation in Rocky Mountain fens. Wetlands, 22, 100- 110.

Chiverrell, R.C., (2001). A proxy record of late Holocene climate change from May Moss, northeast England. Journal of Quaternary Science: Published for the Quaternary Research Association, 16(1), 9-29.

Clay, G.D., Worrall, F. and Aebischer, N.J., (2015). Carbon stocks and carbon fluxes from a 10 -year prescribed burning chronosequence on a UK blanket peat. Soil use and management, 31(1), 39-51.

Clymo, R, S., (1983). Peat. In: Gore, A., eds., (1983). Mires, Swamps, Bog, Fen and Moor. Ecosystems of the World 4A. Elsevier, Amsterdam, 159-224.

Clymo, R, S., (1991). Peat Growth. In: Shane, L.C.K., Cushing, E.J., eds., (1991). Quaternary Landscapes. University of Minnesota press, Minesota, 76-109.

Clymo, R. S., J. Turunen, and K. Tolonen., (1998). Carbon accumulation in peatland. Oikos 81, 368- 388 .

Clymo, R.S., (1992). Models of peat growth. Suo, 43 (4-5), 127-136.

Clymo, R.S., (1965). Experiments on breakdown of Sphagnum in two bogs. The Journal of Ecology, 1965, 747-758.

Clymo, R.S., (1984). The limits to peat bog growth. Philosophical Transactions of the Royal Society of London. B, Biological Sciences, 303(1117), 605-654.

Daley, T.J. and Barber, K.E., (2012). Multi-proxy Holocene palaeoclimate records from Walton Moss, northern England and Dosenmoor, northern Germany, assessed using three statistical approaches. Quaternary International, 268, 111-127.

Daniels, R.E. and Eddy, A., (1990). A Handbook of European Sphagna. Natural Environment Research Council, Swindon.

Dargie, G.C., Lewis, S.L., Lawson, I.T., Mitchard, E.T., Page, S.E., Bocko, Y.E. and Ifo, S.A., (2017). Age, extent, and carbon storage of the central Congo Basin peatland complex. Nature, 542(7639), 86-90. 
Davies, A.L. and Bunting, M.J., (2010). Applications of palaeoecology in conservation. The Open Ecology Journal, 3(1), 54-67.

Davies, D., (2016). State of Nature 2016: Wales. RSPB. Available online at:> https://www.rspb.org.uk/our-work/conservation/projects/state-of-nature-reporting (Accessed 01/02/2017).

Davis, B.A., Brewer, S., Stevenson, A.C. and Guiot, J., (2003). The temperature of Europe during the Holocene reconstructed from pollen data. Quaternary science reviews, 22(15-17), 1701-1716.

De Jong, R., Blaauw, M., Chambers, F.M., Christensen, T.R., De Vleeschouwer, F., Finsinger, W., Fronzek, S., Johansson, M., Kokfelt, U., Lamentowicz, M. and Le Roux, G., (2010). Climate and peatlands. In: Dodson J., eds., (2010). Changing Climates, Earth Systems and Society. Springer, Dordrecht, 85-121.

De Vleeschouwer, F., Chambers, F.M. and Swindles, G.T., (2011). Coring and sub-sampling of peatlands for palaeoenvironmental research. Mires and Peat, 7, 1-10.

Dean, W.E., (1974). Determination of carbonate and organic matter in calcareous sediments and sedimentary rocks by loss on ignition; comparison with other methods. Journal of Sedimentary Research, 44(1), 242-248.

Dugmore, A.J., Newton, A.J., Sugden, D.E. and Larsen, G., (1992). Geochemical stability of fine-grained silicic Holocene tephra in Iceland and Scotland. Journal of Quaternary Science, $7(2), 173-183$.

Dunbar, E., Cook, G.T., Naysmith, P., Tripney, B.G. and Xu, S., (2016). AMS 14 C dating at the Scottish Universities Environmental Research Centre (SUERC) radiocarbon dating laboratory. Radiocarbon, 58(1), 9-23.

Dunn, C, and Freeman, C., (2011). Peatlands: our greatest source of carbon credits? Carbon Management 2(3), 289-301.

Dupont, L.M., (1986). Temperature and rainfall variation in the Holocene based on comparative palaeoecology and isotope geology of a hummock and a hollow (Bourtangerveen, The Netherlands). Review of Palaeobotany and Palynology, 48(1-3), 71-159.

Edwards, K.J., Langdon, P.G. and Sugden, H., (2007). Separating climatic and possible human impacts in the early Holocene: biotic response around the time of the 8200 cal. yr BP event. Journal of Quaternary Science, 22(1), 77-84.

Ellis, C.J. and Tallis, J.H., (2000). Climatic control of blanket mire development at Kentra Moss, north-west Scotland. Journal of Ecology, 88(5), 869-889. 
Ellis, C.J. and Tallis, J.H., (2001). Climatic control of peat erosion in a North Wales blanket mire. New Phytologist, 313-324.

Evans, C., Artz, R., Moxley, J., Smyth, M-A., Taylor, E., Archer, N., Burden, A., Williamson, J., Donnelly, D., Thomson, A., Buys, G., Malcolm, H., Wilson, D., Renou-Wilson, F., Potts J. (2017). Implementation of an emission inventory for UK peatlands. Report to the Department for Business, Energy and Industrial Strategy, Centre for Ecology and Hydrology, Bangor.

Evans, J., (1800). A tour through part of North Wales, in the year 1798, and at other times: principally undertaken with a view to botanical researchers in the Alpine Country, interspersed with observations on its scenery, agriculture, manufactures, customs, history. Baldwin and Son, London.

Evans, M.G., Burt, T.P., Holden, J. and Adamson, J.K., (1999). Runoff generation and water table fluctuations in blanket peat: evidence from UK data spanning the dry summer of 1995. Journal of Hydrology, 221(3-4), 141-160.

Frolking, S., Roulet, N.T., Moore, T.R., Lafleur, P.M., Bubier, J.L. and Crill, P.M., (2002). Modeling seasonal to annual carbon balance of Mer Bleue Bog, Ontario, Canada. Global Biogeochemical Cycles, 16(3), 4-1.

Watkins and Froyd (2017). Pollen reconstruction of Pyllau Cochion Bog. Swansea University, 2017.

Froyd, C.A. (2006). Holocene fire in the Scottish Highlands: evidence from macroscopic charcoal records. The Holocene, 16(2), 235-249.

Fyfe, R.M., Brown, A.G. and Rippon, S.J., (2003). Mid-to late-Holocene vegetation history of Greater Exmoor, UK: estimating the spatial extent of human-induced vegetation change. Vegetation History and Archaeobotany, 12(4), 215-232.

Gallego-Sala, A.V., Charman, D.J., Brewer, S., Page, S.E., Prentice, I.C., Friedlingstein, P., Moreton, S., Amesbury, M.J., Beilman, D.W., Björck, S. and Blyakharchuk, T., (2018). Latitudinal limits to the predicted increase of the peatland carbon sink with warming. Nature Climate Change, 8(10), 907-913.

Gallego-Sala, A.V., Charman, D.J., Harrison, S.P., Li, G. and Prentice, I.C., (2015). Climatedriven expansion of blanket bogs in Britain during the Holocene. Climate of the Past Discussions, 11(5), 4811-4832.

Gallego-Sala, A.V., Clark, J.M., House, J.I., Orr, H.G., Prentice, I.C., Smith, P., Farewell, T. and Chapman, S.J., (2010). Bioclimatic envelope model of climate change impacts on blanket peatland distribution in Great Britain. Climate Research, 45, 151-162.

Gardener, M. and Roberts, C., (2010). Guide to common grasses. FSC publication, Telford. 
Garnett, M.H., Ineson, P. and Stevenson, A.C., (2000). Effects of burning and grazing on carbon sequestration in a Pennine blanket bog, UK. The Holocene, 10(6), 729-736.

Gkinis, V., Simonsen, S.B., Buchardt, S.L., White, J.W.C. and Vinther, B.M., (2014). Water isotope diffusion rates from the NorthGRIP ice core for the last 16,000 years-Glaciological and paleoclimatic implications. Earth and Planetary Science Letters, 405, 132-141.

Glasser, N.F., Davies, J.R., Hambrey, M.J., Davies, B.J., Gheorghiu, D.M., Balfour, J., Smedley, R.K. and Duller, G.A.T., (2018). Late Devensian deglaciation of south-west Wales from luminescence and cosmogenic isotope dating. Journal of Quaternary Science, 33(7), 804818.

Godfrey, M., (2014). Guide to mosses and liverworts of woodlands. FSC publication, Telford.

Gorham, E., (1991). Northern peatlands: role in the carbon cycle and probable responses to climatic warming. Ecological applications, 1(2), 182-195.

Gorham, E., Lehman, C., Dyke, A., Janssens, J. and Dyke, L., (2007). Temporal and spatial aspects of peatland initiation following deglaciation in North America. Quaternary Science Reviews, 26(3-4), 300-311.

Granath, G., Strengbom, J. and Rydin, H., (2010). Rapid ecosystem shifts in peatlands: linking plant physiology and succession. Ecology, 91(10), 3047-3056.

Grand-Clement, E., Anderson, K., Smith, D., Angus, M., Luscombe, D.J., Gatis, N., Bray, L.S. and Brazier, R.E., (2015). New approaches to the restoration of shallow marginal peatlands. Journal of Environmental Management, 161, 417-430.

Grant, F. R., (2012). Assessment of a peat core from Clogwynygarreg. Report for Royal Commission on the ancient and historical monuments of Wales. Report no: 02/12.

Greiser, C., (2011). Macrofossil analysis: a deep look into the peat archive. PhD diss., Uppsala University. Accessible online via:> https://pdfs.semanticscholar.org/8956/483f9da82e45dc4484f6fa2226abf3784bf5.pdf (Accessed 20/02/2020).

Grosse-Brauckmann, G., (1972). Über pflanzliche Makrossilien mitteleuropäischer Torfe - I. Gewebereste krautiger Pflanzen und ihre Merkmale. Telma, 2, 19-55.

Gumbricht, T., Roman-Cuesta, R.M., Verchot, L., Herold, M., Wittmann, F., Householder, E., Herold, N. and Murdiyarso, D., (2017). An expert system model for mapping tropical wetlands and peatlands reveals South America as the largest contributor. Global Change Biology, 23(9), 3581-3599. 
Hall, V.A. and Pilcher, J.R., (2002). Late-Quaternary Icelandic tephras in Ireland and Great Britain: detection, characterization and usefulness. The Holocene, 12(2), 223-230.

Harris, D., Horwáth, W.R. and Van Kessel, C., (2001). Acid fumigation of soils to remove carbonates prior to total organic carbon or carbon-13 isotopic analysis. Soil Science Society of America Journal, 65(6), 1853-1856.

Heal, 0. W., Latter, P. M. and Howson, G., (1978). A study of the rates of decomposition of organic matter. In: Heal, O.W., Perkins, D.F. with Brown, W.M., eds., (1978). Production ecology of British moors and montane grasslands, Berlin, Springer, 136-159.

Heaton, T.J., Köhler, P., Butzin, M., Bard, E., Reimer, R.W., Austin, W.E., Ramsey, C.B., Grootes, P.M., Hughen, K.A., Kromer, B. and Reimer, P.J., (2020). Marine20 - the marine radiocarbon age calibration curve (0-55,000 cal BP). Radiocarbon, 62(4), 779-820.

Heijmans, M.M., Mauquoy, D., Van Geel, B. and Berendse, F., (2008). Long-term effects of climate change on vegetation and carbon dynamics in peat bogs. Journal of Vegetation Science, 19(3), 307-320.

Heinemeyer, A., Asena, Q., Burn, W.L. and Jones, A.L., (2018). Peatland carbon stocks and burn history: Blanket bog peat core evidence highlights charcoal impacts on peat physical properties and long-term carbon storage. Geo: Geography and Environment, 5(2), e00063.

Hilbert, D.W., Roulet, N. and Moore, T., (2000). Modelling and analysis of peatlands as dynamical systems. Journal of Ecology, 88(2), 42-230.

Holden, J., Chapman, P.J. and Labadz, J.C., (2004). Artificial drainage of peatlands: hydrological and hydrochemical process and wetland restoration. Progress in physical geography, 28(1), pp.95-123.

Holder, K.L., (2015). Reconstructing environmental change and Holocene fire history at Pyllau Cochion Bog, Carmarthenshire: Assessing evidence for Mesolithic-Neolithic burning and the role of fire in peatland development. Thesis (M.Sc.), Swansea University, 2015.

Holder, K.L., (2020) (a). Pyllau Cochion. OS MasterMap, Scale 1:500, using Digimap Ordanance Survey Collection, https://digimap.edina.ac.uk/.

Holder, K.L., (2020) (b). Figyn Common. OS MasterMap, Scale 1:500, using Digimap Ordanance Survey Collection, https://digimap.edina.ac.uk/.

Holder, K.L., (2020) (c). Pyllau Cochion. OS MasterMap, Scale 1:500, using Digimap Ordanance Survey Collection, https://digimap.edina.ac.uk/. 
Holmquist, J.R., Finkelstein, S.A., Garneau, M., Massa, C., Yu, Z. and MacDonald, G.M., (2016). A comparison of radiocarbon ages derived from bulk peat and selected plant macrofossils in basal peat cores from circum-arctic peatlands. Quaternary Geochronology, 31, 53-61.

Hörnberg, G., Ohlson, M. and Zackrisson, O. (1995). Stand dynamics, regeneration patterns and long-term continuity in boreal old-growth Picea abies swamp-forests. Journal of Vegetation Science, 6(2), 291-298.

Huang, X. and Meyers, P.A., (2019). Assessing paleohydrologic controls on the hydrogen isotope compositions of leaf wax n-alkanes in Chinese peat deposits. Palaeogeography, Palaeoclimatology, Palaeoecology, 516, 354-363.

Hughes, P.D., Mauquoy, D., Barber, K.E. and Langdon, P.G., (2000). Mire-development pathways and palaeoclimatic records from a full Holocene peat archive at Walton Moss, Cumbria, England. The Holocene, 10(4), 465-479.

Hughes, P.D.M. and Barber, K.E., (2004). Contrasting pathways to ombrotrophy in three raised bogs from Ireland and Cumbria, England. The Holocene, 14(1), 65-77.

Hughes, P.D.M. and Dumayne-Peaty, L., (2002). Testing theories of mire development using multiple successions at Crymlyn Bog, West Glamorgan, South Wales, UK. Journal of Ecology, 456-471.

Hughes, P.D.M. and Schulz, J., (2001). The development of the Borth Bog (Cors Fochno) mire system and the submerged forst beds at Ynyslas. In Walker, M.J.C. and McCarroll, D., eds., (2001). The Quaternary of West Wales field guide, Quaternary Research Association, 104-12.

Hughes, P.D.M., (1997). The palaeoecology of the fen/bog transition during the early to midHolocene in Britain. PhD thesis, University of Southampton, 1997.

Hughes, P.D.M., (2000). A reappraisal of the mechanisms leading to ombrotrophy in British raised mires. Ecology Letters, 3(1), 7-9.

Hughes, P.D.M., Lomas-Clarke, S.H., Schulz, J. and Jones, P., (2007). The declining quality of late-Holocene ombrotrophic communities and the loss of Sphagnum austinii (Sull. ex Aust.) on raised bogs in Wales. The Holocene, 17(5), 613-625.

Hughes, P.D.M., Mallon, G., Essex, H.J., Amesbury, M.J., Charman, D.J., Blundell, A., Chambers, F.M., Daley, T.J. and Mauquoy, D., (2012). The use of k-values to examine plant 'species signals' in a peat humification record from Newfoundland. Quaternary International, 268, 156-165. 
Hulme, P.D., Ingram, H.A.P. and Robertson, R.A., eds., (1992): Proceedings of the International Symposium: Peatland Ecosystems and Man: An Impact Assessment. Department of Biological Sciences, University of Dundee, UK, and International Peat Society, Jyväskylä, Finland.

Ingram, H.A.P., (1982). Size and shape in raised mire ecosystems: a geophysical model. Nature, 297(5864), 300-303.

Innes, J., Blackford, J. and Simmons, I., (2010). Woodland disturbance and possible land-use regimes during the Late Mesolithic in the English uplands: pollen, charcoal and non-pollen palynomorph evidence from Bluewath Beck, North York Moors, UK. Vegetation History and Archaeobotany, 19(5), 439-452.

Innes, J.B. and Blackford, J.J., (2003). The ecology of late Mesolithic woodland disturbances: model testing with fungal spore assemblage data. Journal of Archaeological Science, 30(2), 185-194.

Innes, J.B. and Simmons, I.G., (2000). Mid-Holocene charcoal stratigraphy, fire history and palaeoecology at North Gill, North York Moors, UK. Palaeogeography, Palaeoclimatology, Palaeoecology, 164(1-4), 151-165.

Innes, J.B., Blackford, J.J. and Rowley-Conwy, P.A., (2013). Late Mesolithic and early Neolithic Forest disturbance: a high-resolution palaeoecological test of human impact hypotheses. Quaternary Science Reviews, 77, 80-100.

Joint Nature Conservation Committee (JNCC)., (2011). Towards an assessment of the state of UK peatlands. JNCC report: No.445.

Jones, C. and Roberts, C., (2002). A key to plants common on moorlands. FSC publication, Telford.

Jones, M.C., Wooller, M. and Peteet, D.M., (2014). A deglacial and Holocene record of climate variability in south-central Alaska from stable oxygen isotopes and plant macrofossils in peat. Quaternary Science Reviews, 87, 1-11.

Joosten, H. and Clarke, D. (2002). Wise use of mires and peatlands - Background and principles including a framework for decision-making. International Mire Conservation Group / International Peat Society: Report, 2002.

Joosten, H., (2008 (a)). Peatlands and Carbon In: Parish, F., Sirin, A., Charman, D., Joosten, H., Minayeva, T., Silvius, M. and Stringer, L., eds., (2008). Assessment on Peatlands, Biodiversity and Climate Change: Main Report. Global Environment Centre, Kuala Lumpur and Wetlands International, Wageningen, 99-117. 
Joosten, H., (2008 (b)). What are Peatlands? In: Parish, F., Sirin, A., Charman, D., Joosten, H., Minayeva, T., Silvius, M. and Stringer, L., eds., (2008). Assessment on Peatlands, Biodiversity and Climate Change: Main Report. Global Environment Centre, Kuala Lumpur and Wetlands International, Wageningen, 8-19.

Katz, N.J., Katz, S.V. and Kipiani, M.G., (1965). Atlas and Keys of Fruits and Seeds Occurring in the Quaternary Deposits of the USSR. Publishing House Nauka, Moscow.

Kilian, M.R, van Geel, B. and van der Plicht, J., (2000). 14C AMS wiggle matching of raised bog deposits and models of peat accumulation. Quaternary Science Reviews, 19, 33-1011.

Kilian, M.R., Van der Plicht, J. and Van Geel, B., (1995). Dating raised bogs: new aspects of AMS 14C wiggle matching, a reservoir effect and climatic change. Quaternary Science Reviews, 14(10), 959-966.

Klinger, L.F., (1996). The Myth of the Classic Hydrosere Model of Bog Succession. Arctic and Alpine Research, 28 (1), 1-9.

Korhola, A., (1992). Mire induction, ecosystem dynamics and lateral extension on raised bogs in the southern coastal area of Finland. Fennia-International Journal of Geography, 170(2), 2594.

Korhola, A., (1994). Radiocarbon evidence for rates of lateral expansion in raised mires in southern Finland. Quaternary Research, 42(3), 299-307.

Korhola, A., Alm, J., Tolonen, K., Turunen, J. and Jungner, H., (1996). Three-dimensional reconstruction of carbon accumulation and $\mathrm{CH} 4$ emission during nine millennia in a raised mire. Journal of Quaternary Science, 11(2), 65-161.

Korhola, A., Tolonen, K., Turunen, J. and Jungner, H., (1995). Estimating long-term carbon accumulation rates in boreal peatlands by radiocarbon dating. Radiocarbon 37(2), 84-575.

Koster, E and Favier, T., (2005). Peatlands, Past and Present. In: Koster, E. eds., (2005). The Physical Geography of Western Europe. Oxford University Press, Oxford, 161-181.

Labadz, J., Allott, T., Evans, M., Butcher, D., Billet, M., Stainer, S., Yallop, A., Jones, P., Innerdale, M., Neasa, H., Kieron, M., Bradbury, R., Mount, D., O’Brien, H. and Hart, R., (2010). Peatland Hydrology. Draft Scientific Review, October 2010, ICUN UK. Available online at:> http://www.iucn-uk-peatlandprogramme.org/sites/www.iucn-ukpeatlandprogramme.org/files/Review\%20Peatland\%20Hydrology,\%20June\%202011\%20Dra ft_0.pdf (Accessed 06/12/2020).

Langdon, P.G., Barber, K.E. and Hughes, P.D.M., (2003). A 7500-year peat-based palaeoclimatic reconstruction and evidence for an 1100-year cyclicity in bog surface wetness 
from Temple Hill Moss, Pentland Hills, southeast Scotland. Quaternary science reviews, 22(24), 259-274.

Le Roux, G. and Marshall, W.A., (2011). Constructing recent peat accumulation chronologies using atmospheric fall-out radionuclides. Mires and Peat, 7(8), 1-14.

Leifeld, J. and Menichetti, L., (2018). The underappreciated potential of peatlands in global climate change mitigation strategies. Nature communications, 9(1), 1-7.

Lindsay, R (2010). Peatbogs and carbon: a critical synthesis to inform policy development in oceanic peat bog conservation and restoration in the context of climate change. Environmental Research Group, University of East London. Commissioned by the RSPB, Scotland, 2010.

Lindsay, R., Birnie, R. and Clough, J., (2014). Peat Bog Ecosystems: Key Definitions. IUCN UK Committee Peatland Programme Briefing Note No.1, 2010.

Lindsay, R.A. (1992). Peatland conservation: the Cinderella Syndrome. In Bragg, O.M., Hulme, P.D., Ingram, H. A. P. Robertson, R. A., eds., (1992). Peatland ecosystems and man: an impact assessment. University of Dundee/British Ecological Society, Mires Research Group, 331-344.

Loader, N.J., Street-Perrott, F.A., Mauquoy, D., Roland, T.P., Van Bellen, S., Daley, T.J., Davies, D., Hughes, P.D.M., Pancotto, V.O., Young, G.H.F. and Amesbury, M.J., (2016). Measurements of hydrogen, oxygen, and carbon isotope variability in Sphagnum moss along a micro-topographical gradient in a southern Patagonian peatland. Journal of Quaternary Science, 31(4), 426-435.

Loisel, J. and Garneau, M., (2010). Late Holocene paleoecohydrology and carbon accumulation estimates from two boreal peat bogs in eastern Canada: Potential and limits of multi-proxy archives. Palaeogeography, Palaeoclimatology, Palaeoecology, 291(3-4), 493533.

Loisel, J. and Yu, Z., (2013). Holocene peatland carbon dynamics in Patagonia. Quaternary Science Reviews, 69, 125-141.

Loisel, J., Yu, Z., Beilman, D.W., Camill, P., Alm, J., Amesbury, M.J., Anderson, D., Andersson, S., Bochicchio, C., Barber, K. and Belyea, L.R., (2014). A database and synthesis of northern peatland soil properties and Holocene carbon and nitrogen accumulation. The Holocene, 24(9), 1028-1042.

Low, R., (2013). Peat thickness determination at six Carmarthenshire bogs. RIGARE Report, 1578_r1.Sept 2014, prepared for Carmarthenshire Council. 
Lowe, D.J., (2011). Tephrochronology and its application: a review. Quaternary Geochronology, 6(2), 107-153.

Lowe, J.J., Ammann, B., Birks, H.H., Björck, S., Coope, G.R., Cwynar, L., De Beaulieu, J.L., Mott, R.J., Peteet, D.M. and Walker, M.J.C., (1994). Climatic changes in areas adjacent to the North Atlantic during the last glacial-interglacial transition (14-9 ka BP): A contribution to IGCP-253. Journal of Quaternary Science, 9(2), 185-198.

Luscombe, D.J., (2014). Understanding the ecohydrology of shallow, drained, and marginal blanket peatlands. Doctoral dissertation, University of Exeter. Available online at:> https://core.ac.uk/download/pdf/43093915.pdf (Accessed 05/11/2020).

MacDonald, G.M., Beilman, D.W., Kremenetski, K.V., Sheng, Y., Smith, L.C. and Velichko, A.A., (2006). Rapid early development of circumarctic peatlands and atmospheric $\mathrm{CH}_{4}$ and $\mathrm{CO}_{2}$ variations. science, 314(5797), 285-288.

MacDonald, G.M., Larsen, C.P., Szeicz, J.M. and Moser, K.A., (1991). The reconstruction of boreal forest fire history from lake sediments: a comparison of charcoal, pollen, sedimentological, and geochemical indices. Quaternary Science Reviews, 10(1), 53-71.

Magnan, G., Lavoie, M. and Payette, S. (2012). Impact of fire on long-term vegetation dynamics of ombrotrophic peatlands in northwestern Québec, Canada. Quaternary Research, 77(1), 110-121.

Magny, M., (2004). Holocene climate variability as reflected by mid-European lake-level fluctuations and its probable impact on prehistoric human settlements. Quaternary international, 113(1), 65-79.

Manning, M.P. and Reid, R.C., (1977). CHO systems in the presence of an iron catalyst. Industrial and Engineering Chemistry Process Design and Development, 16(3), 358-361.

Marcisz, K., Tinner, W., Colombaroli, D., Kołaczek, P., Słowiński, M., Fiałkiewicz-Kozieł, B., Łokas, E. and Lamentowicz, M., (2015). Long-term hydrological dynamics and fire history over the last 2000 years in CE Europe reconstructed from a high-resolution peat archive. Quaternary Science Reviews, 112, 138-152.

Marcott, S.A., Shakun, J.D., Clark, P.U. and Mix, A.C., (2013). A reconstruction of regional and global temperature for the past 11,300 years. Science, 339(6124), 1198-1201.

Marlon, J.R., Bartlein, P.J., Daniau, A.L., Harrison, S.P., Maezumi, S.Y., Power, M.J., Tinner, W. and Vanniére, B., (2013). Global biomass burning: a synthesis and review of Holocene paleofire records and their controls. Quaternary Science Reviews, 65, 5-25. 
Mauquoy, D. and Van Geel, B., (2007). Plant macrofossil methods and studies: mire and peat macros. In: Elias, S.A., eds., (2007). Encyclopedia of quaternary science, Elsevier Science, $2315-2336$.

Mauquoy, D., Engelkes, T., Groot, M.H.M., Markesteijn, F., Oudejans, M.G., Van Der Plicht, J. and Van Geel, B., (2002). High-resolution records of late-Holocene climate change and carbon accumulation in two north-west European ombrotrophic peat bogs. Palaeogeography, Palaeoclimatology, Palaeoecology, 186(3-4), 275-310.

Mauquoy, D., Hughes, P.D.M. and Van Geel, B., (2011). A protocol for plant macrofossil analysis of peat deposits. Mires and Peat, 7(6), 1-5.

Mauquoy, D., Payne, R.J., Babeshko, K.V., Bartlett, R., Boomer, I., Bowey, H., Evans, C.D., Ring-Hrubesh, F., Muirhead, D., O'callaghan, M. and Piotrowska, N., (2020). Falkland Island peatland development processes and the pervasive presence of fire. Quaternary Science Reviews, 240, 106391.

Mayewski, P.A., Rohling, E.E., Stager, J.C., Karlén, W., Maasch, K.A., Meeker, L.D., Meyerson, E.A., Gasse, F., van Kreveld, S., Holmgren, K. and Lee-Thorp, J., (2004). Holocene climate variability. Quaternary research, 62(3), 243-255.

McCarroll, D., (2016). Simple statistical tests for geography. Chapman and Hall/CRC, Boca Raton.

McCarroll, J., Chambers, F.M., Webb, J.C. and Thom, T., (2016). Using palaeoecology to advise peatland conservation: An example from West Arkengarthdale, Yorkshire, UK. Journal for Nature Conservation, 30, 90-102.

McClymont, E.L., Pendall, E. and Nichols, J., (2010). Stable isotopes and organic geochemistry in peat: tools to investigate past hydrology, temperature, and biogeochemistry. PAGES news., 18(1), 15-18.

Millspaugh, S.H. and Whitlock, C., (1995). A 750-year fire history based on lake sediment records in central Yellowstone National Park, USA. The Holocene, 5(3), 283-292.

Millspaugh, S.H., Whitlock, C., Bartlein, P.J., (2000). Variations in fire frequency and climate over the past 17,000 yr in central Yellowstone National Park. Geology, 28(3), 211-214.

Montanarella, L., Jones, R.J. and Hiederer, R., (2006). The distribution of peatland in Europe. Mires and Peat, 1, 1-11.

Mooney, S.D. and Tinner, W., (2011). The analysis of charcoal in peat and organic sediments. Mires and Peat, 7(9), 1-18. 
Moore, P.D. and Bellamy, D.J., (1974). Peatlands. Elek Science, London.

Moore, P.D., (1973). The influence of prehistoric cultures upon the initiation and spread of blanket bog in upland Wales. Nature, 241(5388), 350-353.

Moore, P.D., (1975). Origin of blanket mires. Nature, 256(5515), 267-269.

Moore, P.D., (1993). The origin of blanket mire, revisited. In: Chamber, F. M., eds., (1993). Climate change and human impact on the landscape. Chapman and Hall, London, 217-224.

Morris, P.J., Waddington, J.M., Benscoter, B.W. and Turetsky, M.R., (2011). Conceptual frameworks in peatland ecohydrology: looking beyond the two-layered (acrotelm-catotelm) model. Ecohydrology, 4(1), 1-11.

Morris, P.J., Swindles, G.T., Valdes, P.J., Ivanovic, R.F., Gregoire, L.J., Smith, M.W., Tarasov, L., Haywood, A.M. and Bacon, K.L., (2018). Global peatland initiation driven by regionally asynchronous warming. Proceedings of the National Academy of Sciences, 115(19), 4851-4856.

Naafs, B.D.A., Inglis, G.N., Blewett, J., McClymont, E.L., Lauretano, V., Xie, S., Evershed, R.P. and Pancost, R.D., (2019). The potential of biomarker proxies to trace climate, vegetation, and biogeochemical processes in peat: A review. Global and Planetary Change, 179, 57-79.

Natural Resources Wales., (2021). Peatlands. Accessible online at:> https://cdn.cyfoethnaturiol.cymru/media/692172/information-note-peatlands.pdf (Accessed 06/10/2021).

Nichols, J.E., (2011). Procedures for extraction and purification of leaf wax biomarkers from peats. Mires and Peat, 7(13), 1-7.

Nichols, J.E., Booth, R.K., Jackson, S.T., Pendall, E.G. and Huang, Y., (2006). Paleohydrologic reconstruction based on n-alkane distributions in ombrotrophic peat. Organic Geochemistry, 37(11), 1505-1513.

Nichols, J.E., Peteet, D.M., Moy, C.M., Castañeda, I.S., McGeachy, A. and Perez, M., (2014). Impacts of climate and vegetation change on carbon accumulation in a south-central Alaskan peatland assessed with novel organic geochemical techniques. The Holocene, 24(9), 11461155 .

Nilsson E, Vorren K.D., (1991). Peat humification and climate history. Norsk Geologisk Tidsskrift, 71, 215-217. 
Nilsson, M., Klarqvist, M., Bohlin, E. and Possnert, G., (2001). Variation in 14C age of macrofossils and different fractions of minute peat samples dated by AMS. The Holocene, 11(5), 579-586.

Noble, A., Palmer, S.M., Glaves, D.J., Crowle, A. and Holden, J., (2019). Peatland vegetation change and establishment of re-introduced Sphagnum moss after prescribed burning. Biodiversity and Conservation, 28(4), 939-952.

O'Reilly, J. O'Reilly, C. and Tratt, R. (2012). Field guide to Sphagnum Mosses in Bogs. FSC publication, Telford.

Ohlson, M. and Tryterud, E. (2000). Interpretation of the charcoal record in forest soils: forest fires and their production and deposition of macroscopic charcoal. The Holocene, 10(4), 519525 .

Ohlson, M., Korbøl, A. and Økland, R.H., (2006). The macroscopic charcoal record in forested boreal peatlands in southeast Norway. The Holocene, 16(5), 731-741.

Oldfield, F., Richardson, N. and Appleby, P.G., (1995). Radiometric dating (210Pb, 137Cs, $241 \mathrm{Am}$ ) of recent ombrotrophic peat accumulation and evidence for changes in mass balance. The Holocene, 5(2), 141-148.

Olsson, I.U. (1986). Radiometric dating. In: Berglund, B.E., eds., (1986). Handbook of Holocene palaeoecology and palaeohydrology. United Kingdom: John Wiley and Sons, 271312.

Oxcal (2021). calendar. Available at:> https://c14.arch.ox.ac.uk/oxcalhelp/hlp_analysis_calend.html (Accessed 14/01/2021).

Packalen, M.S. and Finkelstein, S.A., (2014). Quantifying Holocene variability in carbon uptake and release since peat initiation in the Hudson Bay Lowlands, Canada. The Holocene, 24(9), 1063-1074.

Palmer, A.P., Matthews, I.P., MacLeod, A., Abrook, A., Akkerman, K., Blockley, S.P.M., Candy, I., Francis, C., Hoek, W.Z., Kingston, F. and Maas, D., (2021). The Late Quaternary sediment successions of Llangorse Lake, South Wales. Proceedings of the Geologists' Association, 132 (3), 284-296.

Parish, F., Sirin, A., Lee, D. and Silvius, M., (2008). Introduction. In: Parish, F., Sirin, A., Charman, D., Joosten, H., Minayeva, T., Silvius, M. and Stringer, L., eds., (2008). Assessment on Peatlands, Biodiversity and Climate Change: Main Report. Global Environment Centre, Kuala Lumpur and Wetlands International, Wageningen. 1-7. 
Payne, R.J. and Blackford, J.J., (2008). Peat humification and climate change: a multi-site comparison from mires in south-east Alaska. Mires and peat, 1-11.

Piilo, S.R., Zhang, H., Garneau, M., Gallego-Sala, A., Amesbury, M.J. and Väliranta, M.M., (2019). Recent peat and carbon accumulation following the Little Ice Age in northwestern Québec, Canada. Environmental Research Letters, 14(7), 075002.

Pilcher, J.R. and Hall, V.A., (1992). Towards a tephrochronology for the Holocene of the north of Ireland. The Holocene, 2(3), 255-259.

Piotrowska, N., Blaauw, M., Mauquoy, D. and Chambers, F.M., (2011). Constructing deposition chronologies for peat deposits using radiocarbon dating. Mires and Peat, 7, 1-14.

Piper, A (2021). Personal communication with Alice Piper from Dyfed Archaeological Trust about the history of Mynydd Bach. (06/01/2021).

Pitkänen, A., Turunen, J. and Tolonen, K., (1999). The role of fire in the carbon dynamics of a mire, eastern Finland. The Holocene, 9(4), 453-462.

Price, J.S., (1996). Hydrology and microclimate of a partly restored cutover bog, Quebec. Hydrological processes, 10(10), 1263-1272.

Pugh, E., (1816). Cambria Depicta: A Tour through North Wales, illustrated with Picturesque Views. E Williams, London: No. 11, Strand.

Rasmussen, S.O., Vinther, B.M., Clausen, H.B. and Andersen, K.K., (2007). Early Holocene climate oscillations recorded in three Greenland ice cores. Quaternary Science Reviews, 26(1516), 1907-1914.

Ratcliffe, J.L., Payne, R.J., Sloan, T.J., Smith, B., Waldron, S., Mauquoy, D., Newton, A., Anderson, A.R., Henderson, A. and Andersen, R., (2018). Holocene carbon accumulation in the peatlands of northern Scotland. Mires and Peat. 23(3), 1-30.

Reimer, P.J., Austin, W.E., Bard, E., Bayliss, A., Blackwell, P.G., Ramsey, C.B., Butzin, M., Cheng, H., Edwards, R.L., Friedrich, M. and Grootes, P.M., (2020). The Intcal20 Northern Hemisphere radiocarbon age calibration curve (0-55 cal kBP). Radiocarbon, 62(4), 725-757.

Remy, C.C., Fouquemberg, C., Asselin, H., Andrieux, B., Magnan, G., Brossier, B., Grondin, P., Bergeron, Y., Talon, B., Girardin, M.P. and Blarquez, O. (2018). Guidelines for the use and interpretation of palaeofire reconstructions based on various archives and proxies. Quaternary Science Reviews, 193, 312-322. 
Renssen, H., Seppä, H., Heiri, O., Roche, D.M., Goosse, H. and Fichefet, T., (2009). The spatial and temporal complexity of the Holocene thermal maximum. Nature Geoscience, 2(6), 411414.

Rieley, J.O., (2020). Facts, Figures and Fallacy - Half Truths Driving the Phasing Out of Peat Use in Horticulture in England. Oral Presentation, School of Geography, University of Nottingham. Available online at:> http://www.stockbridgeonline.co.uk/wpcontent/uploads/2012/06/rieley_phasing-out-peat2_IPC14070312.pdf (Accessed 22/11/2020).

Roberts, N., (2014). The Holocene: an environmental history. John Wiley and Sons, Chichester.

Robinson, D.E. and Dickson, J.H., (1988). Vegetational history and land use: a radiocarbondated pollen diagram from Machrie Moor, Arran, Scotland. New Phytologist, 109(2), 223-251.

Robinson, S.D. and Moore, T.R., (1999). Carbon and peat accumulation over the past 1200 years in a landscape with discontinuous permafrost, northwestern Canada. Global Biogeochemical Cycles, 13(2), 591-601.

Roland, T.P., Daley, T.J., Caseldine, C.J., Charman, D.J., Turney, C.S.M., Amesbury, M.J., Thompson, G.J. and Woodley, E.J., (2015). The 5.2 ka climate event: Evidence from stable isotope and multi-proxy palaeoecological peatland records in Ireland. Quaternary Science Reviews, 124, 209-223.

Rose, N.L., (2008). Quality control in the analysis of lake sediments for spheroidal carbonaceous particles. Limnology and Oceanography: Methods, 6(4), 172-179.

Rotherham, I.D. (2009). Peat and Peat Cutting. Shire Publications, Oxford.

Rotherham, I.D., (2020). Peatlands: Ecology, Conservation and Heritage. Routledge, Abingdon.

Ruppel, M., Väliranta, M., Virtanen, T. and Korhola, A., (2013). Postglacial spatiotemporal peatland initiation and lateral expansion dynamics in North America and northern Europe. The Holocene, 23(11), 1596-1606.

Rydin, H. and Jeglum, J., (2006). The Biology of Peatlands. Oxford University Press, New York.

Schlesinger, W., (1997) Carbon balance in Terrestrial Detritus. Annual Review of Ecology and Systematics, 8, 51-81.

Schumann, M. and Joosten, H., (2008). Global Peatland Restoration Manual. Institute of Botany and Landscapes Ecology, Greifswald University, Germany. 
Sernander, R., (1908). On the evidence of postglacial changes of climate furnished by the peatmosses of Northern Europe. Geologiska Föreningen i Stockholm Förhandlingar, 30(7), 465-473.

Shiller, J.A., Finkelstein, S.A. and Cowling, S.A., (2014). Relative importance of climatic and autogenic controls on Holocene carbon accumulation in a temperate bog in southern Ontario, Canada. The Holocene, 24(9), 1105-1116.

Shore, J.S., Bartley, D.D. and Harkness, D.D., (1995). Problems encountered with the 14C dating of peat. Quaternary Science Reviews, 14(4), 373-383.

Seigel, D.I. and Glaser, P., (2006). The Hydrology of Boreal Peatlands. In: Weider, R.K. and Vitt, D.H., eds. (2006). Boreal Peatland Ecosystems. Springer, Berlin. 280-313.

Simmons, I. G., (1996). The environmental impact of later Mesolithic cultures. Edinburgh University Press, Edinburgh.

Simmons, I. G., (2003) The Moorlands of England and Wales: An environmental history 8000 BC-AD 2000. Edinburgh University Press, Edinburgh.

Sjörs, H., (1950). On the relation between vegetation and electrolytes in north Swedish mire waters. Oikos 2, 241-258.

Slater, F.M., (1983). Peat-cutting in mid-Wales: a brief introduction. Nature in Wales, 17(3), 149-152.

Smith, A.G. and Cloutman, E.W., (1988). Reconstruction of Holocene vegetation history in three dimensions at Waun-Fignen-Felen, an upland site in South Wales. Philosophical Transactions of the Royal Society of London. B, Biological Sciences, 322(1209), 159-219.

Smith, A.G. and Green, C.A., (1995). Topogenous peat development and late-Flandrian vegetation history at a site in upland South Wales. The Holocene, 5(2), 172-183.

Staff, R., (2017). Personal communication during a lecture on Radiocarbon dating and Bayesian Chronological Analysis. 22/03/2017.

Stivrins, N., Ozola, I., Galka, M., Kuske, E., Alliksaar, T., Andersen, T.J., Lamentowicz, M., Wulf, S. and Reitalu, T., (2017). Drivers of peat accumulation rate in a raised bog: impact of drainage, climate, and local vegetation composition. Mires and Peat, 19(8), 1-19.

Street-Perrot, A (2015). Personal communication during a meeting discussing the interpretation of $\mathrm{C}: \mathrm{N}$ ratios in lakes. 01/06/2015. 
Stuiver, M. and Braziunas, T.F., (1998). Anthropogenic and solar components of hemispheric 14C. Geophysical Research Letters, 25(3), 329-332.

Succow, M., and Joosten, H., eds., (2001). Landschaftsökologische Moorkunde: Second Edition. Schweizerbart, Stuttgart.

Swain, A.M., (1978). Environmental changes during the past 2000 years in north-central Wisconsin: analysis of pollen, charcoal, and seeds from varved lake sediments. Quaternary Research, 10(1), 55-68.

Swindles, G.T., (2010). Dating recent peat profiles using spheroidal carbonaceous particles (SCPs). Mires and Peat, 7.

Swindles, G.T., Blundell, A., Roe, H.M. and Hall, V.A., (2010(b)). A 4500-year proxy climate record from peatlands in the North of Ireland: the identification of widespread summer 'drought phases'?. Quaternary Science Reviews, 29(13-14), 1577-1589.

Swindles, G.T., Galloway, J.M., Rushworth, G., Wheeler, J., Murphy, P. and Taylor, T.F., (2021). Natural to cultural: The vegetation history of the southern Yorkshire Dales, UK. Review of Palaeobotany and Palynology, 284, 104328.

Swindles, G.T., Morris, P.J., Mullan, D.J., Payne, R.J., Roland, T.P., Amesbury, M.J., Lamentowicz, M., Turner, T.E., Gallego-Sala, A., Sim, T. and Barr, I.D., (2019). Widespread drying of European peatlands in recent centuries. Nature Geoscience, 12(11), 922-928.

Swindles, G.T., Patterson, R.T., Roe, H.M. and Galloway, J.M., (2012). Evaluating periodicities in peat-based climate proxy records. Quaternary Science Reviews, 41, 94-103.

Tanneberger, F., Moen, A., Joosten, H. and Nilsen, N., (2017). The peatland map of Europe. Mires and Peat, 19 (22), 1-17.

Tansley, A. G., (1939). The British Islands and Their Vegetation. Cambridge University Press, London.

Taylor, R., (1987). Radiocarbon Dating: An Archaeological Perspective. Academic Press, Cambridge.

The British Geological Survey, (2020). The Geology of Britain viewer. Accessible online at:> https://mapapps.bgs.ac.uk/geologyofbritain/home.html (Accessed 24/04/2020).

The International Peatland Society (2020). Peat Formation. Available online at:> https://peatlands.org/peat/peat-formation/ (Accessed 06/07/2020). 
Tillman, P.K., Holzkämper, S., Kuhry, P., Sannel, A.B.K., Loader, N.J. and Robertson, I., (2010). Stable carbon and oxygen isotopes in Sphagnum fuscum peat from subarctic Canada: Implications for palaeoclimate studies. Chemical Geology, 270(1-4), 216-226.

Tipping R (1995) Holocene landscape change at Carn Dubh, near Pitlochry, Perthshire. J Quaternary Science Reviews, 10, 59-75.

Tipping, R., (2008). Blanket peat in the Scottish Highlands: timing, cause, spread and the myth of environmental determinism. Biodiversity and Conservation, 17(9), 2097-2113.

Tolonen, K. and Turunen, J., (1996). Accumulation rates of carbon in mires in Finland and implications for climate change. The Holocene, 6(2), 171-178.

Troels-Smith, J., (1955). Karakterisering af lose jordarter. Characterization of unconsolidated sediments. Danmarks Geologiske Undersøgelse, 4, 1-73.

Turetsky M, Wieder K, Halsey L, Vitt D (2002). Current disturbance and the diminishing peatland carbon sink. Geophysical research letters, 11, 21-1.

Turner, T.E., Swindles, G.T. and Roucoux, K.H., (2014). Late Holocene ecohydrological and carbon dynamics of a UK raised bog: impact of human activity and climate change. Quaternary Science Reviews, 84, 65-85.

Turunen, J., Tomppo, E., Tolonen, K. and Reinikainen, A., (2002). Estimating carbon accumulation rates of undrained mires in Finland-application to boreal and subarctic regions. The Holocene, 12(1), 69-80.

Van Bellen, S., Dallaire, P.L., Garneau, M. and Bergeron, Y., (2011). Quantifying spatial and temporal Holocene carbon accumulation in ombrotrophic peatlands of the Eastmain region, Quebec, Canada. Global Biogeochemical Cycles, 25(2).

van der Linden, M., Heijmans, M.M. and van Geel, B., (2014). Carbon accumulation in peat deposits from northern Sweden to northern Germany during the last millennium. The Holocene, 24(9), 1117-1125.

van Geel, B., (1978). A palaeoecological study of Holocene peat bog sections in Germany and the Netherlands, based on the analysis of pollen, spores and macro- and microscopic remains of fungi, algae, cormophytes and animals. Review of Palaeobotany and Palynology 25, 1-120.

van Geel, B., Buurman, J. and Waterbolk, H.T. (1996). Archaeological and palaeoecological indications of an abrupt climate change in the Netherlands, and evidence for climatological teleconnections around 2650 BP. Journal of Quaternary Science 11, 451-60. 
van Geel, B., Buurman, J. and Waterbolk, H.T., (1996). Archaeological and palaeoecological indications of an abrupt climate change in The Netherlands, and evidence for climatological teleconnections around 2650 BP. Journal of Quaternary Science: Published for the Quaternary Research Association, 11(6), 451-460.

Vandeputte, K., Moens, L. and Dams, R., (1996). Improved sealed-tube combustion of organic samples to $\mathrm{CO} 2$ for stable carbon isotope analysis, radiocarbon dating and percent carbon determinations. Analytical Letters, 29(15), 2761-2773.

von Post, L. and Sernander, R., (1910). Pflanzen-physiognomische Studien auf Torfmooren in Närke. Excursion, A7.

Waddington, J.M. and Price, J.S., (2013). Effect of peatland drainage, harvesting, and restoration on atmospheric water and carbon exchange. Physical geography, 21(5), 433-451.

Waddington, J.M., Morris, P.J., Kettridge, N., Granath, G., Thompson, D.K. and Moore, P.A., (2015). Hydrological feedbacks in northern peatlands. Ecohydrology, 8(1), 113-127.

Waddington, J.M., Warner, K.D. and Kennedy, G.W., (2002). Cutover peatlands: a persistent source of atmospheric CO2. Global biogeochemical cycles, 16(1), 1-7.

Walker, D., (1970). Direction and rate in some British post-glacial hydroseres. In: Walker, D. and West, R. G., eds., (1970). Studies on the Vegetational History of the British Isles. Cambridge University Press, London, 117-139.

Walker, M., 2005. Quaternary dating methods. John Wiley and Sons. Chichester.

Walker, M., Gibbard, P., Head, M.J., Berkelhammer, M., Björck, S., Cheng, H., Cwynar, L.C., Fisher, D., Gkinis, V., Long, A. and Lowe, J., (2019). Formal subdivision of the Holocene series/epoch: a summary. Journal of the Geological Society of India, 93(2), 135-141.

Watson, E.J., Swindles, G.T., Lawson, I.T. and Savov, I.P., (2015). Spatial variability of tephra and carbon accumulation in a Holocene peatland. Quaternary Science Reviews, 124, 248-264.

Wheeler, B. D., and Proctor, M. C. F., (2000). Ecological gradients, subdivisions, and terminology of north-west European mires. Journal of Ecology, 88, 187-203.

Whitlock, C. and Anderson, R.S., (2003). Fire history reconstructions based on sediment records from lakes and wetlands. In: Veblen. T.T., Baker, W. L., Montenegro, G and Sweetnam, T.W., eds., (2003). Fire and climatic change in temperate ecosystems of the western Americas. Springer, New York, 3-31. 
Whitlock, C. and Millspaugh, S.H. (1996). Testing the assumptions of fire-history studies: an examination of modern charcoal accumulation in Yellowstone National Park, USA. The Holocene, 6(1), 7-15.

Whitlock, C., and Larsen, C. (2001). Charcoal as a fire Proxy. In: Smol, J.P., Birks, H.J.B. and Last, W.M., eds., (2001). Tracking Environmental Change Using Lake Sediments. Volume 3: Terrestrial, Algal and Siliceous Indicators. Kluwer Academic Publishers, Dordrecht, 75-97.

Wrubleski, D.A., (1987). Chironomidae (Diptera) of peatlands and marshes in Canada. The Memoirs of the Entomological Society of Canada, 119 (S140), 141-161.

Xu, J., Morris, P.J., Liu, J. and Holden, J., (2018). PEATMAP: Refining estimates of global peatland distribution based on a meta-analysis. Catena, 160, 134-140.

Young, D.M., Baird, A.J., Charman, D.J., Evans, C.D., Gallego-Sala, A.V., Gill, P.J., Hughes, P.D., Morris, P.J. and Swindles, G.T., (2019). Misinterpreting carbon accumulation rates in records from near-surface peat. Scientific reports, 9(1), 1-8.

Yu, Z., (2006). Modeling ecosystem processes and peat accumulation in boreal peatlands. In: Weider, R.K. and Vitt, D.H., eds., (2003). Boreal peatland ecosystems. Springer, Berlin, Heidelberg, 313-329.

Yu, Z., (2011). Holocene carbon flux histories of the world's peatlands: Global carbon-cycle implications. The Holocene, 21(5), 761-774.

Yu, Z., Beilman, D.W. and Jones, M.C., (2009). Sensitivity of northern peatland carbon dynamics to Holocene climate change. Carbon cycling in northern peatlands, 184, 55-69.

Yu, Z., Beilman, D.W., Frolking, S., MacDonald, G.M., Roulet, N.T., Camill, P. and Charman, D.J., (2011). Peatlands and their role in the global carbon cycle. Eos, Transactions American Geophysical Union, 92(12), 97-98.

Yu, Z., Campbell, I.D., Campbell, C., Vitt, D.H., Bond, G.C. and Apps, M.J., (2003(a)). Carbon sequestration in western Canadian peat highly sensitive to Holocene wet-dry climate cycles at millennial timescales. The Holocene, 13, 801-808.

Yu, Z., Loisel, J., Brosseau, D.P., Beilman, D.W. and Hunt, S.J., (2010). Global peatland dynamics since the Last Glacial Maximum. Geophysical research letters, 37(13).

Yu, Z., Loisel, J., Charman, D.J., Beilman, D.W. and Camill, P., (2014). Holocene peatland carbon dynamics in the circum-Arctic region: An introduction. The Holocene, 24(9), 1021 1027. 
Yu, Z., Vitt, D.H., Campbell, I.D. and Apps, M.J., (2003 (b)). Understanding Holocene peat accumulation pattern of continental fens in western Canada. Canadian Journal of Botany, 81(3), 267-282.

Yu, Z.C., (2012). Northern peatland carbon stocks and dynamics: a review. Biogeosciences, 9(10), 4071.

Zennaro, P., Kehrwald, N., Marlon, J., Ruddiman, W.F., Brücher, T., Agostinelli, C., DahlJensen, D., Zangrando, R., Gambaro, A. and Barbante, C., (2015). Europe on fire three thousand years ago: Arson or climate?. Geophysical Research Letters, 42(12), 5023-2033.

Zigang, L. and Xintu, L. (2009). The Global Distribution of Peat, Vol. 2. EOLSS Publications, $166-402$. 
